Universidade de São PaUlo

Programa Interunidades de Pós-GraduAÇÃo EM Bioinformática FaCUldade de Filosofia, CiÊnCias e letras de Ribeirão Preto

\author{
Ricardo Cacheta Waldemarin
}

\title{
Suporte ao Desenvolvimento e à Integração de Ontologias no Domínio Biomédico
}


UNIVERSIDAdE DE SÃo PAULO

Programa Interunidades de Pós-GraduaÇão Em Bioinformática FaCUldade de Filosofia, CiÊnCias e letras de Ribeirão Preto

\section{Ricardo Cacheta Waldemarin}

\section{Suporte ao Desenvolvimento e à Integração de Ontologias no Domínio Biomédico}

Documento apresentado ao Programa Interunidades de Pós-Graduação em Bioinformática - USP para a obtenção do título de Mestre em Ciências pela Universidade de São Paulo.

Orientador: Prof. Dr. Cléver Ricardo Guareis de Farias

Durante a elaboração desse trabalho o estudante recebeu apoio finaceiro da CAPES.

Ribeirão Preto, SP 
W161s Waldemarin, Ricardo Cacheta.

Suporte ao desenvolvimento e à integração de ontologias no domínio biomédico / Ricardo Cacheta Waldemarin ; orientador Cléver Ricardo Guareis de Farias. - - Ribeirão Preto, 2015.

$152 p$.

Dissertação (Mestrado - Programa Interunidades de Pósgraduação em Bioinformática) - - Universidade de São Paulo, 2015.

1. Ontologias. 2. UML. 3. Model-driven development 4. MDD 5. OBO I. Cléver Ricardo Guareis de Farias, orient. II. Título.

Ficha elaborada por Elizabeth B. Santos - Biblioteca do IME-USP 
"This rejection of modeling for software is particularly ironic when you consider that software is the engineering medium best positioned to benefit from it.

— SELIC, B. The pragmatics of model-driven development, 2003 - 


\section{Agradecimentos}

Agradeço a...

... toda a paciência e conhecimento que recebo de meu orientador;

... toda a inspiração que recebo ao conhecer os trabalhos de grandes pesquisadores;

...todo o exemplo de força e luta que recebo de minha mãe e família;

... todo o modelo de caráter que recebo de meu avô;

...todo a alegria e apoio que recebo de meus amigos ${ }^{1}$;

...e todas as coincidências que me mostram que estou no meu caminho.

\footnotetext{
${ }^{1}$ Vocês merecem terem seus nomes aqui, uma vez que foram importantes faróis nestes anos: Parx, Guinho, RSilva, Lívia Zaramela, Gabi Guardia, Marj Pontelli, ĐiNaRussia Martinez, Jacque Santoro, Bruna Guria, Abraão, Caten, o Pandão e a Moniquinha, e Bisteka. Também merecem estar aqui o pessoal de casa: Lobo e Danillão. E, claro, Patrícia Martorelli (que nunca me deixou perdido em meio aos processos do programa).
} 


\section{Resumo}

O surgimento e o uso crescente de novas tecnologias têm levado à produção e armazenamento de grandes volumes de dados biomédicos. Tais dados são provenientes de diferentes técnicas, armazenados em formatos de representação diversos e utilizados por diferentes ferramentas. Esta heterogeneidade representa um empecilho ao maior uso desses dados em abordagens integrativas de pesquisa como, por exemplo, a biologia sistêmica. Neste cenário, artefatos de modelagem conceitual, tais como ontologias, têm sido utilizados para organizar e integrar dados heterogêneos de uma forma coerente.

A $O B O$ Foundry representa, atualmente, o maior esforço no desenvolvimento de ontologias biomédicas de forma colaborativa. Dentre as ontologias desenvolvidas pela $O B O$ Foundry, destaca-se Ontologia de Relacionamentos (OR-OBO). A OR-OBO provê definições formais para um conjunto de relacionamentos de propósito geral utilizados nas ontologias biomédicas e busca promover a criação de ontologias mais corretas e integráveis.

Um perfil UML foi proposto para representar formalmente o conjunto de conceitos e relacionamentos existentes na OR-OBO. Este perfil permite desenvolver modelos UML utilizando os conceitos presentes nesta ontologia, bem como torna possível o desenvolvimento de suporte à validação sintática dos modelos criados em relação a um conjunto de restrições formalmente definidas. Adicionalmente, percebe-se na literatura que o suporte à integração de modelos UML e ontologias $\mathrm{OBO}$, em particular as ontologias representadas na linguagem OBO File Format, é limitado.

Neste sentido, este trabalho teve como objetivo geral investigar o suporte ao desenvolvimento de ontologias biomédicas na linguagem UML. De forma específica, investigou-se o desenvolvimento de um editor gráfico, chamado $O B O-R O$ Editor, para o suporte à construção de ontologias utilizando o perfil UML proposto, bem como a integração de ontologias desenvolvidas utilizando UML e ontologias desenvolvidas na linguagem OBO File Format.

De forma a atingir nossos objetivos, uma arquitetura de referência foi definida e um processo de desenvolvimento orientado a modelos foi utilizado. A arquitetura definida é composta por uma série de artefatos inter-relacionados os quais são transformados (semi) automaticamente em código de aplicação, possibilitando a obtenção de ciclos de desenvolvimento mais rápidos e confiáveis.

O OBO-RO Editor disponibiliza um conjunto de elementos gráficos de modelagem definidos a partir do perfil UML proposto, bem como provê mecanismos para a validação sintática (semi) automática de uma ontologia desenvolvida segundo as restrições definidas neste perfil. Adicionalmente, o $O B O-R O$ Editor também provê suporte à integração de modelos UML a outras ontologias da $O B O$ Foundry, permitindo o reuso e o desenvolvimento menos propenso a erros de ontologias no domínio biomédico. 


\section{Abstract}

The development and increasing use of new technologies has resulted in the production and storage of a huge amount of biomedical data. These data are produced using different techniques, stored in different formats and consumed by different (software) tools. This heterogeneity hinders effective data usage in integrative research approaches, including systems biology. In this scenario, conceptual modeling artifacts, such as ontologies, have been used to organize and integrate heterogeneous data in a coherent manner.

Nowadays, the OBO Foundry represents the most important effort for the collaborative development of ontologies in the biomedical domain. The OBO Relation Ontology (OBO-RO) can be considered one of the most relevant ontologies in the domain. This ontology provides formal definitions for a number of general purpose relationships used in biomedical ontologies, thus facilitating the integration of existing ontologies and the development of new ontologies in the domain.

An UML profile has been proposed to formally define the different types of concepts and relationships provided by the OBO-RO. This profile enables the creation of UML models using such concepts and allows the development of support for the automatic validation of these models based on formal constraints. Additionally, the support for the integration between UML models and $\mathrm{OBO}$ ontologies, particularly ontologies represented using the OBO File Format, is limited.

In this sense, this project aimed at investigating the support for the development of biomedical ontologies using UML. In particular, we investigated the development of a graphical editor, named OBO-RO Editor, to support ontology development using the proposed UML profile. Additionally, we also investigated the integration of ontologies developed using UML and ontologies developed using the OBO File Format.

In order to achieve our goals, we have defined a reference architecture and a model-driven development process. The reference architecture consists of a number of related artifacts that are transformed to application code (semi) automatically. Such characteristic allowed us to obtain faster and more reliable development cycles.

The OBO-RO Editor provides a number of graphical elements defined in the proposed UML profile for the modeling of biomedical ontologies and support the (semi) automatic syntactic validation of such ontologies against the contraints defined in the profile. Additionally, OBORO Editor also provides support for the integration of developed UML models and other OBO ontologies, allowing the reuse and the accurate development of biomedical ontologies. 


\section{Lista de Figuras}

Figura 1 Atividades de desenvolvimento do projeto. . . . . . . . . . 7

Figura 2 Uso de diferentes visões para a modelagem de um sistema computacional. 13

Figura 3 Redução sistemática da distância semântica através de refinamentos sucessivos. . . . . . . . . . . . . . . . 15

Figura 4 Pontos de vista e trajetória de desenvolvimento da arquitetura orientada a modelos. . . . . . . . . . . . . . . . . . . . . 26

Figura 5 Transformação de modelos ao meta-nível com um meta-metamodelo comum $($ adaptado de $[1]) . \ldots \ldots$. . . . . . . . . . . . . . . 27

Figura 6 Arquitetura de metamodelagem UML em quatro camadas. (Adaptado de

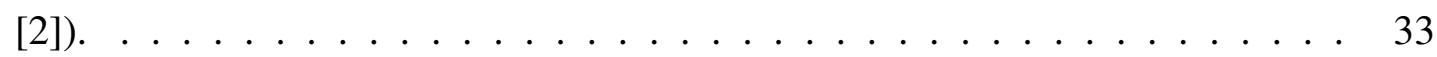

Figura 7 Alinhamento entre as camadas de modelagem EMF e camadas de modelagem UML. . . . . . . . . . . . . . . . . . . . . . . . . . 39

Figura 8 Linguagens de modelagem envolvidas num projeto GMF. (Adaptado de

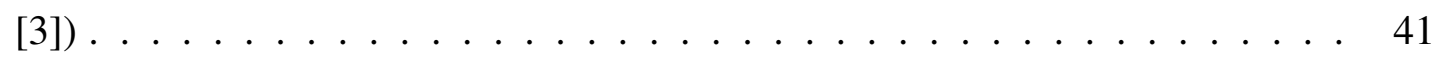

Figura 9 Fragmento apresentando um termo da ontologia de processos biológicos da OBO [4]. . . . . . . . . . . . . . . . . . . . 50

Figura 10 Fragmento OWL apresentando um termo da ontologia de processos biológicos da OBO [4]. . . . . . . . . . . . . . . . . . . . 53

Figura 11 Exemplo do uso das restrições OCL presentes no perfil proposto para a modelagem de ontologias OBO utilizando UML na validação de uma ontologia. (Adaptado de [5].) . . . . . . . . . . . . . . . . . . 62

Figura 12 Visão geral da arquitetura de referência para o desenvolvimento do $O B O$ RO Editor. . . . . . . . . . . . . . . . . . . . . . 66

Figura 13 Passos para a definição do metamodelo OR-OBO. . . . . . . . . . . . 68

Figura 14 Passos para a criação da sintaxe gráfica concreta do editor. . . . . . . . . 69 
Figura 15 Passos para a definição do metamodelo ODM. . . . . . . . . . . . 71

Figura 16 Passos para o desenvolvimento de transformações entre os metamodelos ODM e OR-OBO . . . . . . . . . . . . . . . . . . . . 73

Figura 17 Fragmentos das metaclasses UML de interesses definidas no metamodelo OR-OBO. Um retângulo nomeado representa uma metaclasse UML presente do metamodelo OR-OBO. Um retângulo cinza representa metaclasses diretamente estendidas por uma metaclasse definida no perfil. Um retângulo branco representa metaclasses estendidas ou referenciadas indiretamente por uma metaclasse definida no perfil. A) metaclasses de interesse para a representação de ontologias, classes de entidades e instâncias dessas classes; B) metaclasses de interesse para a representação de relações entre elementos de uma ontologia.

Figura 18 Metaclasses de interesse para a definição de classes OboClass e Obo Instance. Um retângulo branco representa metaclasses UML de interesse, enquanto um retângulo cinza representa metaclasses introduzidas para a implementação da extensão ao metamodelo.

Figura 19 Metaclasses de interesse para a definição de OboRelati on. Um retângulo branco representa metaclasses UML de interesse, enquanto um retângulo cinza representa metaclasses introduzidas para a implementação da extensão ao metamodelo.

Figura 20 Metaclasses de interesse para a definição de Is_a. Um retângulo branco representa metaclasses UML de interesse, enquanto um retângulo cinza representa metaclasses introduzidas para a implementação da extensão ao metamodelo. 82

Figura 21 Metaclasses de interesse para a definição de Instance_of. Um retângulo branco representa metaclasses UML de interesse, enquanto um retângulo cinza representa metaclasses introduzidas para a implementação da extensão ao me-

Figura 22 Metaclasses de interesse para a definição das demais relações fundamentais da OR OBO. Um retângulo branco representa metaclasses UML de interesse, enquanto um retângulo cinza representa metaclasses introduzidas para a implementação da extensão ao metamodelo. . . . . . . . . . . . . . . . . . . 84 
Figura 23 Metaclasses Part_of, Has_part e Oboclass e o relacionamento destas com o metamodelo UML. Um retângulo branco representa metaclasses UML de interesse, enquanto um retângulo cinza representa metaclasses introduzidas para a implementação do perfil. A) Fragmento do metamodelo UML original; B) Fragmento modificado para a implementação do perfil.

Figura 24 Metaclasses de interesse para a definição das relações temporais, especiais e de participação da OR OBO. Um retângulo branco representa metaclasses UML de interesse, enquanto um retângulo cinza representa metaclasses introduzidas para a implementação do perfil.

Figura 25 Metaclasses de interesse para a definição de novos tipos de relacionamento e para o uso desses relacionamentos em uma ontologia sendo editada. Um retângulo branco representa metaclasses UML de interesse, enquanto um retângulo cinza representa metaclasses introduzidas para a implementação da extensão ao metamodelo.

Figura 26 Metaclasses de interesse para a definição das relações built-in disponíveis implicitamente em todas as ontologias OBO. Um retângulo branco representa metaclasses UML de interesse, enquanto um retângulo cinza representa metaclasses introduzidas para a implementação do perfil. . . . . . . . . . . . . . . . 92

Figura 27 Interface gráfica do editor como um plug-in Eclipse. . . . . . . . . . . . 94

Figura 28 Definição de restrições OCL no metamodelo OR-OBO no editor $O C L i$ -

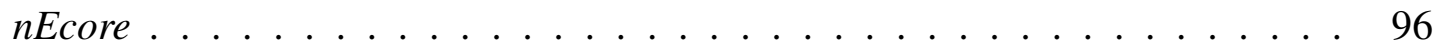

Figura 29 Fragmento de interesse da GEXPO no instante de tempo inicial. . . . . . 98

Figura 30 Ação de edição do usuário com a adição da relação has_part entre as entidades "transcription" e"gene".

Figura 31 Erro sintático identificado pelo mecanismo de validação live validation durante a ação de edição executada pelo usuário.

Figura 32 Fragmento de interesse após a adição da relação has_participant entre as classes de entidade "transcription" e "gene" e entre as classes de entidades "RNA processing" e "primary transcript". . . . . . . . . . . . . . . . 100

Figura 33 Arquitetura para a integração de ontologias OBO e o metamodelo OROBO. 
Figura 34 Metaclasses do metamodelo ODM associadas à representação de classes, instâncias e tipos de relacionamentos de uma ontologia OBO. . . . . . . . . . . 107

Figura 35 Metaclasses do metamodelo ODM associadas à representação de relacionamentos entre dois elementos de uma ontologia OBO . . . . . . . . . . 108

Figura 36 Metaclasses do metamodelo ODM associadas à organização de uma ontologia OBO. . . . . . . . . . . . . . . . . . . . 109

Figura 37 Visão geral do algoritmo de injeção em pseudocódigo . . . . . . . . . . 111

Figura 38 Representação visual de um conjunto de regras de transformação entre o metamodelo ODM e o metamodelo OR-OBO . . . . . . . . . . . . . 115

Figura 39 Regras de transformação definidas em ATL. . . . . . . . . . . . . . . 117

Figura 40 Estágios da exportação de uma ontologia em um cenário de ediçãoexportação. . . . . . . . . . . . . . . . . . . . . . . 120

Figura 41 Especificação ATL das regras entry e finally. . . . . . . . . . 122

Figura 42 Estágios de representação de uma ontologia em um cenário de importaçãoedição-exportação. . . . . . . . . . . . . . . . . . . . . . . 123

Figura 43 Fragmento da ontologia de expressão gênica (GEXPO) . . . . . . . . . 125

Figura 44 Instâncias das metaclasses do metamodelo ODM obtido após a injeção do fragmento da Ongologia GEXPO . . . . . . . . . . . . . . . . 126

Figura 45 Fragmento de interesse após a transformação para o metamodelo OROBO. Um retângulo cinza representa uma classe de entidades da ontologia. Um retângulo branco representa a definição de um novo tipo de relacionamento. . . .

Figura 46 Fragmento de interesse como modelo OR-OBO após ediçao pelo usuário. Um retângulo cinza claro representa uma classe de entidades da ontologia que foi estereotipada como «process». Um retângulo cinza escuro representa uma classe de entidades da ontologia que foi estereotipada como «material». Um retângulo branco representa a definição de um novo tipo de relacionamento. 128

Figura 47 Ontologia como modelo ODM atualizado. A figura apresenta em destaque as instâncias da metaclasse PropertyValue adicionadas para armazenar a informação do estereótipo associado às classes de entidade modeladas. . . . . 129

Figura 48 Ontologia após serialização como OBO File Format. . . . . . . . . . . . 131 


\section{Lista de Tabelas}

Tabela 1 Exemplos de relações primitivas da OR OBO. $c_{i}$ e $p_{i}$ representam instâncias de continuantes e processos; $C_{i}$ e $P_{i}$ representam classes de continuantes e processos; $r_{i}$ representa uma região espacial (tridimensional); $t_{i}$ representa um instante no tempo. . . . . . . . . . . . . . . . . 5

Tabela 2 Exemplos das definições providas pela Ontologia de Relacionamentos da OBO. $c_{i}$ e $p_{i}$ representam instâncias de continuantes e processos; $C_{i}$ e $P_{i}$ representam classes de continuantes e processos; $r_{i}$ representa uma região espacial (tridimensional); $t_{i}$ representa um instante no tempo. . . . . . . . . . . . 58

Tabela 3 Relações definidas da Ontologia de Relacionamentos da OBO. . . . . . 59 


\section{Lista de Siglas}

$\begin{array}{ll}\text { API } & \text { Auxiliar Programmer Interface } \\ \text { ATL } & \text { ATLAS Transformation Language } \\ \text { BFO } & \text { Basic Formal Ontology } \\ \text { BPMN } & \text { Business Process Model and Notation } \\ \text { CIM } & \text { Computation Independent Model } \\ \text { CMOF } & \text { Complete MOF } \\ \text { CORBA } & \text { Common Object Request Broker Architecture } \\ \text { CWM } & \text { Common Warehouse Metamodel } \\ \text { DSL } & \text { Domain Specific Language } \\ \text { EJB } & \text { Enterprise Java Beans } \\ \text { EMF } & \text { Eclipse Modeling Framework } \\ \text { EMOF } & \text { Essential MOF } \\ \text { EMP } & \text { Eclipse Modeling Project } \\ \text { GEF } & \text { Graphical Editing Framework } \\ \text { GEXPO } & \text { Gene Expression Ontology } \\ \text { GMF } & \text { Graphical Modeling Framework } \\ \text { GMP } & \text { Graphical Modeling Project } \\ \text { IDE } & \text { Integrated Development Environment } \\ \text { JMI } & \text { Java Metadata Interface } \\ \text { MDA } & \text { Model-Driven Architecture } \\ \text { MDD } & \text { Model-Driven Development } \\ \text { MDT } & \text { Model Development Tools } \\ \text { MOF } & \text { Meta Object Facility } \\ \text { MVC } & \text { Model-View-Controller } \\ \text { MWE2 } & \text { Modeling Workfow Engine } \\ \text { OBO } & \text { Open Biological and Biomedical Ontologies } \\ \text { OCL } & \text { Object Contraint Language } \\ \text { ODM } & \text { OBO Data Model } \\ \text { OMG } & \text { Object Management Group } \\ & \end{array}$


OR-OBO Ontologia de Relacionamentos da OBO

OWL Web Ontology Language

OUP Ontology UML Profile

PCO Population and Community Ontology

PIM Platform Independent Model

PSM Platform Specific Model

RDF Rich Description Format

RNAO RNA Ontology

TMF Textual Modeling Framework

UML Unified Modeling Language

W3C World Wide Web Consortium

XMI XML Metadata Interchange

XML Extensible Markup Language

XSLT Extensible Stylesheet Language Transformations 


\section{Sumário}

1 Introdução 1

1.1 Motivação . . . . . . . . . . . . . . . . . . . . . . 1

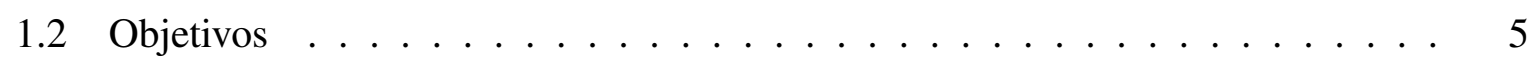

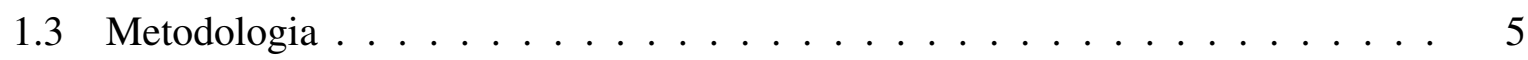

1.4 Estrutura do documento . . . . . . . . . . . . . . . . 8

2 Modelos, metamodelos e ontologias 9

2.1 Modelos e metamodelos . . . . . . . . . . . . . . . . . . . 9 9

2.1.1 Definição de modelo . . . . . . . . . . . . . . . . . . . 10

2.1.2 Representação de modelos . . . . . . . . . . . . . . . . . 11

2.1.3 Níveis de abstração e pontos de vista . . . . . . . . . . . . . . . . . 12

2.1.4 Definição de metamodelo . . . . . . . . . . . . . . . . . 15

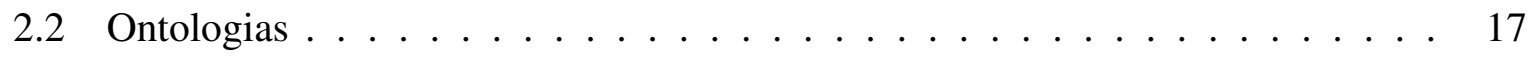

2.2.1 Definição de ontologia . . . . . . . . . . . . . . . . 17

2.2.2 Representação de ontologias . . . . . . . . . . . . . . . . . . 18

2.2.3 Desenvolvimento de ontologias . . . . . . . . . . . . . 20

3 Desenvolvimento orientado a modelos $\quad 24$

3.1 Visão geral . . . . . . . . . . . . . . . . . . . . . . 24

3.1.1 Transformações entre modelos . . . . . . . . . . . . . 26

3.1 .2 Aplicações de MDD . . . . . . . . . . . . . . . 28

3.2 Arquitetura de metamodelagem UML $\ldots \ldots \ldots$. . . . . . . . . . 31 
3.2.1 Visão geral da arquitetura UML . . . . . . . . . . . . . . . . . 32

3.2.2 Meta Object Facility $(\mathrm{MOF}) \ldots \ldots \ldots 33$

3.2.3 Object Constraint Language (OCL) . . . . . . . . . . . . . . . 34

3.2 .4 Perfis UML $\ldots \ldots \ldots \ldots \ldots$

3.3 Frameworks para o suporte ao desenvolvimento orientado a modelos . . . . . 36

3.3.1 Eclipse Modeling Framework (EMF) . . . . . . . . . . . . . . . . 37

3.3.2 Graphical Modeling Framework (GMF) . . . . . . . . . . . . . . . 39

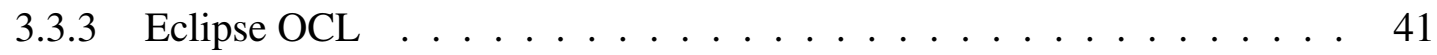

3.3.4 ATLAS Transformation Language (ATL) . . . . . . . . . . . . . . . . 42

4 Modelagem de ontologias biomédicas 44

4.1 Ontologias biomédicas . . . . . . . . . . . . . . . . 45

4.2 OBO Foundry . . . . . . . . . . . . . . . . . . . . . 46

4.3 Linguagens de representação de ontologias . . . . . . . . . . . . . . . . . 47

4.3 .1 OBO Flat File Format . . . . . . . . . . . . . . . . . 47

4.3.2 Web Ontology Language $(\mathrm{OWL}) \ldots \ldots . \ldots . \ldots . \ldots 51$

4.4 Ontologia de Relacionamentos da OBO $\ldots \ldots \ldots$. . . . . . . . . . . 54

4.4 .1 Visão geral . . . . . . . . . . . . . . . 55

4.4.2 Relações entre classes de entidades . . . . . . . . . . . . . . . . . 57

4.5 Modelagem de ontologias biomédicas usando UML . . . . . . . . . . . . 60

4.6 Conclusão . . . . . . . . . . . . . . . . . . . . . . 62

5 OBO-RO Editor: Arquitetura de referência e processo de desenvolvimento $\quad 64$

5.1 Arquitetura de referência e integração . . . . . . . . . . . . . . . . 64

5.2 Processo de desenvolvimento . . . . . . . . . . . . . . 67

5.2.1 Definição do metamodelo OR-OBO . . . . . . . . . . . . . . . . 67

5.2.2 Definição da sintaxe gráfica concreta para modelagem . . . . . . . . . . 68 
5.2.3 Definição de expressões OCL para o metamodelo OR-OBO . . . . . 70

5.2.4 Definição do metamodelo OBO Data Model (ODM) . . . . . . . . . . 71

5.2.5 Definição de mecanismos de injeção e extração de ontologias OBO . . 72

5.2.6 Definição das transformações entre os metamodelos OR-OBO e ODM . 72

6 Suporte ao desenvolvimento de ontologias em UML 74

6.1 Definição do metamodelo OR-OBO . . . . . . . . . . . . . . 74

6.1.1 Definição das metaclasses UML de interesse . . . . . . . . . . . . . 75

6.1.2 Definição de classes de entidades e instâncias . . . . . . . . . . . . 76

6.1.3 Definição de OboRelation . . . . . . . . . . . . . . . . 79

6.1 .4 Definição da relação Is $\_$a . . . . . . . . . . . . . . . . . 81

6.1.5 Definição da relação Instance _of . . . . . . . . . . . . . . . . 82

6.1.6 Definição das demais relações fundamentais da OR OBO . . . . . . . 83

6.1.7 Definição das relações temporais, espaciais e de participação da OR OBO 88

6.1.8 Definição dos tipos de relacionamento declarados em outras ontologias OBO .............................. 90

6.1.9 Definição das relações built-in de uma ontologia OBO . . . . . . . . . 91

6.2 Definição da sintaxe gráfica concreta para modelagem . . . . . . . . . . . 93

6.3 Definição de expressões OCL para o metamodelo OR-OBO . . . . . . . . . . 95

6.4 Conclusão . . . . . . . . . . . . . . . . . . . . . . . 101

7 Suporte à integração de ontologias OBO 102

7.1 Visão geral . . . . . . . . . . . . . . . . . . . . 103

7.2 Definição do metamodelo ODM . . . . . . . . . . . . . . . . . 105

7.3 Definição de mecanismos de injeção e extração de ontologias . . . . . . . . . . 109

7.4 Definição de transformações ATL entre os metamodelos OR-OBO e ODM . . . 112

7.4.1 Transformação de modelos ODM em modelos OR-OBO . . . . . . . . 112

7.4.2 Transformação de modelos OR-OBO em modelos ODM . . . . . . . 118 
7.5 Transformações na prática . . . . . . . . . . . . . . . . . . 124

7.6 Conclusão . . . . . . . . . . . . . . . . . . . . 130

8 Conclusão $\quad 133$

8.1 Principais contribuições . . . . . . . . . . . . . . . 133

8.2 Discussão . . . . . . . . . . . . . . . . . . . . 134

8.3 Considerações finais e trabalhos futuros $\ldots \ldots \ldots \ldots$. . . . . . . . 138

$\begin{array}{ll}\text { Referências Bibliográficas } & 141\end{array}$ 


\section{$1 \quad$ Introdução}

O grande crescimento na quantidade e na variedade de dados sendo produzidos e armazenados demanda a utilização de tecnologias e ferramentas mais sofisticadas para fazer um bom uso das informações contidas nestes dados. Neste sentido, ontologias estão sendo utilizadas com sucesso em bioinformática e em outras áreas da ciência. A Open Biological and Biomedical Ontologies Foundry (OBO Foundry) é um esforço colaborativo que busca coordenar o desenvolvimento de ontologias para o domínio biomédico de forma a criar ontologias mais corretas, modulares e interoperáveis para este domínio. Neste sentido, a disponibilidade de técnicas e ferramentas de suporte favorece o processo de desenvolvimento de ontologias no domínio biomédico de maneira geral, bem como a criação de ontologias mais corretas e menos propensas a erros.

O restante deste capítulo está estruturado da seguinte forma: a seção 1.1 apresenta o contexto e a motivação para o desenvolvimento deste projeto; a seção 1.2 apresenta os objetivos deste projeto; a seção 1.3 apresenta a metodologia utilizada no desenvolvimento do projeto; por fim, a seção 1.4 apresenta a estrutura dos demais capítulos deste documento.

\subsection{Motivação}

Atualmente, várias áreas da ciência estão enfrentando um crescimento muito grande na quantidade e na variedade dos tipos de dados sendo produzidos e armazenados [6]. Novos experimentos e simulações geram enormes quantidades de dados todos os anos. Em bioinformática, o advento e a acessibilidade de novas técnicas levam à produção de um volume cada vez maior de dados extremamente heterogêneos. Outros campos de pesquisa também enfrentam desafios 
no gerenciamento e no armazenamento de dados produzidos nos laboratórios e armazenados digitalmente em arquivos, bancos de dados, páginas Web, wikis, entre outras formas. Para fazer a integração e o bom uso das informações contidas nesses dados é necessário o uso de tecnologias e ferramentas mais sofisticadas [6]. Neste cenário, artefatos de modelagem conceituais, tais como ontologias, têm sido utilizados de forma crescente para organizar e integrar dados de diferentes fontes de uma forma coerente $[7,8,9]$.

Ontologias foram inicialmente definidas e estudadas no campo da Filosofia, na qual ontologia é um ramo da metafísica que estuda a natureza e a existência das coisas e busca descrever as entidades existentes no universo e suas características [7]. Posteriormente, a área de Ciência da Computação trouxe para si as ontologias como artefatos de modelagem conceitual. Neste contexto, uma ontologia é um artefato representacional que apresenta declarações formais sobre os elementos existentes em um domínio ou universo de discurso [8].

Ontologias têm importância reconhecida em várias áreas de pesquisas da Ciência da Computação [7], tais como sistemas de informações e bancos de dados, engenharia de software (em especial engenharia de domínio) e inteligência artificial. Ontologias também têm sido utilizadas com sucesso em outros domínios, tais como Química [10], Matemática [11], Direito [12] e, principalmente, o domínio biomédico $[13,14,15,16]$. O sucesso obtido no domínio biomédico levou à proliferação de ontologias para esse domínio. Porém, essa proliferação tornou-se um empecilho ao uso efetivo dessas ontologias, dada a ausência de esforços de padronização e alinhamento entre as ontologias desenvolvidas [17, 18, 19].

A Open Biological and Biomedical Ontologies Foundry (OBO Foundry) foi criada como um experimento colaborativo para o alinhamento e a coordenação dos esforços no desenvolvimento e gerenciamento de ontologias para os domínios biológicos e biomédicos $[18,20]$. Esta organização tem como objetivo prover um conjunto de princípios e melhores práticas para o desenvolvimento, revisão e curação colaborativos de ontologias para esses domínios, de forma a obter ontologias mais corretas, modulares e integráveis. Atualmente, a $O B O$ Foundry possui 10 ontologias recomendadas e 110 ontologias candidatas à recomendação, englobando ontologias sobre experimentos, genes, proteínas, anatomia e bioquímica, entre outros domínios [20]. 
Uma das dificuldades encontradas no desenvolvimento e na integração de ontologias é que em geral desprende-se muito esforço para a definição e formalização das entidades que fazem parte dessas ontologias e pouco esforço na definição e formalização dos relacionamentos entre esses termos [21]. Sem uma definição formal, um mesmo tipo de relacionamento pode ser utilizado de forma inconsistente em diferentes ontologias ou em diferentes pontos de uma mesma ontologia. Nesse sentido, a $O B O$ Foundry desenvolveu uma Ontologia de Relacionamentos (OR OBO) [21] de forma a prover definições formais para um conjunto de tipos de relacionamento de propósitos gerais usado no domínio biomédico. A OR OBO foi criada para garantir a máxima confiabilidade na curação de cada ontologia e prover um ponto de apoio sólido para a integração de conhecimento na área biomédica. Dessa forma, a OR OBO torna-se uma ferramenta de raciocínio para a criação de ontologias mais corretas e menos propensas a erros.

Ontologias curadas pela OBO Foundry são representadas principalmente através de duas linguagens: o $O B O$ File Format [22] e a Web Ontology Language (OWL) [23]. Tanto o $O B O$ File Format e a OWL são linguagens textuais que não possuem uma representação gráfica definida. Por outro lado, alguns autores argumentam que artefatos de modelagem conceitual são criados primariamente para serem utilizados por seres humanos, e que o sucesso do uso de ontologias e outros padrões de modelagem na área biomédica depende de que esses artefatos sejam não apenas compreensíveis por computadores, mas também corretos e intuitivos aos biologistas que os utilizam [7, 24]. Neste sentido, o desenvolvimento e a compreensão de modelos conceituais, tais como ontologias, pode ser facilitado pelo uso de notações gráficas, tais como a linguagem Unified Modeling Language (UML) [2, 25].

UML é uma linguagem para modelagem de propósito geral padronizada pelo Object Management Group (OMG) [26]. UML provê um conjunto rico de elementos de modelagem conceitual para o desenvolvimento de sistemas computacionais, além de representações gráficas para esses elementos. Adicionalmente, UML é uma linguagem bem estabelecida com extenso suporte de ferramentas de modelagem.

De maneira geral, UML pode ser usada para a modelagem de sistemas computacionais em diferentes domínios do conhecimento. Porém, a linguagem pode ser estendida através do de- 
senvolvimento e aplicação de perfis, que podem ser utilizados para adaptá-la às especificidades de um domínio em particular e/ou para prover novos elementos de modelagem $[25,2]$. Perfis podem ser utilizados para criar terminologias específicas em um domínio, incluindo sintaxe e semântica adicionais e/ou restrições sobre o uso de elementos da linguagem. Exemplos de perfis padronizados pela OMG incluem perfis para computação distribuída [27], integração de aplicações [28] e telecomunicações [29].

Um perfil UML foi proposto para permitir a criação usando UML de modelos e ontologias baseados no conjunto de relacionamentos definidos na $O B O$ Relation Ontology [5]. O perfil proposto [5] provê diretrizes concretas para a definição dos diferentes tipos de entidades e dos relacionamentos entre essas entidades. Os elementos gráficos presentes no perfil permitem a modelagem e a visualização das ontologias biomédicas de forma facilitada em relação aos formatos textuais atuais. Adicionalmente, os usuários e desenvolvedores podem beneficiar-se de uma linguagem gráfica bem estabelecida e de fácil aprendizado.

Ontologias biomédicas costumam ser artefatos grandes e complexos, o que representa uma limitação para a representação e visualização gráfica dessas ontologias. Contudo, tal limitação pode ser superada através do suporte adequado de uma ferramenta para modelagem. Embora as definições contidas no perfil proposto possam ser usadas em qualquer ferramenta de modelagem UML de propósito geral, estas também podem ser incluídas em uma ferramenta de propósito específico para prover uma notação específica do domínio. Adicionalmente, uma vez que estas definições do perfil estão formalmente definidas, é possível que essa ferramenta seja desenvolvida para suportar técnicas para o raciocínio automático e a prevenção de inconsistências sintáticas nas ontologias modeladas [5].

Outra característica importante que o desenvolvimento dessa ferramenta pode trazer é permitir a integração de ontologias desenvolvidas utilizando UML com ontologias já desenvolvidas utilizando o $O B O$ File Format, uma vez que tal característica não é contemplada pelas ferramentas de modelagem UML de propósito geral. Contudo, até onde sabemos, não existe atualmente suporte a essa integração. 


\subsection{Objetivos}

O objetivo geral desse projeto é investigar o suporte ao desenvolvimento e à integração de ontologias no domínio biomédico. Neste sentido, o projeto possui dois objetivos específicos: i) investigar o desenvolvimento de uma ferramenta de modelagem gráfica para o suporte à construção de ontologias utilizando o perfil UML proposto em [5]; e, ii) investigar a integração de ontologias desenvolvidas utilizando UML e ontologias desenvolvidas usando o OBO File Format.

O desenvolvimento dessa ferramenta teve como meta principal permitir a edição gráfica de uma dada ontologia, garantindo a correção sintática da mesma usando os elementos de modelagens definidos no perfil. Esta correção é garantida por meio da avaliação de um conjunto de restrições sintáticas definidas pelo perfil. Estas restrições definem as combinações válidas dos elementos de modelagem e são avaliadas de uma forma (semi) automática pela ferramenta desenvolvida. Adicionalmente, a ferramenta desenvolvida deve permitir a integração das ontologias desenvolvidas com ontologias representadas na linguagem OBO File Formatpor meio da importação e exportação de ontologias representadas nesta linguagem.

\subsection{Metodologia}

Inicialmente estudamos o desenvolvimento de modelos, metamodelos e ontologias. Este estudo objetivou construir uma base de conhecimento sólida sobre a área de modelagem conceitual. Foram estudados uma série de conceitos fundamentais sobre a área, incluindo definições de modelos, metamodelos, níveis de abstração, etc. Adicionalmente, estudamos a definição, representação e desenvolvimento de ontologias.

A seguir, realizamos um estudo bibliográfico sobre o desenvolvimento orientado a modelos. Este estudo objetivou obter uma visão geral sobre o uso de modelos no processo de desenvolvimento de software. Estudamos arquiteturas utilizadas para o uso e definição de modelos na área de desenvolvimento, bem como técnicas para a obtenção de código de implementação a partir dos modelos definidos. Finalmente, estudamos um conjunto de frameworks para o suporte a de- 
senvolvimento orientado a modelos disponibilizados pela Eclipse Foundation e posteriormente utilizados no contexto deste trabalho.

Realizamos, então, um estudo sobre o uso e desenvolvimento de ontologias no domínio biomédico. Este estudo objetivou obter uma visão clara sobre ontologias biomédicas e o papel da $O B O$ Foundry neste cenário. Estudamos também as linguagens para representação de ontologias biomédicas utilizadas para as ontologias da $O B O$ Foundry e o papel da Ontologia de Relacionamentos (OR) da OBO na curação e correção e integração destas ontologias. Por fim, estudamos a modelagem de ontologias biomédicas usando UML e um perfil UML utilizado para representar os conceitos definidos na OR em modelos desta linguagem.

Em seguida, definimos uma arquitetura de referência e um processo de desenvolvimento orientado a modelos para a implementação de uma ferramenta de modelagem gráfica para ontologias biomédicas utilizando os elementos de modelagem definidos no perfil UML para a ontologia de relacionamentos. O processo de desenvolvimento definido utiliza linguagens e frameworks disponibilizados pela Eclipse Foundation para o desenvolvimento orientado a modelos de linguagens específicas de domínio, bem como uma API Java provida pela OBO Foundry para a manipulação de ontologias biomédicas.

A implementação da ferramenta de modelagem gráfica foi realizada em duas etapas. Primeiramente desenvolvemos o suporte ao desenvolvimento de uma ontologia como um modelo UML e a validação sintática desta ontologia segundo um conjunto de restrições sintáticas. Neste sentido, definimos um metamodelo para a representação dos conceitos definidos pelo perfil UML (metamodelo OR-OBO), um conjunto de restrições ao uso dos elementos desse metamodelo e a sintaxe gráfica para representar os diferentes conceitos definidos no metamodelo OR-OBO. Em seguida, desenvolvemos o suporte à integração das ontologias desenvolvidas com a ferramenta com ontologias representadas na linguagem OBO File Format. Este suporte foi provido por meio da definição de um metamodelo para a representação dos conceitos implícitamente definidos nessa linguagem (metamodelo ODM), o mapeamento entre os conceitos presentes neste metamodelo e os conceitos existentes no metamodelo OR-OBO e de um conjunto de regras de transformação entre esses dois domínios. Adicionalmente, mecanismos 
para a importação e exportação de modelos ODM como ontologias representadas na linguagem OBO File Format foram implementados em Java.

A Figura 1 ilustra as atividades relacionadas ao desenvolvimento deste projeto, bem como os relacionamentos existentes entre as mesmas.

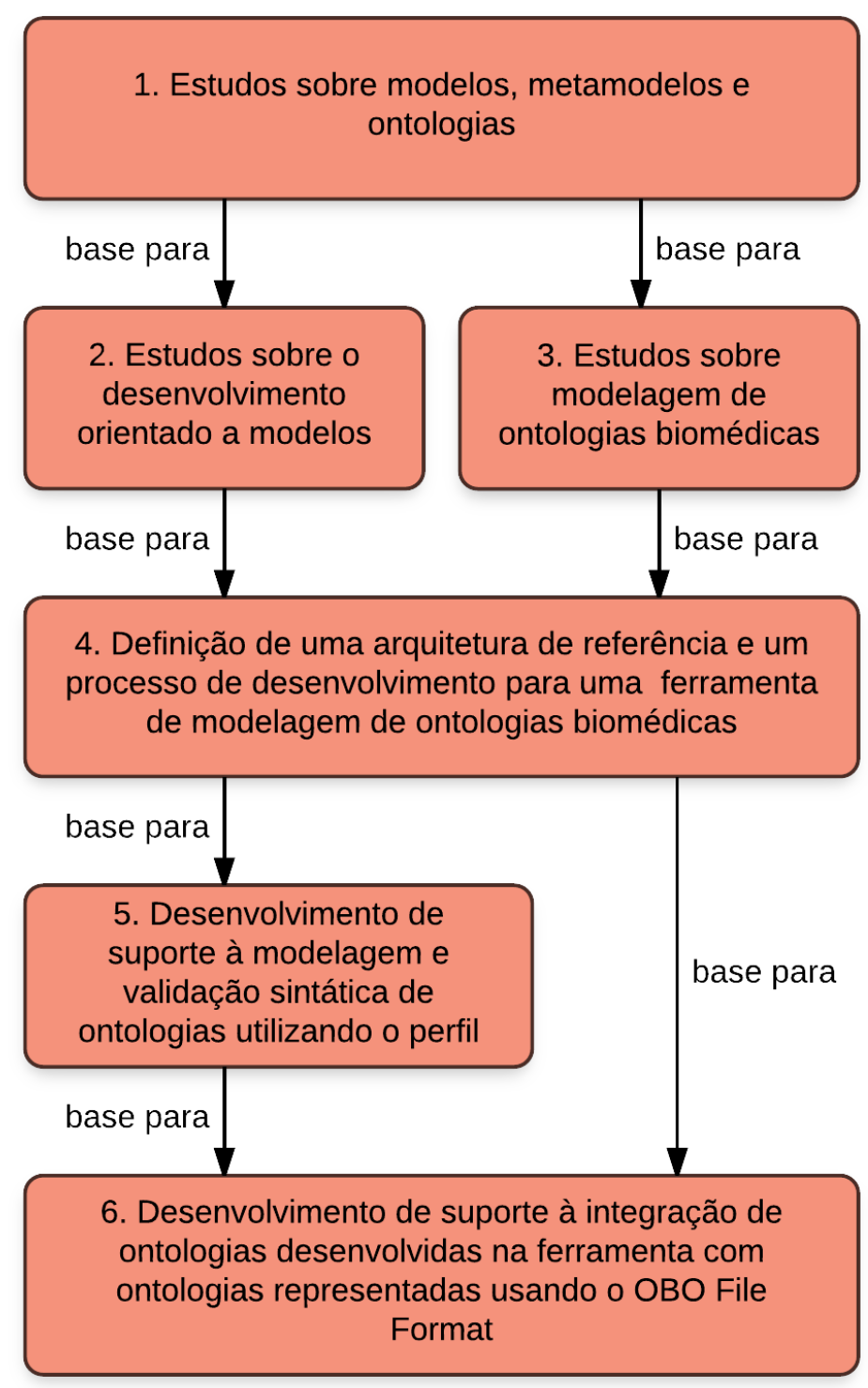

Figura 1: Atividades de desenvolvimento do projeto. 


\subsection{Estrutura do documento}

O restante do documento está organizado da seguinte forma: o Capítulo 2 apresenta uma visão geral sobre modelos, metamodelos e ontologias; o Capítulo 3 apresenta uma visão geral sobre o desenvolvimento orientado a modelos; o Capítulo 4 apresenta uma visão geral sobre a modelagem de ontologias biomédicas, a Ontologia de Relacionamentos da OBO, e o perfil UML proposto para esta ontologia; o Capítulo 5 apresenta a arquitetura de referência proposta para o desenvolvimento da ferramenta de modelagem e uma visão geral do processo de desenvolvimento orientado a modelos definido a partir desta arquitetura; o Capítulo 6 apresenta os principais aspectos relacionados ao desenvolvimento do suporte à modelagem de ontologias utilizando as definições apresentadas pelo perfil proposto; o Capítulo 7 apresenta os principais aspectos relacionados ao desenvolvimento do suporte à integração de ontologias desenvolvidas utilizando a ferramenta de modelagem e ontologias representadas no OBO File Format; o Capítulo 8 apresenta as conclusões do trabalho, bem como identifica um conjunto de trabalhos futuros. 


\section{Modelos, metamodelos e ontologias}

Este capítulo apresenta uma visão geral sobre modelos, metamodelos e o uso de técnicas de modelagem no desenvolvimento de sistemas computacionais. Modelos são abstrações utilizadas para representar as principais características de um sistema em desenvolvimento. Dessa forma, modelos facilitam a compreensão das características de um sistema e podem ser utilizados como auxílio ao desenvolvimento.

Adicionalmente, este capítulo apresenta uma visão geral sobre o desenvolvimento e representação de ontologias utilizadas em sistemas computacionais de maneira geral e no domínio biomédico em particular. Uma ontologia é um artefato representacional que contém uma série de declarações descritivas precisas sobre um dado domínio de interesse e sobre as entidades existentes nesse domínio. Ontologias permitem representar e compartilhar o conhecimento sobre um determinado domínio de forma concisa, evitando ambiguidades e garantindo que diferentes agentes de software se comportem de forma consistente quando compartilham dada informação.

O restante deste capítulo está estruturado da seguinte forma: a seção 2.1 apresenta um conjunto de conceitos básicos relacionados à modelagem e à metamodelagem de sistemas computacionais; a seção 2.2 apresenta um conjunto de conceitos básicos associados e discute o desenvolvimento e o representação de ontologias.

\subsection{Modelos e metamodelos}

De forma a compreender o papel de modelos no desenvolvimento de sistemas computacionais é necessário a compreensão dos aspectos gerais sobre modelagem e metamodelagem. 
Neste sentido, esta seção apresenta uma visão geral sobre modelos e suas características chaves, representação de modelos e critérios de abstração utilizados, e as relações entre modelos e metamodelos.

\subsubsection{Definição de modelo}

Um modelo consiste de um conjunto coerente de declarações e outros elementos formais que representam características de interesse sobre um determinado sistema [30,31]. O uso de modelos para representar as principais características de um artefato em desenvolvimento é uma prática tradicional em disciplinas científicas e de engenharia, nas quais modelos são normalmente construídos para propósitos de análise e/ou comunicação. Como exemplo de uso de modelos nessas disciplinas temos o uso de maquetes e plantas previamente à construção de um edifício, de forma a verificar aspectos estruturais e estéticos do prédio; o uso de diagramas de corpo livre e distribuição de cargas concentradas no estudo de alavancas e reações de apoio de vigas; bem como o uso de túneis de vento e modelos reduzidos em estudos sobre efeitos aerodinâmicos de um avião em desenvolvimento.

Um modelo possui as seguintes características chaves [32]: abstração, correção, preditividade e baixo-custo. Um modelo captura os aspectos mais importantes para a compreensão da estrutura e comportamento de um dado sistema, abstraindo de detalhes menos relevantes. Apesar de abstrair alguns detalhes de um sistema, um modelo deve representar correta e coerentemente as propriedades estruturais e comportamentais do sistema, de forma a permitir a utilização desse modelo para a análise destas propriedades. Finalmente, o custo do desenvolvimento e análise de um modelo deve ser baixo comparativamente ao custo de desenvolvimento e análise do próprio sistema de modo a justificar o desenvolvimento e uso desse modelo. Um sistema implementado a partir das especificações contidas em um determinado modelo realiza esse modelo.

Modelos podem ser classificados em modelos descritivos e modelos prescritivos. Modelos descritivos são criados para abstrair e descrever um sistema existente, enquanto modelos prescritivos são utilizados para prescrever um sistema a ser desenvolvido [1]. Um modelo des- 
critivo é dito válido (ou correto) se todas as declarações e elementos existentes no modelo são verdadeiras para o sistema, ou seja, todo elemento (ou informação sobre um elemento) que esteja representado no modelo é encontrado no sistema que o modelo descreve [31]. Já um sistema desenvolvido a partir de um modelo prescritivo é dito válido (ou correto) se nenhuma das declarações e elementos existentes no modelo que o prescreve é falsa para o sistema, ou seja, se todas as informações contidas naquele modelo foram realizadas corretamente no sistema que ele prescreve [31].

\subsubsection{Representação de modelos}

As declarações presentes em um modelo podem ser expressas informalmente, usando uma linguagem natural, ou formalmente, usando uma linguagem formal ou um formalismo lógicomatemático.

Uma linguagem é composta por sintaxe e semântica. A sintaxe de uma linguagem provê um conjunto de regras para a representação dos elementos da linguagem e pode ser dividida em sintaxe abstrata e sintaxe concreta. A sintaxe abstrata de uma linguagem define uma taxonomia dos elementos legais daquela linguagem e restrições sintáticas de como esses elementos podem ser combinados entre si para formar construtos válidos naquela linguagem. A sintaxe concreta de uma linguagem define um mapeamento da taxonomia definida pela sintaxe abstrata para um alfabeto concreto. Adicionalmente, a sintaxe concreta define também um mapeamento das restrições sintáticas, definidas pela sintaxe abstrata, para a gramática desta linguagem [33]. O alfabeto e a gramática de uma linguagem podem ser tanto textuais quanto gráficos. Dessa forma, os conceitos existentes no modelo descrito através dessa linguagem podem ser representados tanto por um conjunto de declarações textuais quanto por um conjunto de figuras geométricas.

A semântica de uma linguagem provê o significado contido em uma dada declaração feita utilizando a linguagem. A semântica de uma linguagem é constituída por um domínio semântico e por um mapeamento semântico. O domínio semântico de uma linguagem especifica os objetos que existem no universo de discurso [33], ou seja, apresenta o conjunto de elementos reais (elementos semânticos) ao qual declarações escritas naquela linguagem podem referir-se 
[34]. O domínio semântico captura as decisões sobre o que desejamos que a linguagem seja capaz de representar. O mapeamento semântico de uma linguagem, por sua vez, representa o mapeamento entre elementos e expressões legais escritas naquela linguagem e elementos do domínio semântico, de forma que toda expressão permitida pela sintaxe daquela linguagem seja relacionada a um conceito real do universo de discurso [33].

\subsubsection{Níveis de abstração e pontos de vista}

Em geral, a tentativa de capturar todos os aspectos de sistemas não-triviais em um único modelo resulta na criação de modelos muito complexos e pouco úteis para a compreensão e realização do sistema [24]. Por essa razão, um modelo deve ser criado utilizando critérios de abstração que permitam aos usuários daquele modelo focar em um conjunto de aspectos relevantes para o desenvolvimento do sistema em um dado momento [1]. O conjunto de critérios de abstração utilizados para a criação de um modelo caracteriza esse modelo e define o que deve ser incluído nele. Pontos de vista e níveis de abstração são exemplos de critérios de abstração que podem ser utilizados no desenvolvimento de modelos.

Um ponto de vista define um conjunto de aspectos estruturais e/ou comportamentais relevantes para a criação de modelos de um sistema $[1,35]$. Nesse sentido, uma visão é um modelo que representa o sistema de acordo com um dado ponto de vista [35, 36]. Ao incluir apenas aspectos relevantes de acordo com um determinado ponto de vista podemos entender a essência da estrutura e do funcionamento do sistema mais facilmente [32]. Diferentes pontos de vistas podem ser definidos para particionar os detalhes presentes no modelo de acordo com diferentes aspectos de interesse em relação ao sistema, possibilitando a criação de visões mais especializadas sobre o sistema $[1,32]$. Porém, uma vez que um mesmo elemento do sistema pode estar presente em mais de uma visão, o uso de diferentes pontos de vista no desenvolvimento de um modelo demanda atenção em relação à consistência entre as diversas visões que compõe o modelo.

Um exemplo desses conceitos pode ser encontrado durante a construção de um edifício. Um modelo do edifício deve ser criado anteriormente à sua construção para avaliar as características 
do edifício e guiar a construção. Esse modelo é particionado em diferentes artefatos: diagramas estruturais e de distribuição de forças, a planta do sistema elétrico, maquetes apresentando o exterior do prédio, entre outros. Esses artefatos representam visões diferentes e complementares daquele edifício para prover suporte à contrução do mesmo. Outro exemplo desses conceitos é o uso de diferentes diagramas UML $[25,2]$ para a modelagem de um sistema computacional. Cada diagrama UML permite capturar aspectos estruturais ou comportamentais diferentes sobre um dado sistema em desenvolvimento: classes de objetos presentes no sistema, sequência de passagens de mensagens entre esses objetos, casos de uso dos usuários desse sistema, entre outros.

A Figura 2 ilustra esses conceitos através da representação de diferentes visões de um sistema. A Figura 2a representa através de um diagrama de classes UML uma visão estrutural do sistema, enquanto a Figura 2 b representa através de um diagrama de sequência UML uma visão comportamental desse mesmo sistema.

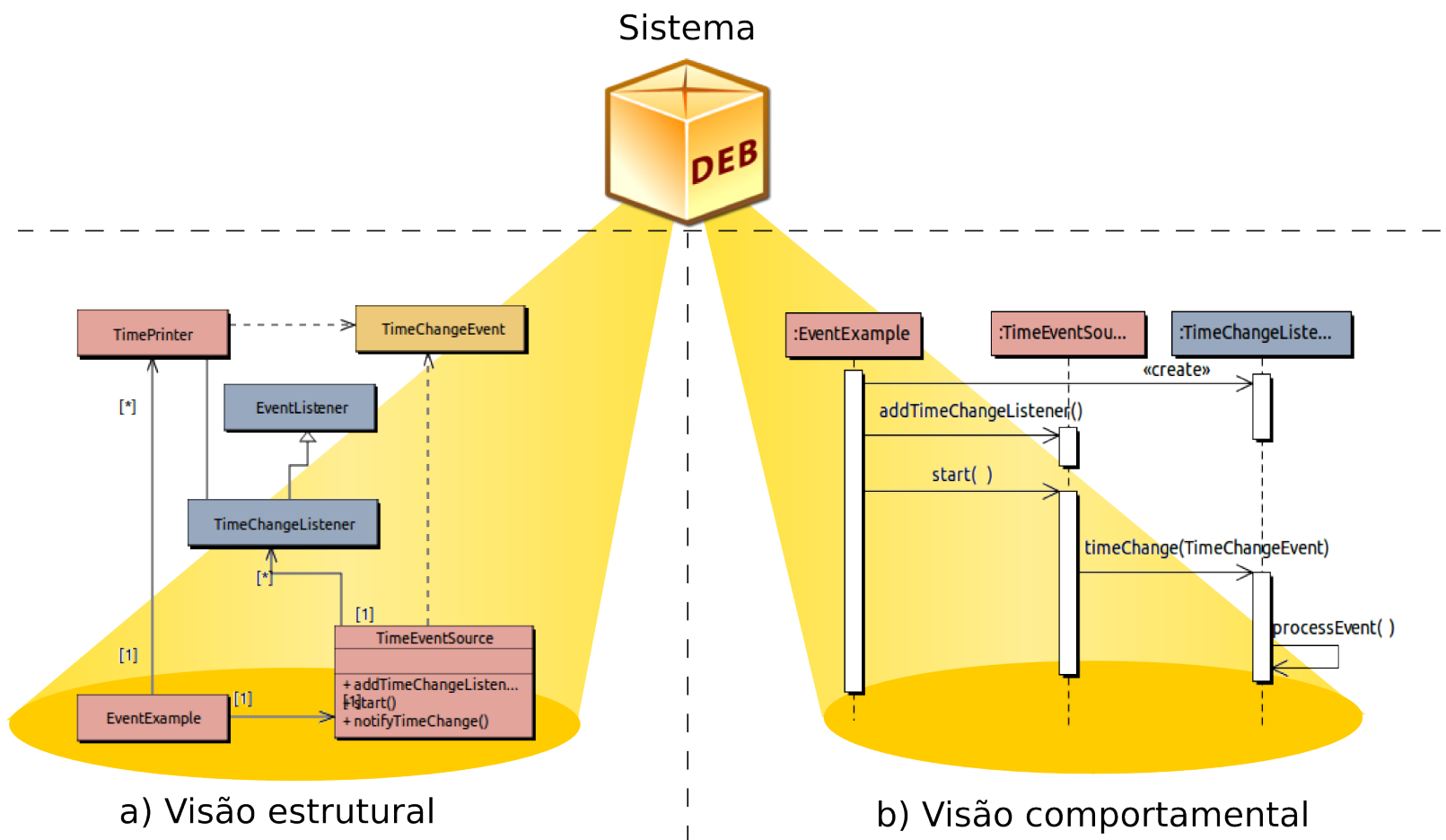

Figura 2: Uso de diferentes visões para a modelagem de um sistema computacional.

Abstração representa uma operação na qual detalhes irrelevantes de um modelo são suprimidos a fim de obter um modelo simplificado (ou mais abstrato) para facilitar a compreensão 
do sistema em um dado momento. Assim, dizemos que um modelo A é o resultado de uma operação de abstração de um modelo B se o conjunto de elementos/detalhes do modelo A é um subconjunto dos elementos pertencentes ao modelo B. Refinamento representa a operação inversa da abstração. Neste sentido, dizemos que o modelo B é o resultado de uma operação de refinamento do modelo A se o modelo B acrescenta detalhes ao modelo A de forma a tornálo mais concreto. Tanto uma abstração de um modelo quanto um refinamento desse modelo precisam necessariamente estar em conformidade com o modelo original.

O objetivo final do processo de desenvolvimento de um sistema é obter uma realização concreta do mesmo que possa ser executada em uma dada plataforma computacional e que apresente todos os aspectos modelados corretamente. Chamamos de distância semântica ao conjunto de decisões de projeto e/ou implementação ainda necessárias de serem tomadas para obter-se uma realização de um sistema a partir de um dado modelo deste sistema [37, 34]. Esta distância será tão maior quanto mais abstrato for o modelo de referência utilizado como base para a obtenção da implementação do sistema.

Uma boa prática de desenvolvimento é avaliar e tomar uma pequena quantidade dessas decisões isolada e sistematicamente, produzindo especificações mais detalhadas do sistema a cada passo [37, 34]. Assim, durante o desenvolvimento de um sistema podemos partir de um modelo do sistema em um alto nível de abstração e realizar sucessivos refinamentos para acrescentar detalhes incrementalmente a esse modelo até obtermos uma representação do sistema mais facilmente realizável (uma implementação). Este processo é chamado de desenvolvimento via refinamentos sucessivos [37,34]. Dessa forma, diminui-se a distância semântica existente entre o sistema esperado e sua implementação gradativamente, capturando-se e documentando-se as decisões de implementação de forma sistemática e rastreável. Este processo também garante a conformidade dos modelos e do sistema em relação à sua especificação [32].

A Figura 3 ilustra um processo de desenvolvimento via refinamentos sucessivos. Na Figura não há distância semântica entre a implementação de um sistema computacional (em essência, o código-fonte desse sistema) e a realização desse sistema (em essência, arquivos executáveis). Isso ocorre pois todas as decisões de implementação foram tomadas anteriormente de forma 
que a transformação (compilação) dessa implementação no sistema completo pode ocorrer automaticamente, sem a necessidade da inclusão de detalhes adicionais. Adicionalmente, algumas linguagems de programação possuem a implementação do sistema prontamente executável em uma máquina virtual. Neste cenário, a implementação do sistema computacional é semelhante à sua realização.
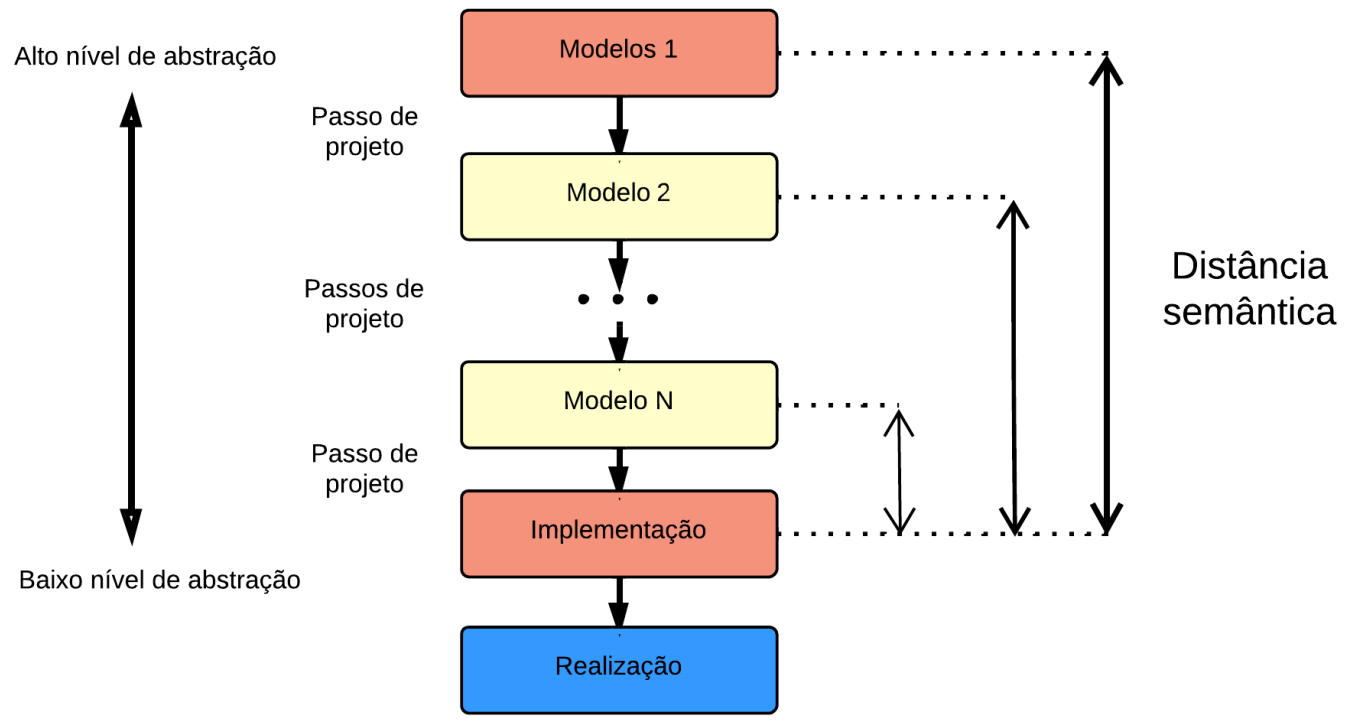

Figura 3: Redução sistemática da distância semântica através de refinamentos sucessivos.

\subsubsection{Definição de metamodelo}

Um metamodelo representa um modelo que especifica a sintaxe e a semântica de um conjunto de modelos que podem ser instanciados a partir dessa especificação [1]. Neste sentido, o propósito principal de um metamodelo é definir uma metalinguagem, ou seja, um conjunto sintático e semântico que descreve como elementos de modelagem podem ser instanciados e combinados de forma válida na definição de um modelo [1, 31, 38]. Para tanto, um metamodelo define uma taxonomia dos conceitos da linguagem e um conjunto de restrições sintáticas relacionadas [39]. A sintaxe concreta de uma linguagem deriva da sintaxe abstrata da linguagem, em um processo no qual a taxonomia é mapeada para o alfabeto da linguagem e as restrições sintáticas são mapeadas para a gramática dessa linguagem. Adicionalmente, uma vez que metamodelos são também modelos, os conceitos anteriormente apresentados para mode- 
los são também pertinentes também para metamodelos. Assim, metamodelos apresentam um conjunto de declarações e elementos formais que devem ser expressos em uma linguagem de modelagem com sintaxe e semântica bem definidas.

A sintaxe abstrata de um dado metamodelo pode ainda ser definida por outro metamodelo, também chamado meta-metamodelo. Este meta-metamodelo, por sua vez, pode ter sua sintaxe abstrata definida por um metamodelo próprio. Embora o número de metaníveis que podem ser definidos em uma arquitetura de metamodelagem seja arbitrário, um número máximo de níveis deve ser definido de modo a facilitar o suporte e a utilização desta arquitetura [1]. Por exemplo, a especificação da arquitetura UML define quatro níveis de metamodelagem [2], viz., o metametamodelo Meta Object Facility (MOF) [40], o metamodelo UML, o modelo UML do sistema a ser implementado e, finalmente, os objetos presentes no sistema em tempo de execução.

Um metamodelo é dito reflexivo quando este é definido usando-se o mesmo (sub-)conjunto de elementos de modelagem especificado pelo metamodelo, ou seja, as declarações no metamodelo são expressas na mesma linguagem que o metamodelo descreve [31]. Por exemplo, o metamodelo UML é expresso, em parte, utilizando-se diagramas de classes definidos pela linguagem UML [2]. Como o metamodelo reflexivo é expresso na mesma linguagem que descreve, sua interpretação provê um mapeamento dos elementos da linguagem para um subconjunto de elementos dessa linguagem. Múltiplas iterações de interpretação desse metamodelo levam a um metamodelo reflexivo mínimo, ou seja, um conjunto mínimo de elementos do metamodelo que permite expressar qualquer declaração sobre aquela linguagem de modelagem.

Interpretações a partir do metamodelo reflexivo mínimo mapeiam os elementos para o próprio metamodelo reflexivo mínimo, de forma a gerar uma circularidade que não consegue prover nenhuma expressão útil a respeito do significado do metamodelo. Adicionalmente, essa circularidade gera representações cada vez mais complexas do modelo original. Neste sentido, é desejável quebrar esta circularidade de modo que a interpretação do modelo não dependa de uma nova interpretação reflexiva do metamodelo para ser avaliada [31]. Este processo envolve a definição de informações adicionais sobre os elementos do metamodelo reflexivo mínimo usando uma linguagem mais expressiva que possa descrever conceitos ainda mais elementares. 
Por exemplo, a especificação da linguagem UML alia descrições textuais adicionais sobre o significado esperado para os elementos básicos da linguagem de forma a prover uma interpretação adequada a esses elementos e quebrar essa circularidade [2].

\subsection{Ontologias}

Ontologias têm sido utilizadas de forma crescente na área de Modelagem de Dados e Informação. Neste contexto, o uso de teorias ontológicas busca encontrar maneiras melhores para a organização e uso da grande quantidade de dados produzidos e armazenados diariamente [7, 41]. Técnicas inconsistentes de modelagem de informação, historicamente presentes no início das atividades de modelagem conceitual, levaram a muitos problemas de integração de bancos de dados e aplicações. Nesse sentido, cientistas procuraram nas ontologias uma forma de construir uma base sólida para a definição e a seleção de conceitos de modelagem para as gramáticas de sistemas de informações. Adicionalmente, ontologias têm sido utilizadas de forma crescente na modelagem e anotação de recursos e dados na área biomédica, tendo aplicações em gestão de conhecimento, integração de informação e interoperabilidade semântica e suporte à decisão e ao raciocínio [9]. Esta seção apresenta uma definição de ontologias e uma visão geral sobre a representação e o desenvolvimento de ontologias.

\subsubsection{Definição de ontologia}

Ontologia é a disciplina da Filosofia que trata do desenvolvimento de teorias e sistemas de categorias sobre a natureza e estrutura de um domínio de discurso a partir de uma dada visão de mundo [8]. Tais sistemas de categorias são abstratos, existindo de forma independente da linguagem utilizada para representá-los. Na área de Ciência da Computação, porém, uma ontologia é um artefato de engenharia que descreve um vocabulário formal e um conjunto de declarações lógicas explícitas (uma teoria lógica) sobre o significado esperado dos termos desse vocabulário [8]. Neste sentido, uma ontologia é dependente de uma linguagem de representação.

Ambos significados de ontologia são relacionados. Contudo, na Ciência da Computação o 
termo conceitualização é utilizado para referir-se ao significado filosófico da palavra, ou seja, uma visão abstrata e independente de linguagem de um dado domínio [8, 7, 42]. Neste sentido, uma ontologia é uma especificação explícita de uma dada conceitualização por meio de uma linguagem de representação [43].

Diferentes autores definem e utilizam o termo ontologia em Ciência da Computação de maneiras diferentes $[42,44,7,43,45]$. Nesse sentido, no contexto deste trabalho utilizamos a definição provida por Gruber [43], segundo a qual uma ontologia representa um modelo descritivo sobre um dado domínio de discurso que caracteriza explicitamente uma conceitualização sobre esse domínio. Dessa forma, uma ontologia captura as principais entidades e/ou conceitos presentes nesse domínio, bem como as relações mais importantes existentes entre essas entidades, em uma dada linguagem de representação.

Há grande diversidade entre os domínios de discurso descritos por ontologias. Uschold [42] apresenta três categorias para ontologias de acordo com seu domínio de discurso: ontologias de domínio, as quais definem entidades e conceitos relacionados a domínios genéricos, como medicina ou automóveis; ontologias de tarefa, as quais definem conceitos relacionados a atividades e resoluções de problemas de forma independente de um dado domínio; e meta-ontologias, as quais tratam de conceitos relacionados a linguagens de representação de conhecimento. Guarino [8] mantém a distinção de ontologias de domínio e ontologias de tarefa e ainda define ontologias de aplicação, as quais combinam ontologias de domínio e ontologias de tarefa para a descrição de métodos e atividades realizados em um dado domínio de aplicação; e ontologias de alto nível (top-level), as quais descrevem os conceitos mais abstratos e de maior nível de generalidade em relação a um conjunto de domínios.

\subsubsection{Representação de ontologias}

A linguagem utilizada para representar uma ontologia deve possuir um comprometimento ontológico com a conceitualização que fundamenta aquela ontologia $[8,7]$. Comprometimento ontológico é uma relação entre uma linguagem de representação e uma conceitualização. Esta relação define um mapeamento entre os termos do vocabulário dessa linguagem e os elemen- 
tos e relações do domínio presentes na conceitualização, tal que a conotação dos termos do vocabulário da linguagem possa ser facilmente interpretado e, portanto, que o vocabulário possa ser utilizado de uma forma consistente [43]. Adicionalmente, o comprometimento ontológico define um conjunto de modelos esperados para a linguagem em relação a uma dada conceitualização. O conjunto de modelos esperados é um conjunto formado pelos construtos da linguagem que são válidos em relação à conceitualização e que devem ser contidos pela ontologia.

Uma dada linguagem de representação permitirá não apenas a representação do conjunto de modelos esperados definidos pelo comprometimento ontológico, mas também será capaz de representar outros modelos (não esperados) [8, 7]. Dessa forma, pode haver alguma distância semântica entre a ontologia e a conceitualização a qual esta ontologia representa. Neste contexto, podemos aproximar uma ontologia de sua conceitualização por meio do desenvolvimento de uma axiomatização rica ou da adoção de um domínio e/ou conjunto de relações mais rico, obtendo assim ontologias mais detalhadas e que se aproximam melhor da conceitualização a qual caracterizam.

Naturalmente há uma escolha a ser feita em relação a ontologias com maior ou menor detalhamento. Enquanto ontologias de maior detalhamento aproximam melhor o significado esperado para um dado vocabulário, e portanto podem ser utilizadas mais facilmente para estabelecer um consenso em relação ao compartilhamento desse vocabulário, a grande quantidade de axiomas e a grande expressividade da linguagem adotada tornam essas ontologias mais difíceis de serem desenvolvidas e de serem utilizadas para a descoberta de conhecimento [8,9]. Já ontologias de menor detalhamento podem consistir em um número mínimo de axiomas escritos em uma linguagem de expressividade mínima. Essas características tornam as ontologias menos detalhadas mais interessantes para o suporte às funcionalidades principais de um dado sistema de informação e para o compartilhamento entre usuários que já compartilhem uma dada conceitualização $[8,9]$. 


\subsubsection{Desenvolvimento de ontologias}

Metodologias de desenvolvimento são muito utilizadas na engenharia de software de maneira geral e na engenharia de conhecimento de forma específica, uma vez que provêem um processo repetitível para alcançar um dado objetivo de projeto [46]. Dessa forma, o sucesso de um projeto torna-se menos sensível à variação de experiência prévia do time de desenvolvimento em projetos similares.

Diversas metodologias foram propostas para o desenvolvimento de ontologias. Enquanto algumas dessas metodologias lidam principalmente com o problema de construir uma nova ontologia ab initio [47, 48, 49, 50], outras metodologias propõem abordagens orientadas ao reuso de ontologias já existentes, com ou sem modificação destas ontologias [45, 51]. Adicionalmente, há propostas de metodologias para a construção colaborativa de ontologias $[52,53]$ e reengenharia de ontologias existentes [54].

Fernández-López et al. [51] propõe um ciclo de vida para o desenvolvimento de ontologias composto de algumas atividades ordenadas: planejamento, a qual trata da alocação de recursos para as principais tarefas realizadas durante o desenvolvimento da ontologia; especificação, a qual trata do levantamento dos requisitos e do propósito da nova ontologia; conceitualização, a qual trata da criação de modelos conceituais representando o problema e a solução provida pela ontologia, podendo haver uma série de representações intermediárias sobre o conhecimento do domínio envolvido; formalização, a qual trata da transformação dos modelos conceituais não-formais em modelos representados através de uma linguagem (semi) formal; integração, a qual trata do reuso de ontologias existentes para evitar duplicação de conceitos e reaproveitar esforços já desprendidos anteriormente; implementação, a qual trata da codificação da ontologia em uma linguagem formal computável; e, por fim, manutenção, a qual trata da inclusão de termos ou relacionamentos ou da modificação da ontologia de acordo com a necessidade e/ou a aquisição de novos conhecimentos. Adicionalmente, atividades de aquisição de conhecimento, documentação e avaliação podem ser realizadas durante todo esse ciclo de vida que, por sua vez, pode ser adaptado para uma abordagem de desenvolvimento baseada em prototipagem $[34,51]$. 
Durante a conceitualização, diferentes estratégias para a identificação dos conceitos e entidades a serem incluídos em uma ontologia em desenvolvimento podem ser utilizadas. Essas estratégias normalmente são baseadas em abordagens bottom-up, top-down ou middle-out $[46,8,50]$.

Uma estratégia bottom-up inicia-se pela descrição das entidades mais concretas do domínio, e segue agrupando-as em superclasses de entidades e conceitos mais gerais ou abstratos. Estratégias bottom-up costumam resultar em ontologias com um alto nível de detalhamento, porém aumentam o esforço necessário para o desenvolvimento dessas ontologias e tornam mais difícil a visualização de características comuns entre as várias entidades do domínio. Por esse motivo, essas abordagens aumentam o risco de inconsistências. Por sua vez, uma estratégia top-down parte da escolha e descrição dos conceitos e entidades mais abstratas do domínio e segue em direção à descrição das entidades mais concretas. Estratégias top-down resultam em um melhor controle em relação ao nível de detalhamento da ontologia resultante, porém podem necessitar de escolhas e imposições arbitrárias de um conjunto de conceitos e entidades de nível mais alto de abstração. Por fim, um estratégia middle-out balanceia todas essas características. Estas estratégias iniciam-se com a descrição dos termos mais importantes de um domínio, em qualquer nível de abstração, que por sua vez são especializados ou agrupados segundo a necessidade.

Durante o processo de desenvolvimento de uma ontologia, frequentemente faz-se necessário o reuso de ontologias já disponíveis $[51,55,8,18]$. O reuso permite reaproveitar esforços passados desprendidos na conceitualização e representação formal de um dado domínio de conhecimento. Esta atividade é realizada por meio da fusão ou da integração de ontologias [55].

A fusão de ontologias é um processo por meio do qual constrói-se uma ontologia para um dado domínio a partir de duas ou mais ontologias descrevendo o mesmo domínio ou diferentes aspectos do mesmo domínio [55]. Em um processo de fusão, as ontologias iniciais são unificadas em uma única ontologia final. Assim, dificilmente podemos identificar regiões da ontologia final que foram tomadas das ontologias iniciais e deixadas mais ou menos inalteradas.

O reuso de ontologias baseado em fusão apresenta dificuldades. Por exemplo, para que a fusão possa ser realizada é necessário que as ontologias iniciais comprometam-se com uma 
mesma conceitualização ou que os modelos esperados para as conceitualizações próprias de cada ontologia se sobreponham de alguma forma. Porém, o conjunto de modelos esperados por uma conceitualização é apenas aproximado por uma ontologia, de forma que os modelos das ontologias iniciais podem sobrepor-se parcialmente mesmo que os modelos esperados pelas conceitualizações a que essas ontologias se comprometem não se sobreponham. Isso faz com que as abordagens de reuso de ontologias baseado em fusão possam não funcionar adequadamente [8].

A integração de ontologias é um processo por meio do qual constrói-se uma ontologia para um dado domínio a partir do reuso de ontologias de outros domínios (ou sub-domínios). Em um processo de integração, as ontologias iniciais são agregadas, combinadas e estendidas em uma ontologia resultante. Neste caso, podemos identificar claramente as regiões que foram reutilizadas de cada ontologia inicial dado que o conhecimento representado nessas regiões normalmente é mantido inalterado [55].

O reuso de ontologias baseado em integração é facilitado se houver um esforço prévio na construção de bibliotecas de ontologias modulares [18, 49]. Adicionalmente, a construção modular permite criar ontologias com diferentes níveis de generalidade. Dessa forma, ontologias mais específicas do domínio podem reutilizar as mesmas ontologias de maior nível de generalidade, facilitando ainda mais o processo de integração [8].

Finalmente, o reuso e integração de ontologias descritas em diferentes linguagens de representação pode ser desejado. Neste cenário, além das dificuldades já presentes na integração de ontologias, torna-se necessário um mapeamento prévio entre os elementos das linguagens envolvidas. Este mapeamento deve buscar aproximar as linguagens em vários níveis de interoperabilidade, de forma a prover maneiras de transformar (ou traduzir) as declarações da linguagem fonte em declarações válidas e corretas da linguagem alvo. Neste sentido, cinco níveis diferentes de interoperabilidade entre linguagens podem ser definidos [56]: codificação, o qual permite segmentar e reconstruir o significado dos caracteres do alfabeto utilizado; léxico, o qual permite segmentar e reconstruir a representação de palavras e/ou símbolos; sintático, o qual permite estruturar e reconstruir a representação presente em sentenças ou fórmulas da lin- 
guagem; semântico, o qual permite recontruir o significado proposicional de uma declaração, i.e, preservar a consequência daquela declaração na nova linguagem; e semiótico, o qual permite reconstruir o significado pragmático de uma declaração, i.e., preservar a intepretação dos usuários em relação a um conjunto de declarações (contexto) ao ser representado na nova linguagem. Uma completa interoperabilidade em todos esses níveis nem sempre é possível, de forma que informação pode ser perdida durante uma tradução. Adicionalmente, linguagens são desenvolvidas para suportar diferentes teorias lógicas e níveis de expressividade, de forma que usuários de diferentes linguagens podem discordar no nível semiótico,obtendo diferentes conclusões em relação à inferências realizadas sobre uma mesma ontologia. Dessa maneira, a definição destes mapeamentos é facilitada se ambas as linguagens expressam comprometimento ontológico com uma mesma conceitualização/meta-metamodelo e possuem expressividade semelhante. 


\section{Desenvolvimento orientado a modelos}

Nos últimos anos, abordagens de desenvolvimento de software orientado a modelos têm sido utilizadas para direcionar o foco do desenvolvimento para as atividades de modelagem com o intuito de elevar o nível de abstração utilizado no processo de desenvolvimento. Estas abordagens procuram representar tanto aspectos relacionados ao domínio do problema quanto aspectos independentes de uma dada tecnologia de implementação. Por consequência, o desenvolvimento orientado a modelos facilita a compreensão do problema, o reuso de software e a redução do custo no desenvolvimento e manutenção desses sistemas em diversas plataformas.

O restante deste capítulo está estruturado da seguinte forma: a seção 3.1 apresenta uma visão geral sobre o desenvolvimento orientado a modelos; a seção 3.2 apresenta a arquitetura de metamodelagem da UML; finalmente, a seção 3.3 apresenta os frameworks de suporte ao desenvolvimento orientado a modelos utilizados no contexto deste trabalho.

\subsection{Visão geral}

O Desenvolvimento Orientado a Modelos (Model-Driven Development ou simplesmente MDD) é uma abordagem de desenvolvimento de sistemas computacionais que visa o refinamento e a transformação sistemática de modelos de alto nível de abstração em modelos mais concretos até a obtenção final de uma implementação de um sistema computacional em uma dada linguagem de programação [30, 32].

Esta abordagem de desenvolvimento altera o foco de desenvolvimento de um sistema computacional, normalmente posicionado sobre a atividade de programação, para a atividade de modelagem $[30,57]$. Adicionalmente, a premissa básica do desenvolvimento orientado a mo- 
delos é que uma dada aplicação seja completamente criada a partir de modelos, de modo a aproveitar todo o potencial de automação obtido por meio do suporte a padrões de modelagem e tecnologias para transformação de modelos em uma aplicação completa [32]. Neste sentido, a maior vantagem desta abordagem reside, em um primeiro momento, na criação de modelos independentes de uma dada tecnologia de implementação e mais próximos do domínio da aplicação [30, 32]. Esta característica facilita tanto a compreensão e especificação quanto a manutenção do sistema propriamente dito. Adicionalmente, modelos também são menos suscetíveis a mudanças tecnológicas que a representação de uma aplicação em uma dada linguagem de implementação. Dessa maneira, o suporte adequado pode permitir o reuso de um mesmo conjunto de modelos no desenvolvimento de aplicações para diferentes tecnologias de implementação e/ou a atualização facilitada do código da aplicação após a atualização de uma dada plataforma de execução.

A Arquitetura Orientada a Modelos (Model-Driven Architecture ou simplesmente MDA) [58] é uma abordagem de desenvolvimento orientado a modelos proposta pela OMG para o desenvolvimento de sistemas computacionais. De acordo com esta arquitetura, modelos são definidos a partir de três pontos de vista [36]: modelos independentes de computação, os quais são criados para capturar o ambiente do sistema e seus requisitos, sem apresentar preocupações com detalhes da estrutura e da execução do sistema; modelos independentes de plataforma, os quais representam a operação do sistema, escondendo detalhes necessários para sua execução em uma dada plataforma; por fim, modelos específicos de plataforma, os quais acrescentam detalhes específicos de uma dada plataforma aos modelos independentes de plataforma.

A trajetória de desenvolvimento utilizando MDA inicia-se com a captura do ambiente e dos requisitos do sistema em modelos independentes de computação. Em seguida, os esforços são concentrados na definição de detalhes sobre a estrutura e as operações do sistema. Esses detalhes são formalizados em modelos independentes de plataforma. Por fim, transformações automáticas devem ser definidas e utilizadas para transformar esses modelos em implementações adequadas a diferentes plataformas. Dessa maneira, podemos reduzir os custos e os esforços necessários para a criação de diferentes implementações do sistema. A Figura 4 ilustra os dife- 
rentes pontos de vista definidos pela arquitetura orientada a modelos para a implementação de um sistema computacional, bem como a trajetória de desenvolvimento utilizando estes pontos de vista.

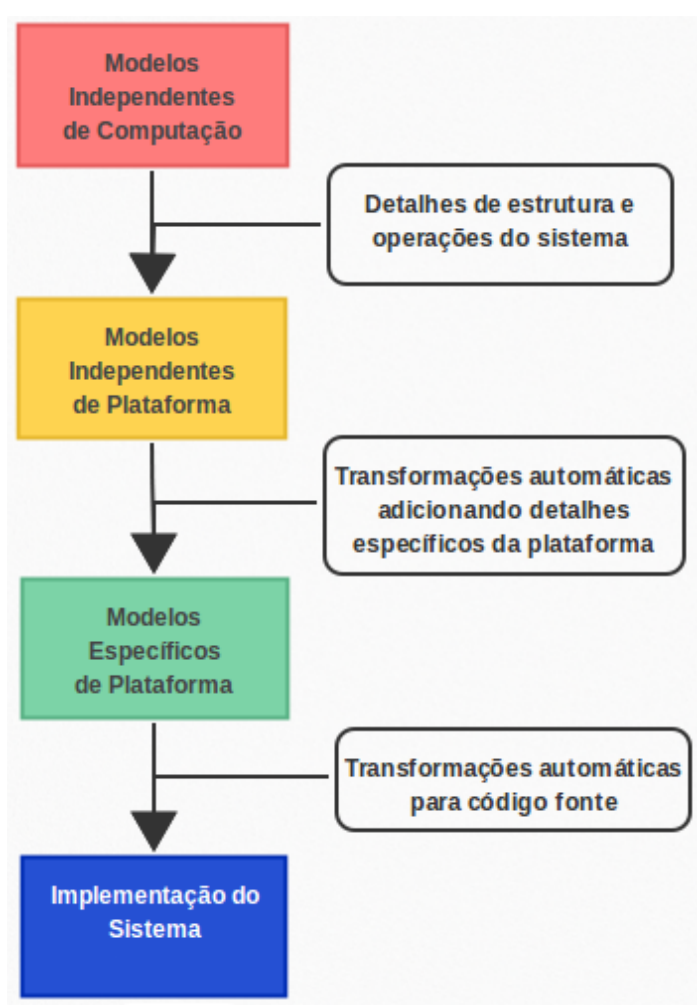

Figura 4: Pontos de vista e trajetória de desenvolvimento da arquitetura orientada a modelos.

\subsubsection{Transformações entre modelos}

O suporte completo ao desenvolvimento orientado a modelos só pode ser alcançado se houver suporte a transformações sucessivas que permitam obter uma implementação do sistema em uma dada linguagem de programação a partir dos modelos iniciais. Nesse sentido, uma transformação de modelos pode ser vista como um mapeamento entre elementos de um modelo (o modelo fonte) para elementos de outro modelo (o modelo alvo) [1]. Quando uma transformação de modelos é executada, um modelo fonte é transformado em um modelo alvo por meio de um conjunto de regras de transformação. Transfomações sucessivas podem ser aplicadas a partir de um modelo inicial, de forma que o modelo obtido após uma transformação possa ser usado como modelo fonte para uma nova transformação.

Uma transformação torna-se mais útil se esta for definida de modo formal e sistemático para 
que possa ser aplicada automaticamente. Uma transformação pode ser definida mapeando-se elementos dos metamodelos dos modelos envolvidos (metamodelo fonte e metamodelo alvo). Esta abordagem de transformação possui como vantagem principal a aplicação dessa transformação em qualquer modelo que seja instância do metamodelo fonte. Nesse sentido, a definição dessa transformação pode ser facilitada se ambos os metamodelos envolvidos compartilham o mesmo meta-metamodelo. A Figura 5 ilustra este tipo de processo de transformação.

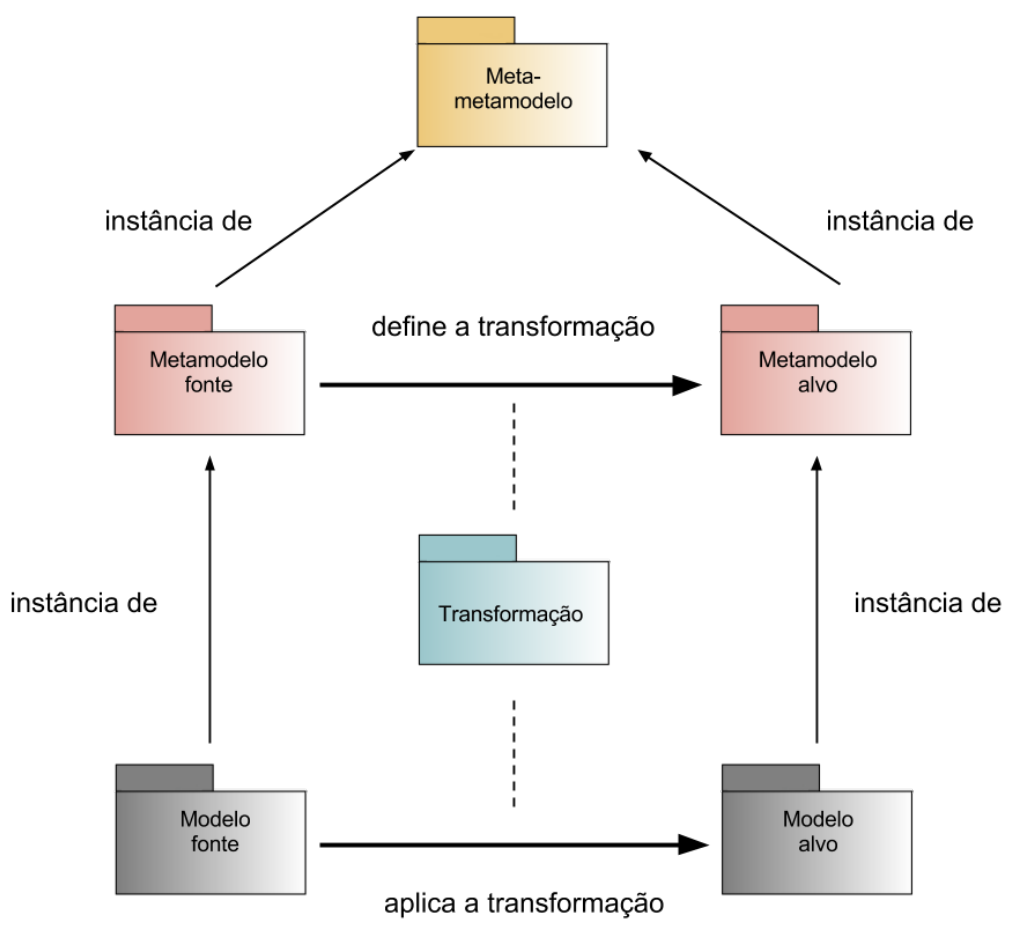

Figura 5: Transformação de modelos ao meta-nível com um meta-metamodelo comum (adaptado de [1]).

Qualquer artefato gerado durante o desenvolvimento de um sistema pode ser tratado como um modelo, seja esse artefato código-fonte, um artefato textual ou mesmo a documentação do sistema [1]. Cada um desses artefatos possui uma estrutura própria definida a partir do metamodelo desse artefato. Em um contexto de desenvolvimento orientado a modelos, é desejável que todos esses artefados de desenvolvimento sejam, de alguma forma, gerados a partir de transformações dos modelos desenvolvidos. Dessa forma, alterações realizadas nos modelos fontes podem ser propagadas de forma mais rápida e confiável aos artefatos produzidos a partir desses modelos, gerando ciclos de desenvolvimento mais rápidos e menor custo de manutenção.

Os conceitos definidos para transformações de modelos têm extensa área de aplicação, não 
sendo restritos apenas ao desenvolvimento de novos softwares. Por exemplo, transformações entre modelos também são úteis na integração semântica de sistemas computacionais já existentes. Neste sentido, quaisquer artefatos que carregam informação de interesse compartilhado por ambos os sistemas podem ser vistos como modelos, e transformações podem ser formalmente definidas para obter uma representação adequada dessa informação para cada uma das aplicações [59].

\subsubsection{Aplicações de MDD}

Diferentes trabalhos envolvendo aplicações do desenvolvimento orientado a modelos em diversos domínios podem ser encontrados na literatura. Tais trabalhos utilizam esta abordagem de desenvolvimento de forma a tratar diferentes necessidades em diferentes contextos.

O acesso a repositórios de dados no domínio biomédico é, tipicamente, realizado por meio de páginas Web e aplicações. As interfaces utilizadas para esse acesso por vezes apresentam funcionalidades semelhantes e são tipicamente desenvolvidas com recursos limitados (pequena quantidade de desenvolvedores). Neste cenário, Garwood et al. [60] propõe o uso da arquitetura orientada a modelos para o desenvolvimento de interfaces para repositórios de dados no domínio biomédico com o intuito de reduzir a quantidade de tempo dispensada pelos especialistas do domínio na criação de tais interfaces. Neste sentido, modelos independentes de computação são utilizados para descrever a estrutura do repositório de dados, enquanto modelos independentes de plataforma são utilizados para descrever propriedades relacionadas à criação dos diferentes campos dos formulários da interface. Adicionalmente, um sistema chamado Pierre foi desenvolvido para suporte à transformação do conjunto de modelos definidos em interfaces para acesso ao repositório alvo.

MDArte [61] é uma extensão proposta para framework AndroMDA para suporte ao desenvolvimento utilizando a arquitetura orientada a modelos [62]. O MDArte foi utilizado com sucesso no desenvolvimento do Sistema de Gerenciamento de Dados de Catalogação Parametrizado (SGDC-P) do Centro de Catalogação das Forças Armadas (CECAFA). Este sistema permite a codificação de mensagens das forças armadas e do Ministério da Defesa segundo os 
padrões definidos pela Organização do Tratado do Atlântico Norte (OTAN). Adicionalmente, o MDArte também foi utilizado para o desenvolvimento do Sistema de Informação de Convênios e Contratos de Repasse da Administração Pública Federal (SICONV) do Ministério do Planejamento. O SICONV é um sistema Web de informação governamental online aberto a todos os cidadãos brasileiros e permite o rastreio de acordos e outros instrumentos de lei utilizados para transferir fundos do governo federal para agências e entidades públicas e/ou particulares. Entre as lições aprendidas durante o desenvolvimento de ambos projetos, os autores indicam que o sucesso obtido no uso de desenvolvimento orientado a modelos foi facilitado pela identificação clara dos principais benefícios esperados pelo uso de um conjunto tecnologias, bem como pelo reuso de soluções não orientadas a modelos já disponíveis para tratar problemas específicos de implementação. Este reuso pode ser suportado por meio do desenvolvimento de adaptadores para os modelos desenvolvidos. Adicionalmente, também é apresentado como um fator importante para esse sucesso a capacidade da equipe de desenvolvimento em assumir controle total sobre as transformações de modelos envolvidas.

As atividades de análise de requisitos e de projeto arquitetônico de um sistema computacional não são necessariamente executadas de forma sequencial. Estas atividades também podem ser executadas em paralelo [63]. Neste cenário, torna-se ainda mais importante manter a consistência entre os diversos artefatos utilizados no desenvolvimento frente às mudanças no conjunto de requisitos funcionais do sistema. Em contextos tradicionais de desenvolvimento, essa consistência costuma ser verificada continuamente por meio da execução de testes de execução e de análises de conformidade arquiteturais da implementação do sistema. Suporte semelhante tem sido desenvolvido para o contexto de desenvolvimento orientado a modelos. Neste sentido, Vogelsang et al. [63] estuda como derivar sistematicamente testes de conformidade a partir da especificação de requisitos do sistema e/ou descrições de casos de uso. O trabalho define um conjunto de artefatos e uma trajetória de desenvolvimento orientada a modelos que podem ser utilizadas para a obter os testes automáticos e associá-los à definição da arquitetura do sistema. Adicionalmente, o trabalho investiga como integrar esses testes no ambiente de desenvolvimento, de maneira a gerenciar continuamente possíveis mudanças que ocorram no conjunto de requisitos funcionais. 
O projeto Timeless Business Process and Services (TIMBUS) visa promover o acesso continuado a processos de negócio em meio digital, fazendo frente à rápida evolução e crescente necessidade de interoperabilidade encontrada pelas empresas de tecnologia na União Européia. Neste contexto, Coutinho et al. [64] propõem o uso da arquitetura orientada a modelos para prover o desenvolvimento ágil de serviços Web corporativos. A interoperabilidade entre esses serviços é modelada e suportada por meio de um conjunto de transformações horizontais, definidas em cada nível da arquitetura orientada a modelos. Adicionalmente, um processo para a negociação de decisões de desenvolvimento é proposto, de forma a ser utilizado em todas as camadas da arquitetura orintada a modelos em busca das melhores soluções para o desenvolvimento dos serviços dadas as experiências pregressas da empresa.

Kropf et al. [65] propõem o uso da arquitetura orientada a modelos para o desenvolvimento de sistemas de prontuário eletrônico de paciente. Neste sentido, os autores utilizam padrões definidos pela World Wide Web Consortium (W3C) em conjunto com padrões para a interoperabilidade de sistemas de $e$-health definidos pela openEHR Foundation [66]. Adicionalmente, o processo de desenvolvimento definido desacopla a atividade de modelagem das demais atividades de desenvolvimento. Tal característica permite que os profissionais de saúde definam os modelos conceituais dos dados a serem armazenados pelo sistema sem a necessidade de conhecimento profundo sobre os demais aspectos, necessitando apenas o conhecimento dos arquétipos definidos pelo openEHR. Os modelos conceituais definidos são, então, exportados como modelos XML Schema Definitions (XSD) e utilizados na definição dos documentos em bancos de dados de XML, bem como transformados de maneira a obter interfaces HTML para esses bancos de dados.

O metamodelo Model Interchange Format (MIF) [67] é um metamodelo proprietário utilizado para a definição de modelos específicos de domínio propostos pela Health Level Seven International (HL7 International) [68]. HL7 International é uma organização que visa criar e promover padrões para sistemas de informação no domínio do cuidado à saúde. Por ser proprietário, o metamodelo MIF possui pequeno suporte de ferramentas de desenvolvimento. Neste sentido, Martínez-García et al. [69] apresenta o uso do metamodelo MIF em um con- 
texto de desenvolvimento orientado a modelos. Este trabalho propõe o uso de mapeamentos e transformações entre o metamodelo UML e o metamodelo MIF de maneira a permitir o uso de UML para o desenvolvimento de modelos que serão, posteriormente, representados como modelos HL7.

\subsection{Arquitetura de metamodelagem UML}

Unified Modeling Language (UML) [2, 25] é uma linguagem para modelagem de propósito geral padronizada pela Object Management Group (OMG) [26]. A OMG é um consórcio internacional sem fins lucrativos para o desenvolvimento e manutenção de padrões abertos utilizados na engenharia, modelagem e integração de sistemas computacionais e de informação.

A UML provê sintaxe e semântica formalmente definidas para a modelagem orientada a objetos de sistemas computacionais. A UML provê uma sintaxe gráfica para a representação dos conceitos modelados e diferentes tipos de diagramas utilizados para modelar diferentes visões do sistema, divididos em três categorias: modelagem estrutural, modelagem comportamental e modelagem de interações.

Diagramas para modelagem estrutural são utilizados para representar estruturas estáticas da aplicação, tais como classes, objetos, componentes e pacotes. Diagramas para modelagem comportamental são utilizados para representar comportamentos gerais da aplicação, tais como atividades, máquinas de estados e casos de uso. Por fim, diagramas para a modelagem de interações derivam dos diagramas de modelagem comportamental mais gerais e especificam interações entre os conceitos modelados, tais como comunicação entre partes da aplicação e sequência de eventos.

A UML independe de uma metodologia de desenvolvimento. Dessa forma, esta linguagem pode ser utilizada em conjunto com qualquer metodologia de desenvolvimento disponível. Adicionalmente, a OMG define um padrão para a serialização dos modelos desenvolvidos em XML, o XML Metadata Interchange (XMI) [70]. O XMI padroniza como esses modelos devem ser representados em arquivos e possibilita a integração e utilização de diferentes ferramentas 
para o refinamento e visualização durante o desenvolvimento de um sistema.

A UML é especificada em duas partes, chamadas infraestrutura [2] e superestrutura [25]. A infraestrutura UML define um núcleo de metalinguagem reflexivo, reutilizável e extensível. Adicionalmente, a infraestrutura UML define o uso de perfis para prover aos usuários da linguagem um mecanismo de extensão da mesma. Por sua vez, a superestrutura da linguagem complementa a infraestrutura e define um conjunto de subpacotes especializados para modelagem estrutural e comportamental.

\subsubsection{Visão geral da arquitetura UML}

A arquitetura UML é definida por meio de uma abordagem de metamodelagem em quatro camadas especificadas hierarquicamente $[2,25]$. A camada superior da UML é a camada de meta-metamodelagem, ou M3, e define uma linguagem para a especificação de metamodelos. Adicionalmente, essa camada define o núcleo de metalinguagem usado para definir uma variedade de metamodelos, como o metamodelo UML, o Meta Object Facility (MOF) [40] e o Common Warehouse Metamodel (CWM) [71].

A camada de metamodelagem, ou M2, consiste em uma instância da camada de metametamodelagem e define a linguagem UML propriamente dita. Esta camada apresenta todos os elementos de modelagem da linguagem UML e define como esses elementos podem ser combinados na descrição de um dado domínio.

A camada de modelagem, ou M1, consiste em uma instância da camada de metamodelagem. Esta camada descreve um domínio de interesse por meio de um conjunto de modelos UML. Adicionalmente, esta camada permite modelos contendo tanto elementos de modelagem quanto ilustrações de instâncias desses elementos.

Por fim, a camada de objetos, ou M0, representa a camada mais baixa da arquitetura UML. Esta camada contém instâncias dos elementos de modelagem e objetos de informação em tempo de execução. A Figura 6 apresenta um exemplo das relações entre as camadas de metamodelagem definidas na arquitetura UML. 


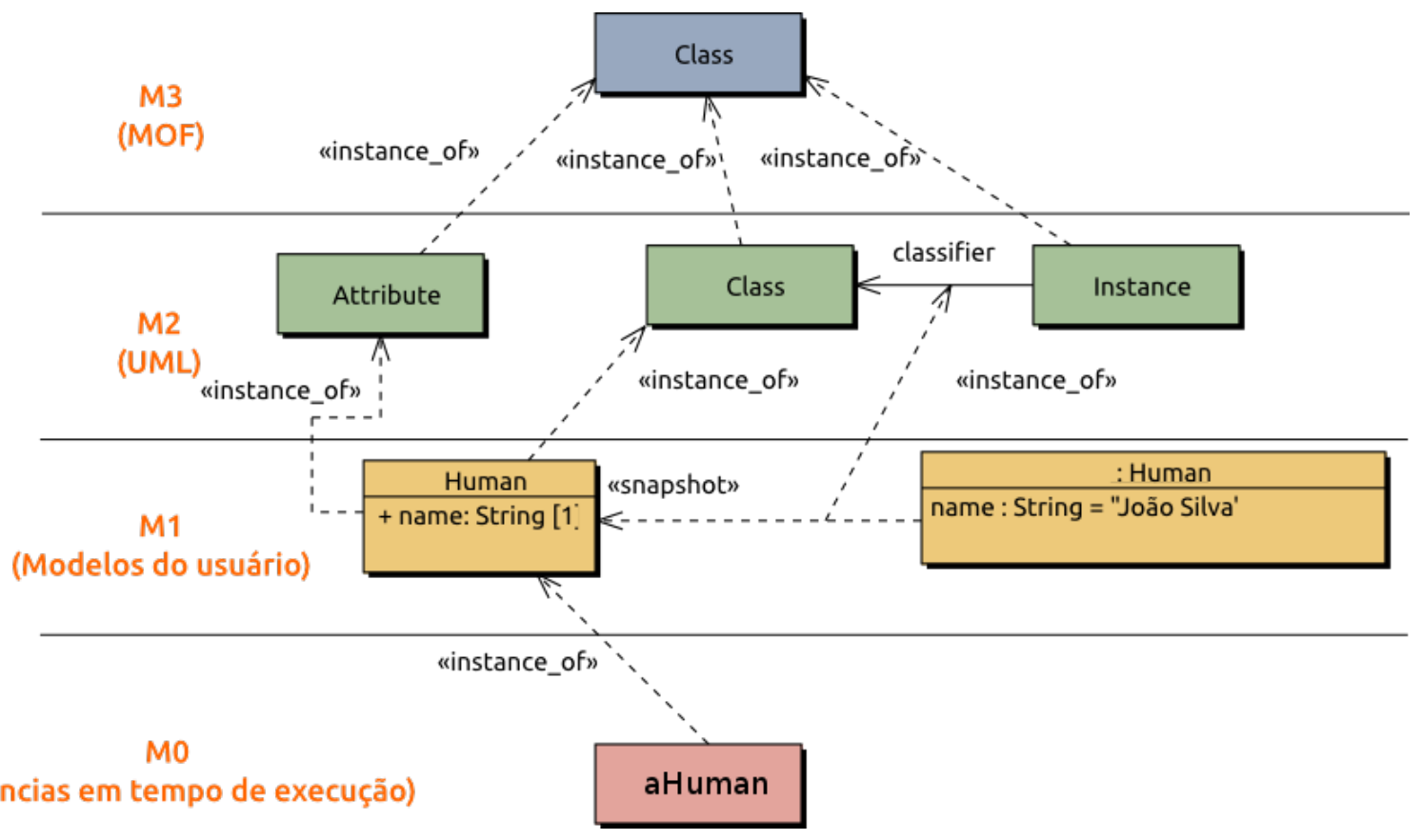

Figura 6: Arquitetura de metamodelagem UML em quatro camadas. (Adaptado de [2]).

\subsubsection{Meta Object Facility (MOF)}

Meta Object Facility (MOF) [40] é uma linguagem de metamodelagem para o desenvolvimento orientado a modelos desenvolvido pela OMG. Várias outras tecnologias padronizadas pela OMG, incluindo UML, utilizam o MOF (ou tecnologias derivadas) como linguagem de metamodelagem. .

A linguagem UML está alinhada ao MOF por meio da infraestrutura de modelagem da própria linguagem [2]. Duas abordagens complementares são utilizadas para conseguir esse alinhamento: primeiramente, um núcleo comum de metalinguagem (pacote InfrastructureLibrary) é definido para ambas as linguagens, de forma que elementos de modelagem são compartilhados entre MOF e UML; em seguida, a especificação do MOF adiciona interfaces reflexivas ao núcleo comum das duas linguagens, enquanto a especificação UML estende esse núcleo comum ao adicionar novas propriedades a seus elementos. As interfaces reflexivas adicionadas pelo MOF possibilitam ao usuário da linguagem o uso de técnicas de instrospecção nos modelos criados, de forma a permitir modelar a descoberta e manipulação de elementos de um modelo sem conhecimento prévio das características específicas desse elemento. Adicionalmente, as interfaces reflexivas providas pelo MOF funcionam não apenas para o próprio MOF, 
mas também para UML, CWM e outros metamodelos que sejam instanciados utilizando o MOF como meta-metamodelo. Por sua vez, as propriedades adicionadas pela UML aos elementos do núcleo comum permitem capturar melhor as necessidades na modelagem de aplicações de natureza diversa.

Neste sentido, a UML é definida como um modelo que utiliza essencialmente o MOF como metamodelo, uma vez que o núcleo destas linguagens é o mesmo, e todo elemento UML é essencialmente uma instância de um único elemento de modelagem MOF. Dessa forma, o pacote InfrastructureLibrary é utilizado nos metaníveis M2 e M3, uma vez que o mesmo é reutilizado e extendido tanto pela UML quanto pelo MOF.

MOF é dividido em dois subconjuntos: Essential MOF (EMOF) e Complete MOF (CMOF). EMOF é o conjunto básico da linguagem baseado no pacote básico da InfrastructureLibrary e provê os mecanismos básicos para a definição de reflexão. Por sua vez, CMOF é construído através de uma fusão do EMOF com o pacote mais completo da InfrastructureLibrary e provê as capacidades básicas de metamodelagem do MOF. Adicionalmente, MOF define como modelos UML, e/ou outros modelos que utilizam o MOF como meta-metamodelo, devem ser compartilhados entre aplicações usando o padrão XML Metadata Interchange (XMI) [70], o qual provê o mapeamento e serialização de modelos MOF utilizando XML.

\subsubsection{Object Constraint Language (OCL)}

Object Contraint Language (OCL) [72] é uma linguagem formal para a descrição de expressões em modelos UML. Um diagrama UML em geral não é suficientemente refinado para prover todos os aspectos relevantes de uma especificação. Assim, há a necessidade de descrever restrições adicionais em relação aos objetos dos modelos. Restrições podem ser escritas por meio de linguagens naturais ou linguagens formais. Enquanto a descrição dessas restrições utilizando linguagem natural pode levar a ambiguidades, o uso de linguagens formais tradicionais é uma tarefa não trivial para grande parte dos desenvolvedores de modelos. Neste sentido, a OCL foi criada para ser uma linguagem formal para a descrição de restrições facilmente lida e escrita. 
Expressões em OCL podem ser utilizadas para especificar derivações de valores, operações de consultas ao modelo, condições invariantes, valores iniciais de atributos e pré-condições e pós-condições de uma dada operação de um modelo. Derivações de valores e operações de busca podem ser utilizadas para verificar os objetos de um modelo e retornar um dado valor ou objeto de interesse. Expressões OCL que representem condições invariantes especificam condições que devem ser válidas para os objetos modelados em um dado contexto. Neste sentido, expressões OCL que especificam derivações de valores, operações de buscas e condições invariantes não devem causar mudanças em outras partes do modelo ao serem avaliadas. Por sua vez, pré-condições e pós-condições podem ser usadas para especificar operações ou ações que irão modificar o estado do sistema quanto executadas. Porém, como OCL não é uma linguagem de programação, não é possível implementar estruturas de lógica de programação ou controle de fluxo utilizando OCL, invocar subprocessos ou ativar expressões OCL que não sejam buscas. Adicionalmente, como OCL é primariamente uma linguagem para a especificação de restrições, expressões para essa linguagem não podem ser diretamente executadas em um ambiente de execução.

\subsubsection{Perfis UML}

A criação de modelos sobre um domínio em particular pode se beneficiar do uso de elementos de modelagem mais específicos que aqueles providos por uma determinada linguagem de modelagem de propósito geral. Esse benefício pode ser conseguido através da adaptação do metamodelo de forma a prover terminologia e semântica mais específica, bem como uma notação mais adequada para representar os principais conceitos desse domínio. Neste sentido, duas abordagens podem ser utilizadas para prover elementos de modelagem UML específicos para um dado domínio: uma abordagem baseada no MOF ou uma abordagem baseada em perfis.

MOF define um mecanismo de metamodelagem que pode ser utilizado livremente para criar elementos para um novo metamodelo [40], bem como para extender os elementos do metamodelo existente de forma irrestrita. Por sua vez, a UML define um mecanismo chamado perfil [2] que deve ser utilizado em conjunto com um metamodelo de referência. Neste sentido, 
perfis UML são definidos como um subconjunto do mecanismo de extensão do MOF [40].

O mecanismo de perfil foi criado para permitir a criação de extensões que permitissem ajustar o metamodelo UML existente para diferentes plataformas de implementação, tal como o $\mathrm{C}++$, Common Object Request Broker Architecture (CORBA) ou Enterprise Java Beans (EJB), ou para diferentes domínios, tal com como aplicações de tempo real, objetos de negócio ou modelagem do processo de desenvolvimento de software [2]. Ainda que o alvo principal para o uso de perfis seja a UML, podemos utilizar o mecanismo de perfil com qualquer outro metamodelo que seja baseado no núcleo comum da linguagem.

Um perfil é dito um mecanismo de extensão "leve" pois não permite a criação de novos elementos de modelagem para uma linguagem, mas apenas a especialização dos elementos de modelagem existente. Nesse sentido, o uso de perfis permite apenas a definição de estereótipos que são aplicados às metaclasses existentes. Um estereótipo define como uma metaclasse pode ser estendida de forma a incorporar uma terminologia e semântica específicas e adicionar restrições de como esta metaclasse pode ser utilizada para a modelagem em um contexto específico. Dessa forma, um perfil é dependente do metamodelo da linguagem de referência e não pode contradizer as restrições já existentes para os elementos da mesma.

Restrições associadas aos estereótipos podem ser especificadas utilizando linguagem natural ou OCL. A avaliação automática de expressões OCL pode suportar a verificação da integridade de um modelo segundo as restrições definidas em seu metamodelo ou especificar consultas que retornam valores sobre os elementos desse modelo.

\subsection{Frameworks para o suporte ao desenvolvimento orien- tado a modelos}

Eclipse Modeling Project (EMP) [73] é um projeto da Eclipse Foundation voltado para a comunidade de usuários do ambiente de desenvolvimento Eclipse [74]. O EMP busca agregar e fomentar projetos que provejam suporte ao desenvolvimento orientado a modelos para o ambiente Eclipse. 
Os projetos promovidos pelo EMP podem ser agrupados em: suporte ao desenvolvimento de sintaxe abstrata, o qual provê facilidades para suporte à modelagem de software e definição de metamodelos para outras linguagens de modelagem; suporte ao desenvolvimento de sintaxe concreta, o qual provê facilidades para o desenvolvimento de sintaxes concretas textuais ou gráficas de forma (semi) automatizada e para a edição de modelos através da sintaxe desenvolvida; suporte às transformações de modelos, o qual provê facilidades para a definição e execução de uma transformação entre modelos, além de permitir o uso de padrões definidos para estas transformações; suporte à geração de texto a partir de modelos, o qual provê facilidades para a geração de texto (tipicamente código-fonte ou documentação) a partir de um dado modelo; suporte ao desenvolvimento utilizando processos e linguagens padronizadas, o qual provê suporte ao desenvolvimento utilizando processos e linguagens já definidos e utilizados pela indústria de software, tais como MOF, UML, BPMN e OCL; e, finalmente, suporte ao desenvolvimento de linguagens específicas de domínio, o qual provê facilidades para o desenvolvimento (semi) automático de editores para notações textuais de linguagens específicas de domínio.

Os seguintes frameworks do EMP foram estudados no contexto deste trabalho: o Eclipse Modeling Framework (EMF) [75] e o Eclipse OCL [76] para o desenvolvimento de metamodelos; o Graphical Modeling Framework (GMF) [77] para o desenvolvimento de sintaxe concreta gráfica concreta; e o ATLAS Transformation Language (ATL) [78, 79], para o desenvolvimento de transformações de modelos.

\subsubsection{Eclipse Modeling Framework (EMF)}

O Eclipse Modeling Framework (EMF) [75] é um framework de modelagem e geração de código desenvolvido sob o escopo do EMP. Este framework provê facilidades para o desenvolvimento de modelos conceituais e para a construção de aplicações e ferramentas baseados nesses modelos. Adicionalmente, o EMF permite a transformação desses modelos em códigos-fonte para a linguagem Java, os quais podem ser utilizados diretamente ou personalizados conforme a necessidade. O EMF é um projeto central do EMP, uma vez que provê a base de integração para 
os outros projetos e frameworks [80]. Por exemplo, o framework para validação de um modelo, provido pelo EMF, também pode ser utilizado para permitir o uso de OCL como linguagem para a especificação de restrições em modelos EMF e, consequentemente, permitir a validação dessas restrições no sistema criado a partir desse modelo em tempo de execução.

O suporte provido pelo EMF consiste em dois frameworks fundamentais [81]: o framework core, o qual provê suporte à geração de código e à execução de classes Java a partir de um dado modelo desenvolvido; e o framework EMF.Edit, o qual estende o framework core por meio da adição de classes Java para a visualização e a edição do modelo em desenvolvimento. Adicionalmente, o EMF.Edit provê suporte para a reversão de uma dada alteração realizada neste modelo.

O framework core provê um metamodelo reflexivo de propósito geral chamado Ecore. Este metamodelo permite a criação de modelos conceituais independentes de plataforma e a posterior transformação desses modelos em código de aplicação Java. Essa transformação tem como passo intermediário a obtenção de um modelo generativo dependente de plataforma, o qual adiciona detalhes usados para guiar a transformação em código de aplicação. Adicionalmente, as características reflexivas do Ecore permitem que instâncias de classes modeladas com o EMF sejam manipuladas a partir do metamodelo da linguagem. Dessa maneira, é possível fazer uso do suporte à transformação e geração de código provido pelo EMP para modelos Ecore em modelos de linguagens específicas de domínio criadas a partir do Ecore.

O projeto EMF foi iniciado como uma implementação da especificação do MOF e posteriormente evoluiu para ser uma implementação eficiente (em Java) de um subconjunto do núcleo do metamodelo MOF. Por esta razão, o metamodelo Ecore é semelhante ao metamodelo EMOF, havendo apenas pequenas divergências entre ambos. Estas divergências são, em geral, associadas à nomenclatura utilizada. Adicionalmente, o EMF provê facilidades para ler e escrever serializações em XMI de modelos EMOF [81], de forma que modelos UML serializados através de XMI e EMOF podem ser manuseados através do suporte provido pelo EMF.

A Figura 7 apresenta o alinhamento do EMF em relação à arquitetura UML. O metamodelo Ecore é equivalente à camada M3 da arquitetura UML, representada pelo metamodelo 
MOF/EMOF. Linguagens específicas de domínio são equivalentes à camada M2 da arquitetura UML, representada pelo metamodelo UML. Estas linguagens específicas de domínio podem ser a própria linguagem Ecore (reflexivamente instanciada) ou mesmo uma linguagem baseada em Ecore definida pelo usuário. Modelos EMF instanciados a partir dessa linguagem específica de domínio são equivalentes à camada M1 da arquitetura UML, representada pelos modelos UML. Finalmente, instâncias Java criadas a partir de classes representadas nesses modelos e/ou objetos EMF dinâmicos reflexivamente criados a partir dos modelos desenvolvidos são equivalentes à camada M0, representada na arquitetura UML pelas instâncias em tempo de execução.

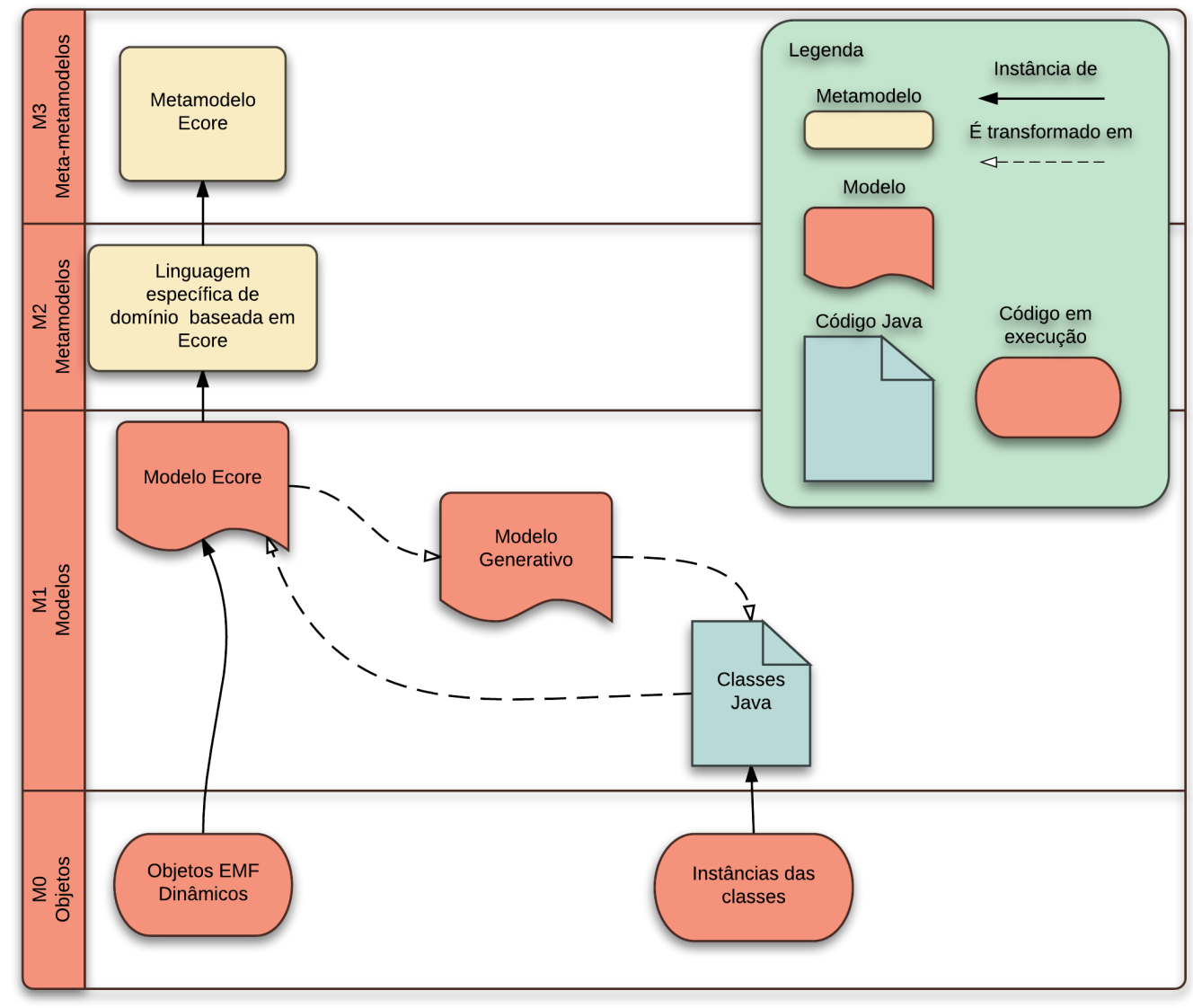

Figura 7: Alinhamento entre as camadas de modelagem EMF e camadas de modelagem UML.

\subsubsection{Graphical Modeling Framework (GMF)}

Graphical Modeling Framework (GMF) [77] é um projeto do EMP voltado para o desenvolvimento de uma sintaxe gráfica concreta para uma linguagem específica de domínio. GMF utiliza o EMF para a representação dos conceitos durante a criação de um modelo da linguagem. 
O GMF provê quatro linguagens de modelagem diferentes, utilizadas na definição de uma sintaxe concreta visual: GMFGraph, GMFTool, GMFMap e GMFGen. A linguagem GMFGraph é utilizada para a definição da representação gráfica dos elementos em um diagrama. A linguagem GMFTool é utilizada para a representação das ferramentas presentes na paleta do editor. A linguagem GMFMap é utilizada para o mapeamento entre elementos do domínio, representações gráficas e ferramentas de criação desses elementos. Por fim, a linguagem $G M F$ Gen é utilizada para a representação do modelo generativo do editor. Adicionalmente, o GMF provê: i) uma ferramenta de transformação, usada para transformar um modelo GMFMap em um modelo GMFGen; ii) um gerador de código, usado para implementar classes Java e artefatos necessários à criação de um editor gráfico a partir de um modelo GMFGen; e iii) um ambiente de execução, usado para a execução do editor criado [3].

A figura 8 apresenta o alinhamento entre os metamodelos envolvidos na construção de um editor baseado em GMF e os diferentes pontos de vista definidos pela arquitetura orientada a modelos. Modelos de domínio, modelos de definição da representação gráfica e modelos de definição de ferramentas de criação de elementos representam modelos independentes de plataforma. Os modelos generativos criados pelo EMF e pelo GMF representam modelos específicos de plataforma. Esta figura também representa as relações de conformidade, dependência e derivação entre os modelos e meta-modelos envolvidos. Todos os metamodelos envolvidos no projeto GMF são instâncias do metamodelo Ecore.

De forma padrão, um editor GMF serializa cada modelo do usuário em dois arquivos diferentes: um arquivo contendo o modelo semântico criado, no qual estão representadas as entidades, os tipos de dados e os valores do modelo; e um segundo arquivo contendo informações sobre a notação do modelo, no qual são representadas as posições e as representações gráficas dos elementos no diagrama. Embora essa serialização seja canonicamente definida usando Ecore e XMI, o usuário deste framework pode desenvolver outros mecanismos de serialização que podem ser utilizados pelo editor GMF 


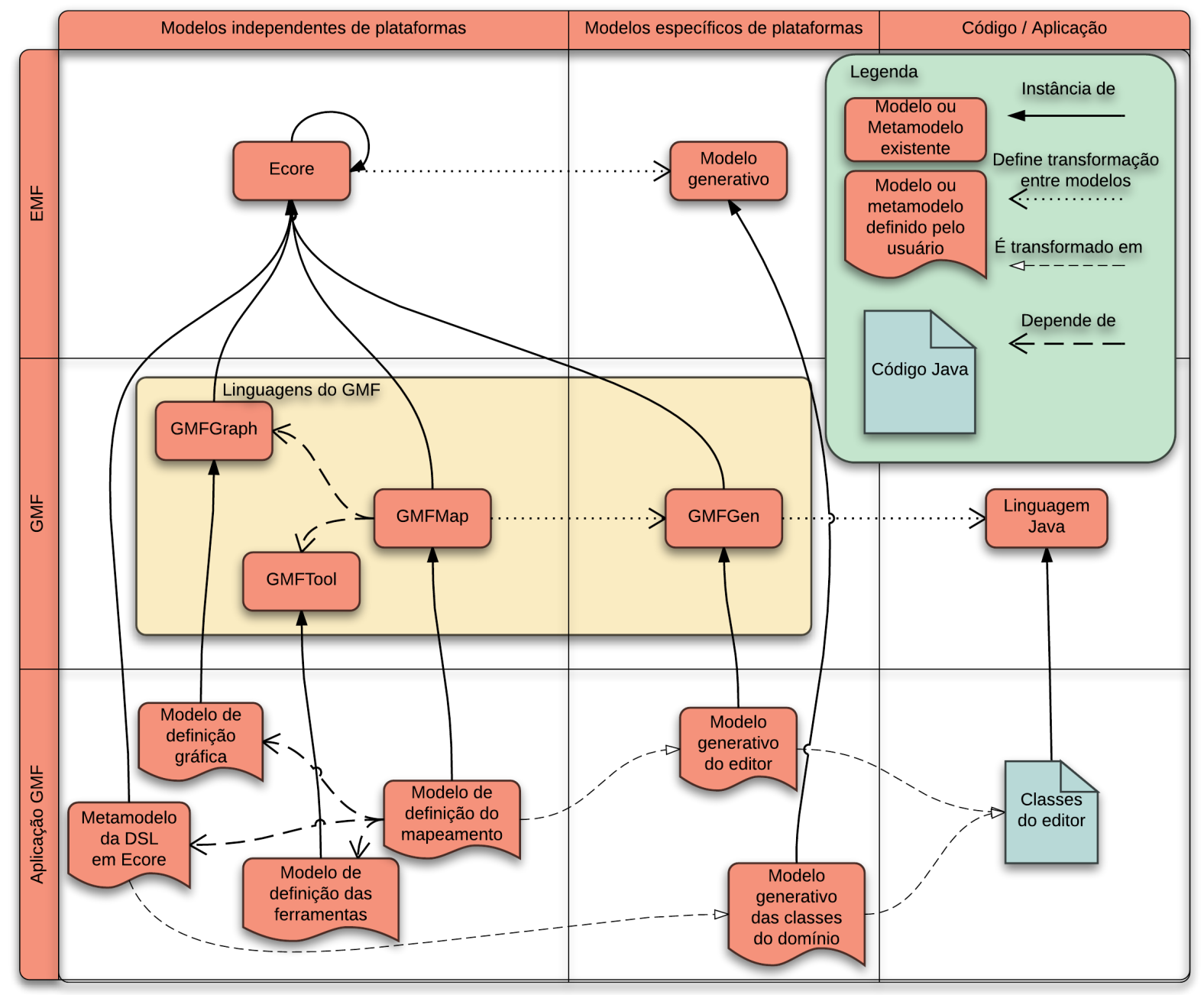

Figura 8: Linguagens de modelagem envolvidas num projeto GMF. (Adaptado de [3])

\subsubsection{Eclipse OCL}

Eclipse OCL provê uma implementação da especificação OMG OCL que pode ser utilizada em conjunto com modelos baseados no EMF [76, 82]. Eclipse OCL faz parte do projeto Model Development Tools (MDT). O MDT é um projeto do EMP relacionado à implementação de linguagens e metamodelos padronizados utilizados no desenvolvimento de software, tais como MOF, CWM e UML. Este projeto provê um conjunto de ferramentas para o desenvolvimento orientado a modelos com base nesses padrões [76, 73].

Eclipse OCL disponibiliza uma API para a análise e a avaliação de restrições e consultas definidas em OCL para modelos Ecore. Dessa forma, podemos representar restrições e consultas associadas a um dado modelo por meio de expressões OCL e utilizar essas expressões em 
instâncias desse modelo [83, 80]. Tal funcionalidade pode ser utilizada em editores e aplicações baseados no EMF para a derivação de valores e validação do modelo em tempo de execução [83].

Diferentes editores para OCL são disponibilizados pelo MDT: CompleteOCL Editor, utilizado para a verificação da sintaxe OCL para documentos independentes; OCLinEcore, utilizado para a criação de metamodelos Ecore e a inclusão de restrições OCL diretamente em metaclasses desses metamodelos Ecore por meio de anotações que são avaliadas em tempo de execução; EssentialOCL Editor, utilizado conjuntamente com o OCL Console para a avaliação interativa de declarações OCL em instâncias em tempo de execução; e o OCLstdlib Editor, utilizado para o desenvolvimento de bibliotecas de restrições OCL reutilizáveis [82, 84].

O suporte provido por Eclipse OCL pode ser utilizado em projetos EMF e/ou GMF. Expressões em OCL podem ser utilizadas em um modelo Ecore para adicionar restrições ao uso da metaclasses modeladas, definir corpos de operações de uma metaclasse e/ou derivações de atributos. Adicionalmente, é possível utilizar expressões OCL em um modelo GMFMap para adicionar restrições que serão validadas em tempo real durante a criação de um modelo pelo editor implementado e/ou inicializar atributos de um dado elemento modelado.

\subsubsection{ATLAS Transformation Language (ATL)}

ATLAS Transformation Language (ATL) [79, 78] é um projeto do EMP voltado para o desenvolvimento de transformações entre modelos. ATL provê uma linguagem semelhante à OCL para a definição de regras de transformação, além de um ambiente de execução, compiladores e editores para essa linguagem.

As regras de transformação desenvolvidas com o ATL são puramente unidirecionais. Neste sentido, uma regra de transformação pode navegar por um (ou mais) modelo(s) fonte da transformação, porém, sem poder modificá-lo(s). Adicionalmente, uma regra de transformação pode criar novos elementos no(s) modelo(s) alvo da transformação, porém, sem poder consultá-los durante a decisão de criação de novos elementos. Transformações bidirecionais podem ser construídas a partir do uso de duas transformações unidirecionais, uma para cada direção, ob- 
servando a possibilidade de perda de informação durante uma das transformações.

A linguagem provida pelo ATL para a definição de tranformações entre modelos é um linguagem híbrida, permitindo tanto a definição de regras de transformação de forma declarativa quanto de forma imperativa. Uma regra de tranformação criada de forma declarativa apresenta essencialmente duas partes: um padrão que deve ser encontrado em elementos do modelo fonte aos quais a regra de transformação será aplicada; e um padrão que deverá ser criado no modelo alvo quando da aplicação da regra, i.e., a criação de um ou mais elementos do modelo alvo. Por sua vez, uma regra de transformação criada de forma imperativa é essencialmente um procedimento que deve ser executado quando da aplicação da regra e pode conter uma declaração de um padrão a ser criado no modelo alvo, como em uma regra declarativa, bem como um conjunto (bloco) de ações executado após a aplicação da regra.

Embora a linguagem provida pelo ATL seja híbrida, recomenda-se utilizar principalmente regras declarativas, uma vez que o uso deste tipo de regra favorece o desenvolvimento de declarações mais abstratas e mais intuitivas para os usuários e desenvolvedores. Dessa forma, o uso de regras declarativas oculta detalhes complexos dos algoritmos de transformação por meio de uma sintaxe mais simples [78]. Ainda assim, regras imperativas podem ser utilizadas para definir transformações que não podem ser representadas facilmente com regras declarativas.

O ATL utiliza o EMF (essencialmente o Ecore) para a representação padrão dos modelos de uma dada transformação. Porém, transformações entre outros formatos de representação podem ser criadas a partir da definição manual de injetores e/ou extratores. Um injetor é um componente de software responsável por criar uma representação Ecore adequada para ser transformada pelo ATL a partir de um modelo fonte em uma linguagem de representação qualquer. Por sua vez, um extrator é um componente de software responsável por criar uma representação de um modelo alvo em uma linguagem de representação qualquer a partir do modelo Ecore produzido por uma dada transformação. Dessa forma, o uso de injetores e extratores permite adaptar o ATL para ser utilizado na transformação entre modelos representados em diversas linguagens de representação distintas. 


\section{$4 \quad$ Modelagem de ontologias biomédicas}

Este capítulo apresenta uma visão geral sobre as linguagens utilizadas para a representação de ontologias biomédicas sob o escopo da $O B O$ Foundry. Ontologias OBO são representadas principalmente em duas linguagens: o $O B O$ File Format, uma linguagem textual de representação amigável à leitura pelo ser humano; e a OWL, uma linguagem textual de representação própria para a Web semântica.

Este capítulo também apresenta uma visão geral sobre a Ontologia de Relacionamentos da OBO (OR-OBO) e sobre o perfil UML definido para esta ontologia. A OR OBO foi desenvolvida para prover uma definição formal para um conjunto de tipos de relacionamentos de propósito geral usado no domínio biomédico, de forma a melhorar a correção e facilitar o processo de análise e integração de ontologias OBO. O perfil UML para a OR OBO foi definido de forma a prover elementos de modelagem mais adequados para a representação de ontologias em UML de acordo com os princípios da OBO Foundry. Assim, o perfil definido permite a criação de modelos UML para ontologias biomédicas de forma consistente e padronizada. $\mathrm{O}$ uso de uma linguagem gráfica de modelagem bem estabelecida como a UML facilita a modelagem e a visualização de ontologias e, assim, ajuda a evitar inconsistências causadas pelo mal-entendimento da linguagem utilizada.

O restante desse capítulo está estruturado da seguinte forma: a seção 4.1 apresenta uma visão geral sobre o uso de ontologias no domínio biomédico; a seção 4.2 apresenta uma visão geral sobre a $O B O$ Foundry; a seção 4.3 apresenta uma visão geral sobre as principais linguagens usadas na representação de ontologias OBO; a seção 4.4 apresenta os principais conceitos presentes na OR-OBO; a seção 4.5 apresenta uma visão geral do perfil UML definido para a 
OR-OBO; finalmente, a seção 6.4 apresenta algumas conclusões.

\subsection{Ontologias biomédicas}

Ontologias têm sido utilizadas de forma crescente na área biomédica. Nesta área, as principais aplicações de ontologias nesta área incluem a gestão de conhecimento, a integração de informação e interoperabilidade semântica e o suporte à decisão e ao raciocínio [9].

Em aplicações para o suporte à gestão de conhecimento, ontologias podem ser usadas como fontes para vocabulários padronizados $[17,85]$. Neste sentido, os termos da ontolgia são utilizados na anotação, codificação, indexação e busca de recursos e dados biológicos. Por exemplo, o projeto Gene Ontology Annotation [86] utiliza os termos padronizados pelo Gene Ontology [13] para a anotação de proteínas nos bancos de dados do Uniprot Knowledgebase [87].

Em aplicações para o suporte à integração de informação e interoperabilidade semântica, ontologias representam um vocabulário controlado de um domínio, o qual pode ser utilizado para a integração de dados baseada em abordagens de data warehousing $[9,88]$. Segundo estas abordagens, a integração de diferentes fontes de dados envolve o mapeamento destas fontes para um esquema conceitual padrão e a extração e conversão da informação semântica de interesse para a gestão dessa informação de forma logicamente centralizada $[8,89,90]$. Ontologias também podem ser utilizadas para definir um esquema global, a partir do qual buscas podem ser realizadas. Por exemplo, Ontocloud [91] é um sistema de integração de banco de dados baseado em ontologias com capacidade de inferência através da expansão dos termos de uma busca. Adicionalmente, ontologias biomédicas podem ser, também, utilizadas para definir como dados biomédicos devem ser compartilhados entre diversos recursos de informação ou agentes de software [88]. Neste contexto, ontologias são utilizadas para anotar informação biológica ou clínica compartilhada, provendo uma especificação explícita dos termos utilizados para expressar a informação e permitindo às aplicações realizar deduções sobre as entidades descritas.

Em aplicações para o suporte à decisão e ao raciocínio, ontologias representam conhecimento sobre um domínio. Tal conhecimento pode ser disponibilizado em um formato pro- 
cessável de forma a ser utilizado para a seleção e agregação de dados, suporte à decisão, processamento de linguagem natural e descoberta de conhecimento no domínio [9]. Ontologias mais detalhadas possuem uma ampla rede de relações entre as entidades do domínio. Desta forma, estas provêem suporte à interpretação de relações presentes em conjuntos de dados. Essas relações podem ser identificadas através de mineração de dados baseada em processamento de linguagem natural ou estatística $[9,88]$. Aplicações de ontologias em processamento de linguagem natural provêem suporte a extração de informação e ao resumo de documentos, identificando não apenas termos nesses documentos, mas também fatos e relações do domínio apresentados [92]. Adicionalmente, pesquisas biomédicas podem se beneficiar do uso de ontologias no suporte ao processamento de dados em larga escala e descoberta de conhecimento em documentos clínicos de pacientes ou em relatórios de experimentos biológicos [6, 41].

\subsection{OBO Foundry}

A grande aceitação e uso de ontologias na área biomédica resultou no surgimento de um grande número de ontologias. Porém, a falta de um esforço de padronização e alinhamento entre as ontologias desenvolvidas representa um obstáculo à integração e, em consequência, a um uso mais efetivo destas ontologias. Os principais problemas são a criação de ontologias com sobreposição de conceitos, com formatos de representação diversos e não interoperáveis [17, 18, 19]. Em resposta a tal situação, a Open Biological and Biomedical Ontologies Foundry (OBO Foundry) foi criada como um experimento colaborativo para o alinhamento e a coordenação dos esforços no desenvolvimento e gestão de ontologias para os domínios biológicos e biomédicos $[18,20]$.

A $O B O$ Foundry tem por objetivo prover um repositório de ontologias abertas, modulares, interoperáveis e bem-formadas para incorporar representações acuradas da realidade biológica. Para atingir tal objetivo, a $O B O$ Foundry define um conjunto de princípios e boas práticas que devem ser utilizados para o desenvolvimento colaborativo de novas ontologias. Exemplos desses princípios são o uso de licenças de uso aberto para as ontologias desenvolvidas, o uso de um formato comum para a disponibilização dessas ontologias e o comprometimento ao desen- 
volvimento colaborativo $[18,20]$.

As ontologias curadas pela OBO Foundry podem ser classificadas em ontologias recomendadas e ontologias candidatas. Ontologias recomendadas são ontologias que passaram por um processo de revisão e atendem a todos os princípios recomendados pela OBO Foundry, enquanto ontologias candidatas são ontologias que ainda não completaram esse mesmo processo de revisão.

Atualmente, a $O B O$ Foundry possui 10 ontologias recomendadas e mais de 110 ontologias candidatas, englobando ontologias sobre experimentos, genes, proteínas, anatomia e bioquímica, entre outros domínios [20]. Exemplos dessas ontologias incluem Foundational Model of Anatomy (FMA) para a descrição de estruturas anatômicas [93]; Gene Ontology para a descrição de processos biológicos, funções moleculares e componentes celulares $[13,94]$; e $S e$ quence Ontology, para descrição de propriedades e atributos das sequencias biológicas [95]. As ontologias curadas pela $O B O$ Foundry são representadas utilizando-se tanto o $O B O$ File Format [22] quanto a Web Ontology Language (OWL) [96].

\subsection{Linguagens de representação de ontologias}

Duas principais linguagens de representação são utilizadas em ontologias $\mathrm{OBO}$ : o $O B O$ File Format, uma linguagem amigável à leitura e compreensão pelo ser humano; e o OWL, uma linguagem de leitura mais difícil e própria para o uso computacional. Esta seção apresenta uma visão geral sobre estas duas linguagems.

\subsubsection{OBO Flat File Format}

OBO Flat File Format (OBO File Format) [22] é uma linguagem criada para a representação de ontologias OBO em arquivos de texto e utilizada pelo software OBO-Edit [97]. O OBO-Edit é um software de código livre e independente de plataforma para a visualização e edição de ontologias OBO. OBO File Format modela conceitos que representam um subconjunto dos conceitos presentes na linguagem OWL (veja a seção 4.3.2), com algumas extensões para mo- 
delagem de metadados e alguns outros conceitos. O OBO File Format foi criado com o objetivo de ser facilmente compreendido por seres humanos, ser facilmente processado e analisado gramaticamente, ser extensível e possuir o mínimo de redundância.

Um documento OBO File Format é estruturado como um cabeçalho (header) seguido de uma sequência de declarações (stanzas). O cabeçalho é uma seção não-rotulada no início do documento que contém uma série de pares tag-valor. Entre as tags definidas como parte do cabeçalho temos informações sobre a ontologia e o arquivo que a contém, tais como a versão da especificação $O B O$ File Format utilizada pela ontologia (tag format-version), a versão da ontologia (tag data-version) e uma URL apontando para outro documento OBO cujo o conteúdo deve ser anexado ao documento atual durante o processamento (tag import). A única tag obrigatória em um cabeçalho é a format-version, sendo as demais opcionais. A seção de cabeçalho termina quando a declaração da primeira declaração rotulada é encontrada.

Uma declaração é uma seção rotulada que apresenta a descrição de um objeto OBO de algum tipo em particular. Uma declaração inicia-se com o rótulo do tipo daquela declaração entre colchetes, o qual é seguido de uma série de pares tag-valor, um par por linha. Valores em múltiplas linhas são possíveis através de caracteres de escape. Em geral, cada tipo de declaração pressupõe um conjunto pré-definido de tags. Porém, processadores para a linguagem não devem gerar erros caso uma tag não definida seja encontrada. Dessa forma, tags experimentais podem ser facilmente adicionadas. Adicionalmente, modificadores para os valores presentes em uma dada tag podem ser adicionados. Contudo, nestes casos o significado desses modificadores não são definidos na especificação da linguagem, sendo responsabilidade particular da aplicação que os usa.

A primeira tag de qualquer declaração $O B O$ File Format é o identificador (id) do objeto a que se refere aquela declaração. Cada objeto descrito pelo $O B O$ File Format deve possuir um identificador único. Um objeto pode ser descrito em mais de uma declaração, desde que todas as declarações que descrevem tal objeto referenciem o mesmo identificador. Assim, a verificação por objetos mal formados só pode ocorrer após a avaliação de todas as declarações.

Três tipos de declarações são suportadas diretamente pelo OBO File Format: Term, Type- 
def e Instance. Term apresenta uma declaração usada para representar um determinado termo da ontologia. Em geral, esses termos são equivalentes a classes de entidades. Typedef apresenta uma declaração usada para representar novos tipos de relações entre termos. As relações declaradas por um Typedef são utilizadas em conjunto com a tag relationship em uma declaração Term. Por fim, Instance apresenta uma declaração usada para representar uma instância de um dado termo. Declarações não suportadas pelo formato devem ser carregadas e salvas com sucesso pelos processadores e serializadores da linguagem (round-trip).

A linguagem já possui alguns objetos Typedef definidos, de forma que as relações definidas por esses objetos podem ser utilizadas em todas as ontologias sem a necessidade de importar recursos, viz. as relações is_a, disjoint_from, instance_of, inverse_of, union_of e intersection_of. Esses objetos definem escopos diferenciados para a utilização dessas relações. Por exemplo, o escopo de union_of são dois objetos Term, pois esta relação é usada para a representar que uma dada classe é uma união de duas outras classes. Por sua vez, o escopo de inverse_of são dois objetos Typedef, pois esta relação é usada para representar que uma dada relação possui uma relação inversa.

A Figura 9 apresenta um fragmento da ontologia de processos biológicos da $\mathrm{OBO}$ [4] representado segundo o $O B O$ File Format. O fragmento apresenta uma declaração de uma subclasse de processo biológico, a regulação da excreção renal de sódio. Nesta figura, observamos o rótulo de uma declaração Term, seguido de uma série de pares tag-valor nas linhas seguintes. Em todos os pares de uma declaração, outros objetos e relações são referenciados por seus identificadores ou seus nomes.

Cada par da declaração inicia-se em uma nova linha com a tag, a qual é representada como uma sequência de caracteres do início da linha até o caracter de dois-pontos (“:”). O valor associado à tag em questão é apresentado a partir desse ponto até o caracter sinalizador de final de linha ou até o início de um comentário ou um modificador. Comentários são apresentados após um ponto de exclamação, enquanto modificadores são representados entre chaves. Embora comentários e modificadores não tenham valor semântico para o OBO File Format, estes podem possuir significado adicional para os usuários das ontologias representadas. 


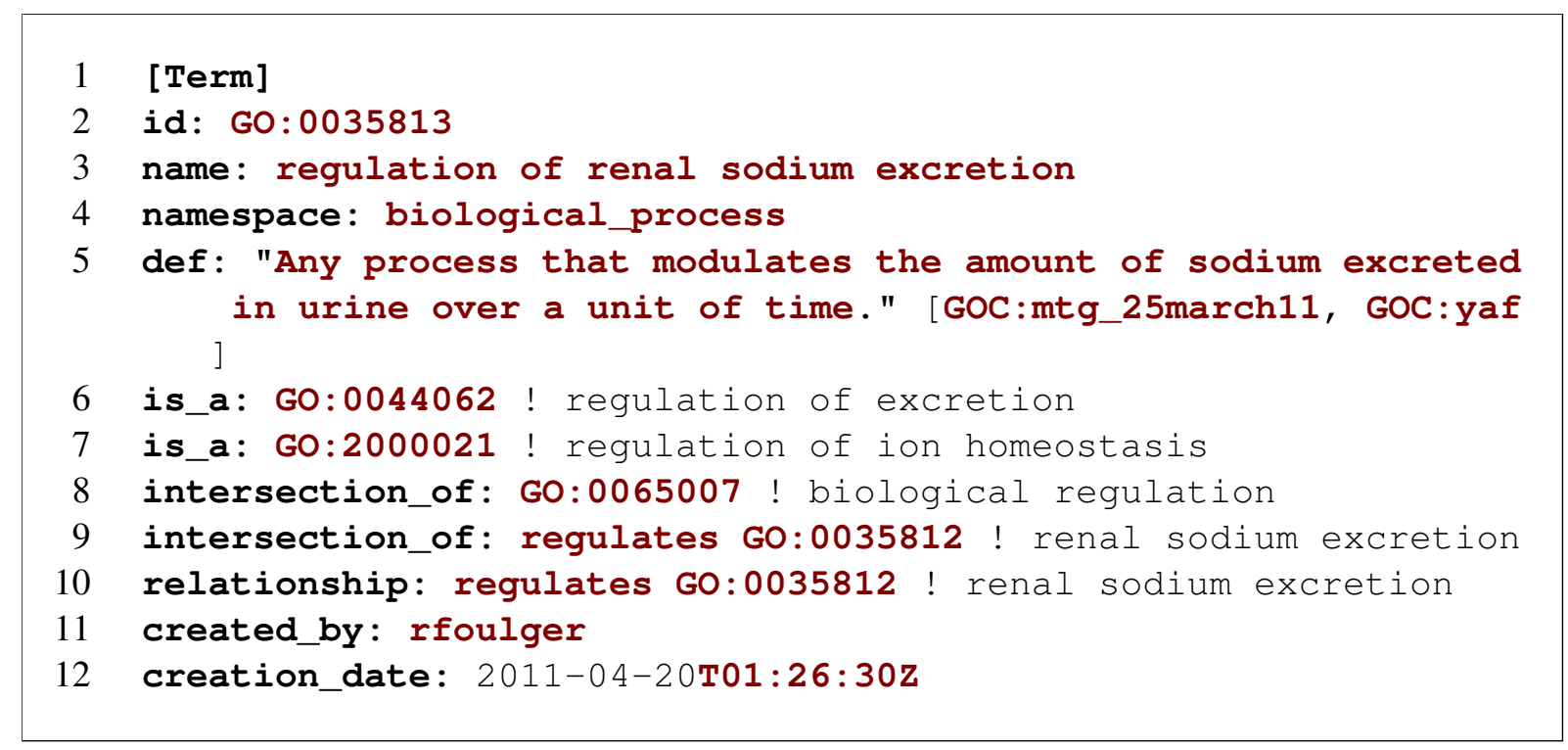

Figura 9: Fragmento apresentando um termo da ontologia de processos biológicos da OBO [4].

Com a excessão do par identificador apresentado na linha 2 da Figura 9, todos os demais pares tag-valor são opcionais para essa declaração. Porém, alguns objetos OBO possuem conjuntos de pares obrigatórios, os quais devem ser apresentados pela ontologia de forma a definir que aquele objeto é válido. Neste sentido, um mesmo objeto OBO pode ser definido completamente por mais de uma declaração, de forma que tais pares poderiam estar definidos em outras declarações sobre o mesmo objeto.

Dessa forma, podemos interpretar a declaração apresentada na figura 9 da seguinte forma: $o$ objeto OBO GO : 0035813 é um termo conhecido como "regulação da excreção renal de sódio" (regulation of renal sodium excretion) que foi definido no namespace de processo biológico (biological process). O namespace não adiciona informação semântica para o objeto o qual a declaração se refere. Este é utilizado para diferenciar logicamente as diversas fontes (i.e., arquivos) usadas para o processamento das informações contidas na ontologia. O objeto GO:0035813 é definido em linguagem natural como "qualquer processo que module a quantidade de sódio excretado na urina numa dade unidade de tempo". Esse objeto é uma regulação de excreção, representada pelo objeto GO:0044062, e é uma regulação da homeostase de íons, representada pelo objeto $\mathrm{GO}: 2000021$. Adicionalmente, $\mathrm{GO}: 0035813$ é uma intersecção entre regulação biológica (GO:0065007) e objetos que regulam a excreção renal de sódio (regulates GO:0035812), e possui uma relação de regulação com esse tipo de excreção. 
Os valores apresentados em um par tag-valor de uma declaração OBO possuem diferentes formas de representação para cada tag ou mesmo de diferentes formas para uma mesma tag. Adicionalmente, há restrições que devem ser respeitadas quando do uso de uma dada tag. Por exemplo, algumas tags precisam aparecer um número mínimo de vezes ou nenhuma vez para um dado objeto. Adicionalmente, há tags que não podem estar presentes conjuntamente para um mesmo objeto OBO. Tais características, aliadas à possibilidade de importar recursos de fontes diferentes que podem estar em outros formatos, como o OWL, tornam o processamento de ontologias representadas em $O B O$ File Format não trivial. Neste sentido, a OBO Foundry disponibiliza uma API aberta de referência, desenvolvida na linguagem Java, que pode ser reutilizada para o desenvolvimento de novas ferramentas de software.

A última especificação normativa do $O B O$ File Format é a versão 1.4, cuja última revisão ocorreu em maio de 2006. Esta versão inclui mapeamentos para a OWL [98].

\subsubsection{Web Ontology Language (OWL)}

Web Ontology Language 2 (OWL) [23] é a segunda versão de uma linguagem recomendada pelo World Wide Web Consortium (W3C) para a representação de ontologias e anotação de recursos para a Web semântica [99]. A Web semântica tem por objetivo prover significados explícitos à informação disponível na Web, de modo a facilitar o processamento e interpretação dessa informação. Por essa razão, a OWL foi planejada para ser usada por computadores e aplicações, não sendo necessariamente amigável ao entendimento humano.

A OWL não permite prescrever como um documento deve ser estruturado sintaticamente, de forma que não é possível obrigar que uma determinada informação esteja ou não presente em um dado documento. Na prática, uma sintaxe concreta é necessária para o armazenamento de ontologias OWL e o compartilhamento dessas ontologias entre ferramentas. A sintaxe primária da OWL é o Rich Description Format (RDF) serializado através da Extensible Markup Language (XML), ou RDF/XML.

RDF [100] é um padrão para a troca de dados na Web que provê facilidades para a integração de informação de bases de dados heterogêneas. XML [101] é uma linguagem textual flexível 
criada para a troca de informação em documentos Web. A sintaxe em RDF/XML deve ser suportada por todas as ferramentas desenvolvidas para a OWL, de forma a garantir a interoperabilidade entre essas ferramentas. Adicionalmente, alternativas de sintaxe para a serialização de documentos OWL são providas, como o XML (OWL 2 XML), uma forma textual compacta para o RDF (Turtle), e uma sintaxe mais legível ao ser humano (Manchester) [102].

Uma declaração OWL é composta por uma ou mais entidades. Entidades OWL podem referir-se a um objeto do mundo real, uma categoria de objetos ou a relações entre esses objetos. A OWL refere-se aos objetos como indivíduos, às categorias de objetos como classes e às relações entre objetos como propriedades. Essas entidades são semelhantes às entidades Instance, Term e Typedef do OBO File Format, respectivamente. Adicionalmente, propriedades OWL podem ser subdivididas em propriedades de objetos (object properties), propriedades de tipos de dados (datatype properties), e propriedades de anotações (annotation properties). Propriedades de objetos relacionam dois indivíduos, como um homem a sua esposa. Propriedades de tipos de dados atribuem campos de dados a objetos, como atribuir que uma pessoa deve possuir uma idade. Por fim, propriedades de anotação são usadas para codificar informações sobre partes da própria ontologia, como o autor e a data de criação de um dado axioma de uma ontologia.

A Figura 10 apresenta um fragmento da ontologia de processos biológicos da OBO [4] representada em OWL e XML. O fragmento apresentado mostra a declaração do mesmo processo biológico apresentado anteriormente na Figura 9, a regulação da excreção renal de sódio. Neste fragmento, temos dois objetos XML principais: um objeto tipificado como owl : Class, que apresenta o termo OBO como uma classe OWL, e um objeto tipificado como ow 1 : Axi om, o qual é usado para associar ao identificador da classe outras informações sobre aquela classe. O objeto owl: Class apresenta um atributo rdf:about, o qual apresenta o identificador unívoco da classe descrita pelo objeto. Este objeto possui também um objeto rdfs: label, o qual é utilizado para prover um rótulo à classe aquela classe de forma semelhante ao que a tag name do $O B O$ File Format. O objeto owl : Class possui também um objeto owl : equivalentClass, o qual epresenta uma definição computável equivalente para aquela classe. 


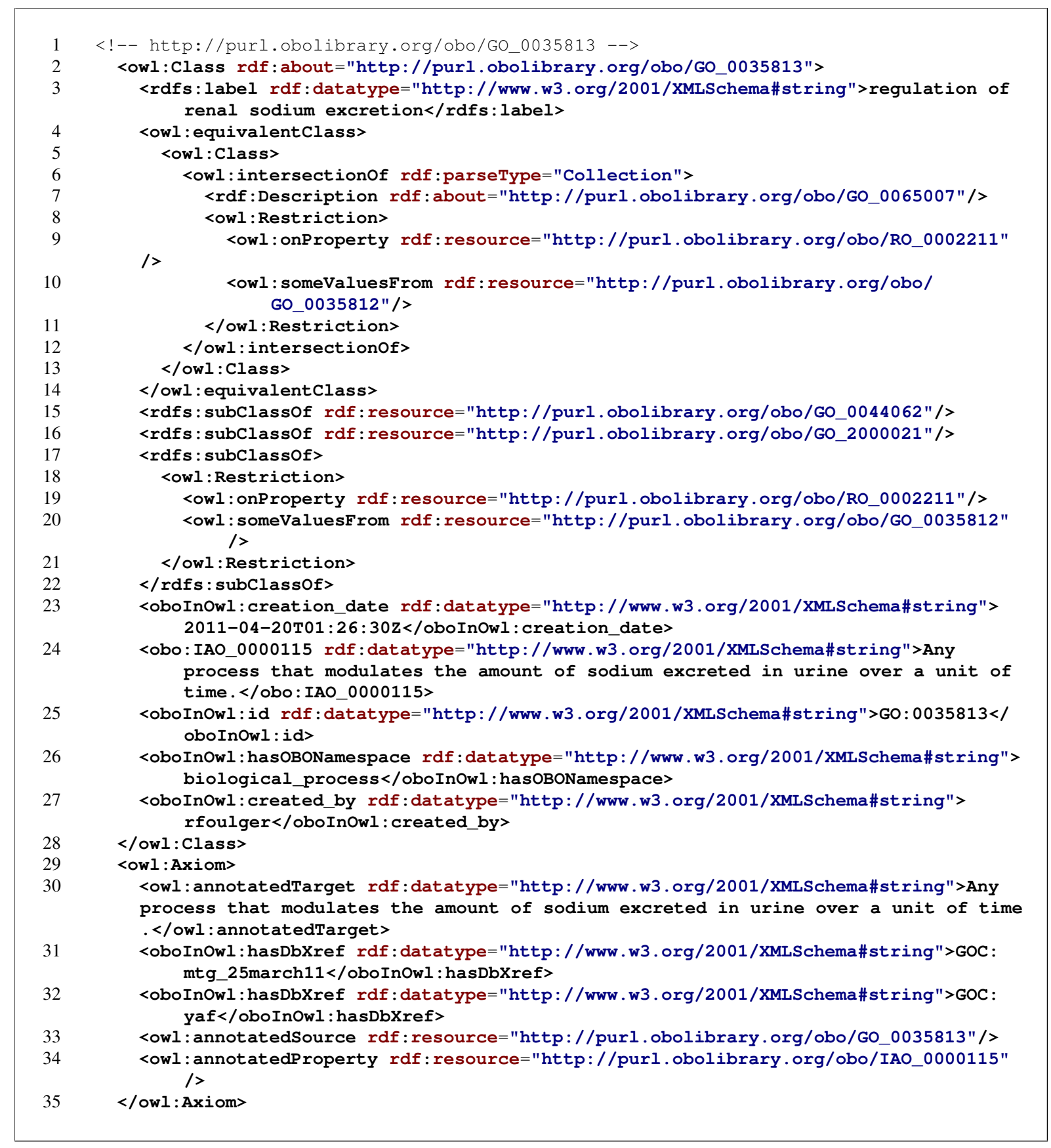

Figura 10: Fragmento OWL apresentando um termo da ontologia de processos biológicos da OBO [4].

Este objeto, em conjunto com o objeto owl : Restriction, traduz para o OWL a semântica apresentada pelas duas tags intersection_of do fragmento em OBO File Format. Objetos rdfs: subClassof traduzem para o OWL a semântica apresentada pelas tags is_a do fragmento $O B O$ File Format. Os demais atributos, que não possuem sintaxe e semântica já definida em OWL, são incluídos por objetos os quais são tipificados com nomes com prefixo obo ou oboInOwl. Maiores informações sobre a sintaxe XML podem ser encontradas em [101]. 
Transformações entre $O B O$ File Format e OWL já foram formalmente definidas e ferramentas para a transformação automática já estão disponíveis [103, 104, 105, 106].

\subsection{Ontologia de Relacionamentos da OBO}

Embora seja comum aplicar um esforço considerável na formulação e definição dos termos de uma ontologia, uma atenção menor costuma ser dada à formalização das relações empregadas para interconectar estes termos. Essa falta de atenção com a definição formal de relações torna-se um problema à medida que novas relações são tipicamente definidas de maneira informal e/ou relações existentes são utilizadas de forma inconsistente em diferentes ontologias ou inclusive em uma mesma ontologia. Por exemplo, a relação part_of possuía três diferentes significados nas primeiras versões do Gene Ontology. Esta relação era utilizada como uma relação de inclusão entre termos e vocabulários, como relação de possível composição entre entidades biológicas ou como relação de composição necessária entre entidades biológicas [21]. Adicionalmente, a falta de uma definição clara do significado de uma relação dificulta a curação e a detecção de erros nessas ontologias.

A Ontologia de Relacionamentos da OBO (OR OBO) [21], atualmente chamada de Ontologia dos Tipos de Relacionamentos da OBO [107], foi desenvolvida para prover definições formais para um conjunto de relacionamentos de propósitos gerais usado no domínio biomédico. Esta ontologia foi definida de modo a garantir a máxima confiabilidade na curação de cada ontologia e prover um ponto de apoio sólido para a integração de conhecimento nas ciências biológicas. Ao mesmo tempo que provê definições formais para cada relacionamento, associando um significado consistente para cada relação, esta ontologia mantém os detalhes que suportam essa formalidade transparentes aos autores e curadores das ontologias OBO. Adicionalmente, foi definida uma metodologia para a inclusão de novas relações através de definições consistentes e não-ambíguas para as mesmas [21].

A identificação do conjunto de relações da OR OBO levou em consideração dois princípios básicos. Primeiro, esta ontologia deveria incluir apenas relações genuinamente ontológicas, isto é, relações que são encontradas entre entidades reais do domínio. Segundo, as relações devem 
ser de propósito geral e passíveis de serem utilizadas em diferentes ontologias no domínio biomédico. Dessa forma, relações como annotates, por exemplo, não seriam consideradas ontológicas, uma vez que ligam entidades do domínio aos termos de um vocabulário construído pelo homem. Adicionalmente, relações específicas de um dado domínio, como, por exemplo, genome_of, também não seriam incluídas.

\subsubsection{Visão geral}

Ontologias descrevem uma conceitualização abstrata de um domínio. Esta descrição inclui um corpo de conhecimento e declarações gerais sobre o domínio. Contudo, de modo a capturar o que é geral em um dado domínio, devemos realizar induções e abstrações a partir dos indivíduos concretos encontrados nesse domínio e das relações existentes entre esses indivíduos. Neste sentido, os indivíduos de um domínio podem ser agrupados em classes de entidades e as relações entre esses indivíduos podem ser utilizadas para definir as relações entre as classes de entidades envolvidas.

Uma classe de entidade define um tipo ou conceito (também chamado universal na Filosofia), ou seja, define um conjunto de características que são comuns a determinados indivíduos do domínio. Por sua vez, um dado indivíduo do domínio que possua as características definidas por uma classe de entidades é dito uma instância dessa classe. Por exemplo, Homem é uma classe de entidades compartilhada por todos os indivíduos da espécie humana que possuam sexo masculino. Por sua vez, se João é um dado indivíduo da espécie humana e possui sexo masculino, João é uma instância de Homem.

A OR OBO define dois tipos de classes de entidades que formam conjuntos sem sobreposição: continuantes e processos. Continuantes representam coisas, objetos ou estruturas, ou seja, entidades que continuam a existir em relação ao tempo e podem passar por uma série de transformações. Continuantes podem ser ainda materiais ou imateriais. Continuantes materiais representam tipos específicos de continuantes que possuem matéria e existência física, como mitocôndrias, membranas ou células; inversamente, continuantes imateriais representam entidades biológicas que não possuem matéria, como cavidades, orifícios e o interior de canais. 
Adicionalmente, continuantes podem ser particionados em regiões, por exemplo, interior e exterior ou esquerda e direita. Por sua vez, processos representam atividades biológicas ou eventos em geral que ocorrem durante um instante no tempo. Processos podem ser particionados em relação ao tempo, por exemplo, em início, meio e fim.

Um vez que ontologias OBO são utilizadas como vocabulários controlados para expressar o resultado das ciências biológicas, expressões realizadas com os termos dessas ontologias, tais como “A relação B”, em geral são declarações gerais sobre classes de entidades biológicas envolvidas, e não declarações sobre instâncias específicas dessas classes. Relações envolvendo instâncias são utilizadas na definição das relações entre classes de forma intuitiva, não-ambígua e, portanto, mais facilmente aplicável. Dessa forma, pode-se distinguir três diferentes tipos de relações binárias [21]: relações entre duas classes de entidade, relações entre uma classe de entidade e uma instância e relações entre duas instâncias.

A relação mais importante entre uma classe de entidade e uma instância é aquela que relaciona o indivíduo à classe de entidade que este instancia. Esta relação, também chamada instance_of, é fundamental para a indução das relações entre classes de entidades a partir de relações entre indivíduos e/ou para a dedução das características de um dado indivíduo a partir da informação existente sobre a(s) classe(s) de entidade associada. Relações entre instâncias de continuantes precisam envolver um índice temporal, uma vez que mudanças podem ocorrer com uma dada instância do continuante durante sua existência. Por exemplo, uma determinada célula pode ser "parte de" um órgão em determinado momento, mas ser extraída em um momento subsequente e, portanto, deixar de ser parte daquele órgão. Já relações envolvendo instâncias de processos não precisam de um índice temporal, uma vez que se um subprocesso for "parte de" um processo, uma instância do subprocesso sempre ocorrerá como parte de uma instância do processo.

A OR OBO utiliza um conjunto de relações que devem ser aceitas como primitivas. Estas relações são utilizadas para prover uma definição formal sobre as relações entre classes de entidades. O uso de relações primitivas evita a necessidade de iterações infinitas de regressão para a interpretação (ou mesmo para a definição) de uma relação modelada. Uma relação primitiva 
deve ser auto-explicativa e neutra em relação ao domínio, isto é, pode ser aplicada a entidades de qualquer domínio. A lista de relações primitivas inclui relações entre instâncias e relações entre uma instância e sua classe associada. A Tabela 1 ilustra algumas relações primitivas da OR OBO.

Tabela 1: Exemplos de relações primitivas da OR OBO. $c_{i}$ e $p_{i}$ representam instâncias de continuantes e processos; $C_{i}$ e $P_{i}$ representam classes de continuantes e processos; $r_{i}$ representa uma região espacial (tridimensional); $t_{i}$ representa um instante no tempo.

\begin{tabular}{|c|c|}
\hline Relação & Descrição \\
\hline$c$ instance_of $C$ at $t$ & $\begin{array}{l}\text { Relação primitiva entre uma instância de um continuante } \\
\text { e a classe de entidade que ela instancia em um momento } \\
\text { específico. Esta relação é abreviada como } C \text { ct. }\end{array}$ \\
\hline$p$ instance_of $P$ & $\begin{array}{l}\text { Uma relação primitiva entre uma instância de um processo } \\
\text { e a classe que ela instancia. Essa relação é independente do } \\
\text { tempo. Esta relação é abreviada como } P p \text {. }\end{array}$ \\
\hline$c$ part_of $c_{1}$ at $t$ & $\begin{array}{l}\text { Uma relação primitiva entre duas instâncias de continuantes } \\
\text { e o momento em que uma é parte de outra. }\end{array}$ \\
\hline $\begin{array}{l}p \text { part_of } p_{1} \text {, } \\
r \text { part_of } r_{1}\end{array}$ & $\begin{array}{l}\text { Uma relação primitiva de composição entre duas instâncias } \\
\text { de processos (uma é um subprocesso da outra) ou entre duas } \\
\text { regiões espaciais (uma região contém a outra). Essa relação } \\
\text { é independente do tempo. }\end{array}$ \\
\hline$t$ earlier $t_{1}$ & $\begin{array}{l}\text { Uma relação primitiva entre dois momentos no tempo, em } \\
\text { que um é anterior ao outro. }\end{array}$ \\
\hline
\end{tabular}

\subsubsection{Relações entre classes de entidades}

Relações entre classes de entidades podem ser divididas em relações fundamentais, as quais representam relações básicas, tipicamente utilizadas em qualquer ontologia biomédica; relações espaciais, as quais representam relações que conectam classes de continuantes em relação à região espacial (continuante) que suas instâncias ocupam; relações temporais, as quais representam relações temporais que conectam classes de entidades biológicas (continuantes ou processos) cujas as instâncias existem em diferentes instantes de tempo; e relações de participação, as quais representam relações entre diferentes tipos de classes de entidades (continuantes participando de processos) $[21,5]$.

Cada relação desta ontologia é formalmente definida a partir do conjunto primitivo de relações. Por exemplo, a Tabela 2 ilustra as definições das relações is_a, part_of, has_part 
e integral_part_of definidas entre classes de entidades continuantes. Estas definições fazem uso de mecanismos quantificadores lógicos universais, tais como "Para todo ..." e “existe um ...", de forma a se referir a instâncias do domínio de discurso sem a necessidade da declaração explícita das instâncias para as quais as definições providas são válidas. Maiores informações sobre a forma de representação dos relacionamentos definidos na OR OBO podem serem encontradas em [21].

Tabela 2: Exemplos das definições providas pela Ontologia de Relacionamentos da OBO. $c_{i}$ e $p_{i}$ representam instâncias de continuantes e processos; $C_{i}$ e $P_{i}$ representam classes de continuantes e processos; $r_{i}$ representa uma região espacial (tridimensional); $t_{i}$ representa um instante no tempo.

\begin{tabular}{ll}
\hline \hline Relação & Definição provida \\
\hline$C$ is_a $C_{1}$ & Para todo $c$ e $t$, se $c$ instance_of $C$ no tempo $t$, então \\
& $c$ instance_of $C_{1}$ no tempo $t$. \\
& Para todo $c$ e $t, \operatorname{se} C c t$ então existe algum $c_{1}$ tal que $C_{1} c_{1} t$ e \\
& $c$ part_of $c_{1}$ no tempo $t$. \\
$C_{1}$ has_part $C$ & Para todo $c_{1}$ e $t$, se $C_{1} c_{1} t$ então existe algum $c$ tal que $C c t$ e \\
& $c$ part_of $c_{1}$ no tempo $t$. \\
$C$ integral_part_of $C_{1}$ & $C$ part_of $C_{1}$ e $C_{1}$ has_part $C$. \\
\hline \hline
\end{tabular}

A Tabela 3 apresenta as relações definidas na OR OBO segundo a divisão entre relações fundamentais, relações espaciais, relações temporais e relações de participação. De acordo com essa tabela, nota-se que muitas relações definidas possuem uma relação aparentemente inversa também provida pela OR OBO. Embora isso pareça redundante, formalmente essas relações não são necessariamente relações inversas.

Dada uma relação $\mathrm{R}$ que interconecta um par de elementos, uma relação inversa a $\mathrm{R}$ é definida como a relação que relaciona o par de elementos interconectados por $\mathrm{R}$ em ordem inversa [21]. Relações inversas podem ser obtidas facilmente para relações entre instâncias. Porém, a definição de relações inversas entre classes pode ser mais complexa [21]. Por exemplo, podemos observar esta característica nas relações part_of e has_part. Entre instâncias, dada a afirmação verdadeira "um dado núcleo $n$ é parte de uma dada célula $c$ no tempo $t$ ", é trivial derivar uma afirmação com a relação inversa "a célula $c$ tem como uma de suas partes o núcleo $n$ no tempo $t$ " que também seja garantidamente verdadeira. Porém, as relações de part_of e has_part entre classes não permitem derivar uma afirmação garantidamente 
verdadeira com a relação inversa interconectando essas classes. Isso ocorre porque ontologicamente uma afirmação como "todo núcleo celular é parte de uma célula" não deve permitir inferir que "toda célula tem como uma de suas partes um núcleo celular" [21].

Essa característica das relações entre classes pode ser observada na OR OBO, por exemplo, a partir das definições de part_of e has_part entre classes de entidades continuantes apresentadas na Tabela 2. Embora ambas as definições de part_of e has_part sejam desenvolvidas a partir da relação part_of definida entre instâncias, podemos perceber que os quantificadores universais estão associados de forma distinta e não inversível em cada uma das definições. No caso de haver a necessidade de unir ambas definições, uma terceira relação pode ser incluída, por exemplo, a relação integral_part_of apresentada.

Tabela 3: Relações definidas da Ontologia de Relacionamentos da OBO.

\begin{tabular}{ll}
\hline Relações fundamentais & instance_of \\
& is_a \\
& part_of \\
& has_part \\
& integral_part_of \\
& has_integral_part \\
& proper_part_of \\
& has_proper_part \\
& located_in \\
& location_of \\
& contained_in \\
& contains \\
& adjacent_to \\
\hline Relações espaciais & transformation_of \\
& derives_from \\
& derived_into \\
& preceded_by \\
Relações temporais & has_participant \\
& participates_in \\
has_agent & agent_in \\
\hline Relações de participação &
\end{tabular}




\subsection{Modelagem de ontologias biomédicas usando UML}

A UML é utilizada para a modelagem de sistemas computacionais em diferentes domínios do conhecimento. Adicionalmente, a linguagem provê ao usuário a capacidade estender e adaptar os elementos da linguagem ao uso em um determinado domínio, de forma a obter elementos de modelagem mais representativos para este domínio, através da definição e uso de perfis [2].

Neste sentido, um perfil UML foi definido em [5] a partir da definição dos diferentes tipos de classes de entidades biológicas e dos diferentes tipos de relações da OR OBO. A definição deste perfil foi realizada em três etapas: inicialmente, o metamodelo UML foi estudado e um conjunto de metaclasses de interesse foram identificadas; em seguida, extensões foram propostas para essas metaclasses; finalmente, um conjunto de estereótipos adequados foi proposto.

Os diferentes tipos de classes de entidades biológicas definidos na OR OBO são representados no perfil como especializações da metaclasse Class. A metaclasse Class é especializada nas metaclasses mutualmente exclusivas Continuant e Process. Tal separação está de acordo com a definição da Ontologia de Relacionamentos que descreve essas categorias como categorias sem sobreposição. Por sua vez, a metaclasse Continuant é especializada nas metaclasses Material e Immaterial, também mutualmente exclusivas.

As diferentes relações definidas na Ontologia de Relacionamentos são modeladas como especializações da metaclasse abstrata OBORelation, que por sua vez é especialização da metaclasse DirectedRelationship. A metaclasse OBORelation representa um relacionamento direcionado que pode ocorrer entre classes de entidades biológicas como continuantes e processos. Adicionalmente, os relacionamentos representados por OBORelat i on são relacionamentos direcionados e binários, de forma que há apenas uma entidade fonte e uma entidade alvo. OBORelation é especializada por quatro metaclasses abstratas: FoundationalRelation, SpatialRelation, TemporalRelation e ParticipationRelation, que representam relacionamentos fundamentais, espaciais, temporais e de participação, respectivamente. Embora estas metaclasses não tenham sido posteriormente mapeadas para estereótipos concretos do perfil, elas são utilizadas para uma melhor estruturação do perfil e para 
a definição de restrições aplicáveis às subclasses concretas que as especializam. Estas metaclasses abstratas foram, por sua vez, especializadas em metaclasses concretas que representam os diferentes relacionamentos presentes na Ontologia de Relacionamentos.

Cada uma das metaclasses propostas para representar os diferentes tipos de classes de entidades biológicas foi transformada em um estereótipo do perfil. Dessa forma, quatro estereótipos foram definidos para as classes de entidades biológicas: «continuant», «material», «immaterial»e «process». Por sua vez, cada metaclasse concreta representando um dos tipos de relações definidos pela OR OBO também foi transformado em um estereótipo adequado.

Cada estereótipo do perfil é definido em termos da(s) metaclasse(s) base, da descrição de sua semântica, da notação proposta e das restrições válidas para esse estereótipo. As restrições de um estereótipo são apresentadas tanto utilizando linguagem natural quanto utilizando a linguagem OCL.

As restrições definidas para as metaclasses e/ou estereótipos do perfil limitam como os estereótipos podem ser utilizados na especificação de uma ontologia. Por outro lado, como as entidades biológicas apresentadas em ontologias OBO nem sempre estão explicitamente classificadas nos diferentes tipos de entidades biológicas da Ontologia de Relacionamentos, o perfil permite o uso dos estereótipos definidos em entidades ainda não classificadas. Dessa forma, sempre é possível utilizar as relações definidas pelo perfil em duas entidades não especificadas como continuantes ou processos. Porém, com os estereótipos corretamente definidos para uma dada entidade da ontologia podemos verificar melhor a integridade das relações modeladas para aquela entidade com o auxílio do perfil. Por exemplo, utilizando como exemplo o estereótipo Is_a definido pelo perfil, se uma dada entidade biológica $A$ possui o estereótipo «material», outra entidade biológica $B$ que participe de uma relação Is_a com $A$ não pode estar estereotipada como «process»ou «immaterial».

A Figura 11 ilustra a validação de relações estereotipadas com Is_a em diferentes instâncias de Class estereotipadas como «material»,《immaterial»e «process». Neste sentido, a Figura exemplifica a possibilidade de validação automática da ontologia e ressalta as in- 


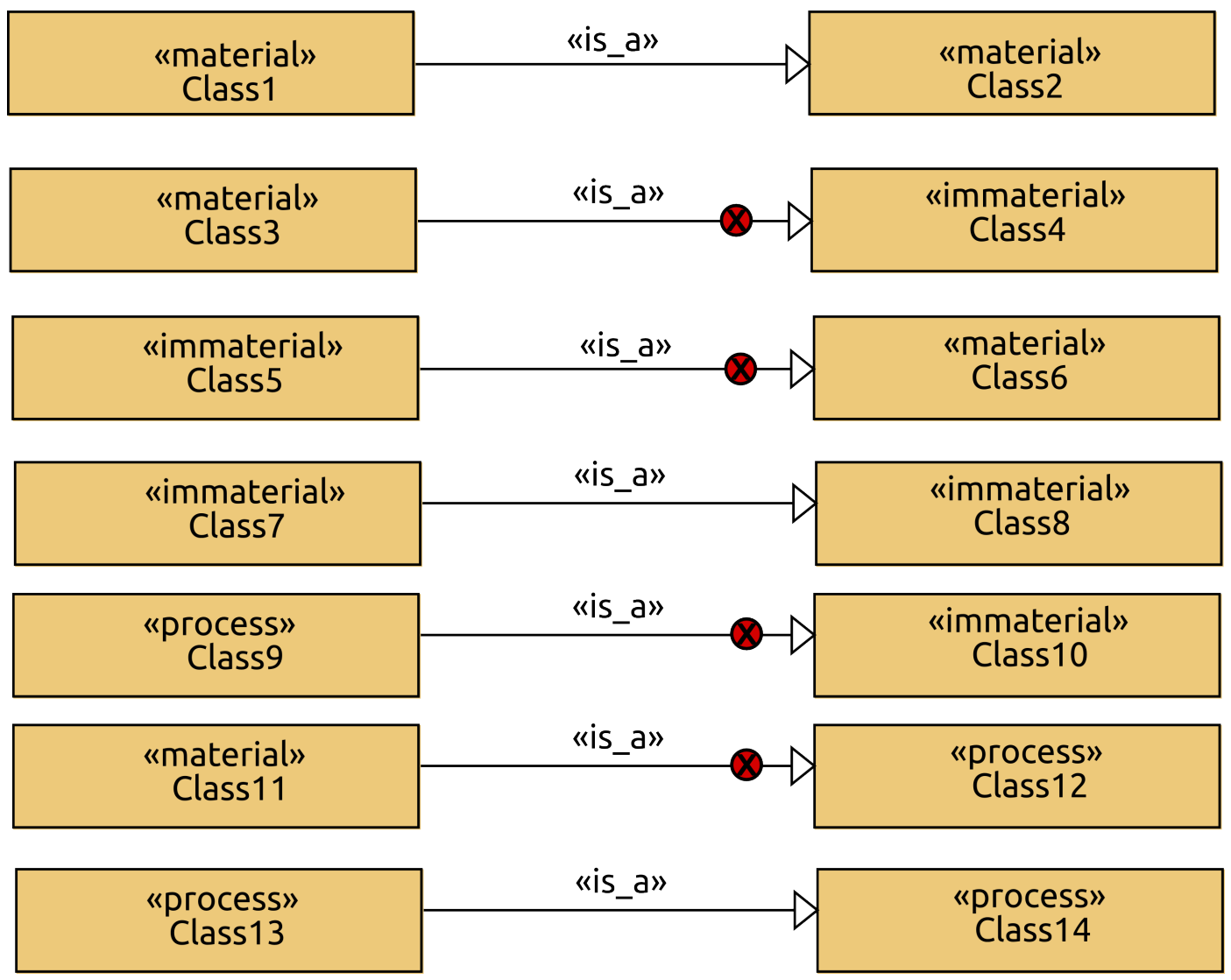

Figura 11: Exemplo do uso das restrições OCL presentes no perfil proposto para a modelagem de ontologias OBO utilizando UML na validação de uma ontologia. (Adaptado de [5].)

consitências na modelagem pelo uso de uma marcação vermelha. Desta maneira, o usuário pode verificar inconsistências existentes mais facilmente, garantindo à ontologia maior correção.

Informações adicionais sobre o perfil UML para a ontologia de relacionamentos da OBO podem ser encontradas em [5].

\subsection{Conclusão}

Neste capítulo apresentamos uma visão geral sobre o uso de ontologias no domínio biomédico. Apresentamos também uma visão geral da $O B O$ Foundry e das principais linguagens utilizadas para a representação de ontologias biomédicas. Finalmente, introduzimos a Ontologia de Relacionamentos da OBO e um perfil UML definido para esta ontologia.

Embora o perfil UML proposto para a OR-OBO possa ser utilizado em conjunto com ferramentas UML de propósito geral que suportem a definição e uso de perfils, uma ferramenta de- 
dicada pode ser desenvolvida de modo a prover suporte à validação sintática (semi) automática dos modelos desenvolvidos segundo as restrições definidas por esse perfil. Adicionamente, modelos UML e ontologias desenvolvidas pela OBO são representados usando diferentes linguagens, não (nativamente) integráveis. Neste sentido, tal ferramenta poderia prover mecanismos para a integração de ontologias biomédicas já existentes com os modelos desenvolvidos. Esta integração permitiria o uso da ferramenta na curação e validação de ontologias $\mathrm{OBO}$, bem como o reuso do conhecimento de domínios já formalizados em ontologias OBO para o desenvolvimento de sistemas computacionais. Adicionalmente, esta integração também possibilitaria aos desenvolvedores de software criar ontologias biomédicas utilizando uma linguagem gráfica que já possuem familiaridade. 


\section{OBO-RO Editor: Arquitetura de referência e processo de desenvolvimento}

Este projeto tem como objetivo geral investigar o suporte ao desenvolvimento de ontologias biomédicas na linguagem UML. Neste sentido, implementamos uma ferramenta de modelagem chamada $O B O-R O$ Editor, a qual provê suporte ao desenvolvimento de modelos/ontologias UML e a integração destes com ontologias representadas em $O B O$ File Format. A ferramenta $O B O-R O$ Editor foi desenvolvida a partir de uma arquitetura de referência, a qual define um conjunto de artefatos interrelacionados usados como base para um processo de desenvolvimento orientado a modelos.

O restante deste capítulo está estruturado da seguinte forma: a seção 5.1 apresenta uma visão geral da arquitetura de referência proposta para o desenvolvimento do trabalho e os principais artefatos definidos; e a seção 5.2 apresenta o processo utilizado no desenvolvimento destes artefatos e na obtenção da implementação correspondente.

\subsection{Arquitetura de referência e integração}

Este projeto tem como objetivo geral investigar o suporte ao desenvolvimento de ontologias biomédicas na linguagem UML. De forma específica, este projeto procura i) investigar o desenvolvimento de uma ferramenta de modelagem gráfica para o suporte à construção de ontologias utilizando o perfil UML proposto em [5]; e, ii) investigar a integração de ontologias desenvolvidas utilizando UML e ontologias desenvolvidas usando o OBO File Format. 
De forma a atingir os objetivos propostos, uma ferramenta de modelagem gráfica específica de domínio foi desenvolvida, chamada $O B O-R O$ Editor, com base nos seguintes requisitos funcionais: 1) permitir a criação de ontologias de forma simples a partir de elementos de modelagem definidos no perfil; 2) permitir a verificação manual ou automática das restrições sintáticas da ontologia sendo modelada; e 3) permitir a integração das ontologias desenvolvidas na ferramenta com ontologias representadas na linguagem $O B O$ File Format, bem como a importação e exportação de ontologias representadas nesta linguagem.

Um processo de desenvolvimento orientado a modelos foi definido para a implementação da ferramenta $O B O-R O$ Editor. Este processo utiliza linguagens e frameworks providos pelo Eclipse Modeling Project (EMP) para suporte ao desenvolvimento orientado a modelos de linguagens específicas de domínio e para o desenvolvimento de transformações entre modelos. O uso de um processo de desenvolvimento orientado a modelos permitiu o desenvolvimento em um nível mais alto de abstração a partir da especificação de um conjunto de modelos relacionados. Adicionalmente, a geração de código fonte de forma (semi) automática a partir dos modelos definidos resultou em ciclos de desenvolvimento mais rápidos. Neste sentido, adições e adaptações durante o desenvolvimento puderam ser realizadas nos modelos definidos e implementações atualizadas da ferramenta puderam ser obtidas de forma mais rápida e confiável. A disponibilidade de variados frameworks para o suporte ao desenvolvimento orientado a modelos permitiu a geração da quase totalidade do código fonte da ferramenta a partir dos modelos desenvolvidos. Nas (raras) ocasiões em que a implementação personalizada foi necessária, foi possível realizar esta implementação diretamente no código fonte produzido a partir dos modelos sem que estas alterações fossem sobrescritas por atualizações (semi) automáticas posteriores.

Neste sentido, definimos um conjunto de artefatos que formam a base para a implementação da ferramenta de modelagem segundo o processo de desenvolvimento orientado a modelos proposto. Chamamos esse conjunto de artefatos e seus relacionamentos de arquitetura de referência. A Figura 12 apresenta uma visão geral da arquitetura de referência da ferramenta desenvolvida. Artefatos obtidos durante o desenvolvimento são apresentados como retângulos 
nomeados na parte superior da figura. Pacotes Java criados com base nesses artefatos são representados na parte inferior da figura. Flechas entre dois artefatos ou pacotes representam uma relação de alto nível entre esses elementos.

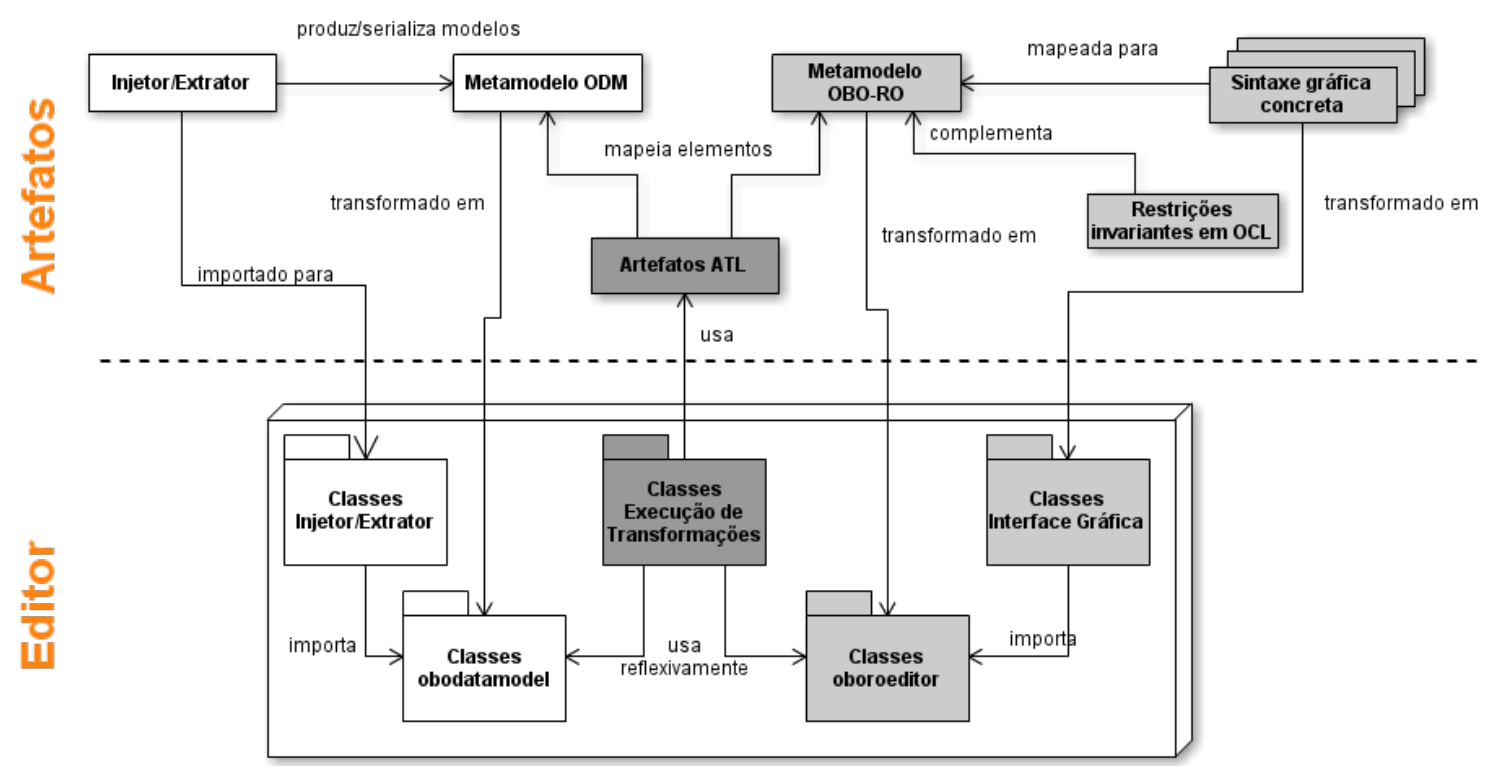

Figura 12: Visão geral da arquitetura de referência para o desenvolvimento do $O B O-R O$ Editor.

Artefatos brancos foram definidos para permitir a leitura/escrita de ontologias no $O B O$ File Format (serialização). Neste sentido, três artefatos principais foram desenvolvidos: um metamodelo Ecore para representação de uma ontologia $\mathrm{OBO}$, chamado metamodelo OBO Data Model (ODM); um artefato para a leitura de uma ontologia e instanciação de um modelo ODM equivalente (injeção); e um artefato para a exportação de um modelo ODM como uma ontologia OBO (extração).

Artefatos representados em cinza claro foram definidos para permitir a representação dos elementos definidos pelo perfil UML e a validação das restrições invariantes definidas neste perfil. Neste sentido, três artefatos principais foram definidos: um metamodelo Ecore para a representação dos elementos de uma ontologia utilizando os elementos definidos no perfil, chamado metamodelo OR-OBO; uma definição GMF da sintaxe gráfica concreta utilizada para a edição das ontologias representadas no metamodelo OR-OBO; e um conjunto de restrições invariantes complementares ao metamodelo OR-OBO, utilizadas para a validação sintática de uma ontologia no editor. 
Por fim, o artefato cinza escuro foi definido para permitir a transformação de uma ontologia UML em uma ontologia $O B O$ File Format e vice-versa. Neste sentido, um conjunto transformações ATL foram desenvolvidas para relacionar elementos dos metamodelos ODM e OR-OBO.

\subsection{Processo de desenvolvimento}

As seguintes atividades foram definidas para o desenvolvimento da ferramenta de modelagem a partir da arquitetura proposta: 1) definição do metamodelo $O R-O B O$; 2) definição da sintaxe gráfica concreta para modelagem; 3) definição das restrições OCL para o metamodelo OR-OBO; 4) definição do metamodelo ODM; 5) definição de mecanismos de injeção e extração para arquivos OBO File Format; e 6) definição das transformações entre os metamodelos desenvolvidos. Uma visão geral dessas atividades é apresentada a seguir.

\subsubsection{Definição do metamodelo OR-OBO}

A definição do metamodelo OR-OBO tem por objetivo criar uma representação dos conceitos definidos pelo perfil e implementar o suporte à edição de modelos instanciados a partir desse metamodelo. Neste sentido, no contexto deste projeto utilizamos o framework EMF para o desenvolvimento do metamodelo OR-OBO. Este metamodelo é formado pelas metaclasses definidas no perfil e expressões OCL que complementam essas metaclasses.

As seguintes atividades foram utilizados para o desenvolvimento do metamodelo OR-OBO: 1) desenvolver um modelo Ecore contendo os aspectos estruturais das metaclasses do metamodelo do editor; 2) adicionar expressões OCL às metaclasses no modelo Ecore contendo restrições e derivações de valores previstas para o metamodelo UML; 3) transformar o modelo Ecore em um modelo generativo; 4) definir diretrizes para a geração automática de código no modelo generativo; 5) transformar o modelo generativo em código na linguagem Java implementando as metaclasses modeladas; e 6) gerar as classes adaptadoras para o suporte à edição do modelo por outros frameworks do EMP. 
O desenvolvimento do metamodelo OR-OBO foi realizado como um diagrama de classes utilizando o suporte do editor gráfico disponibilizado pelo projeto EMF. A inclusão de restrições e derivações em OCL no metamodelo foi realizada utilizando o editor OCLinEcore. A Figura 13 ilustra a sequência de atividades necessárias para a definição do metamodelo OR-OBO. Neste sentido, as atividades de desenvolvimento podem ser manuais ou semi-automáticas. Atividades manuais, apresentadas em cinza, são completamente realizadas pelo desenvolvedor. Atividades semi-automáticas, apresentadas em branco, são executadas completamente pelo framework após a definição de parâmetros de execução. Este processo foi representado usando a linguagem Business Process Model and Notation (BPMN) [108].

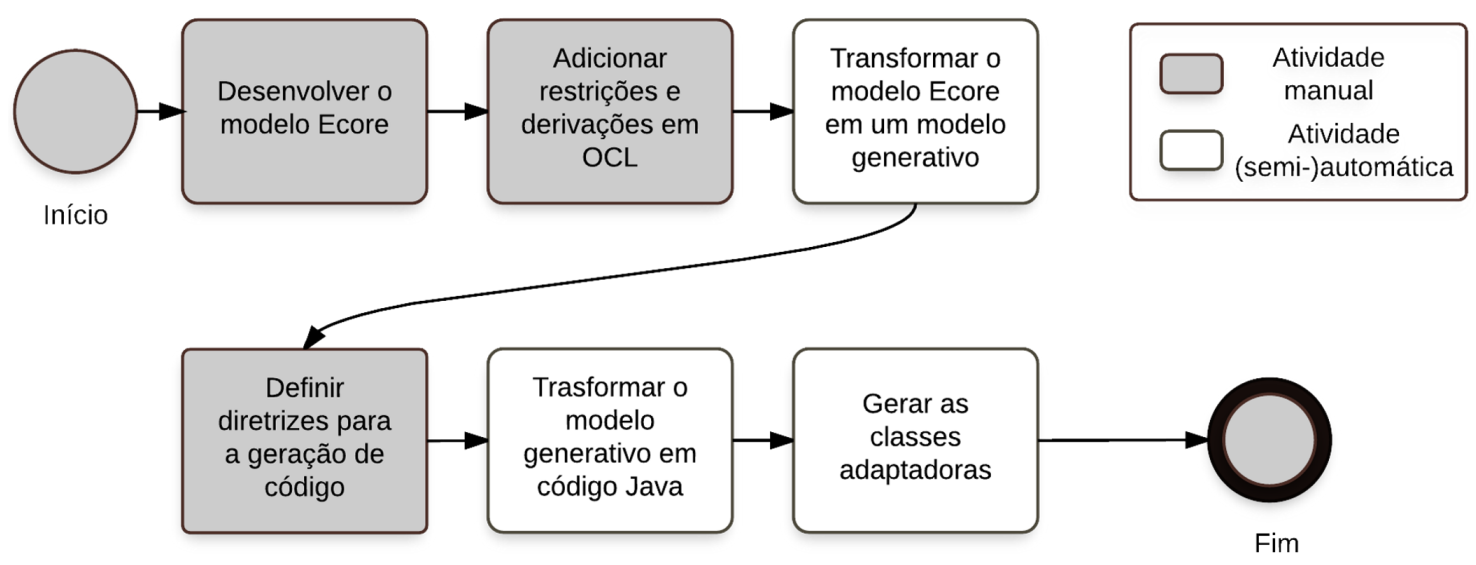

Figura 13: Passos para a definição do metamodelo OR-OBO.

\subsubsection{Definição da sintaxe gráfica concreta para modelagem}

O desenvolvimento da sintaxe gráfica concreta tem por objetivo prover uma notação gráfica adequada para o desenvolvimento de modelos utilizando os elementos de modelagem definidos no perfil. Particularmente, no contexto deste projeto utilizamos o framework GMF para prover a notação definida para as metaclasses do metamodelo OR-OBO e para criar um editor gráfico para ontologias OBO. Adicionalmente, utilizamos o suporte do GMF para a validação sintática das ontologias desenvolvidas em relação às restrições definidas no metamodelo OR-OBO.

As seguintes atividades foram utilizadas para o desenvolvimento da sintaxe gráfica concreta: 1) desenvolver o modelo da definição da notação gráfica dos elementos de modelagem 
(modelo GMFGraph); 2) desenvolver a definição da paleta de ferramentas de modelagem (modelo GMFTool); 3) desenvolver o modelo de mapeamento (modelo GMFMap), associando cada metaclasse de interesse do metamodelo OR-OBO a sua representação, definida no modelo GMFGraph, e ao item da paleta de edição, que será usada para criar instâncias dessa metaclasse, definido no modelo GMFTool; 4) adicionar as restrições OCL usadas para a validação sintática das ontologias desenvolvidas aos elementos do modelo GMFMap; 5) transformar os modelos anteriores em um modelo generativo do GMF; 6) gerar o código Java implementando o editor a partir do modelo generativo; 7) realizar personalizações no código Java gerado para modificar aspectos do editor não suportados por padrão pelo GMF.

A Figura 14 ilustra em BPMN a sequência de atividades necessárias para o desenvolvimento da sintaxe gráfica concreta. O desenvolvimento do modelo da definição da notação gráfica e o desenvolvimento da definição da paleta de ferramentas de modelagem podem ser realizados de forma paralela (não representada no diagrama). A adição das restrições invariantes em OCL para a validação do modelo é um passo relacionado à atividade de definição das restrições OCL para o metamodelo OR-OBO, apresentada na seção 5.2.3. Adicionalmente, o código Java do editor pode ser gerado de duas formas: como um plug-in para o ambiente de desenvolvimento Eclipse e como de uma aplicação isolada (stand-alone). Neste segundo cenário, o editor é criado de forma que todo o suporte básico provido pela plataforma Eclipse e pelo GMF para sua execução (i.e., interface de usuário e ambiente de execução) é incluído nos pacotes Java exportados em conjunto com o editor desenvolvido.

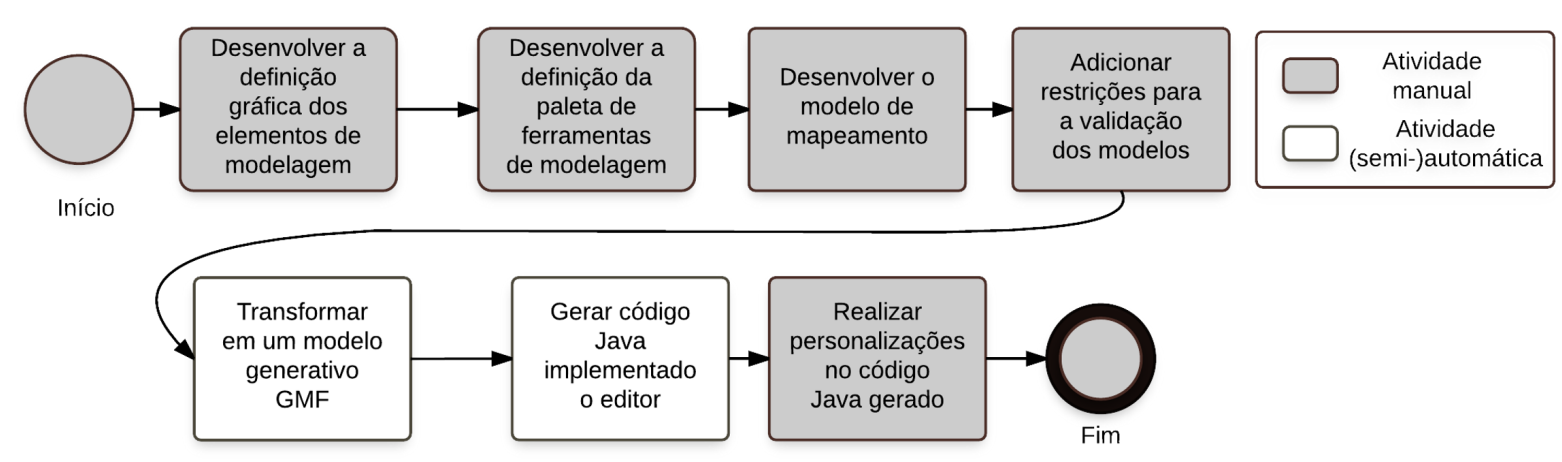

Figura 14: Passos para a criação da sintaxe gráfica concreta do editor. 


\subsubsection{Definição de expressões OCL para o metamodelo OR-OBO}

A definição de expressões OCL para o metamodelo OR-OBO tem por objetivo especificar o conjunto de restrições OCL definido pelo perfil e outras expressões OCL necessárias a este metamodelo. As expressões definidas devem ser avaliadas durante a edição de uma ontologia de forma (semi) automática, e as restrições ao uso dos elementos do metamodelo devem ser validadas. Neste sentido, dois mecanismos de validação podem ser utilizados: live validation e batch validation. O mecanismo de live validation é executado de forma automática após uma ação de edição em um modelo. Este mecanismo é utilizado de forma a impedir a alteração do modelo caso a ação de edição o deixe em um estado inconsistente, no qual uma dada restrição é violada. Por sua vez, o mecanismo de batch validation é executado de forma explícita pelo usuário. Este mecanismo apresenta os elementos que violam alguma das restrições definidas. Adicionalmente, uma vez que o mecanismo de batch validation não executa de forma automática após uma ação de edição, este não impede o modelo de estar (momentaneamente) em um estado inconsistente. Neste sentido, cabe ao usuário executar as ações necessárias para corrigir os problemas identificados.

Durante esta atividade, selecionamos todas as restrições OCL definidas para os elementos do perfil e as separamos em dois grupos: i) restrições que, após violadas, a única forma de atingir novamente a consistência do modelo seja desfazer a ação de modelagem que o deixou inconsistente; e ii) restrições que, após violadas, pode-se atingir novamente a consistência do modelo após novas ações de modelagem que não sejam necessariamente desfazer a ação anterior. As restrições agrupadas em i) devem ser validadas pelo mecanismo de live validation, enquanto as restrições agrupadas em ii) devem ser validadas pelo mecanismo de batch validation.

Esta atividade foi realizada paralelamente às atividades de definição do metamodelo OROBO e definição da sintaxe gráfica concreta para modelagem. Ambas as atividades utilizam as restrições OCL definidas para a inclusão nos mecanismos de validação providos pelos frameworks EMF e GMF. 


\subsubsection{Definição do metamodelo OBO Data Model (ODM)}

A definição do metamodelo OBO Data Model (ODM) tem como objetivo criar um metamodelo para representar os tipos de elementos definidos em uma ontologia representada na linguagem $O B O$ File Format, os quais estão implicitamente definidos pela sintaxe desta linguagem. Neste sentido, no contexto deste projeto utilizamos o framework EMF para desenvolver o metamodelo ODM.

As seguintes atividades foram utilizadas para o desenvolvimento do metamodelo ODM: 1) desenvolver um modelo Ecore contendo os principais aspectos estruturais existentes no $O B O$ File Format; 2) transformar o modelo Ecore em um modelo generativo; 3) definir diretrizes para a geração automática de código a partir do modelo; 4) transformar o modelo generativo em código na linguagem Java implementando as metaclasses modeladas; e 5) gerar as classes adaptadoras para o suporte à edição do modelo por outros frameworks do EMP.

O desenvolvimento do metamodelo ODM é similar ao desenvolvimento do metamodelo OR-OBO, apresentado na seção 5.2.1. Contudo, neste caso não foi necessário definir restrições OCL para complementar a especificação do metamodelo. A Figura 15 ilustra em BPMN a sequência de atividades necessárias para a definição do metamodelo ODM.

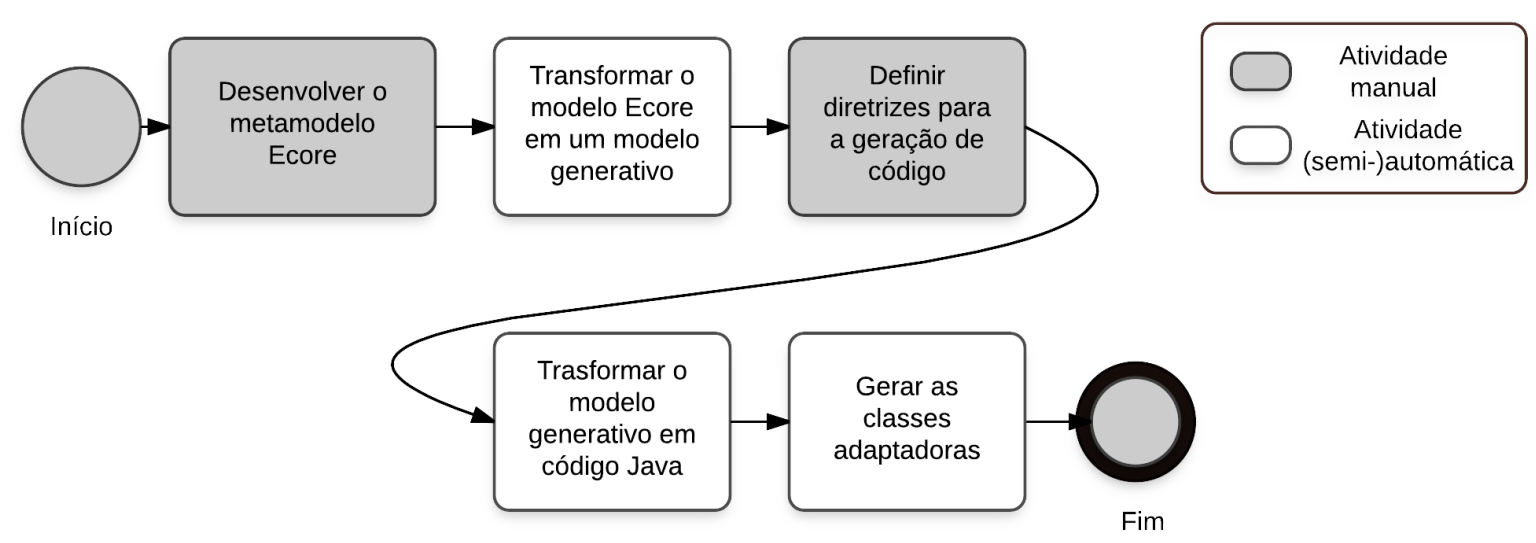

Figura 15: Passos para a definição do metamodelo ODM. 


\subsubsection{Definição de mecanismos de injeção e extração de ontologias OBO}

A definição de mecanismos de injeção e extração para ontologias OBO representadas em OBO File Format tem por objetivo prover suporte à integração destas ontologias com ontologias representadas no metamodelo ODM. Neste sentido, um injetor recebe como entrada um ou mais arquivos contendo uma ontologia representada na linguagem $O B O$ File Format e produz um modelo ODM equivalente. De forma análoga, um extrator recebe como entrada um modelo ODM e produz uma ontologia equivalente em um ou mais arquivos $O B O$ File Format.

Os mecanismos de injeção e extração foram desenvovidos como classes Java que manipulam ontologias representadas no $O B O$ File Format e modelos ODM. Neste sentido, as classes desenvolvidas utilizam a API org . obo . data adapter [97], disponibilizada pela OBO, para a leitura e escrita de ontologias em $O B O$ File Format. Adicionalmente, as classes desenvolvidas também utilizam o código Java automaticamente gerado a partir da definição do metamodelo ODM para a leitura e escrita de modelos ODM em Ecore/XMI.

\subsubsection{Definição das transformações entre os metamodelos OR-OBO e ODM}

A definição das transformações entre os elementos do metamodelo OR-OBO e os elementos do metamodelo ODM tem como objetivo complementar o suporte à integração com ontologias representadas no $O B O$ File Format. Neste sentido, pretende-se permitir a transformação de ontologias representadas no metamodelo ODM em ontologias representadas no metamodelo OR-OBO e vice-versa. No contexto deste projeto utilizamos o framework ATL para prover suporte ao desenvolvimento e à execução das transformações necessárias.

Dois conjuntos de transformação foram definidos: o primeiro conjunto de transformações recebe como entrada um modelo ODM e produz um modelo OR-OBO; o segundo conjunto de transformações recebe como entrada um modelo OR-OBO e produz um modelo ODM. As seguintes atividades foram utilizadas para o desenvolvimento de cada conjunto de transformação: 1) definir um conjunto de regras de transformação para mapear elementos do metamodelo fonte para os elementos do metamodelo alvo utilizando a linguagem ATL; 2) gerar artefatos 
de suporte à transformação, como a representação das regras de transformação em XMI; 3) implementar classes Java que utilizam a transformação definida de forma automatizada.

A Figura 16 ilustra em BPMN a sequência de atividades necessárias para a definição de um conjunto de transformação entre o metamodelo ODM e o metamodelo OR-OBO.

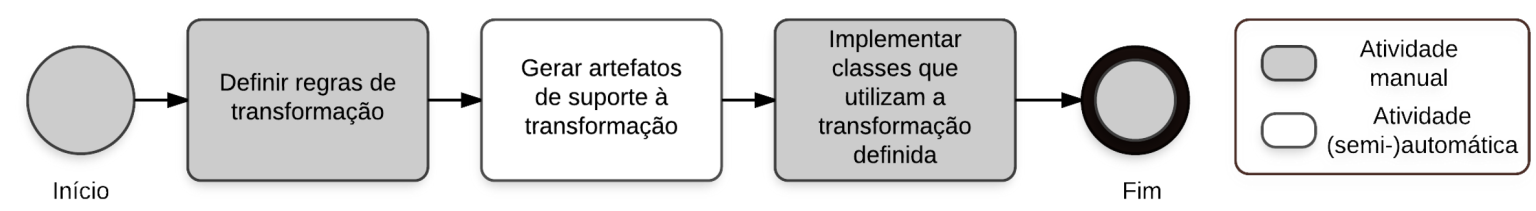

Figura 16: Passos para o desenvolvimento de transformações entre os metamodelos ODM e OR-OBO. 


\section{Suporte ao desenvolvimento de ontologias em UML}

O desenvolvimento de uma ontologia biomédica pode ser beneficiado pelo uso dos elementos de modelagem gráfica definidos no perfil UML para a OR OBO. Estes elementos podem ser utilizados não apenas para prevenir a introdução de inconsistências em uma ontologia em desenvolvimento, mas também para facilitar a identificação e correção de erros em uma ontologia existente [5]. Neste sentido, este capítulo apresenta os principais aspectos do desenvolvimento da ferramenta de modelagem $O B O-R O$ Editor relacionados à criação de um modelo UML utilizando os elementos de modelagem definidos no perfil.

O restante desse capítulo está estruturado da seguinte forma: a seção 6.1 apresenta uma visão geral do desenvolvimento do metamodelo OR-OBO; a seção 6.2 apresenta uma visão geral da modelagem da sintaxe gráfica concreta realizada utilizando o framework GMF; a seção 6.3 apresenta uma visão geral do mapeamento de condições invariantes, existentes para os estereótipos para o perfil, realizado utilizando o suporte do GMF; finalmente, a seção 6.4 apresenta algumas conclusões.

\subsection{Definição do metamodelo OR-OBO}

O metamodelo OR-OBO representa por meio de um modelo Ecore os tipos de elementos definidos no perfil UML para a Ontologia de Relacionamentos da OBO [5]. Neste sentido, o editor gráfico provido pelo EMF foi utilizado para a definição dos aspectos estruturais do metamodelo OR-OBO, ou seja, para a representação das metaclasses e das referências entre essas metaclasses. Em seguida, a especificação do metamodelo foi enriquecida por meio da definição 
de um conjunto de expressões OCL. Estas expressões, necessárias para a completa definição das metaclasses representadas, foram adicionadas ao metamodelo desenvolvido utilizando a linguagem OCLinEcore provida pelo framework Eclipse OCL. Esta linguagem representa um modelo Ecore de maneira textual amigável à compreensão humana, e facilita a definição de expressões OCL para este modelo. Posteriormente, um conjunto de classes Java que implementam o metamodelo OR-OBO foi criado (semi) automaticamente a partir da definição Ecore do metamodelo.

Além dos elementos definidos pelo perfil UML, foram definidas um conjunto de metaclasses de suporte durante o desenvolvimento do metamodelo OR-OBO. Essas metaclasses foram incluídas para aprimorar a organização e a representação dos elementos de uma ontologia OBO no contexto do editor desenvolvido.

\subsubsection{Definição das metaclasses UML de interesse}

A especificação do perfil identifica um conjunto de metaclasses que representam os conceitos relevantes para a representação da Ontologia de Relacionamentos da OBO. Neste sentido, as metaclasses especificadas pelo perfil estendem um conjunto de metaclasses do metamodelo UML, chamadas no contexto desse trabalho de metaclasses UML de interesse, sendo dependentes destas para a sua total definição. Dessa maneira, o primeiro passo para a definição do metamodelo OR-OBO consistiu da representação das metaclasses UML de interesse neste metamodelo.

Neste sentido, o metamodelo OR-OBO não implementa o perfil como uma especialização leve do metamodelo UML (lightweight extension), mas sim fazendo uso de um mecanismo de extensão baseado na criação de novas metaclasses para este metamodelo (heavyweight extension). Este mecanismo de extensão foi utilizado pois os frameworks do EMP não apresentam suporte completo à validação de restrições em perfis UML representados como modelos Ecore. Adicionalmente, o desenvolvimento do $O B O-R O$ Editor teve como um de seus objetivos permitir ao usuário do editor abstrair os aspectos relacionados à infraestrutura da linguagem UML de modelo a focar apenas na ontologia sendo modelada. Dessa maneira, adaptações ao meta- 
modelo UML (discutidas na sequência) foram implementadas de forma que todos os atributos e referências relevantes das metaclasses envolvidas possam ser automaticamente inicializados e/ou modificados à medida em que os elementos da ontologia são modelados utilizando as metaclasses definida pelo perfil.

A Figura 17 ilustra dois fragmentos das metaclasses UML de interesse que foram definidas no metamodelo OR-OBO. A Figura 17a apresenta as principais metaclasses na hierarquia das metaclasses UML InstanceSpecification, Class e Package. Essas metaclasses são as principais metaclasses relacionadas à representação de instâncias, classes de entidades, tipos de relacionamentos e ontologias no metamodelo OR-OBO. A Figura 17b apresenta as principais metaclasses na hierarquia de DirectedRelationship, Generalization e Association. Essas metaclasses são as principais metaclasses relacionadas à representação de relacionamentos entre elementos de uma ontologia no metamodelo OR-OBO.

Durante a representação das metaclasses UML de interesse, alguns aspectos destas metaclasses tiveram de ser adaptados. Em geral, essas adaptações foram necessárias devido à incapacidade da redefinição de tipos e nomes de propriedades em subclasses no Ecore. A redefinição de tipos e nomes de propriedades é utilizada em várias metaclasses da infraestrutura UML, mas tal característica não pode ser utilizada no framework EMF por não ser suportada pela classe Java equivalente gerada após a transformação de um modelo Ecore em código de implementação. Adicionalmente, na definição da metaclasse Classifier foi necessária a adaptação de uma operação de consulta ao modelo definida em OCL pela infraestrutura UML (operação allParents ( ) ). Essa operação não poderia ser implementada tal como definida pela UML, utilizando o suporte do Eclipse OCL de forma segura em relação ao encontro de um ciclo nas instâncias das metaclasses modeladas. Por esta razão, a operação foi adaptada para utilizar o método closure ( ) disponibilizado pelo framework Eclipse OCL.

\subsubsection{Definição de classes de entidades e instâncias}

Classes de entidades e instâncias modeladas em ontologias OBO são representadas no metamodelo OR-OBO pelas classes OboClass e OboInstance, respectivamente. A Figura 18 

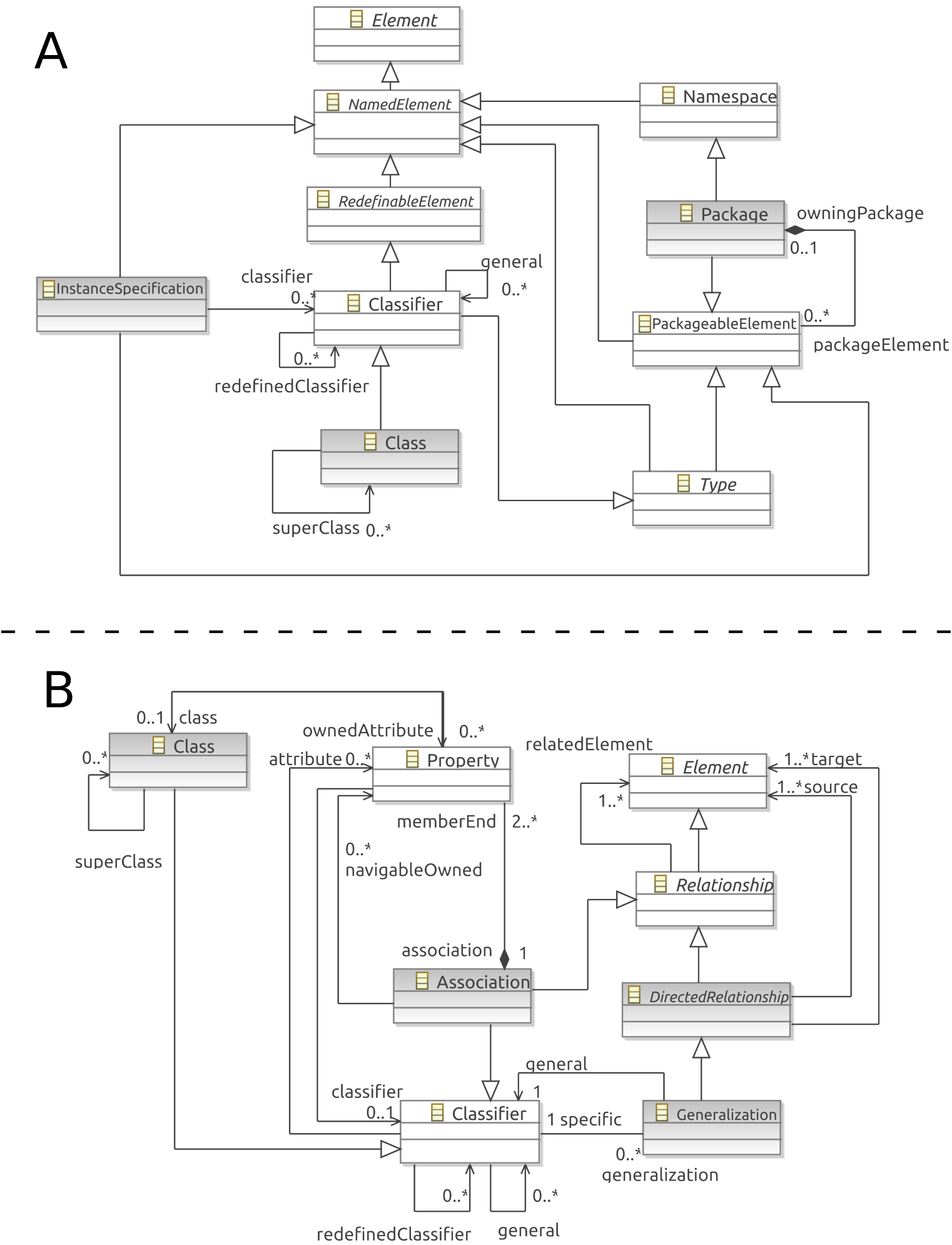

Figura 17: Fragmentos das metaclasses UML de interesses definidas no metamodelo OR-OBO. Um retângulo nomeado representa uma metaclasse UML presente do metamodelo OR-OBO. Um retângulo cinza representa metaclasses diretamente estendidas por uma metaclasse definida no perfil. Um retângulo branco representa metaclasses estendidas ou referenciadas indiretamente por uma metaclasse definida no perfil. A) metaclasses de interesse para a representação de ontologias, classes de entidades e instâncias dessas classes; B) metaclasses de interesse para a representação de relações entre elementos de uma ontologia. 
apresenta as principais metaclasses de interesse na modelagem de OboClas e Obo Instance.

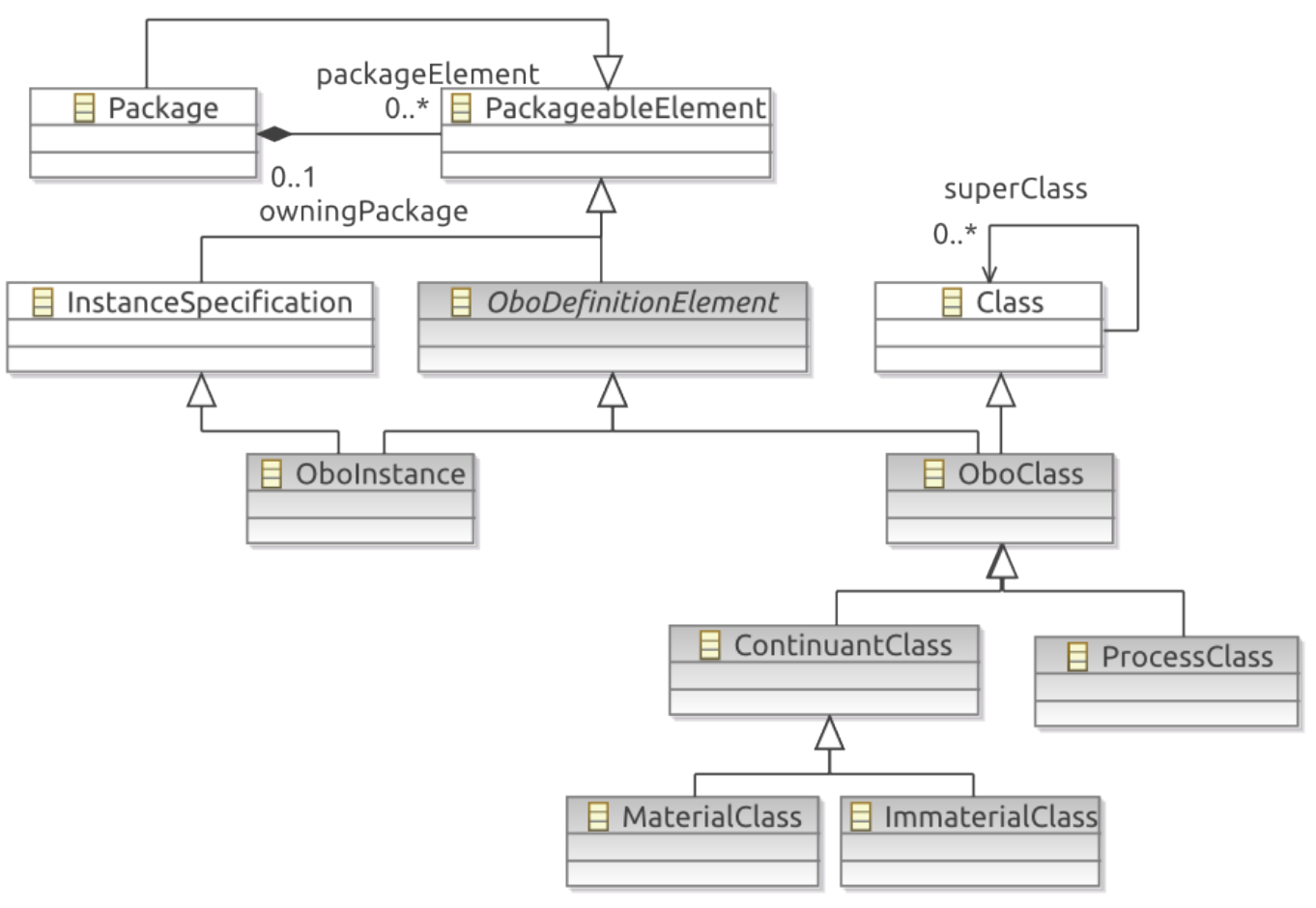

Figura 18: Metaclasses de interesse para a definição de classes OboClass e OboInstance. Um retângulo branco representa metaclasses UML de interesse, enquanto um retângulo cinza representa metaclasses introduzidas para a implementação da extensão ao metamodelo.

Os diferentes tipos de entidades definidos no perfil são implementados como especializações da metaclasse OboClass, que, por sua vez, é uma especialização da metaclasse Class. Neste sentido, os tipos de entidade continuantes e processos são representados pelas metaclasses ContinuantClasse ProcessClass, respectivamente. Adicionalmente, a metaclasse ContinuantClass é especializada pelas metaclasses MaterialClass e ImmaterialClass para a representação de continuantes materiais e continuantes imateriais, respectivamente. OboClass não fora definida no perfil UML mas foi introduzida no metamodelo OROBO de forma a permitir a inclusão de atributos presentes na definição de um termo de uma ontologia OBO como, por exemplo, a definição do termo, e assim possibilitar uma melhor representação de um elemento de uma ontologia OBO. Adicionalmente, a inclusão dessa classe permite generalizar e estruturar melhor o metamodelo desenvolvido.

Uma instância representada em uma ontologia OBO é representada pela metaclasse OboInstance que, por sua vez, é uma especialização da metaclasse InstanceSpecifica- 
ti on. De acordo com as definições do perfil UML, uma instância era representada por meio da metaclasse InstanceSpecification Porém, de forma análoga à inclusão da metaclasse OboClass no metamodelo OR-OBO, OboInstance foi adicionada de forma a permitir a inclusão de atributos presentes na definição de uma instância em uma ontologia OBO.

OboClass e OboInstance também são modeladas como especializações de OboDefinitionElement. OboDefinitionElement foi adicionada ao metamodelo para agregar e organizar atributos existentes em todos os objetos identificados de uma ontologia OBO, como, por exemplo, as entidades, instâncias e tipos de relacionamentos presentes em uma ontologia. Exemplos desses atributos incluem o identificador do objeto OBO e o atributo annonymous, o qual representa o escopo de validade do identificador de um objeto (local ou global).

OboDefinitionElement é modelada como uma especialização da metaclasse PackageableElement. PackageableElement é uma metaclasse UML abstrata que representa um elemento que pode ser contido em um Package. Package representa um container para outros elementos e define um espaço de nomes para a identificação inequívoca dos elementos contidos. Neste sentido, uma instância da metaclasse Package pode ser usada para agregar instâncias de OboDefinitionElement em um espaço de endereçamento de nomes ( $\mathrm{Na}$ mespace) adequado, de forma semelhante à agregação dos elementos em namespaces por uma ontologia. Dessa maneira, modelamos uma ontologia OBO como uma instância da metaclasse Package contendo diversas instâncias de OboDefinitionElement representando os elementos daquela ontologia.

\subsubsection{Definição de OboRelation}

A Figura 19 apresenta as principais metaclasses de interesse na modelagem de OboRelation. A classe OboRelation representa uma relação direcionada entre dois elementos de uma ontologia. Neste sentido, esta metaclasse foi criada para ser utilizada como um arco direcionado entre dois nós da ontologia, associando um elemento fonte a um elemento alvo. Adicionalmente, a partir da criação de uma OboRelation, as propriedades relacionadas das 
entidades interconectadas devem ser automaticamente derivadas.

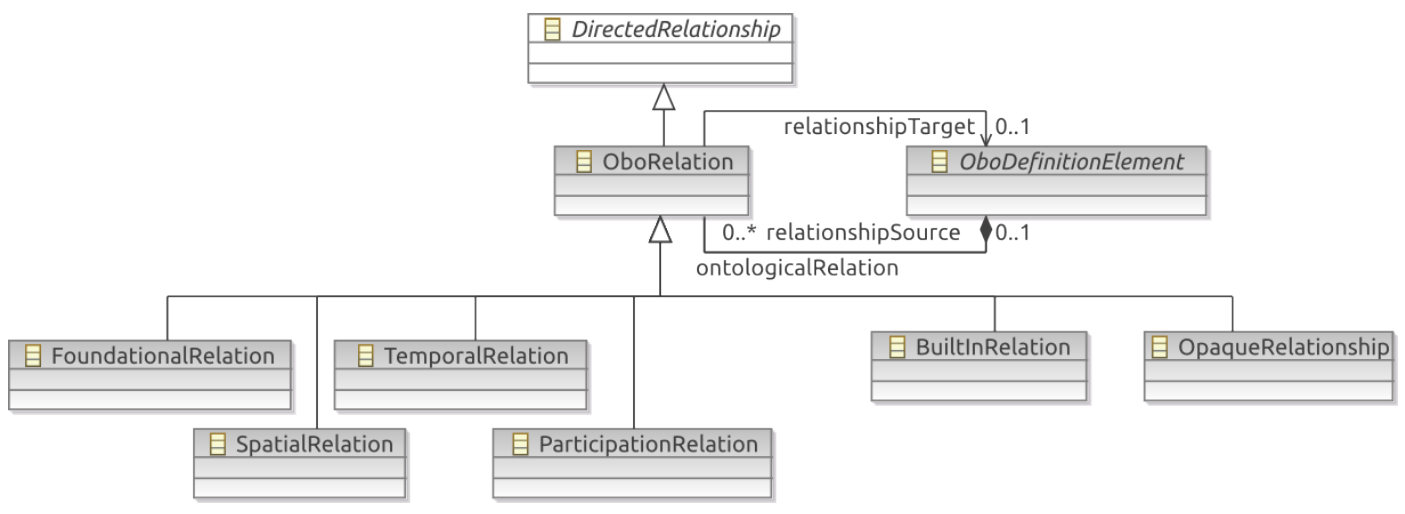

Figura 19: Metaclasses de interesse para a definição de OboRelation. Um retângulo branco representa metaclasses UML de interesse, enquanto um retângulo cinza representa metaclasses introduzidas para a implementação da extensão ao metamodelo.

A associação entre um elemento fonte e um elemento alvo poderia ser realizada por meio das propriedades source e target da metaclasse DirectedRelationship, a metaclasse diretamente superior à metaclasse $\mathrm{OboRelation.} \mathrm{Porém,} \mathrm{essas} \mathrm{propriedades} \mathrm{precisam}$ ser derivadas em outras metaclasses UML que também especializam a metaclasse Di rectedRelationship. Assim, source e target são declaradas como derivadas na metaclasse DirectedRelationship e, portanto, não podem ser diretamente modificadas.

Dessa maneira, de modo a manter o comportamento esperado e conseguir que todas as propriedades do fragmento UML possam ser inicializadas e modificadas automaticamente, definimos duas propriedades para OboRelation: relationshipsource e relationshipTarget. Estas propriedades adicionais representam os dois terminais de uma OboRelation e são utilizadas para derivação dos meta-atributos source e target. Além disso, adicionamos as operações sources ( ) e targets ( ) à metaclasse DirectedRelationship para derivação desses meta-atributos. Essas operações são redefinidas nas metaclasses que especializam DirectedRelationship.

Finalmente, a propriedade relationshipsource de OboRelation possui uma propriedade inversa em OntologyNode, a propriedade ontologicalRelation. Esta propriedade foi definida para ser uma propriedade de composição que contém todas as relações das quais o termo é referenciado como fonte. O uso desta propriedade facilita a manipulação do 
modelo por meio de consultas em OCL.

OboRelation é especializada por todas as outras metaclasses que representam relações direcionadas entre dois elementos de uma ontologia OBO. Neste sentido, as metaclasses que representam os tipos de relacionamentos da OR OBO (FoundationalRelation, SpatialRelation, TemporalRelation e ParticipationRelation), as metaclasses que representam tipos de relacionamentos built-in de uma ontologia OBO (BuiltInRelation) e os relacionamentos definidos por outras ontologias OBO (representados por OpaqueRelation) são especializações de OboRelation. A implementação dessas metaclasses é apresentada nas seções 6.1.4 a 6.1.9.

\subsubsection{Definição da relação Is_a}

A Figura 20 apresenta as principais metaclasses de interesse na modelagem da metaclasse Is_a. A metaclasse Is_a representa a relação is_a definida na OR OBO. Is_a especializa a metaclasse FoundationalRelationship, que por sua vez especializa a metaclasse OboRelation. FoundationalRelationship não adiciona nenhuma propriedade ou operação à OboRelation. Porém, esta é utilizada de forma a obter uma melhor estruturação das metaclasses do perfil. Desse modo, Is_a representa uma relação binária direcionada de uma ontologia e possui dois terminais (relationshipSource e relationshiptarget) que são utilizados para associar dois termos da ontologia.

Is_a também especializa a metaclasse Generalization, de forma a interconectar um Classifier mais específico a outro mais geral. Generalization possui a propriedade specific, a qual indica o Classifier mais específico da generalização. Por sua vez, Classifier possui a propriedade generalization, a qual indica a generalização da qual o Classifier é mais específico. Ambas propriedades são opostas. Assim, para um Classifier c e uma Generalization g, se g: :specific referencia c, então a propriedade c: : generalization possuirá g entre as generalizações existentes. 


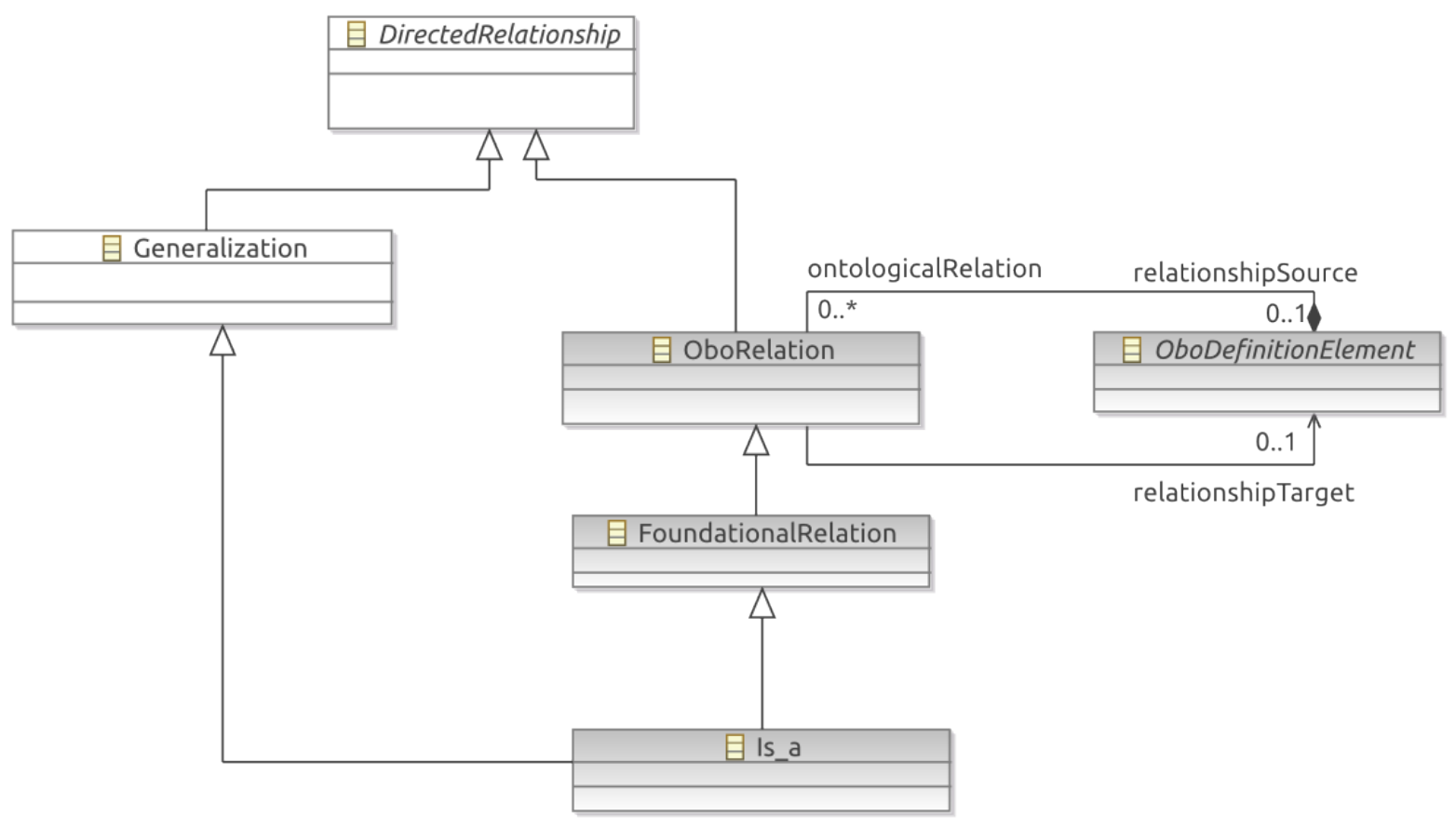

Figura 20: Metaclasses de interesse para a definição de Is_a. Um retângulo branco representa metaclasses UML de interesse, enquanto um retângulo cinza representa metaclasses introduzidas para a implementação da extensão ao metamodelo.

\subsubsection{Definição da relação Instance_of}

A Figura 21 apresenta as principais metaclasses de interesse na modelagem da metaclasse Instance_of. A metaclasse Instance_of representa a relação instance_of definida na OR OBO. Instance_of especializa a metaclasse FoundationalRelation, que por sua vez especializa a metaclasse OboRelation. Dessa forma, Instance_of representa uma relação binária direcionada de uma ontologia e possue dois terminais (relationshipSource e relationshipTarget) que são utilizados para associar dois elementos (um Obo Instance a um Oboclass) da ontologia. Adicionalmente, Instance_of especializa a metaclasse Dependency. Dependency é uma relação direcionada entre dois elementos que representa que um conjunto de elementos (referenciado pela propriedade client) necessita de um segundo conjunto de elementos (referenciado pela propriedade supplier) para a sua completa definição. Neste sentido, esta relação estabelece que a semântica dos elementos em client é dependente da definição da semântica dos elementos em client.

O desenvolvimento de Instance_of apresenta basicamente os mesmos desafios apresen- 


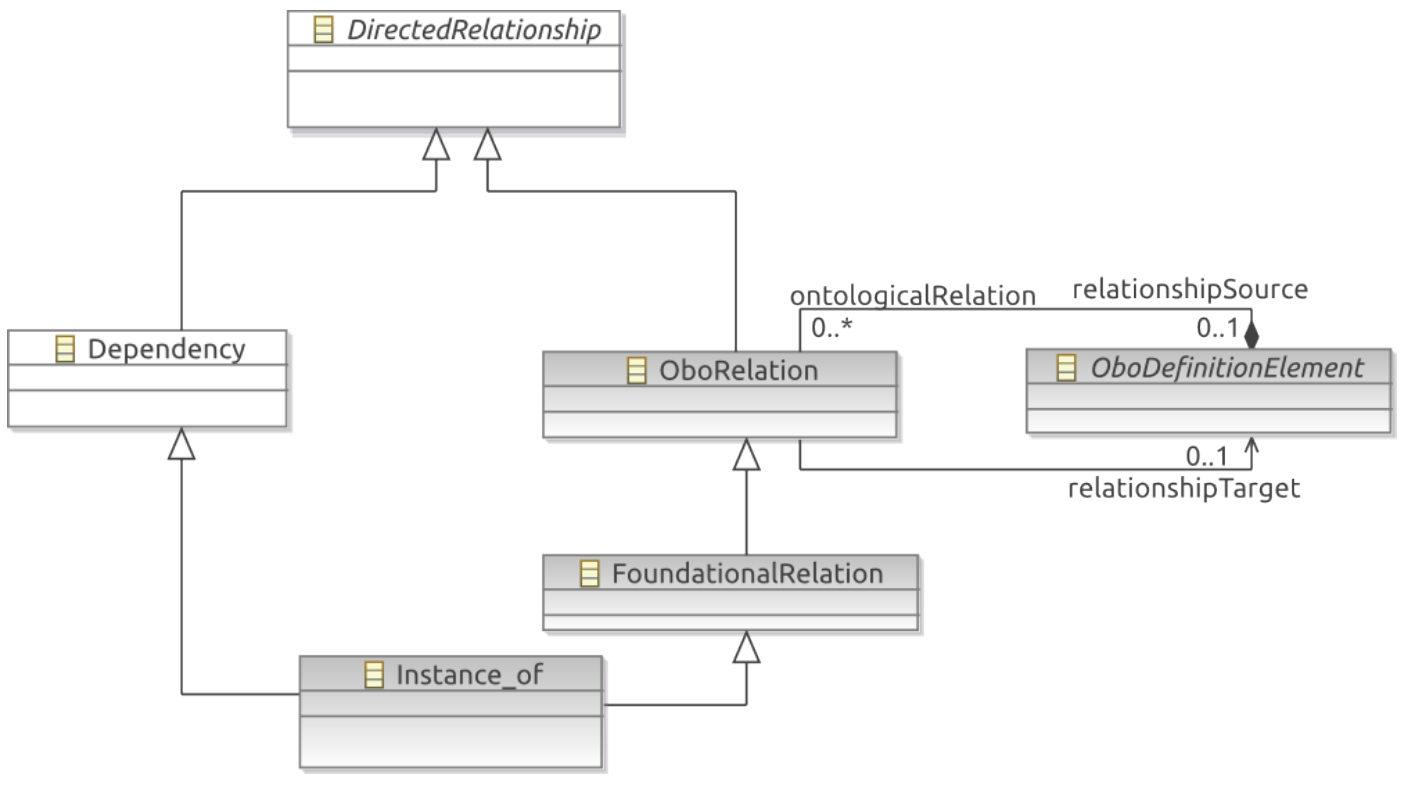

Figura 21: Metaclasses de interesse para a definição de Instance_of. Um retângulo branco representa metaclasses UML de interesse, enquanto um retângulo cinza representa metaclasses introduzidas para a implementação da extensão ao metamodelo.

tados para a metaclasse Is_a para a derivação de todas as propriedades das metaclasses. Assim, as propriedades client e supplier são derivadas automaticamente a partir das propriedades relationshipsource e relationshiptarget. Adicionalmente, as propriedades supplierDependency e clientDependency, definidas em NamedElement (superclasse de OboInstance e OboClass), também são derivadas automaticamente a partir de relationshipsource e relationshiptarget.

\subsubsection{Definição das demais relações fundamentais da OR OBO}

A Figura 22 apresenta as principais metaclasses de interesse na modelagem das metaclasses Part_of, Has_part e demais metaclasses especializadas a partir destas. Em conjunto com Is_a e Instance_of, estas metaclasses compreendem todas as metaclasses representando as relações fundamentais definidas no perfil. Part_of e Has_part especializam a metaclasse FoundationalRelation, que por sua vez especializa a metaclasse OboRelation. Dessa forma, tanto Part_of quanto Has_part representam relações binárias direcionadas de uma ontologia e possuem dois terminais (relationshipsource e relationshipTarget) que são utilizados para associar dois termos da ontologia. 


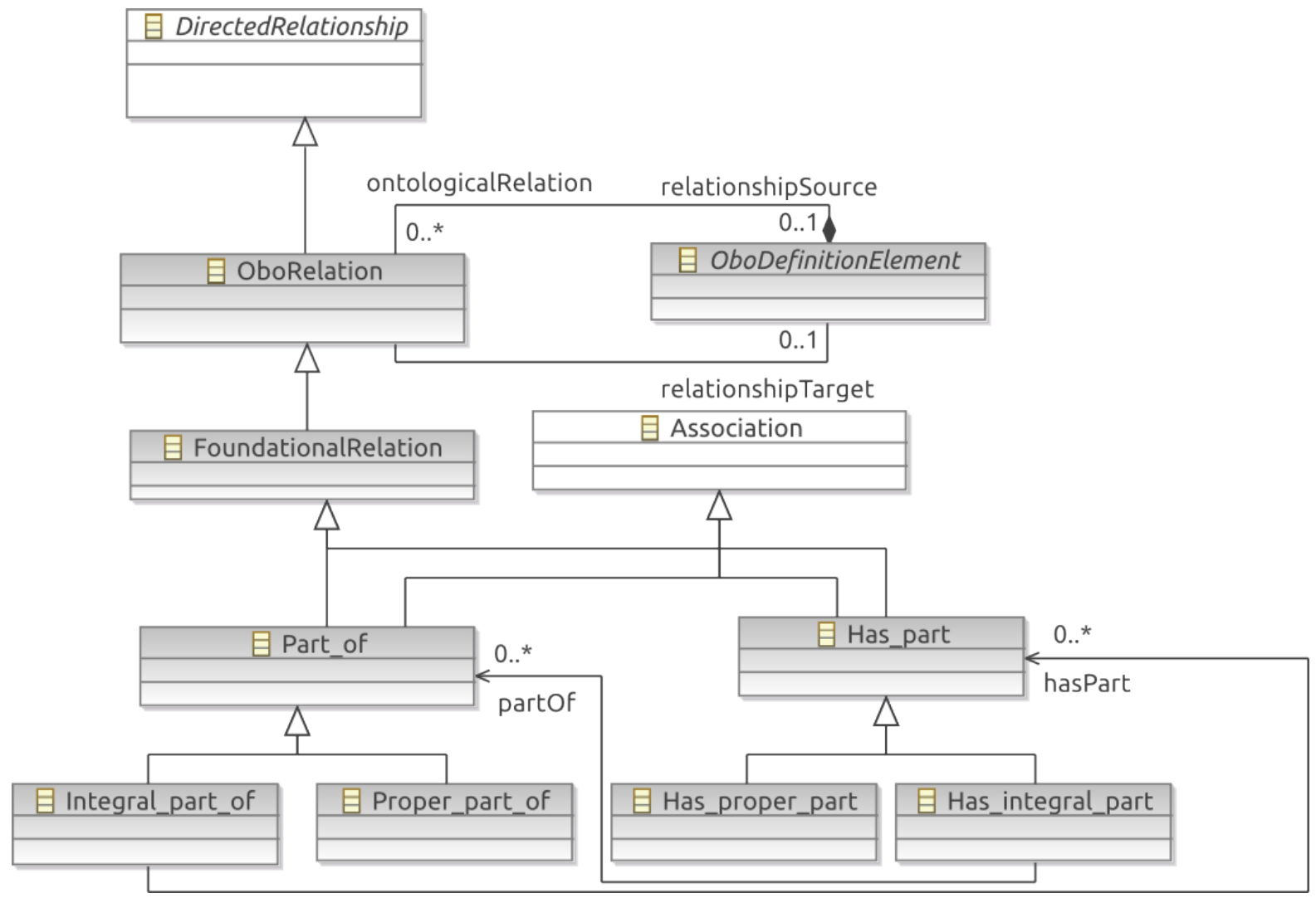

Figura 22: Metaclasses de interesse para a definição das demais relações fundamentais da OR OBO. Um retângulo branco representa metaclasses UML de interesse, enquanto um retângulo cinza representa metaclasses introduzidas para a implementação da extensão ao metamodelo.

Part_of e Has_part também especializam a metaclasse Association. Association interconecta um conjunto de classes por meio de instâncias da metaclasse Property. Essas instâncias de Property são indicadas por uma referência de composição como atributos da instância de Class que a associação interconecta. A Figura 23a ilustra as referências entre as metaclasses Class, Property e Association conforme definidas na UML.

Essa característica permite que associações possuam valores diferentes para atributos em cada um dos terminais de associação, representados pela propriedade memberEnd da associação. Exemplos de atributos de uma instância de Property incluem a cardinalidade, ou seja, a quantidade de elementos aceitos por aquele terminal de associação, o tipo representado por aquele terminal e a classe a qual a propriedade está associada. Adicionalmente, um terminal de associação pode ser navegável, ou seja, pode ser acessado a partir da associação. A navegabilidade de um terminal de associação é representada pela existência ou não da instância de Property que representa o terminal navegável da associação entre os terminais listados pelo 

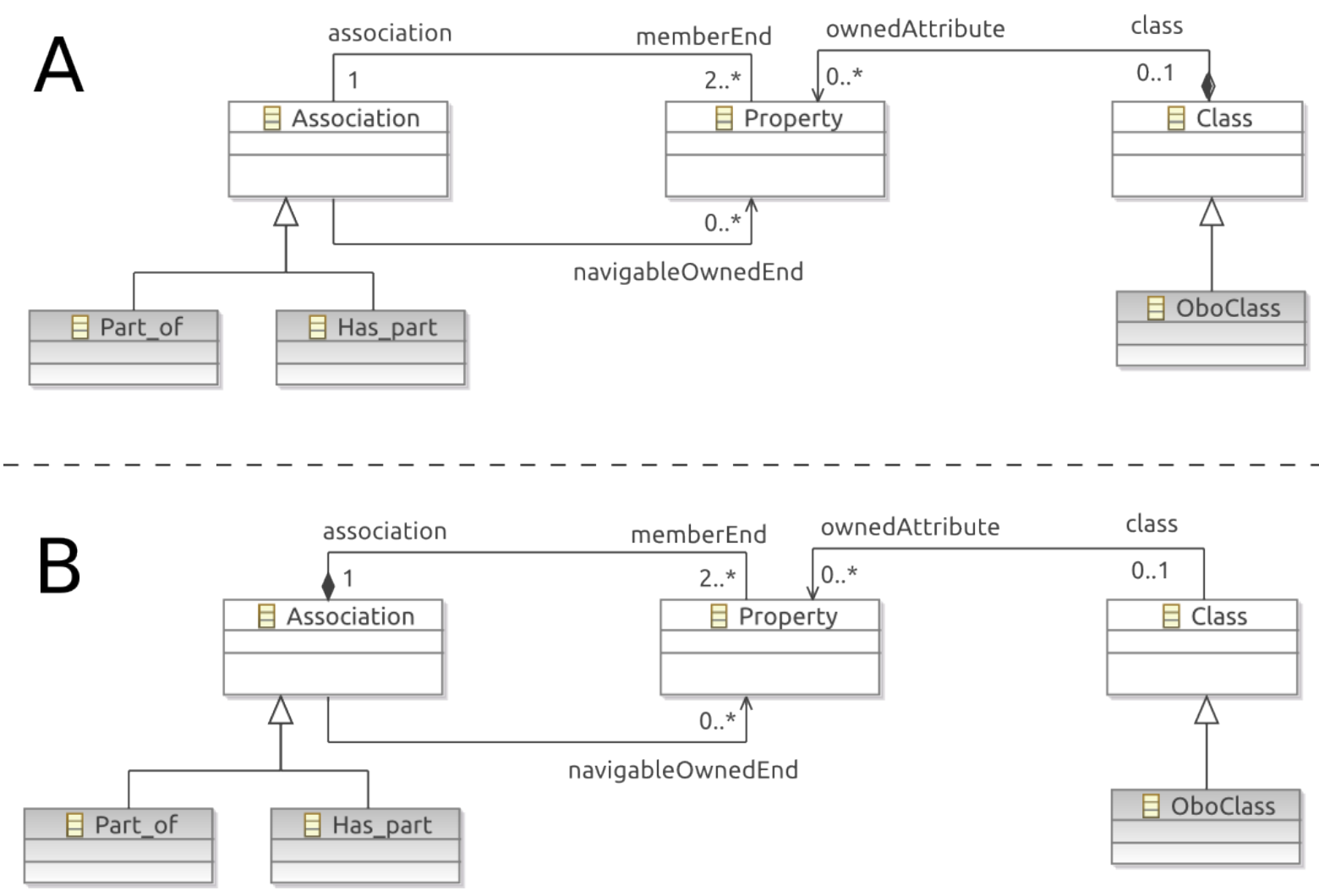

Figura 23: Metaclasses Part_of, Has_part e OboClass e o relacionamento destas com o metamodelo UML. Um retângulo branco representa metaclasses UML de interesse, enquanto um retângulo cinza representa metaclasses introduzidas para a implementação do perfil. A) Fragmento do metamodelo UML original; B) Fragmento modificado para a implementação do perfil.

meta-atributo navigableOwnedEnd dessa associação.

Dado o intuito de desenvolver o editor de forma a prover suporte à modelagem de uma ontologia utilizando os elementos definidos no perfil, enquanto abstrai aspectos próprios da linguagem UML irrelevantes ao desenvolvedor de uma ontologia, instâncias da metaclasse Property deveriam ser automaticamente criadas e associadas às instâncias de Clas s interconectadas por uma relação Part_of ou Has_part durante a criação dessa relação no modelo. Neste sentido, o framework GMF permite definir no modelo GMFMap que instâncias de uma metaclasse sejam criadas automaticamente durante a criação de instâncias de outra metaclasse que represente um elemento do diagrama. Contudo, a criação automática só pode ocorrer em referências de composição das metaclasses envolvidas.

Uma vez que uma instância da metaclasse Association não possui uma referência de composição para instâncias de Property no metamodelo UML, o framework GMF não per- 
mite a definição do comportamento desejado, ou seja, a criação automática de instâncias de Property quando uma instância de Association for criada. Adicionalmente, as propriedades dos terminais de associação não devem ser definidas após a criação de uma instância de OboClass e antes da criação da associação propriamente dita, uma vez que não sabemos quantas associações o usuário pode desejar adicionar a uma classe de entidade.

De forma a obter o comportamento desejado, tendo como critério de escolha a facilidade de uso do editor, modificamos as metaclasses UML de interesse de forma que instâncias de Property fossem associadas por meio de referências de composição às instâncias de Association. Dessa forma, foi possível criar instâncias de Property automaticamente pelo editor e inicializar atributos dessas propriedades durante a criação da associação. A Figura $23 b$ ilustra as referências entre as metaclasses Class, Property e Association conforme definidas no metamodelo OR-OBO.

Após a criação de uma associação Part_of ou Has_part entre duas classes de entidades no editor, o usuário pode realizar uma reorientação do arco entre essas classes de entidade, i.e., arrastar o terminal de ligação que representa relationshipsource ou relationshipTarget retirando-o de uma das entidades e direcionando-o a outra entidade qualquer do modelo. Durante essa reorientação, os atributos das instâncias de Property contidas pela associação também devem ser atualizados. Porém, como essas propriedades são inicializadas pelo framework GMF durante a criação da associação, e não por meio de expressões OCL que seriam avaliadas novamente após a atualização do modelo, faz-se necessário a definição de um mecanismo auxiliar para a atualização automática dessas propriedades.

O framework GMF cria uma classe Java que representa as operações de reorientação de um dado arco do diagrama para cada associação definida no modelo GMFMap. Por exemplo, para a associação Has_part, o framework GMF cria uma classe Java chamada Has_partReorient Command, com métodos que são executados quando um usuário arrasta e solta uma das extremidades do arco da associação de um nó para outro do diagrama. De forma a manter automaticamente atualizados os atributos das propriedades da associação após uma operação de reorientação do arco no editor, personalizamos essas classes modificando o código Java gerado 
pelo GMF para realizar essa atualização. Por fim, utilizamos consultas por expressões OCL para a atualização automática dos atributos dos nós da ontologia que são interconectados pela relação redirecionada após a atualização dos atributos das instâncias de Property envolvidas.

Durante a implementação das restrições definidas para as metaclasses Part_of, Has_part, Integral_part_of e Has_integral_part, concluímos que algumas dessas restrições não poderiam ser avaliadas pelo editor desenvolvido, a saber, as restrições \#2 de Part_of e Has_part, as restrições \#1 de Integral_part_of e de Has_integral_part. Isso ocorre pois estas restrições foram desenvolvidas para serem avaliadas ao nível M0 da hierarquia de metamodelagem UML, ou seja, no nível das instâncias em tempo de execução. Embora essas restrições possam ser definidas e avaliadas automaticamente para um modelo UML que represente um sistema computacional, durante o desenvolvimento de uma ontologia o nível M0 é representado pelas instâncias de entidades no mundo real. Dessa forma, essas instâncias não são acessíveis à validação pelo editor durante o desenvolvimento de uma ontologia.

De maneira a contornar essas dificuldades, substituímos as restrições que seriam avaliadas ao nível M0 por restrições possíveis de serem avaliadas ao nível M1. Neste sentido, as novas restrições foram definidas de maneira a avaliar se as restrições originais poderiam ser satisfeitas em alguma configuração do mundo real (nível M0) dada a ontologia em desenvolvimento. Por exemplo, a restrição \#2 de Part_of avalia ao nível de instâncias se, dado as classes de entidades $C$ e $C_{1}$ tal que $C$ Part_of $C_{1}$, para toda instância $c$ tal que $C c t$ existe ao menos uma instância $c_{1}$ tal que $C_{1} c_{1} t$ e $c$ part_of $c_{1}$ no tempo $t$. Ou seja, sempre que uma instância da classe de entidade $C$ existe, ela existe como parte de uma instância da classe de entidade $C_{1}$. Esta restrição foi substituída por uma restrição que avalia que, dado uma associação Part_of entre duas classes de entidades, a cardinalidade mínima do terminal dessa associação que representa uma agregação seja 1 .

De forma semelhante, a invariante \#1 de Integral_part_of e de Has_integral_part também são propriedades que só podem ser avaliadas ao nível de instâncias (M0). Por exemplo, a restrição \#1 de Integral_part_of obriga que cada instância que esteja no terminal de associação alvo seja associada a cada instância que esteja no terminal de associação fonte 
por uma relação estereotipada como «has_part». A restrição \#1 de Has_integral_part é semelhante, porém envolvendo uma relação estereotipada como «part_of». Embora não seja possível avaliar automaticamente a validade dessas restrições ao M0, é possível avaliar automaticamente que as duas classes de entidades ligadas por uma relação Integral_part_of (ou Has_integral_part) possuem, ou não, também uma associação Has_part (ou Part_of) adequada entre elas no nível M1. Assim, avaliamos uma condição necessária para que uma instância dessas entidades possa obedecer a restrição original.

\subsubsection{Definição das relações temporais, espaciais e de participação da OR OBO}

As demais relações definidas pelo perfil são agrupadas em relações temporais, relações espaciais e relações de participação. Todas essas relações são representadas no modelo de domínio por metaclasses que especializam a metaclasse OboRelation e metaclasse As sociation. Dessa forma, essas relações são modeladas de forma semelhante às relações Part_of, Has_part e suas especializações. A Figura 24 apresenta as principais metaclasses de interesse para a definição dessas relações.

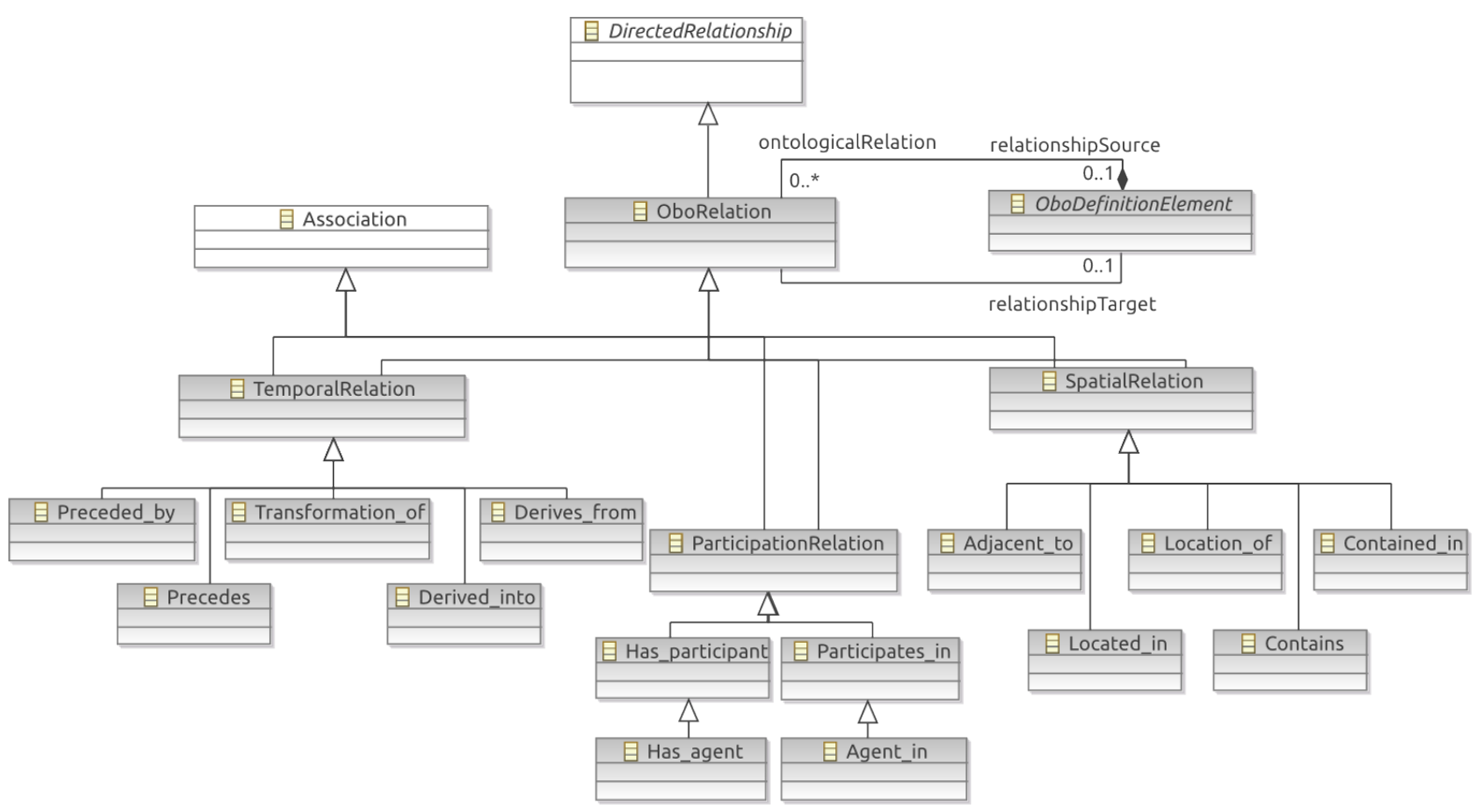

Figura 24: Metaclasses de interesse para a definição das relações temporais, especiais e de participação da OR OBO. Um retângulo branco representa metaclasses UML de interesse, enquanto um retângulo cinza representa metaclasses introduzidas para a implementação do perfil. 
Durante a implementação das metaclasses que representam relações temporais, espaciais e de participação, concluímos que algumas restrições em OCL definidas pelo perfil para OR OBO precisavam ser modificadas para permitir a avaliação pela ferramenta desenvolvida. Essas modificações são apresentadas a seguir.

As restrições \#2 das metaclasses abstratas TemporalRelation, SpatialRelation e ParticipationRelation foram modificadas de forma semelhante à modificação das restrições \#2 de Part_of e Has_part. Essas restrições foram igualmente substituídas por restrições que avaliam que, dado uma associação entre duas classes de entidade, a cardinalidade mínima da propriedade que representa o terminal navegável da associação é 1 .

As invariantes \#1 de Contained_in, Contains, Has_participant, Participates_in, Has_agent e Agent_in foram modificadas substituindo-se a referência a Property: : endType por uma referência a Property: :type. A propriedade endType é, na verdade, uma propriedade de metaclasse Association, não acessível nos contextos em que é chamada. Adicionalmente, a restrição \#1 de Has_participant necessitou de uma substituição na subexpressão y • ocl Is TypeOf (ContinuantClass). A operação y • oclIsTypeof (ContinuantClass) retorna true apenas se y é instância da classe ContinuantClass e não é instância de uma das subclasses que especializam Cont i nuantClass. Porém, neste contexto a restrição deveria ser válida para instâncias da metaclasse Cont inuantClass e para instâncias das metaclasses que especializam ContinuantClass. Neste sentido, a subexpressão correta é y.oclIskindOf (ContinuantClass), que retorna true se y é instância de ContinuantClass ou instância de uma classe que especializa ContinuantClass direta ou indiretamente.

Por fim, as invariantes \#2 de Contained_in e Contains foram modificadas pois referenciavam a propriedade extension da metaclasse Class. Esta propriedade associa um estereótipo a uma classe definida em um modelo UML. Neste sentido, esta propriedade era utilizada no perfil UML como referência para a avaliação do estereótipo associado à classe modelada. No metamodelo OR-OBO, a associação de um estereótipo do perfil uma dada classe é representado pela especialização da metaclasse Class utilizada. Tal condição permite avaliar 
essa informação utilizando a operação OclAny : : ocl IsKindOf ( $<$ Metaclasse $>$ ), sem a necessidade de utilizar a referência à propriedade extension.

\subsubsection{Definição dos tipos de relacionamento declarados em outras ontolo- gias OBO}

Uma ontologia OBO pode declarar novos tipos de relacionamento a serem utilizados para associar classes de entidades, instâncias ou mesmo outros tipos de relacionamento. Esta característica é muito importante para os usuários e desenvolvedores de ontologias OBO. De maneira a prover uma forma adequada para um usuário representar os novos tipos de relacionamento e as relações entre entidades utilizando esses novos tipos declarados, adicionamos ao metamodelo implementado as metaclasses RelationshipDefinition e OpaqueRelationship.

RelationshipDefinition é uma especialização das metaclasses Class e OboDefinitionElement. Como uma Class, RelationshipDefinition representa a declaração de um conjunto de características compartilhadas por um conjunto de instâncias de OboRelation. Neste sentido, RelationshipDefinition é semelhante à declaração Typedef do $O B O$ File Format. Dessa maneira, esta metaclasse possui atributos próprios de uma declaração Typedef, tais como inverse_of, o qual referencia um tipo de relacionamento que é o inverso do relacionamento modelado; e transitive_over, o qual referencia outros tipos de relacionamento aos quais o presente tipo é transitivo. Assim como Class, RelationshipDefinition possui um retângulo nomeado como sua representação em um diagrama. Por ser um OboDefinitionElement, RelationshipDefinition pode ser referenciada por outros tipos de relacionamentos definidos.

Por sua vez, OpaqueRelationship é uma especialização de OboRelation que representa uma relação, entre dois elementos de uma ontologia, que possua como tipo um dos novos tipos de relacionamento declarados. Uma OpaqueDefinition não possui significado próprio para uma ontologia OBO, de forma que sempre deve ser associada a uma RelationshipDefinition que proverá este significado. Assim como as demais subclasses de OboRelation, a representação visual de uma OpaqueRelationship é um arco estereotipado 
entre dois elementos do diagrama.

A Figura 25 apresenta as principais metaclasses de interesse para a definição de novos tipos de relacionamento e para o uso desses relacionamentos em uma ontologia sendo editada.

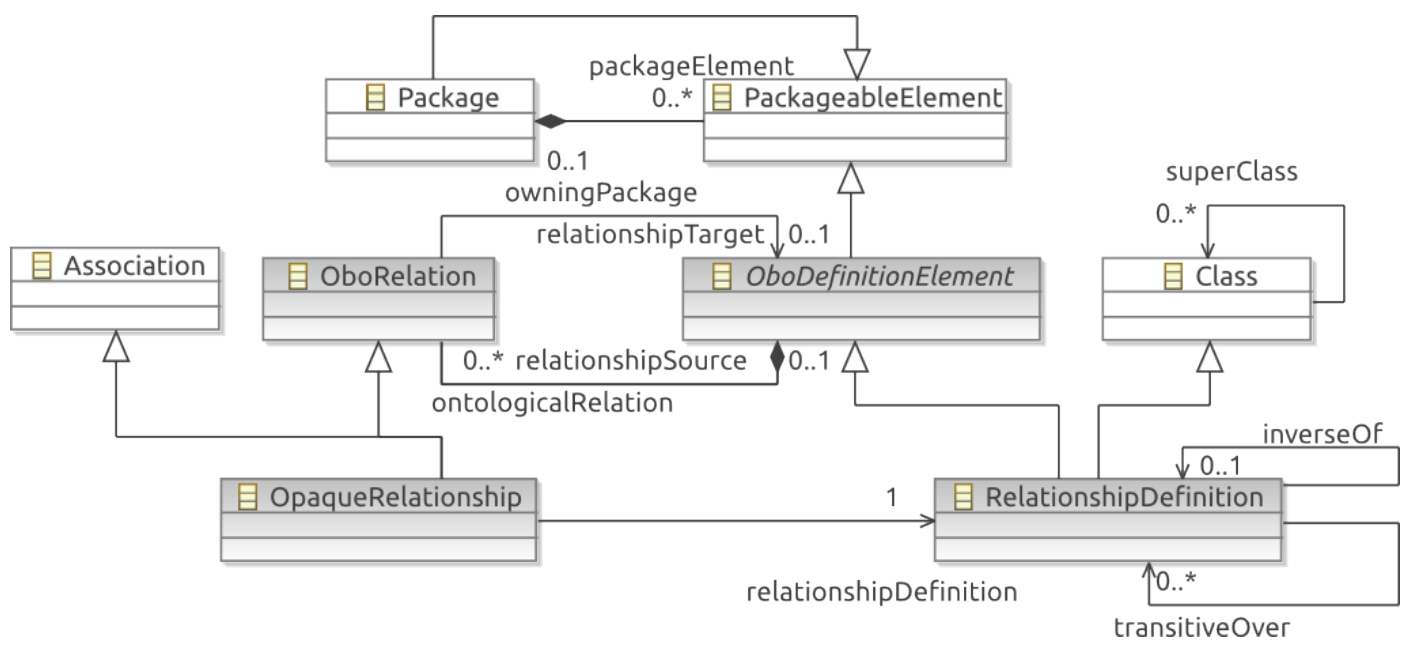

Figura 25: Metaclasses de interesse para a definição de novos tipos de relacionamento e para o uso desses relacionamentos em uma ontologia sendo editada. Um retângulo branco representa metaclasses UML de interesse, enquanto um retângulo cinza representa metaclasses introduzidas para a implementação da extensão ao metamodelo.

\subsubsection{Definição das relações built-in de uma ontologia OBO}

Toda ontologia OBO representada utilizando o OBO File Format possui um conjunto de tipos de relacionamentos disponíveis implicitamente para a criação de relações entre as entidades da ontologia, os quais incluem: Transitive_over, o qual define relações entre dois tipos de relacionamentos e indica que relações do tipo fonte são transitivas sobre relações do tipo alvo; Disjoint_from, o qual define uma relação de disjunção entre duas classes de entidades; Union_of, o qual define relações nas uma classe fonte é uma união de outras classes de entidades alvo; Disjoint_over, o qual define relações entre dois tipos de relacionamentos e indica que relações do tipo fonte são disjuntas sobre relações do tipo alvo; Has_zero_cardinality_over, o qual define relações entre dois tipos de relacionamentos e indica que relações definidas do tipo alvo apresentam cardinalidade nula quando há uma relação definida do tipo fonte entre as mesmas duas classes de entidades; e Inverse_of, o qual define relações entre dois tipos de relacionamentos e indica que estes tipos de relaciona- 
mento são inversos entre si.

De maneira a permitir o uso dos relacionamentos built-in sem a necessidade de declarar instâncias de RelationshipDefinition, adicionamos novas metaclasses ao metamodelo implementado. Essas metaclasses são especializações de BuiltInRelation, uma especialização de $\mathrm{OboRelation} \mathrm{adicionada} \mathrm{ao} \mathrm{metamodelo} \mathrm{para} \mathrm{agrupar} \mathrm{as} \mathrm{relações} \mathrm{built-in}$ da OBO. Assim como as demais subclasses de OboRelation, a representação visual de uma BuiltInRelation é um arco estereotipado entre dois elementos do diagrama. A Figura 26 apresenta as principais metaclasses de interesse para a definição das relações built-in de uma ontologia OBO.

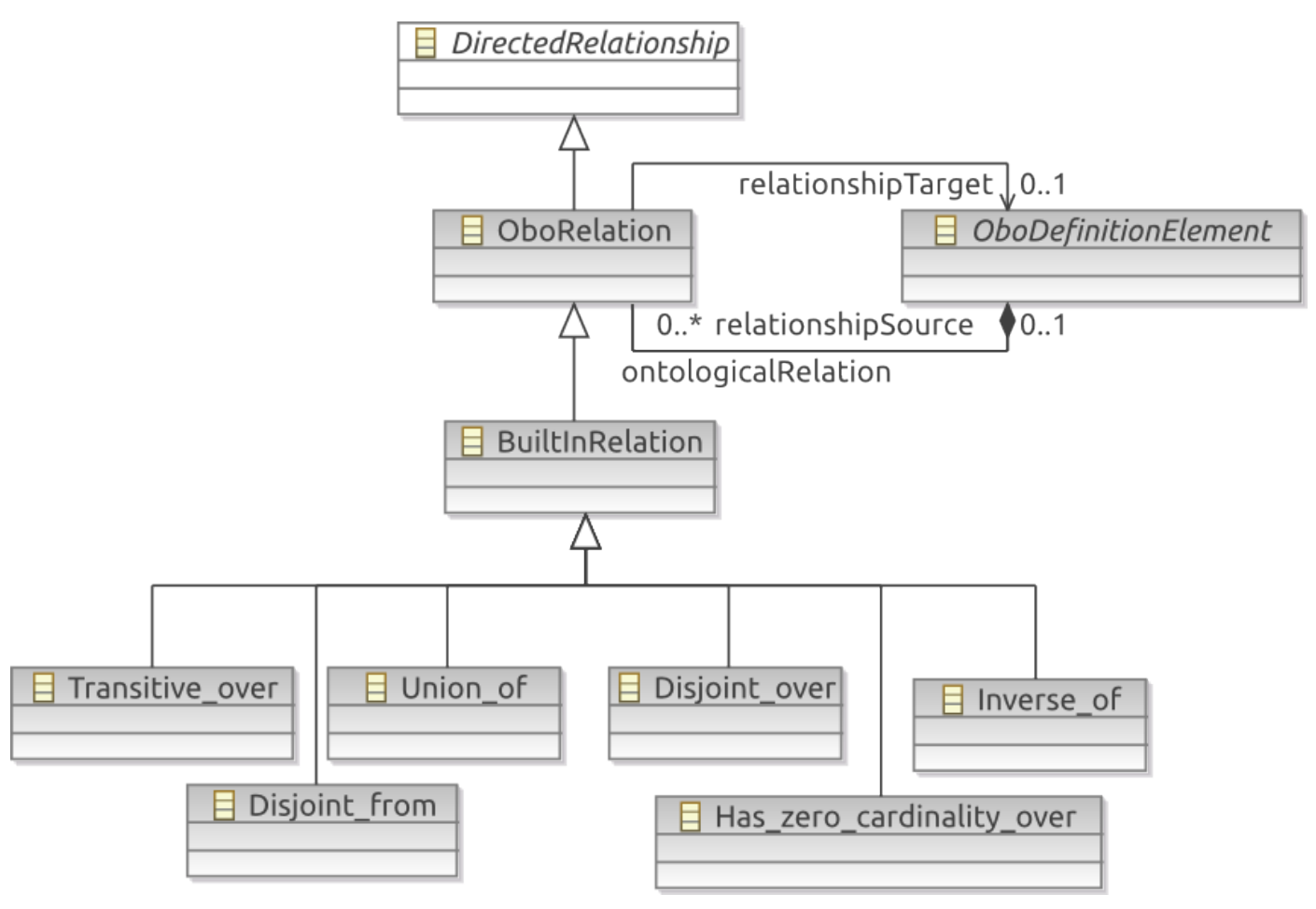

Figura 26: Metaclasses de interesse para a definição das relações built-in disponíveis implicitamente em todas as ontologias OBO. Um retângulo branco representa metaclasses UML de interesse, enquanto um retângulo cinza representa metaclasses introduzidas para a implementação do perfil.

O relacionamento Is_a, presente na OR OBO, é também um relacionamento built-in. Porém, uma vez que Is_a difere das demais subclasses de BuiltInRelation por possuir uma representação explícita na OR OBO, não a incluímos como especialização de Built InRelations. 


\subsection{Definição da sintaxe gráfica concreta para modelagem}

A sintaxe gráfica concreta do editor é mapeada pelo GMF por meio de um modelo $G M F$ Graph, o qual contém a definição da notação dos elementos de modelagem do editor. Em um modelo GMFGraph, quatro tipos de elementos gráficos podem ser utilizados: nós, os quais são polígonos ou outras figuras geométricas; conexões, os quais são representados por linhas que ligam dois elementos; compartimentos, os quais são espaços internos dos nós aos quais podem ser adicionados outros elementos; e rótulos, os quais são objetos que contém texto e que podem ser adicionados aos nós ou às conexões por meio de elos semi-visíveis, ou seja, elos que só são visíveis quando os elementos estão selecionados ou sendo movidos.

Nós e conexões podem assumir diversas formas geométicas ou figuras. Porém, em nosso trabalho limitamo-nos à notação sugerida pelo perfil. Neste sentido, metaclasses que representam classes de entidades são representadas utilizando a mesma notação básica utilizada para a representação de uma classe UML, i.e., um retângulo nomeado. Adicionalmente, essa notação recebe a marcação do estereótipo representado por aquela metaclasse. Por exemplo, a notação para a metaclasse ContinuantClass é um retângulo apresentado o nome do termo modelado abaixo de um rótulo apresentando a marcação «continuant». O mesmo é realizado para cada outra metaclasse que representa um estereótipo para as classes de entidade da OROBO. As demais propriedades dessas metaclasses são apresentadas, por meio da visão de propriedades disponibilizada pelo EMF/GMF, ao selecionar um dado elemento.

Metaclasses que representam relações da ontologia são representadas por meio de diferentes tipos de conexões entre dois elementos. Cada uma das pontas da conexão é relacionada a uma propriedade de OboRelation (relationshipsource ou relationshipTarget). Conexões podem ser decoradas por figuras geométricas em cada uma das extremidades e uma série de rótulos que podem ser associados a cada uma das extremidades ou ao centro da linha. Neste sentido, a notação das diferentes metaclasses mais específicas de OboRelation em geral é uma linha contínua ou tracejada com uma cabeça de flecha ou losango em uma das extremidades e um rótulo com o o nome do estereótipo representado associado ao centro da linha. Por exemplo, a metaclasse Is_a é representada por uma linha contínua com a extremi- 
dade que representa relationshiptarget decorada por uma cabeça de flecha triangular vazada e o centro da linha decorado por um rótulo contendo «is_a», enquanto a metaclasse Instance_of é representada por linha tracejada decorada com uma cabeça de flecha aberta com o centro da linha decorado por um rótulo «instance_of».

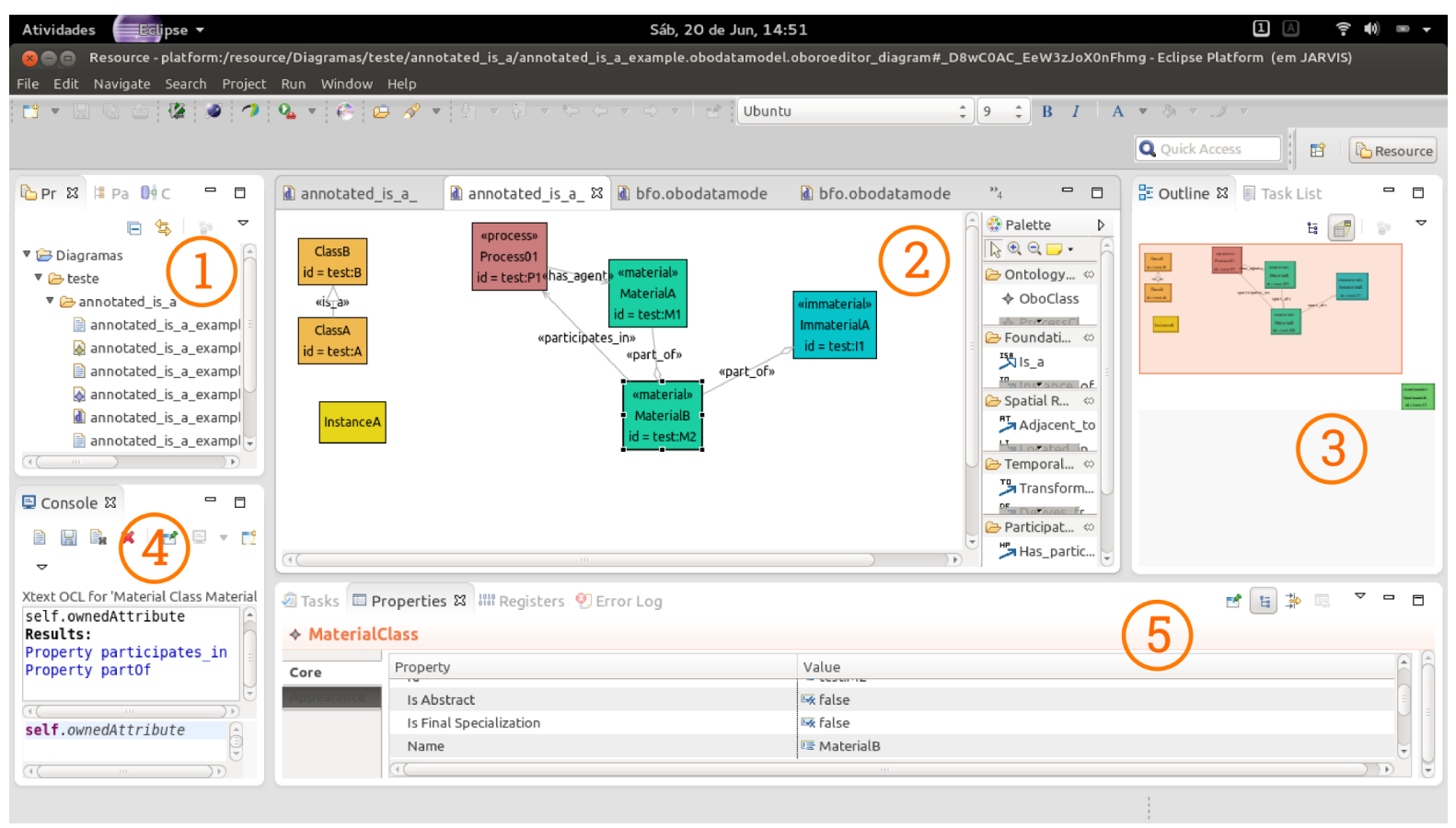

Figura 27: Interface gráfica do editor como um plug-in Eclipse.

A Figura 27 ilustra a interface atual da ferramenta de modelagem enquanto executada como um plug-in para o editor Eclipse. A arquitetura da interface gráfica do Eclipse (e, por extensão, do GMF) possibilita diferentes arranjos dos diferentes painéis da interface. Neste sentido, a Figura apresenta cinco painéis principais durante o desenvolvimento de uma ontologia: o painel superior esquerdo (1) contém um navegador para os arquivos do espaço de trabalho atual; o painel central (2) contém o diagrama em desenvolvimento e a paleta de criação de elementos; o painel superior direito (3) apresenta uma visão geral do diagrama sendo desenvolvido; o painel inferior esquerdo (4) apresenta o console OCL provido pelo ambiente Eclipse, que possibilita a um desenvolvedor com conhecimento em OCL a avaliação interativa de expressões na ontologia em desenvolvimento; por fim, o painel inferior direito (5) apresenta as propriedades de um elemento que esteja selecionado no diagrama. 


\subsection{Definição de expressões OCL para o metamodelo OR- OBO}

Diferentes expressões OCL foram definidas para o metamodelo OR-OBO, as quais foram utilizadas em dois contextos distintos: restrições e consultas definidas durante a criação do metamodelo OR-OBO, de forma a complementar a definição das metaclasses deste metamodelo no contexto do framework EMF; e restrições definidas durante a criação do modelo GMFMap, de forma a validar um modelo/ontologia no contexto do framework GMF.

No contexto da definição do metamodelo OR-OBO, restrições OCL são utilizadas para a definição da derivação de propriedades das instâncias de uma metaclasse, definição de operações de consulta ao modelo e para a definição de restrições invariantes, as quais são utilizadas para a validação de instâncias de uma metaclasse. A Figura 28 apresenta um fragmento OCLinEcore da definição das metaclasses Generalization e Is_a. A definição de uma metaclasse inicia-se com a palavra-chave class seguida do nome da metaclasse. Opcionalmente, a palavra-chave extends pode ser utilizada para declarar uma ou mais superclasses da metaclasse sendo definida. Neste caso, Gereralization estende a metaclasse DirecteRelationshipe Is_a estende as metaclasses FoundationalRelation e Generalization.

O bloco entre chaves que segue a declaração da metaclasse define o escopo das operações, propriedades e restrições definidas para aquela metaclasse. Uma operação é declarada com a palavra-chave operation, seguida do nome da operação e o tipo de elemento retornado. Neste contexto, é possível utilizar OCL para declarar um corpo para uma operação (palavrachave body), de forma a definir uma consulta ao modelo.

Uma propriedade de instâncias de uma metaclasse é declarada com a palavra-chave property, seguida do nome dessa propriedade, o tipo e a quantidade dos elemento referenciados pela propriedade e possíveis modificadores. Neste contexto, é possível utilizar OCL para declarar como uma propriedade pode ser derivada automaticamente a partir da configuração dos elementos de um modelo (palavra-chave derivation). Esta derivação pode utilizar operações 


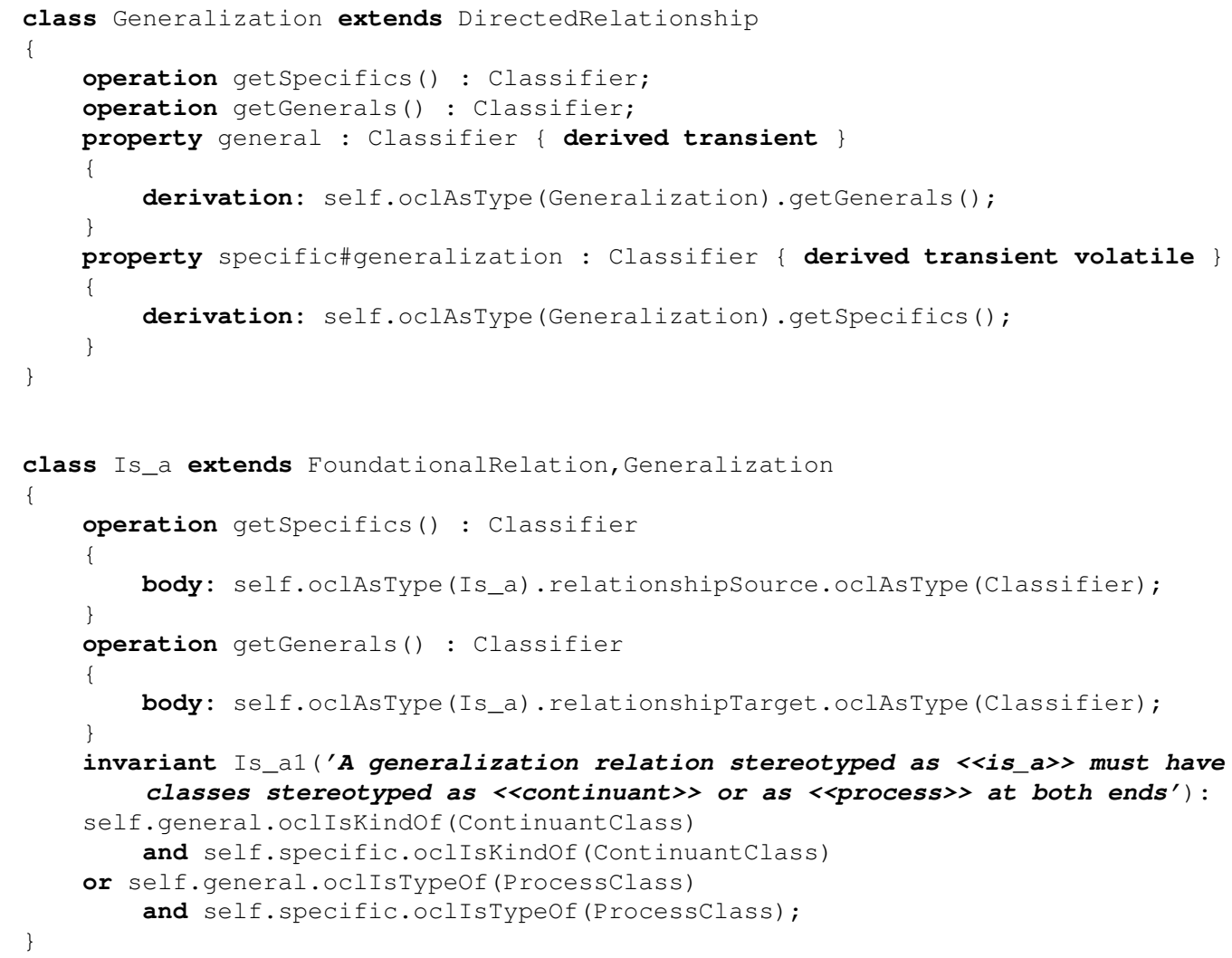

Figura 28: Definição de restrições OCL no metamodelo OR-OBO no editor OCLinEcore

e/ou atributos da própria instância da metaclasse definida ou outros elementos do modelo. Por fim, uma restrição invariante para instâncias de uma metaclasse é declarada utilizando a palavra chave invariant, seguida do nome da restrição, uma mensagem de erro opcional e uma expressão booleana em OCL que avalie a validade do estado das instâncias daquela metaclasses. As restrições invariantes definidas para uma metaclasse podem ser validadas de forma semiautomática pelo framework EMF usando o mecanismo de batch validation. Neste sentido, a Figura 28 apresenta a declaração de duas propriedades e duas operações para a metaclasse Generalization, assim como duas operações e uma restrição OCL invariante para a metaclasse Is_a.

No contexto de um editor GMF, cada restrição invariante pode ser mapeada para um dos dois mecanismos de validação disponíveis (batch validation e live validation). Esse mapeamento é realizado por meio do modelo GMFMap, no qual as restrições podem ser associadas aos elementos de modelagem por meio de regras de consistência (Audit Rules) que podem ter seu 
o atributo Use In Live Mode ajustado para "verdadeiro" ou "falso". Adicionalmente, restrições invariantes adicionadas diretamente no modelo de domínio Ecore são por padrão verificadas em lote (batch validation).

O uso do mecanismo de live validation é interessante para restrições que previnam a realização de uma modificação que tornaria o modelo inconsistente. Neste caso, devemos desfazer a última alteração realizada de modo a recuperar a consistência do modelo. Por exemplo, associar um processo a uma entidade que não seja um processo por meio de um relacionamento Is_a é sintaticamente inválido de acordo com a OR OBO. Assim, a única solução para este estado inconsistente é retirar a relação adicionada entre esses termos.

O uso do mecanismo de batch validation é mais adequado para tratar situações onde uma ação do usuário coloca o modelo em um estado incompleto. Neste caso, ações adicionais do usuário são necessárias para que o modelo seja novamente considerado consistente. Por exemplo, associar dois elementos de uma ontologia com uma relação Integral_part_of é sintaticamente inválido se ambos os elementos não possuírem uma relação Has_part. Porém, a relação Has_part pode ser adicionada posteriormente à adição de Integral_part_of, tornando a ontologia novamente consistente.

Quando uma dada condição invariante é verificada falsa, o editor apresenta uma mensagem de erro ao usuário. Essa mensagem de erro é personalizada durante a criação da restrição utilizando o editor OCLinEcore ou durante a associação da restrição no modelo GMFMap, de forma que uma mensagem de erro significativa pode ser passada ao desenvolvedor da ontologia. Neste trabalho, associamos como mensagem de erro as definições providas pelo perfil e pela UML para as restrições invariantes envolvidas para prover uma definição em linguagem natural de como as metaclasses devem ser utilizadas pelo usuário do editor.

Como apresentado anteriormente, o mecanismo de live validation é utilizado para evitar a inclusão de inconsitências sintáticas em uma ontologia. De forma a exemplificar o uso deste mecanismo, selecionamos um fragmento da Ontologia de Expressão Gênica (GEXPO) [109], chamado de fragmento de interesse. Este fragmento é apresentado em diferentes instantes do tempo, enquanto um usuário do $O B O-R O$ Editor desenvolve esta ontologia. 
A Figura 29 apresenta o fragmento de interesse em uma situação inicial. Neste fragmento estão declarados um novo tipo de relacionamento chamado "produced_by" (GEXPO_0000032), bem como quatro tipos de continuantes materiais e dois tipos de processos. Os tipos de continuantes materiais declarados são "gene” (SO_0000704), "transcript” (GO_0006351), "primary transcript”(GO_0006351), e “mature transcript” (GO_0006351), enquanto os tipos de processos declarados são “transcription”(GO_0006351) e "RNA processing”(GO_0006351).

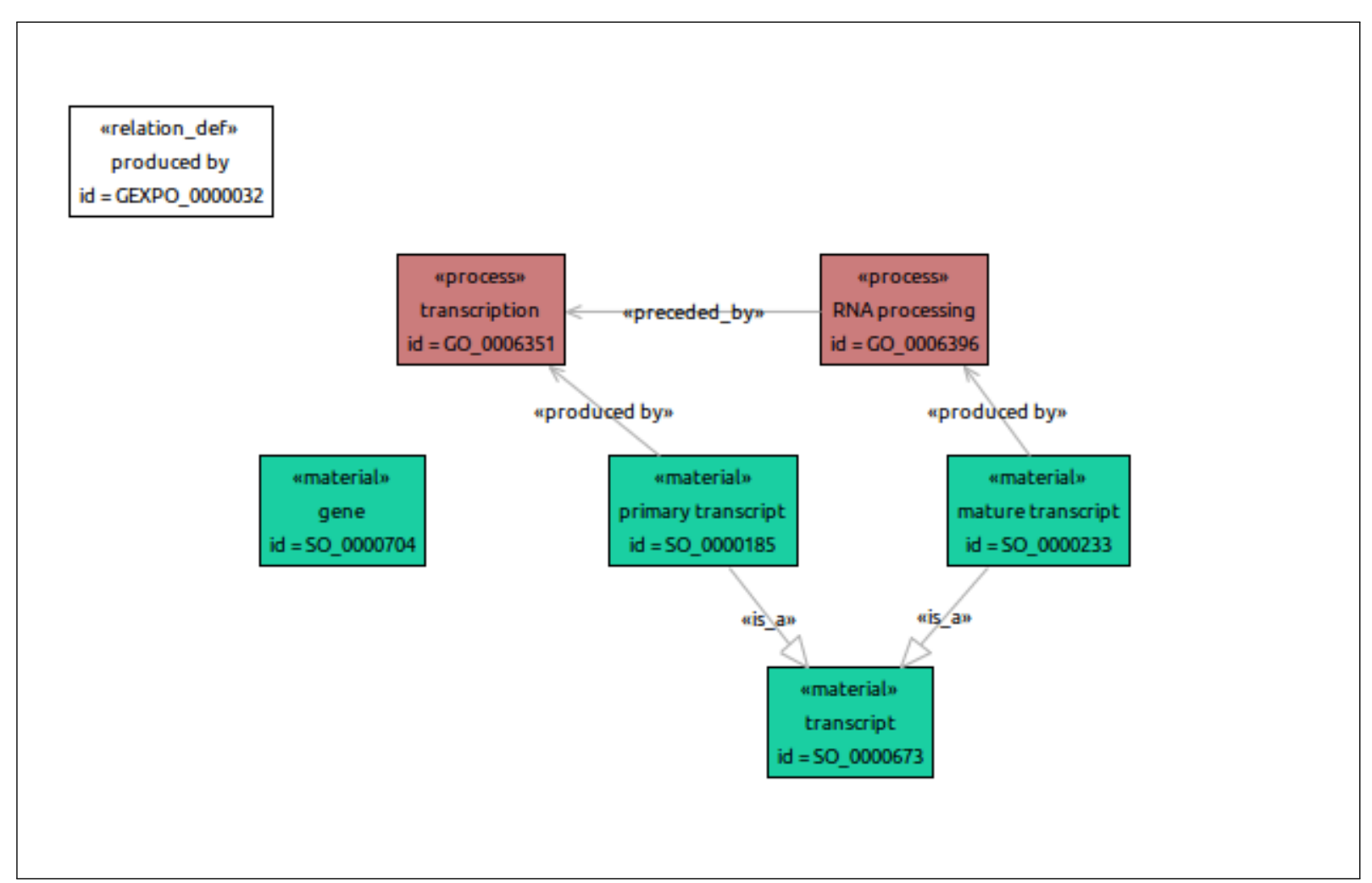

Figura 29: Fragmento de interesse da GEXPO no instante de tempo inicial.

O usuário decide então adicionar uma relação entre "transcription" e "gene", capturando a participação de um gene em um processo de transcrição. Intuitivamente, o usuário tenta criar uma relação do tipo "has_part" entre essas classes de entidade ("transcription" has_part "gene”). Assim, usuário seleciona a ferramenta de criação de instâncias da metaclasse Has__part e conecta ambas as classes de entidade no diagrama. A Figura 30 apresenta o modelo alterado pela ação de edição do usuário, imediatamente antes do término da ação.

Após o término da ação de edição, o OBO-RO Editor executa o mecanismo de live validation. Neste sentido, uma restrição da metaclasse Has_part é verificada falsa após a edição do modelo. Esta restrição define que instâncias da metaclasse Has_part só podem ser utilizadas 


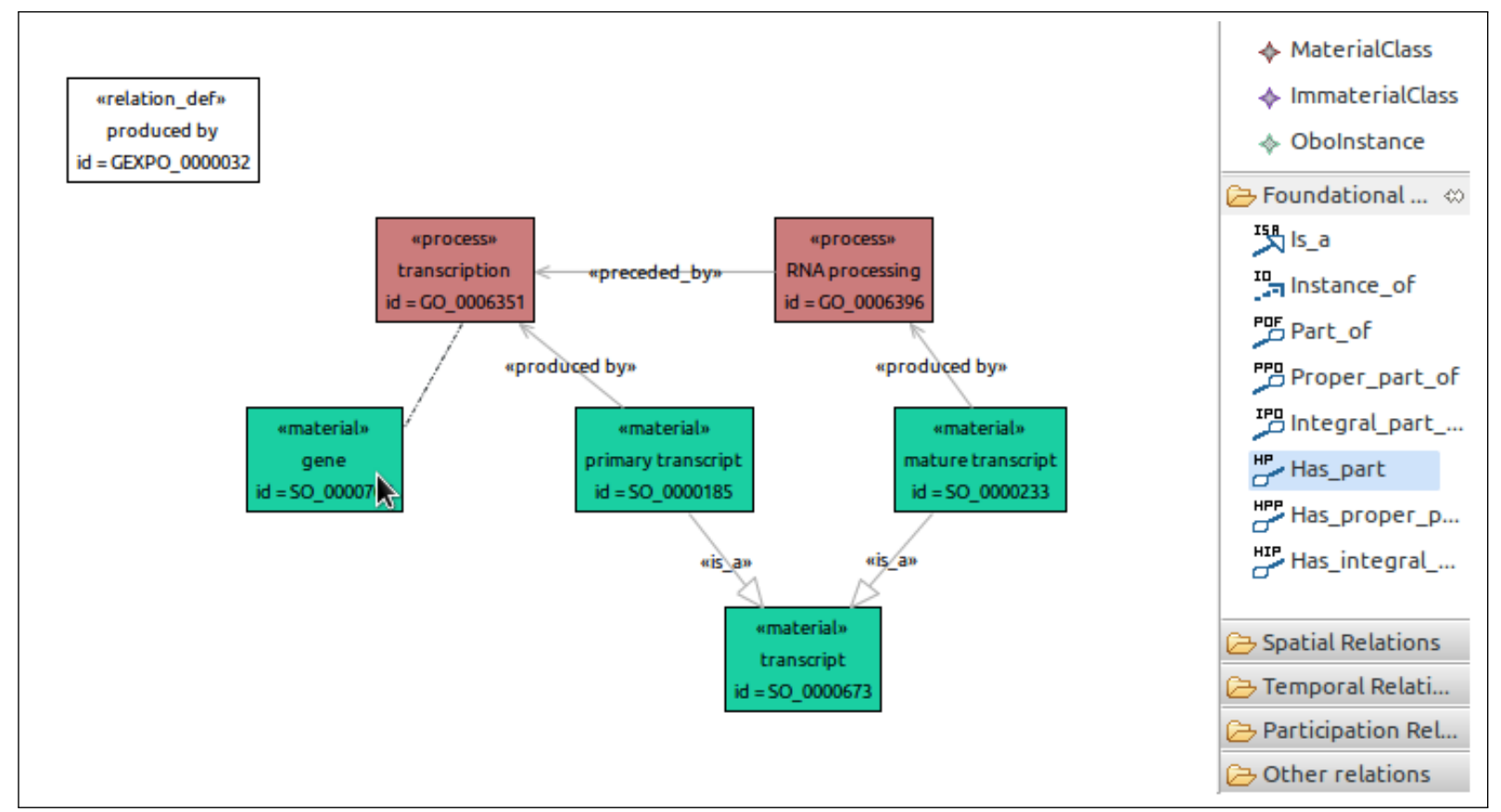

Figura 30: Ação de edição do usuário com a adição da relação has_part entre as entidades "transcription" e"gene".

para associar dois continuantes ou dois processos, sendo sintaticamente inválido associar um continuante a um processo. De forma a prevenir a inserção desta inconsistência, o editor desfaz a última ação de modelagem realizada e mantém a ontologia sintaticamente correta. Adicionalmente, o $O B O-R O$ Editor apresenta uma mensagem descritiva do erro sintático encontrado, de maneira a permitir a compreensão do evento. A Figura 31 ilustra a apresentação desta mensagem de erro.

Após o erro sintático cometido, o usuário identifica has_participant como o tipo de relacionamento adequado para representar uma relação de participação entre "transcription" e "gene". Assim, o usuário utiliza a metaclasse Has_participant para criar a relação entre estas classes de entidade ("transcription" has_participant "gene"). A Figura 32 apresenta o fragmento da ontologia após a criação de relações has_part entre "transcription" e "gene", bem como entre "RNA processing" e "primary transcript". Dessa maneira, o mecanismo de validação do $O B O-R O$ Editor impediu a inserção de um erro sintático na ontologia em desenvolvimento, bem como permitiu ao usuário um maior entendimento sobre as relações disponíveis para o desenvolvimento de uma ontologia. 


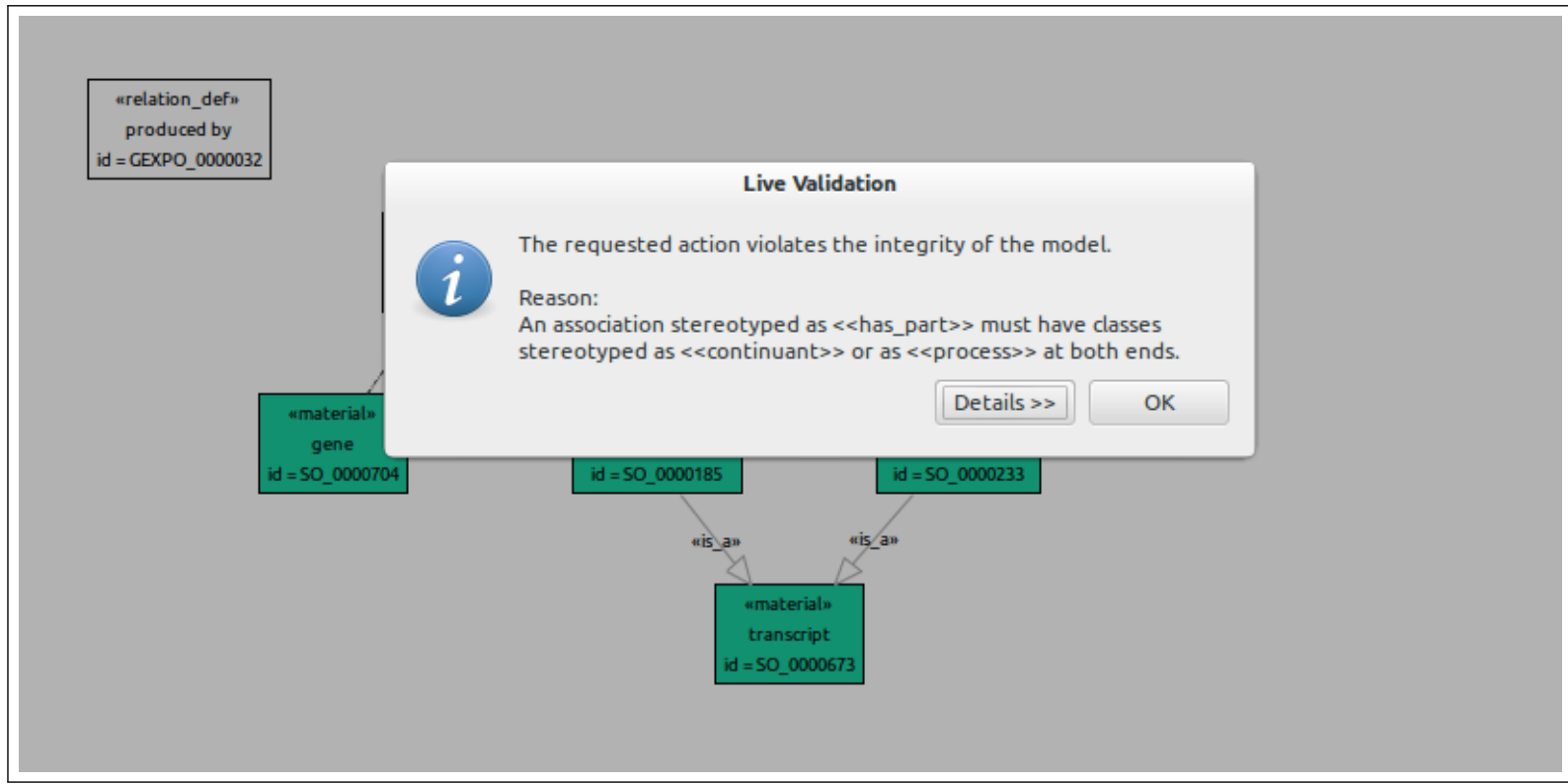

Figura 31: Erro sintático identificado pelo mecanismo de validação live validation durante a ação de edição executada pelo usuário.

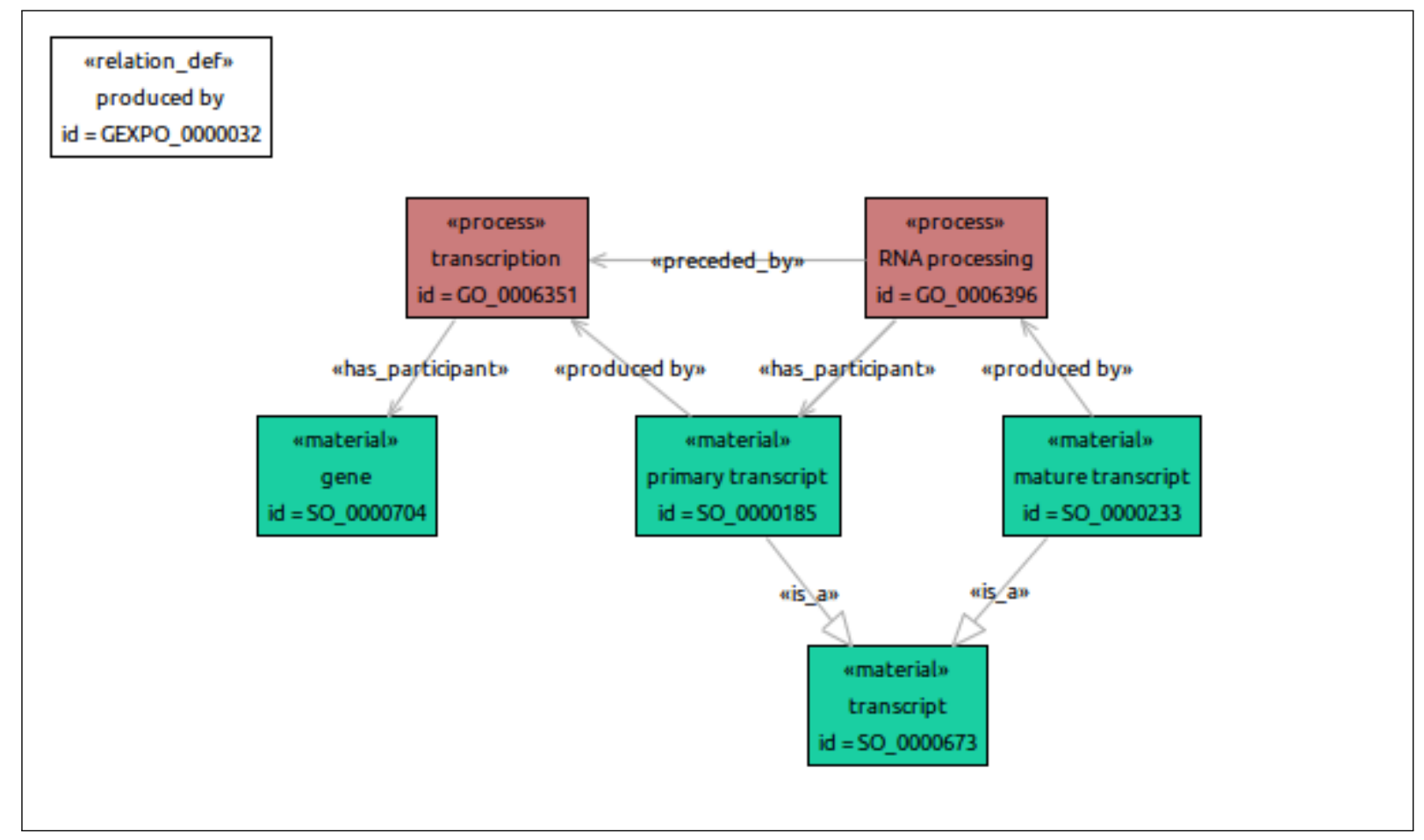

Figura 32: Fragmento de interesse após a adição da relação has_participant entre as classes de entidade "transcription" e "gene" e entre as classes de entidades "RNA processing" e "primary transcript". 


\subsection{Conclusão}

Neste capítulo apresentamos os principais aspectos do desenvolvimento do suporte à criação de modelos utilizando os elementos de modelagem definidos pelo perfil UML para a OR-OBO. Neste sentido, inicialmente apresentamos a definição do metamodelo OR-OBO, utilizado para representar por meio de modelos Ecore os tipos de elementos definidos na OR-OBO. Em seguida, apresentamos aspectos da definição de uma sintaxe gráfica concreta para a representação e edição das ontologias como modelos UML. Por fim, apresentamos a definição das expressões OCL que complementam o metamodelo OR-OBO, bem como permitem a validação (semi) automática da ontologia em desenvolvimento.

O editor desenvolvido permite a criação e edição em UML de ontologias OBO segundo as definições sintáticas apresentadas pelo perfil. Desta maneira, o editor apresenta os conceitos definidos por uma ontologia utilizando uma linguagem gráfica de fácil compreensão, frequentemente utilizada em processos de desenvolvimento de software. O mecanismo de validação sintática (semi) automática da ontologia em desenvolvimento facilita a curação e a detecção de inconsistências sintáticas existentes nesta ontologia. Adicionalmente, este mecanismo de validação pode ser utilizado para impedir a inserção de novas inconsistências durante uma ação de edição do usuário. Por fim, as ontologias criadas são representadas utilizando Ecore e serializadas utilizando a linguagem XMI, duas tecnologias centrais no EMP. Desse modo, tais ontologias também podem ser consumidas, consultadas e/ou modificadas por outros frameworks que manipulam modelos Ecore disponibilizados por este projeto. 


\section{$7 \quad$ Suporte à integração de ontologias $\mathrm{OBO}$}

Este capítulo apresenta o desenvolvimento de um mecanismo de integração entre ontologias OBO e modelos UML criados pela ferramenta de modelagem OBO-RO Editor. Ontologias OBO são desenvolvidas e representadas tradicionalmente utilizando a linguagem OBO File Format. Porém, os modelos UML criados pelo $O B O-R O$ Editor são representados no metamodelo OR-OBO e serializados em Ecore/XMI. Dada a necessidade de reuso e integração de ontologias, faz-se necessário o desenvolvimento de um mecanismo que permita a importação de uma ontologia OBO pela ferramenta $O B O-R O$ Editor, bem como a exportação de um modelo UML como uma ontologia OBO.

O restante desse capítulo está estruturado da seguinte forma: a seção 7.1 apresenta uma visão geral do mecanismo de suporte à integração de ontologias OBO e modelos UML; a seção 7.2 descreve os principais aspectos do metamodelo OBO Data Model (ODM) para a representação de ontologias OBO; a seção 7.3 apresenta uma visão geral da implementação dos mecanismos usados para a serialização (injeção e extração) de ontologias representadas em OBO File Format e sua equivalente representação no metamodelo ODM; a seção 7.4 apresenta uma visão geral das transformações desenvolvidas entre os metamodelo ODM e OR-OBO; a seção 7.5 apresenta um exemplo da execução das transformações definidas nesse capítulo; finalmente, a seção 7.6 apresenta algumas conclusões. 


\subsection{Visão geral}

Ontologias OBO são representadas tradicionalmente utilizando o OBO File Format. Por sua vez, ontologias criadas pela ferramenta $O B O-R O$ Editor são representadas como instâncias do metamodelo OR-OBO e serializadas em Ecore/XMI. Neste sentido, faz-se necessário prover mecanismos de integração entre esses dois domínios de representação de forma a permitir ao desenvolvedor utilizar a ferramenta de modelagem para importar ontologias OBO, criando representações dos conceitos e relacionamentos presentes nestas ontologias em UML, bem como extender estas ontologias com os conceitos e estereótipos definidos no perfil UML. Adicionalmente, ontologias UML desenvolvidas na ferramenta de modelagem podem ser exportadas e compartilhadas por ferramentas e usuários das ontologias OBO.

De maneira a prover suporte à integração com ontologias OBO, inicialmente estudamos frameworks de geração de texto a partir de modelos. Neste sentido, estudamos o framework Xtext, provido pelo EMP [110]. Este framework provê mecanismos para a definição de gramáticas para linguagens específicas de domínio e provê mecanismos para a geração de código de execução para realizar a serialização e desserialização de modelos baseados em Ecore como arquivos de texto nas linguagens definidas.

Dessa maneira, inicialmente pretendíamos desenvolver uma gramática Xtext para o $O B O$ File Format, de forma a exportar e importar ontologias representadas no OBO File Format para o metamodelo OR-OBO. Porém, esta abordagem mostrou-se inadequada. Neste sentido, as diferenças entre o metamodelo OR-OBO e o metamodelo implícito no OBO File Format tornaram a implementação da gramática Xtext para exportação uma tarefa dispendiosa ou mesmo inadequada. Adicionalmente, encontramos dificuldades para representar valores terminais no Xtext para todas as possíveis representações para cadeias de caracteres utilizadas nos valores de tags do $O B O$ File Format, de maneira que esses valores terminais não conflitassem com palavras-chaves definidas para a linguagem.

As dificuldades relacionadas ao uso do framework Xtext tornaram-se um impedimento ao seu uso efetivo na construção de uma gramática $O B O$ File Format para o metamodelo OR- 
OBO. Neste sentido, abandonamos esta abordagem e buscamos uma solução baseada na criação de um metamodelo equivalente, agregado ao uso de transformações de modelos, para prover o suporte necessário. Regras de transformação especificam como elementos de um metamodelo relacionam-se com os elementos de um segundo metamodelo. Estas regras são, então, aplicadas para os elementos que instanciam o primeiro metamodelo, de forma a obter um modelo equivalente no segundo metamodelo.

O framework ATL [79] foi utilizado para prover suporte para as transformações entre metamodelos. Este framework consiste de uma linguagem para definições de transformações unidirecionais e de um ambiente para a execução dessas transformações. ATL permite apenas a definição de transformações entre elementos pertencentes a metamodelos Ecore. Assim, tivemos que primeiramente desenvolver um metamodelo, chamado OBO Data Model (ODM), para representar os conceitos e relacionamentos definidos implicitamente na linguagem OBO File Format. Adicionalmente, mecanismos para injeção e extração foram implementados para permitir a transformação de uma ontologia representada no OBO File Format em uma representação equivalente (instância) no metamodelo ODM definido e permitir a transformação de uma instância do metamodelo ODM para a representação equivalente usando o OBO File Format, respectivamente.

Essas atividades acarretam em um esforço adicional para utilizar a tecnologia ATL em modelos que não sejam primariamente representados em Ecore. Porém, em geral é necessário apenas a criação de um metamodelo Ecore mínimo para a representação dos dados do domínio original, contendo apenas a estrutura e dados desse domínio. Esse metamodelo pode ser obtido por meio de engenharia reversa de classes ou interfaces de uma API já existente para a representação esses dados em tempo de execução. Neste sentido, a $O B O$ Foundry provê uma API Java para a representação de ontologias em tempo de execução e a serialização destas ontologias para o $O B O$ File Format [97], o que minimiza o esforço extra necessário ao uso do framework ATL neste cenário.

A Figura 33 apresenta uma visão geral das transformações definidas para o suporte à integração com ontologias representadas em $O B O$ File Format. Três atividades principais fo- 
ram definidas: i) o desenvolvimento do metamodelo ODM; ii) a implementação de injetores e extratores em Java para a serialização em $O B O$ File Format de modelos neste metamodelo; e iii) a definição de transformações em ATL entre os metamodelos ODM e OR-OBO.

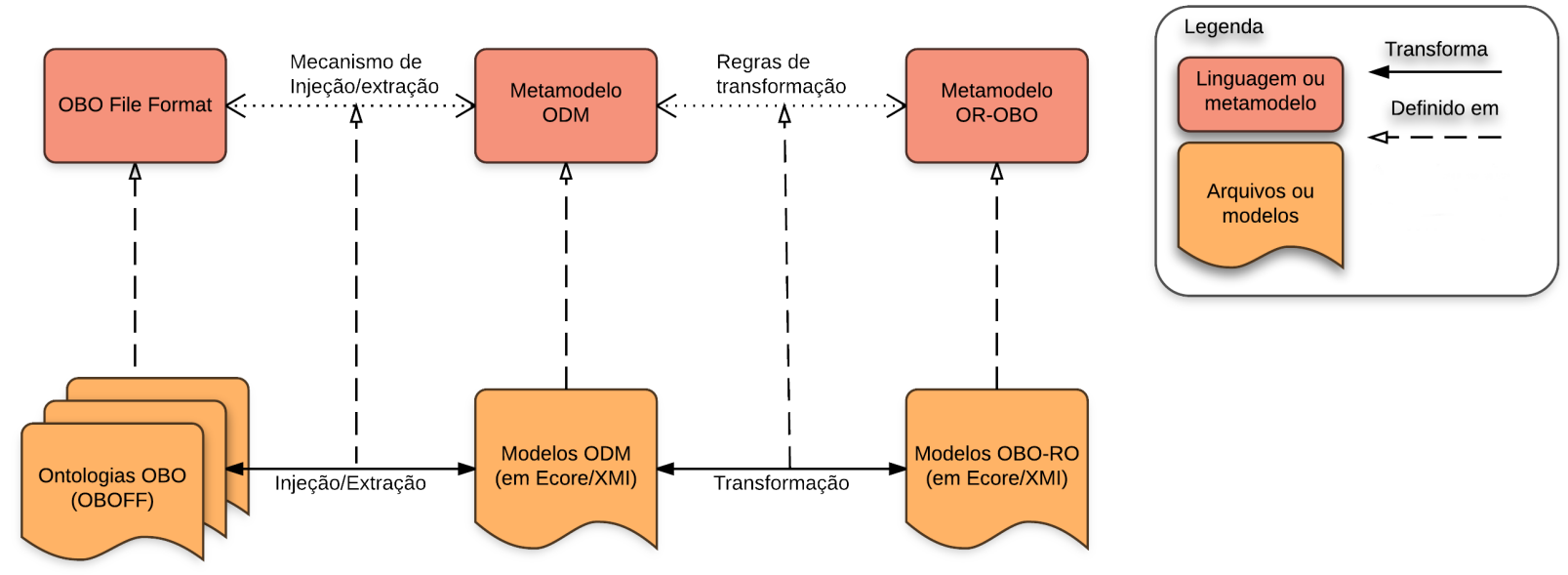

Figura 33: Arquitetura para a integração de ontologias OBO e o metamodelo OR-OBO.

\subsection{Definição do metamodelo ODM}

O metamodelo OBO Data Model (ODM) representa por meio de um modelo Ecore os tipos de elementos definidos em uma ontologia OBO, os quais estão implicitamente definidos na sintaxe da linguagem $O B O$ File Format. Dado que a $O B O$ Foundry disponibiliza uma API Java de código aberto [97] (pacote org - obo. datamodel) para representar os conceitos e relacionamos definidos em uma ontologia $\mathrm{OBO}$, usamos as definições contidas nessa API para extrair os elementos do metamodelo ODM.

O pacote org.obo. datamodel da API OBO define um conjunto de interfaces Java públicas que representam o metamodelo de uma ontologia OBO. Adicionalmente, este pacote disponibiliza uma classe Factory para abstrair a criação de instâncias de classes que implementam as interfaces definidas neste pacote. O metamodelo ODM foi obtido por meio de engenharia reversa das interfaces presentes no pacote org. obo. dat amodel. Cada interface definida foi mapeada para uma metaclasse Ecore utilizando o editor OCLinEcore. Este metamodelo Ecore foi transformado em um modelo generativo EMF e, então, transformado em código 
implementando essas metaclasses como classes Java de forma análoga ao desenvolvimento do metamodelo OR-OBO. Dessa maneira, foi possível obter um conjunto de classes e interfaces Java para representar a ontologia como um modelo Ecore.

Durante o desenvolvimento do metamodelo ODM, representamos apenas atributos públicos e atributos representados pela declarações de métodos acessores das interfaces encontradas no pacote org . obo . datamodel. Métodos representando operações mais complexas para consulta ou atualização das informações da ontologia em tempo de execução, os quais são dependentes da implementação de cada interface, não foram representados. Neste sentido, o metamodelo ODM é utilizado como uma representação da ontologia OBO para ser acessada apenas durante as transformações. Nestas transformações, consultas ao modelo são realizadas utilizando expressões OCL. Neste sentido, a representação de métodos mais complexos foi desnecessária.

A Figura 34 apresenta um fragmento do metamodelo ODM contendo as principais metaclasses envolvidas na representação de classes de entidades, instâncias e tipos de relacionamento. Os atributos destas metaclasses foram suprimidos para facilitar a representação gráfica das mesmas. As metaclasses OBOClass, Instance e OboProperty representam respectivamente classes de entidades, instâncias dessas classes e tipos de relacionamentos possíveis entre duas entidades. OBOClass, Instance e OboP roperty são especializações de OBOObject. A metaclasse OBOOb ject é uma especialização das metaclasses AnnotatedOb ject e LinkedObject. OBOOb ject representa um objeto anotado de uma ontologia OBO, o qual pode possuir relações com outros objetos. A metaclasse Annotatedob ject herda características de diversas metaclasses do metamodelo. Neste sentido, AnnotatedObject representa um elemento que possui um identificador principal (metaclasse IdentifiedOb ject), assim como um possível conjunto de identificadores secundários (metaclasse MultIDObject), comentários (metaclasse Commentedobject) e uma definição textual (metaclasse Definedobject).

A metaclasse OBOClass também especializa a metaclasse Type, de forma a representar as classes de entidades definidas em uma ontologia como conjuntos de elementos que são 


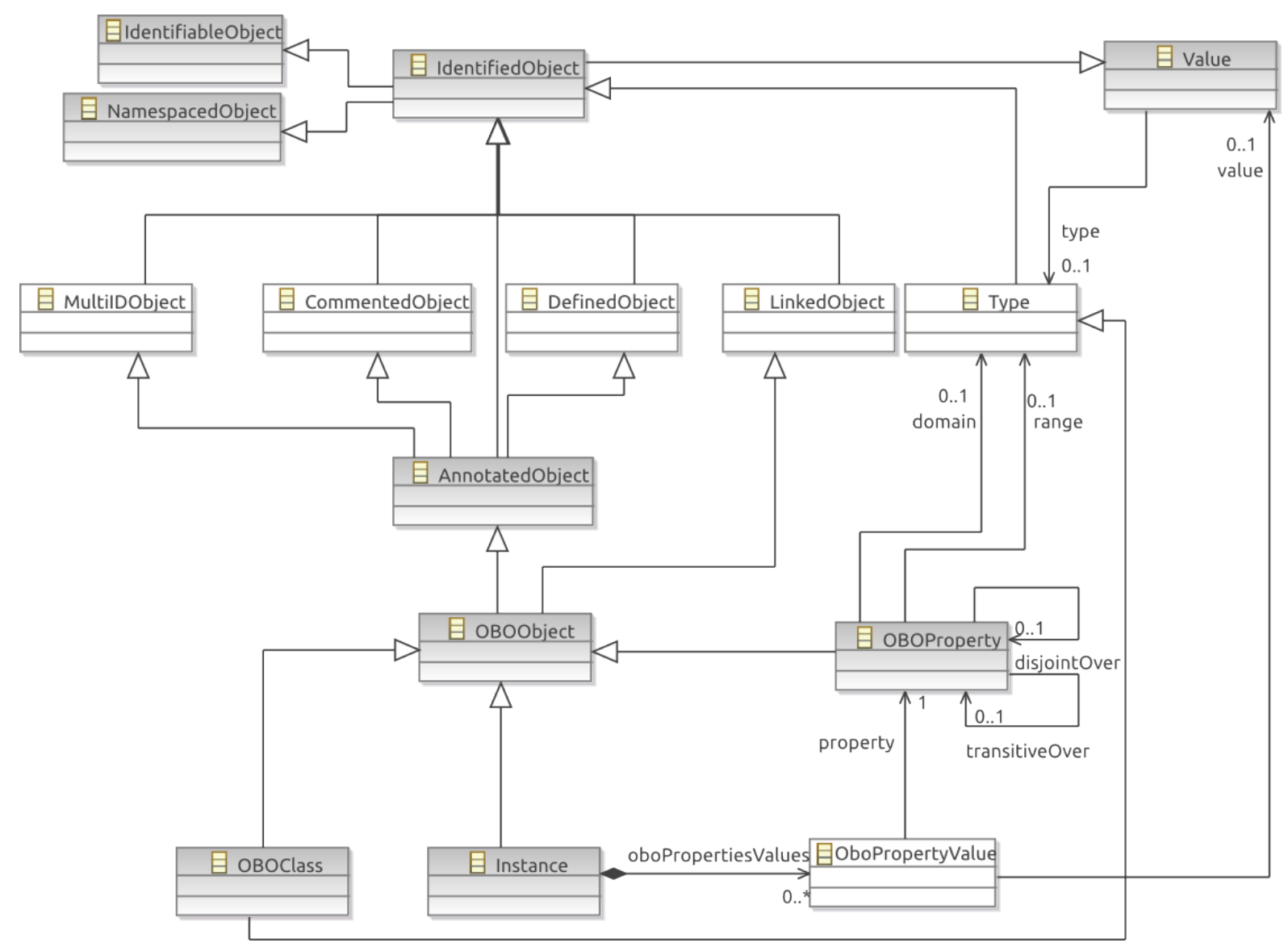

Figura 34: Metaclasses do metamodelo ODM associadas à representação de classes, instâncias e tipos de relacionamentos de uma ontologia OBO.

domínio e/ou imagem de um tipo de relacionamento. Por sua vez, a metaclasse OBOP roperty define um tipo de relacionamento que pode ser instanciado entre dois elementos e apresenta os meta-atributos domain e range que referenciam os tipos de elementos (Type) aos quais o relacionamento definido pode ser aplicado. Por fim, a metaclasse Instance define uma instância de um dos termos modelado na ontologia. Instance referencia uma lista de pares OboProperty-Value, a qual representa as relações que aquela instância possui com outros elementos.

A Figura 35 apresenta um fragmento do metamodelo ODM contendo as principais metaclasses envolvidas na representação de relações entre elementos de uma ontologia. A metaclasse Relationship referencia os elementos relacionados por meio de suas associações parent e child. Toda relação em uma ontologia OBO é modelada como uma instância de uma subclasse de Relationship. Adicionalmente, Relationship possui um atributo 
type, o qual referencia uma OboProperty que define o tipo de relacionamento instanciado por aquela relação.

A metaclasse abstrata Link especializa Relationship. Link também especializa a metaclasse Impliable. Neste sentido, Link permite a representação explícita de relações implícitas na ontologia. Estas relações podem ser encontradas por um motor de inferência baseado nas declarações explícitas da ontologia. Por exemplo, is_a é uma relação transitiva, de forma que se se as relações A is_a B e B is_a C estão definidas explicitamente na ontologia, é possível inferir que $A$ is_a $C$ é verdade. Link permite a diferenciação dessa relação inferida das demais relações explícitas pela ontologia.

Link é especializada pelas metaclasses OBORestriction e ValueLink, as quais são utilizadas efetivamente para a representação das relações em uma ontologia. OBORestriction permite a representação da cardinalidade e de outros argumentos adicionais em uma relação, enquanto ValueLink permite a associação de valores (Value) à relação. Adicionalmente, relações nas quais um dado elemento da ontologia pode ser definido pela intersecção de outros elementos de uma ontologia são modeladas por um atributo booleano, chamado completes, definido em OBORestriction.

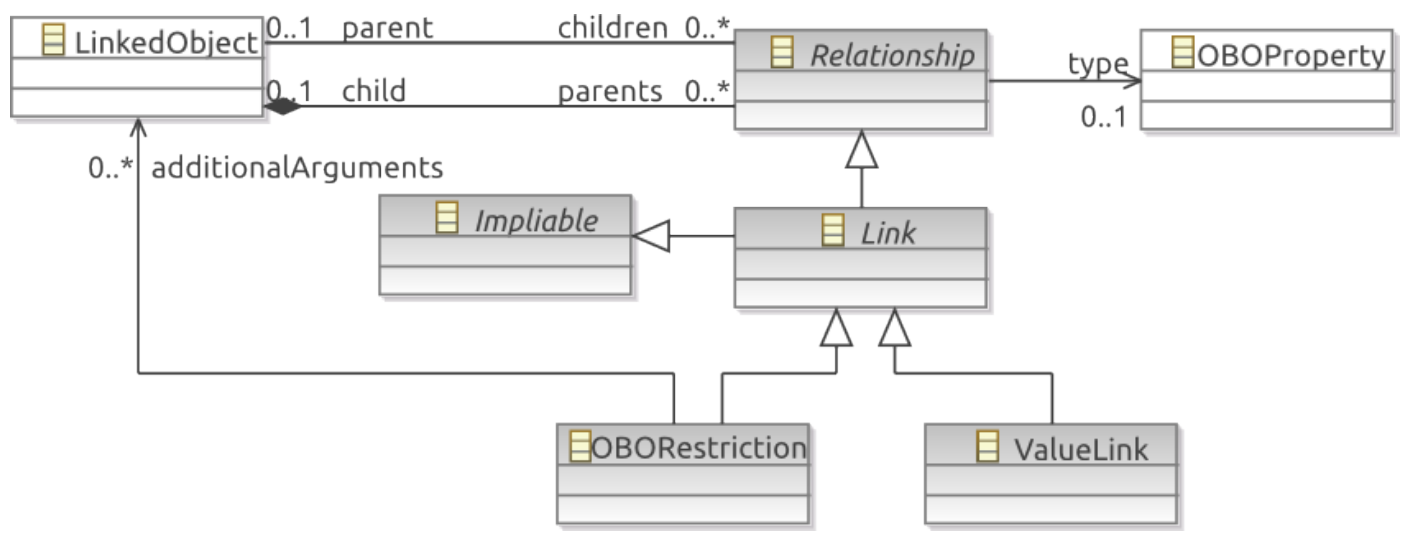

Figura 35: Metaclasses do metamodelo ODM associadas à representação de relacionamentos entre dois elementos de uma ontologia OBO.

A Figura 36 apresenta um fragmento do metamodelo ODM contendo as principais metaclasses envolvidas na organização de uma ontologia em um contexto de trabalho, ou seja, durante a representação e/ou edição dessa ontologia de forma independente do OBO File Format. A metaclasse OBOSession representa toda a informação contida em uma ou mais ontologias 
em trabalho. OBOSession agrupa os elementos das ontologias por meio de uma associação objects.

Como a API OBO permite a associação de vários diferentes arquivos em uma mesma OBOSession, um Namespace é utilizado para definir uma ontologia lógica em um contexto de trabalho. Cada ontologia pode definir um ou mais namespaces para agrupar seus elementos. Dessa forma, objetos que sejam instâncias de subclasses de NamespacedObject (i.e., instâncias de OBOClass, Instance ou OBOProperty) referenciam um Namespace ao qual pertencem. Adicionalmente, instâncias de Link também referenciam o Namespace no qual as relações foram declaradas. Por fim, declarações que não são entendidas durante a análise de um dado arquivo OBO são armazenadas como instâncias de UnknowStanza para uma serialização posterior, também referenciando um dado Namespace.

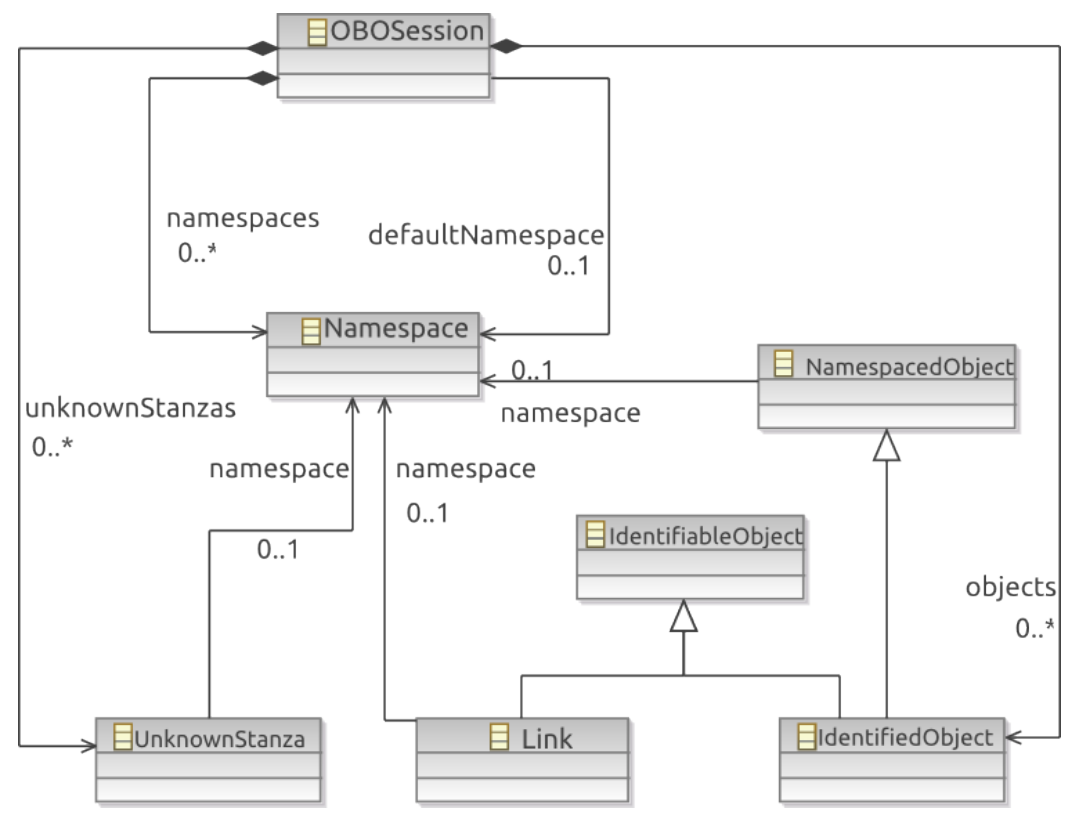

Figura 36: Metaclasses do metamodelo ODM associadas à organização de uma ontologia OBO.

\subsection{Definição de mecanismos de injeção e extração de onto- logias}

Um mecanismo de injeção foi desenvolvido para permitir a obtenção de um modelo ODM a partir de uma ontologia representada em OBO File Format (ontologia OBO). Adicionalmente, um mecanismo de extração foi desenvolvido para a exportação de um modelo ODM como uma 
ontologia OBO.

O pacote org.obo.dataadapter, também disponibilizado pela API OBO, foi utilizado durante o desenvolvimento dos mecanismos de injeção e extração. Este pacote provê as classes OBOAdapter e OBOFileAdapter, utilizadas para a manipulação das ontologias representadas no $O B O$ File Format. Em essência, essas classes permitem obter ou serializar uma ontologia representada por meio de instâncias das interfaces providas pelo pacote org .obo . datamodel em arquivos OBO. Dessa maneira, o maior esforço na implementação dos injetores e extratores foi implementar na linguagem Java o código para transformar instâncias das classes que implementam interfaces definidas no pacote org. obo. datamodel para o metamodelo ODM e vice-versa.

O processo de injeção é dividido em duas etapas: i) leitura dos arquivos OBO utilizando as classes do pacote org. obo. dataadapter, de modo a obter um conjunto de instâncias das interfaces do pacote org . obo. dat amodel representando esta ontologia; e ii) transformação das instâncias das interfaces do pacote org . obo . datamodel em um modelo ODM. Adicionalmente, a segunda etapa também é realizada em duas sub-etapas: i) a criação para cada instância fonte de uma instância equivalente no modelo alvo; e ii) a passagem de todos os atributos e referências das instâncias fontes para as instâncias criadas no modelo alvo.

A Figura 37 apresenta uma visão geral do algoritmo de injeção em pseudocódigo. A função principal a ser executada para a obtenção de um modelo equivalente a um modelo de entrada é a in jeção. Essa função recebe o elemento raiz do modelo original, i.e., o container de todos os elementos do modelo original, e retorna um modelo equivalente no qual cada instância foi transformada em uma instância da classe equivalente no metamodelo alvo. Neste sentido, o elemento raiz do modelo original recebido é a instância de uma classe Java que implementa a interface OBOSession, definida no pacote org.obo. datamodel.

Dentro da função in jeção, um mapeamento entre o elemento do modelo original e o elemento equivalente do novo modelo é mantido. Como uma operação de injeção cria no máximo um elemento novo para cada elemento presente no modelo original, esse mapeamento pôde ser utilizado posteriormente à criação do objeto de forma a permitir a passagem de propriedades e 


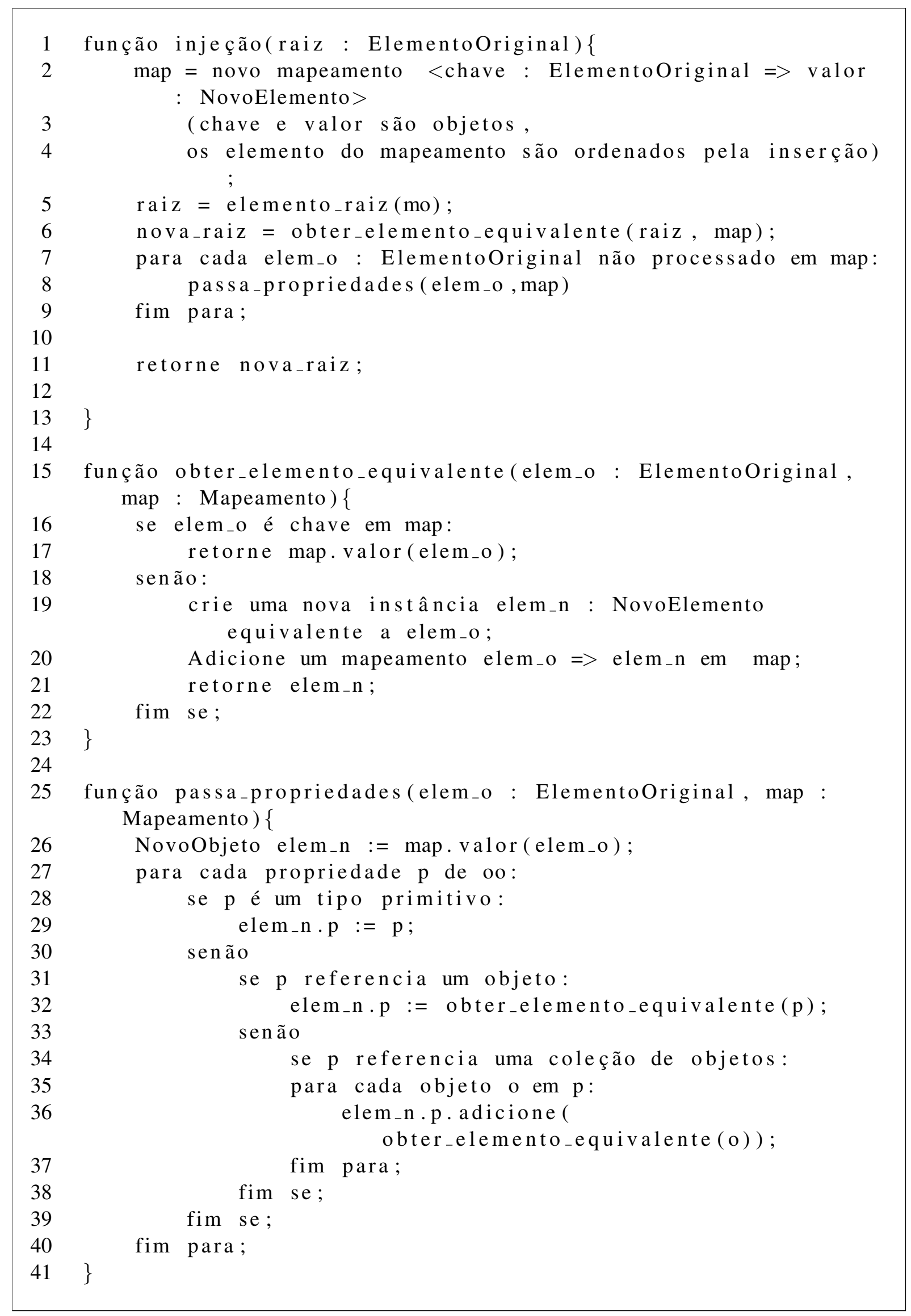

Figura 37: Visão geral do algoritmo de injeção em pseudocódigo 
referências entre os elementos.

A extração é análoga à injeção. Neste sentido, a extração difere da injeção basicamente pelo uso de um modelo ODM como fonte e a produção de uma ontologia representada na linguagem OBO File Format ao final do processo. Assim como durante a injeção, um mapeamento entre cada elemento do modelo original e o elemento equivalente do novo modelo é mantido. Este modelo equivalente, i.e. um conjunto de instâncias de classes Java implementando as intefaces definidas no pacote org . obo. datamodel, é, por fim, exportado para a linguagem $O B O$ File Format.

\subsection{Definição de transformações ATL entre os metamodelos OR-OBO e ODM}

Transformações entre o metamodelo ODM e o metamodelo OR-OBO foram desenvolvidas utilizando o framework ATL. Este framework permite apenas a definição de regras de transformação unidirecionais entre dois metamodelos. Dessa maneira, foram definidos dois diferentes conjuntos de transformações entre os metamodelos envolvidos: um conjunto de tranformações tendo um modelo ODM como fonte e um modelo OR-OBO como alvo, e um conjunto de transformações em sentido contrário.

\subsubsection{Transformação de modelos ODM em modelos OR-OBO}

O primeiro conjunto de transformações ATL foi definido para obter um modelo OR-OBO alvo a partir de um modelo ODM fonte. Durante a transformação, um conjunto de elementos do modelo ODM é associado a um conjunto de regras de transformação. Essas regras de transformação são, então, executadas de forma a produzir um conjunto de elementos no modelo OR-OBO alvo e conectar esses elementos entre si.

As regras de transformação foram definidas de acordo com o seguinte processo: Primeiramente, os elementos de interesse do modelo fonte foram divididos em conjuntos de pareamento. Esses conjuntos de pareamento são definidos, de forma mutualmente exclusiva, pelas metaclas- 
ses dos elementos fontes e condições de pareamento e/ou exclusão adicionais, tais como o valor esperado para algum atributo dos elementos pareados. Neste sentido, não é necessário definir conjuntos de pareamento até obter uma cobertura completa do conjunto total de elementos de um modelo, mas sim definir conjuntos de pareamento que incluam todos (e apenas os) elementos de interesse. Em seguida, cada conjunto de pareamento é associado a um conjunto de elementos produzidos no modelo alvo após a transformação. Diferentemente dos conjuntos de pareamentos, os conjuntos de elementos produzidos podem ter sobreposição entre si.

Cada associação entre conjunto de pareamento e conjunto de elementos produzidos foi, então, implementado como uma regra de transformação concreta. Neste sentido, atributos e associações de interesse do(s) elemento(s) fonte(s) foram utilizados para a inicialização do(s) elemento(s) criado(s) pela transformação.

Quando da criação de determinadas regras foi possível observar a sobreposição de aspectos de transformação envolvendo duas ou mais regras. Por exemplo, duas regras de transformação diferentes podem ser pareadas a elementos com superclasses em comum e produzirem elementos que também possuam superclasses em comum. Neste sentido, se ambas as regras inicializam atributos e associações de forma semelhante, essas inicializações podem ser incluídas em uma regra mais geral especializada pelas regras originais. Dessa maneira, regras de transformação mais gerais foram desenvolvidas de maneira a modularizar os aspectos comuns a mais de uma regra de transformação. Essas regras mais gerais foram definidas como abstratas, para que estas não possam ser executadas fora do contexto de execução das regras concretas originais. Adicionalmente, durante o desenvolvimento, funções auxiliares (Helpers) foram criadas de maneira a modularizar operações de consulta ao modelo definidas em OCL e reutilizadas em uma ou mais regras.

Durante a execução de uma transformação, as regras de transformação são associadas aos elementos fontes de acordo com critérios de pareamento. Dessa maneira, apenas uma regra concreta deve ser associada a um elemento do modelo fonte. Porém, diferentes instâncias de uma mesma metaclasse fonte podem ser pareadas a regras de transformação diferentes e, portanto, produzir um conjunto de elementos alvo diferente durante a transformação. 
A Figura 38 ilustra algumas regras de transformação definidas entre os metamodelo ODM e OR-OBO. As metaclasses do metamodelo ODM são apresentadas em cinza, enquanto as metaclasses do metamodelo OR-OBO são apresentadas em branco. Uma regra de transformação é graficamente representada como um círculo nomeado. Regras de transformação concretas são representadas por um círculo cinza. Regras de transformação abstratas, as quais apenas podem ser executadas quando da execução de regras concretas que as estendam, são representadas por um círculo branco. Dois tipos de arco entre uma regra e uma metaclasse são utilizados. Um arco com uma seta simples direcionada a uma metaclasse representa que instâncias daquela metaclasse são utilizadas como elementos fontes da regra de transformação. Um arco com uma seta dupla direcionada a uma metaclasse representa que instâncias daquela metaclasse são criadas durante a execução da regra de transformação. Adicionalmente, um arco com uma seta vazada direcionada de uma regra de transformação a outra representa que a regra no terminal com cabeça de seta é estendida pela regra no outro terminal do arco. Neste sentido, ambas as regras são executadas para os mesmos elementos fonte e alvo, de forma que a regra mais geral é executada anteriormente à regra mais específica.

A regra OboSession2RootPackage transforma uma instância da metaclasse OBOSession em uma instância da metaclasse Package. A instância de Package criada tornase a raiz do modelo OR-OBO produzido ao final da transformação.

A regra Namespace2Package transforma uma instância da metaclasse Namespace em uma instância da metaclasse de Package. Neste sentido, esta regra inicializa o atributo name da instância de Package com o valor do atributo id da instância de Namespace. Adicionalmente, Namespace2Package inclui na associação packageElement da instância de Package produzida todas as instâncias da metaclasse PackageableElement produzidas a partir de instâncias de NamespacedOb ject referenciando a instância de Namespace original.

A regra Identifiedobject2OboDefElement transforma uma instância da metaclasse Identifiedobject em uma instância da metaclasse OboDefinitonElement. Porém, IdentifiedObject2OboDefElement é uma regra abstrata e não pode ser exe- 


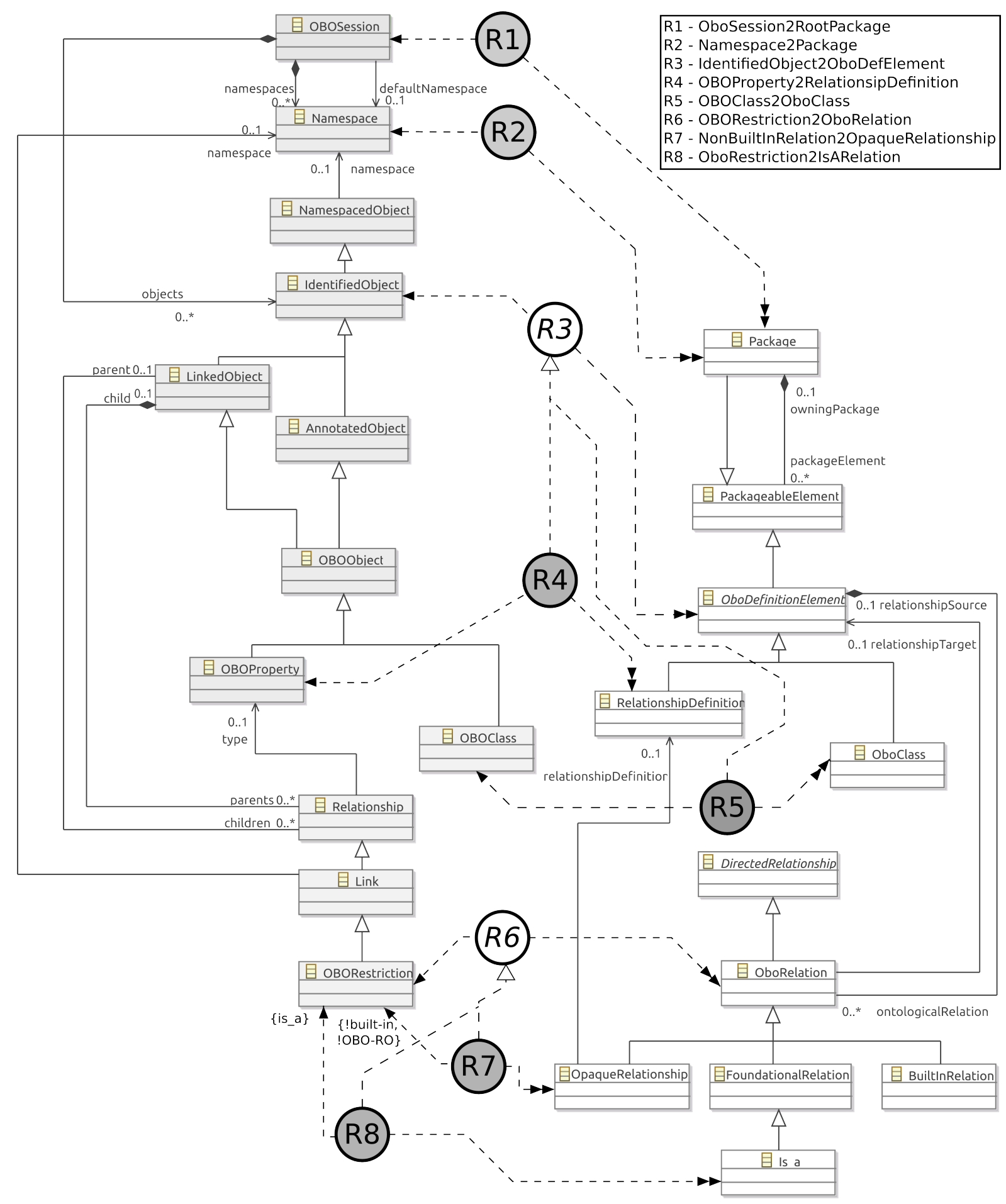

Figura 38: Representação visual de um conjunto de regras de transformação entre o metamodelo ODM e o metamodelo OR-OBO.

cutada diretamente, mas apenas por meio da execução de uma regra de transformação concreta que a estenda. Neste sentido, regras OBOProperty2RelationshipDefinition e OBOClass2OboClass estendem a regra IdentifiedOb ject2OboDefElement. A regra OBOProperty2RelationshipDefinition transforma uma instância da metaclasse 
OBOProperty em uma instância da metaclasse RelationshipDefinition. Por sua vez, a regra OBOClass2OboClass transforma uma instância da metaclasse OBOClass (do metamodelo ODM) em uma instância da metaclasse Oboclass (do metamodelo OR-OBO). A regra $O B O C l a s s 2 O b \circ C l a s s$ é especializada por outras regras que produzem subclasses de OboClass representando as diferentes classes de entidades definidas na OR-OBO.

A regra OBORestriction2OboRelation transforma uma instância da metaclasse OBORestriction em uma instância da metaclasse OboRelation. Assim como a regra IdentifiedObject2OboDefElement, a regra OBORestriction2OboRelation é abstrata, apenas sendo executada por meio de regras concretas que a estendem. Neste sentido, a regra NonBuiltInRelation2OpaqueRelationship estende a regra OBORestriction2OboRelation de maneira a produzir instâncias da metaclasse opaqueRelationship e a regra OBORestriction2IsARelation estende a regra OBORestriction20boRelation de maneira a produzir instâncias da metaclasse Is_a. Adicionalmente, a regra NonBuilt InRelation2OpaqueRelationship inicializa o atributo relationshipDefinition com a instância da metaclasse RelationshipDefinition adequada.

A especificação de cada regra começa com a palavra-chave rule seguida pelo nome da regra. Opcionalmente outras palavras-chaves podem ser utilizadas antes de rule, como por exemplo, abstract. Adicionalmente, uma regra pode estender outra regra se após o nome da regra houver a palavra-chave extends e o nome de outra regra.

O corpo da regra possui seções definidas. A seção iniciada pela palavra-chave f rom declara o conjunto de pareamento da regra e nomeia os elementos e metaclasses envolvidos. Adicionalmente, após o último elemento desse bloco pode ser declarado uma expressão booleana, envolvendo os elementos do conjunto de pareamento, a qual deve ser avaliada como verdadeira quando do pareamento do conjunto de entrada. Uma segunda seção, iniciada pela palavrachave to, declara o conjunto de elementos produzidos pela regra e inicializa os atributos desses elementos de acordo com declarações envolvendo os elementos do conjunto de pareamento.

A Figura 39 apresenta a especificação ATL das regras OBORestriction2OboRelation, NonBuiltInRelation2OpaqueRelationship e IsARelation. OBORes- 
triction20boRelation é uma regra abstrata que transforma uma instância de OBORestriction em uma instância de OboRelation. Durante a transformação, esta regra inicializa os atributos relationshipsource, relationshiptarget e intersection de OboRelation. Esses atributos recebem instâncias transformadas dos elementos associados às referências child, parent e completes da instância de OBORestriction à qual a regra é aplicada. Porém, como OBORestriction2OboRelation é uma regra abstrata, ela não pode ser executada diretamente.

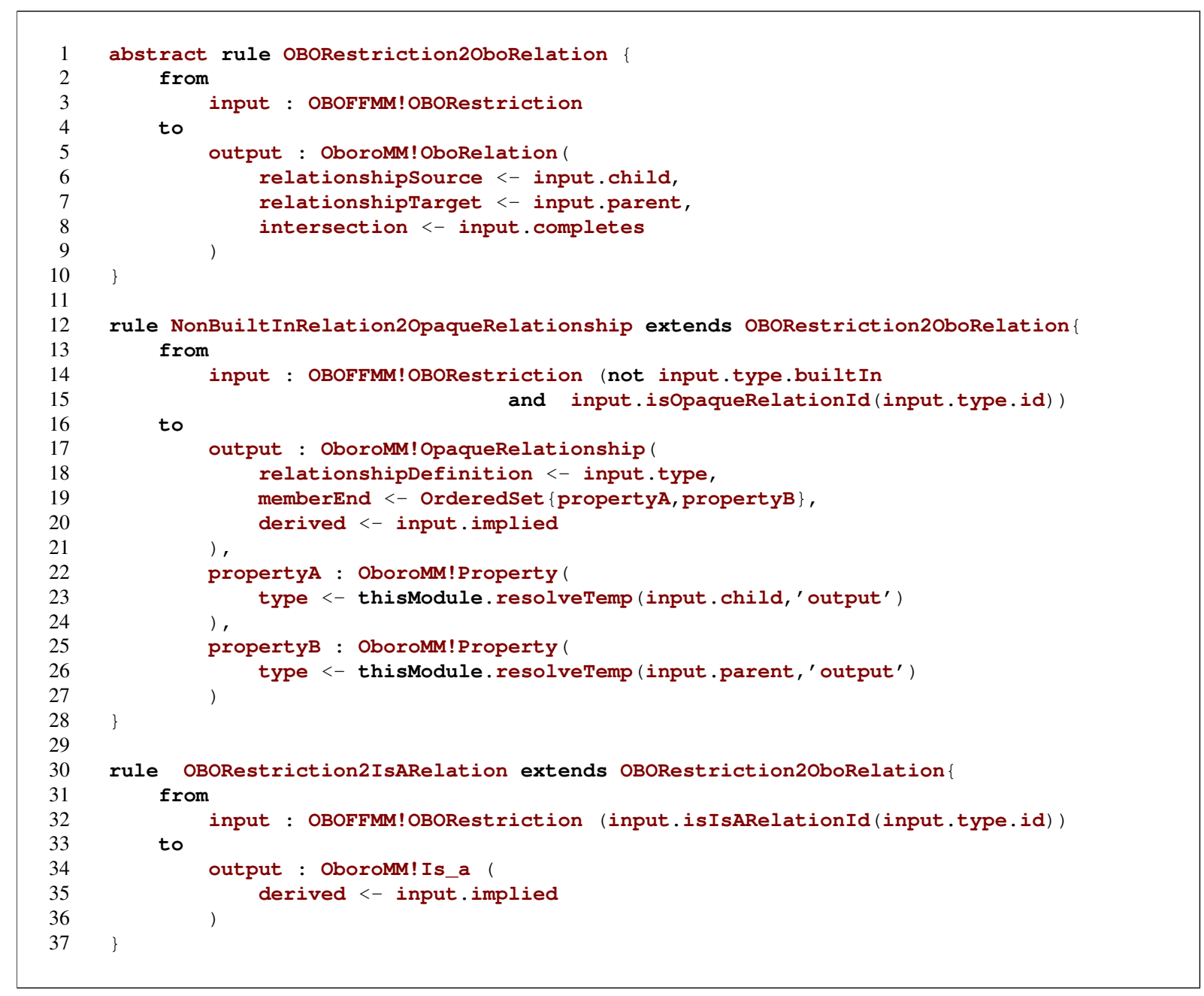

Figura 39: Regras de transformação definidas em ATL.

As regras NonBuiltInRelation2OpaqueRelationship e IsARelation estendem a regra OBORestriction2OboRelation de forma a permitir a execução da regra abstrata para uma instância de OBORestriction. As regras NonBuiltInRelation2OpaqueRelationship e IsARelation definem conjuntos de elementos fonte os quais 
são subconjuntos mutualmente exclusivos do conjunto de elementos fonte de OBORestriction2OboRelation. Adicionalmente, estas regras mais específicas produzem elementos que são um subconjunto dos elementos produzidos pela regra mais geral, além de possíveis elementos não declarados pela regra mais geral. Neste sentido, a regra NonBuilt InRelation20paqueRelationship produz um elemento chamado output. Este elemento é declarado como instância OpaqueRelationship. OBORestriction2OboRelation também produz um elemento chamado de output. Porém, declara esse elemento como uma instância de OboRelation, superclasse de OpaqueRelationship. Adicionalmente, NonBuiltInRelation2OpaqueRelationship produz duas instâncias de Property não declaradas na regra mais geral. As regras mais específicas são executadas após a regra mais geral, e inicializam atributos não existentes no elemento alvo desta regra.

\subsubsection{Transformação de modelos OR-OBO em modelos ODM}

Um segundo conjunto de transformações ATL foi definido de forma a obter um modelo ODM alvo a partir de um modelo OR-OBO fonte. Este conjunto de transformações é utilizado após uma sessão de edição da ontologia no editor, de forma a obter um modelo ODM que será posteriormente serializado em $O B O$ File Format.

A transformação de um modelo OR-OBO em um modelo ODM precisa lidar com uma diferença no nível de detalhamento existente entre os dois modelos. Neste sentido, dois conjuntos de elementos existentes em um modelo ODM são omitidos durante a produção de um modelo OR-OBO. O primeiro conjunto de elementos omitidos inclui os objetos implicitamente definidos em uma ontologia OBO, tais como as declarações dos tipos de relacionamento builtin, bem como as declarações dos tipos de relacionamentos definidos na OR. Estes elementos não estão presentes em um modelo OR-OBO uma vez que o metamodelo OR-OBO define um conjunto de metaclasses específicas para representar instâncias destas relações. O segundo conjunto de elementos omitidos inclui alguns conceitos menos relevantes para o nível de abstração pretendido para o metamodelo OR-OBO. Por exemplo, detalhes como sinônimos e valores aninhados não são incluídos em um modelo OR-OBO. Dessa maneira, um mecanismo para 
tratar a diferença do nível de detalhamento entre os metamodelos teve de ser definido para a transformação de modelos OR-OBO em modelos ODM.

Dois cenários de transformação foram identificados. No primeiro cenário, o desenvolvimento da ontologia foi iniciado diretamente no OBO-RO Editor. Neste cenário, toda a informação modelada até então para esta ontologia está representada no modelo OR-OBO. Durante a transformação em um modelo ODM alvo, o primeiro conjunto de elementos omitidos precisa ser incluído, uma vez que outros elementos poderão referenciar os elementos deste conjunto após a transformação. Detalhes relacionados ao segundo conjunto de elementos omitidos ainda não terão sido definidos para essa ontologia. Neste sentido, estes detalhes poderão ser definidos posteriormente por outra ferramenta de modelagem, como por exemplo o OBO-Edit.

No segundo cenário de transformação, uma ontologia representada no OBO File Format foi importada e posteriormente editada no OBO-RO Editor. De acordo com este cenário, o modelo ODM obtido durante a importação poderia conter, originalmente, elementos pertencentes ao segundo conjunto de elementos omitidos. Neste sentido, o segundo cenário de transformação necessita de um mecanismo adicional para a reconciliação do modelo ODM produzido com um modelo auxiliar de maneira a permitir a reincorporação desse segundo conjunto de elementos antes que a ontologia seja exportada para a linguagem $O B O$ File Format.

Dessa maneira, a transformação de um modelo OR-OBO em um modelo ODM foi definida em duas fases: 1) a transformação de um modelo OR-OBO em um modelo ODM inicial equivalente com a inclusão dos elementos do primeiro conjunto de elementos omitidos; e 2) o enriquecimento desse modelo ODM com os elementos do segundo conjunto de elementos omitidos, providos por um modelo ODM auxiliar, de maneira a obter o modelo que será exportado para o $O B O$ File Format. A primeira fase é compartilhada por ambos os cenários de transformação. Porém, a segunda fase da transformação é própria do segundo cenário, não sendo necessária quando o desenvolvimento de uma ontologia é iniciado diretamente no $O B O$ RO Editor (primeiro cenário).

A primeira fase da transformação faz uso de um modelo ODM fonte auxiliar, o qual será usado para complementar as informações do primeiro conjunto de elementos omitidos. Dessa 
maneira, o modelo ODM produzido pela transformação contém dois conjuntos de elementos: os elementos obtidos a partir da transformação dos elementos presentes no modelo OR-OBO e os elementos obtidos (copiados) deste modelo ODM auxiliar. Referências entre estes elementos são inicializadas corretamente durante a transformação. O modelo ODM auxiliar foi obtido pela injeção da OR, representada no OBO File Format, como um modelo ODM. Essa injeção foi realizada previamente e o modelo resultante foi armazenado entre os artefatos que compõe a ferramenta, de maneira a ser reutilizado quando da execução desta transformação.

A Figura 40 ilustra os estágios da exportação de uma ontologia para o OBO File Format em um cenário de edição-exportação. Neste cenário, o desenvolvimento da ontologia é iniciado diretamente no $O B O-R O$ Editor. Neste sentido, a figura apresenta o modelo OR-OBO definido pelo usuário e o modelo ODM obtido pela injeção da OR sendo utilizados como modelos fontes para a primeira fase de transformação. Uma vez que o desenvolvimento foi iniciado diretamente no $O B O-R O$ Editor, o segundo conjunto de elementos omitidos inexiste. Dessa maneira, o modelo ODM inicial é, também, o modelo utilizado para a extração da ontologia durante a exportação para o $O B O$ File Format.

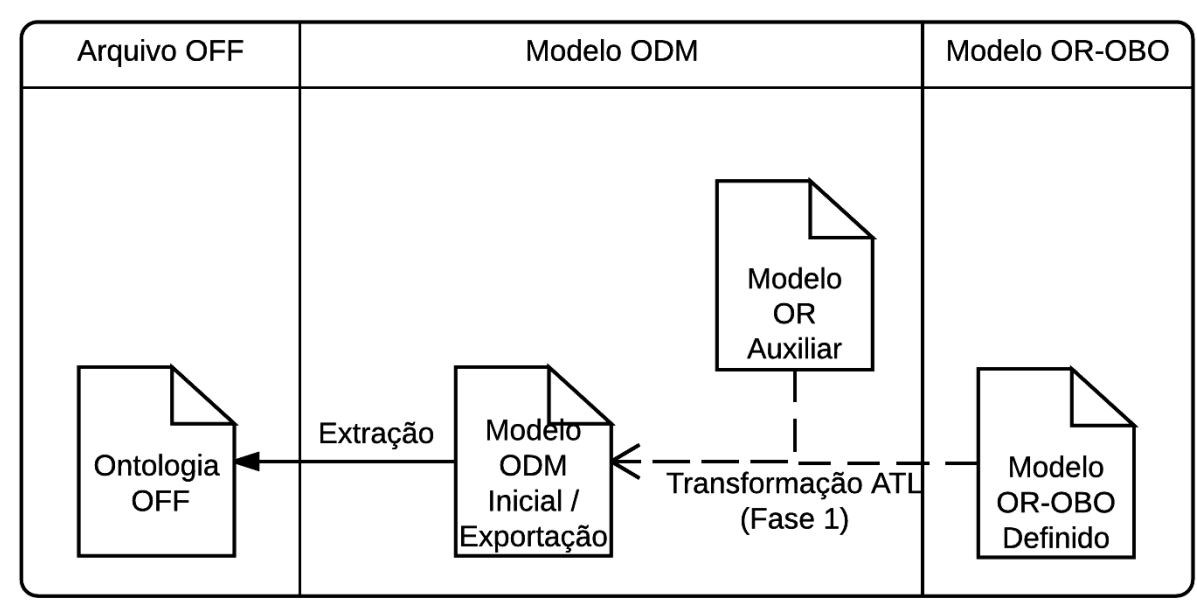

Figura 40: Estágios da exportação de uma ontologia em um cenário de edição-exportação.

Durante a primeira fase da transformação, a associação entre os elementos da ontologia e as classes de entidades definidas pela OR-OBO é mantida pela adição de instâncias de PropertyValue às instâncias de OBOClass do modelo ODM produzido. Neste sentido, 
cada instância de PropertyValue criada possui o atributo property inicalizado como ' ro-entity-type' e o atributo value inicializado com ' continuant' , material', ' immaterial' ou 'process', de acordo com a classe de entidade OR-OBO modelada.

A Figura 41 apresenta um fragmento da especificação ATL da transformação de um modelo OR-OBO em um modelo ODM. Este fragmento apresenta as regras entry, finally e CopyDefaultNamespace. A regra entry é executada antes das demais regras de transformação (entrypoint rule). Esta regra é utilizada para criar uma instância de OBOSession a partir da instância de Package raiz do modelo OR-OBO. A instância criada é armazenada, durante a transformação, na variável auxiliar (helper) session. Por sua vez, a regra $f$ inally é a última regra executada durante uma transformação (endpoint rule). Esta regra inicializa as associações da instância de OBOSession criada por entry com as instâncias dos outros elementos do modelo criadas durante a fase de mapeamento e transformação. Tanto a regra entry quanto a regra $f i n a l l y$ apresentam duas seções adicionais: a seção using, a qual declara variáveis locais ao contexto de execução da regra, de forma a permitir o uso dessas variáveis nas demais seções, e a seção do, a qual define uma seção imperativa executada após as demais seções da regra de transformação. Por fim, a regra CopyDefault Namespace é uma das regras utilizadas para incluir os objetos do primeiro conjunto de elementos omitidos. Neste sentido, esta regra faz uma cópia das instâncias da metaclasse Namespace existentes no modelo auxiliar e inclui essa cópia entre os namespaces contidos pela instância de OBOSession criada durante a execução da regra entry. Regras semelhantes são utilizadas para copiar os demais elementos do primeiro conjunto omitidos a partir do modelo ODM auxiliar e inclú́-los no modelo ODM alvo.

A segunda fase da transformação objetiva enriquecer o modelo ODM obtido na fase anterior (modelo ODM inicial) com informações não representáveis no metamodelo OR-OBO, pertencentes ao segundo conjunto de elementos omitidos. Neste sentido, esta transformação também faz uso de um segundo modelo ODM fonte auxiliar, o qual é utilizado para obter os elementos a serem incluídos. Durante esta fase de transformação, elementos dos dois modelos fonte são pareados pelos seus identificadores. Em seguida, as informações do modelo auxiliar 


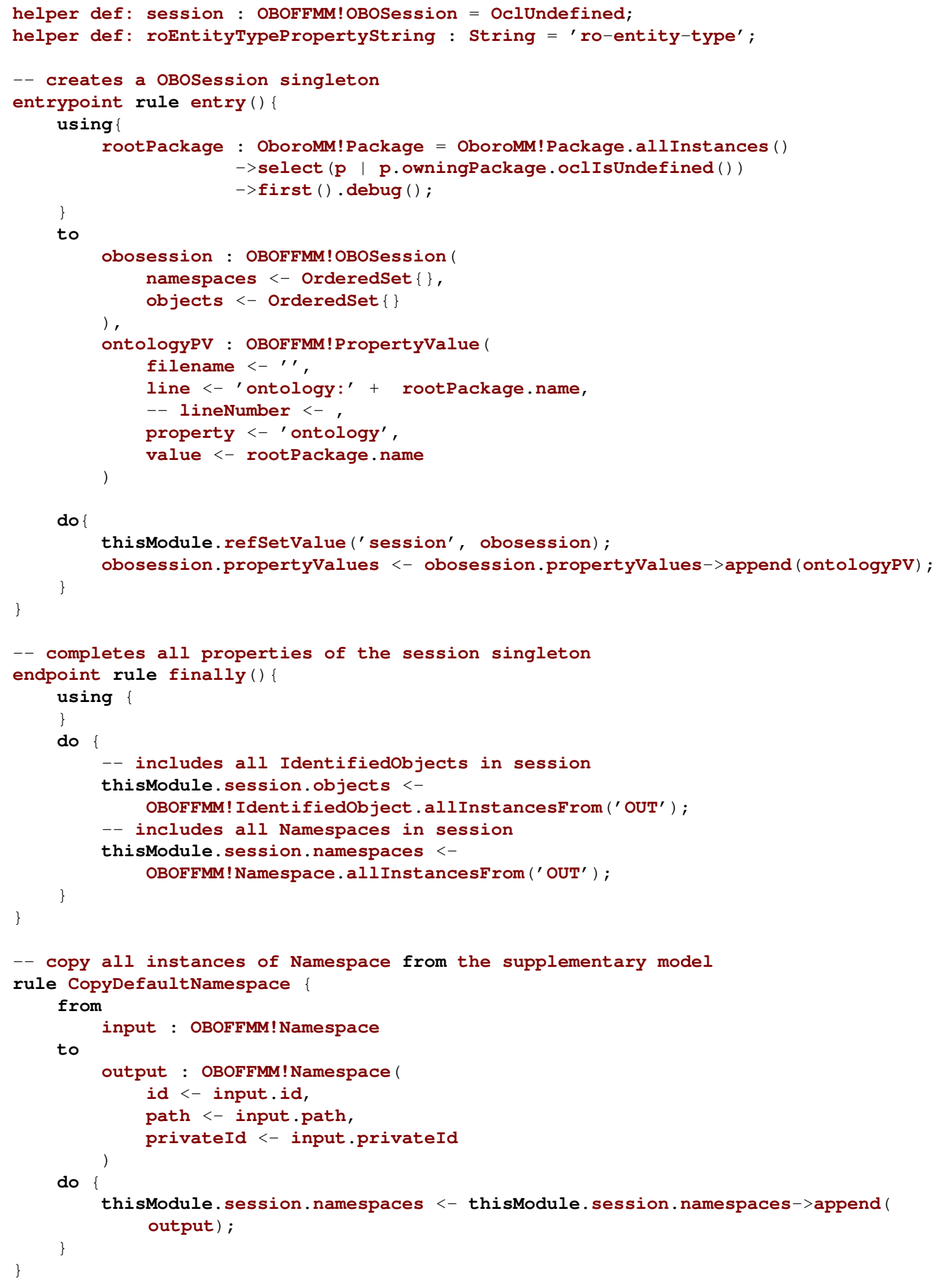

Figura 41: Especificação ATL das regras entry e finally.

são transferidas para o modelo original, de forma a produzir o modelo ODM exportação.

Na segunda fase de transformação, as informações presentes no segundo modelo auxiliar que já são representadas no metamodelo OR-OBO são ignoradas. Neste sentido, estas 
informações já se encontram de forma atualizada no modelo ODM inicial, obtido ao final da primeira fase. Dessa maneira, utiliza-se o modelo ODM importação gerado anteriormente como o segundo modelo auxiliar, uma vez que apenas informações não editáveis pela ferramenta OBO-RO Editor serão extraídas deste modelo.

A Figura 42 apresenta os diferentes estágios da representação de uma ontologia importada a partir da linguagem $O B O$ File Format até a exportação da ontologia editada novamente para esta linguagem. Neste sentido, a figura apresenta a importação de uma ontologia original como um modelo ODM importação (injeção) e a transformação desse modelo em um modelo OR-OBO importação. Edições no modelo OR-OBO são realizadas por um usuário de maneira a obter um modelo OR-OBO modificado. Após a edição da ontologia, a primeira fase de transformação é executada de maneira a incluir os objetos pertencentes ao primeiro conjunto de elementos omitidos e obter um modelo ODM inicial. Em seguida, a segunda fase de transformação é executada com o objetivo de obter um modelo ODM exportação. A segunda fase de transformação faz uso do modelo ODM importação, armazenado anteriormente, de maneira a incluir os elementos pertencentes ao segundo conjunto de elementos omitidos. Por fim, o modelo ODM exportação é exportado novamente como uma ontologia na linguagem OBO File Format (extração).

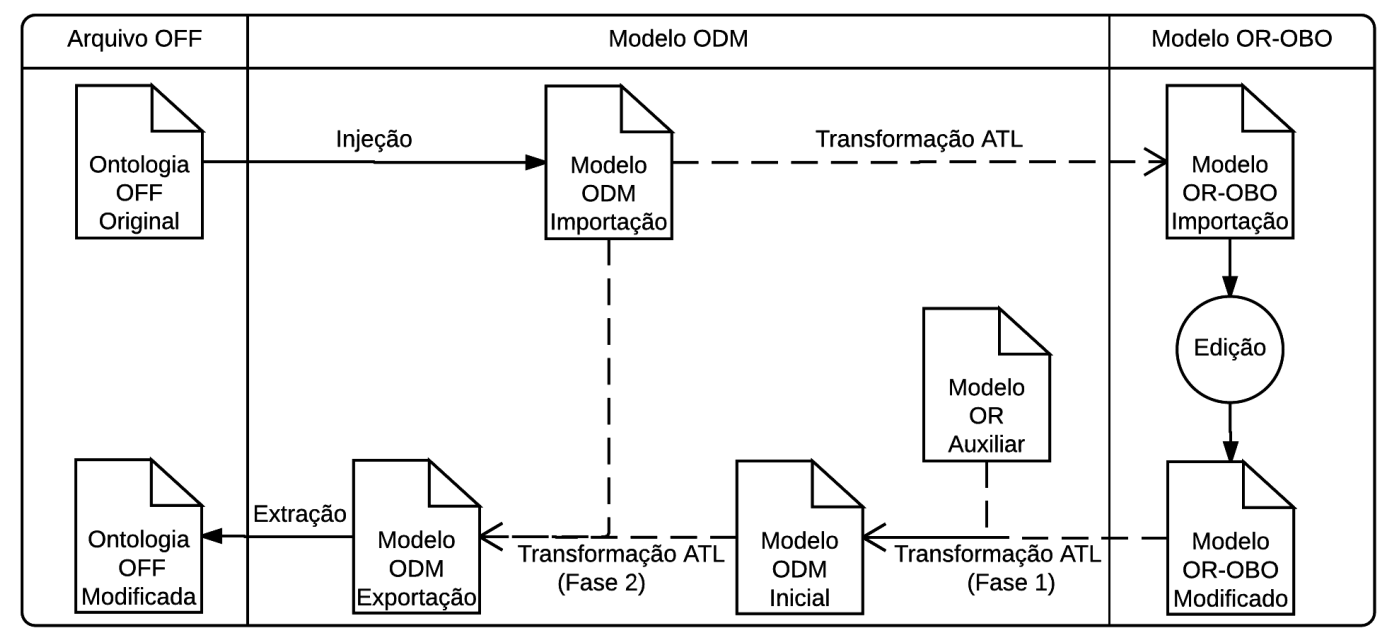

Figura 42: Estágios de representação de uma ontologia em um cenário de importação-ediçãoexportação. 


\subsection{Transformações na prática}

De maneira a exemplificar a execução das transformações durante o desenvolvimento de uma ontologia no $O B O-R O$ Editor, selecionamos um fragmento da Ontologia de Expressão Gênica (GEXPO) [109], chamado de fragmento de interesse, e apresentamos este fragmento em suas diferentes representações durante o desenvolvimento da ontologia. Como a GEXPO foi desenvolvida inicialmente em OWL, utilizamos o software ROBOT [111] para obter uma representação desta ontologia em OBO File Format.

A Figura 43 apresenta o fragmento de interesse representado no OBO File Format. Neste fragmento estão declarados seis classes de entidades da ontologia: "gene” (SO_0000704), "transcription” (GO_0006351), “transcript” (GO_0006351), "RNA processing” (GO_0006351), “primary transcript" (GO_0006351), e "mature transcript" (GO_0006351). Um novo tipo de relacionamento, “produced by” (GEXPO_0000032), é também definido no fragmento. Adicionalmente, a ontologia importa tipos de relacionamento da OR-OBO (linha 3) e define relações entre as classes de entidades apresentadas. Por exemplo, a ontologia define que "RNA processing" preceeded_by "transcription" e "transcription" has_participant "gene".

O fragmento de interesse representado no $O B O$ File Format é consumido pelo mecanismo de injeção de maneira a obter um modelo ODM. A Figura 44 apresenta por meio de um diagrama de classes UML o modelo ODM obtido após a injeção. Cada elemento do modelo ODM é representado como uma especificação de uma instância de uma metaclasse do metamodelo ODM. Alguns atributos de cada elemento e os valores inicializados para esses atributos são apresentados na divisão inferior do retângulo que representa este elemento. Referências entre dois elementos são apresentadas como arcos com pontas nomeadas conectando esses elementos. De modo a simplificar a representação, algumas referências e instâncias são omitidas. Adicionalmente, os objetos implicitamente definidos no $O B O$ File Format também são omitidos.

Cada classe de entidade definida ou importada pela ontologia é representada por uma instância de OBOClass. A definição de um tipo de relacionamento utilizado é representada por uma instância de OBOP roperty. Relações entre elementos são representadas por 


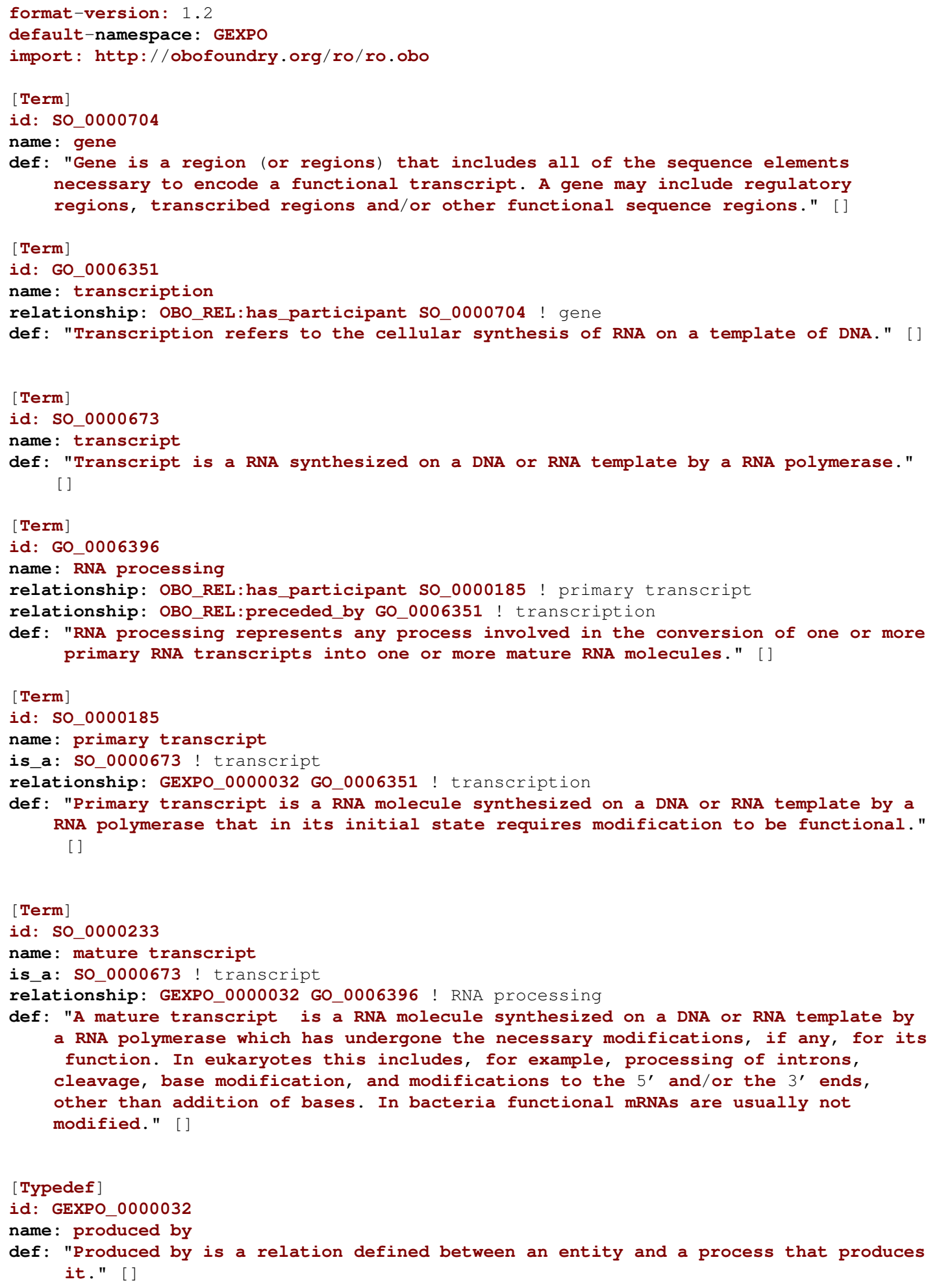

Figura 43: Fragmento da ontologia de expressão gênica (GEXPO).

instâncias de OBORestriction, de forma que a propriedade parent da instância é associada à classe de entidade que declara o relacionamento no $O B O$ File Format, enquanto a 


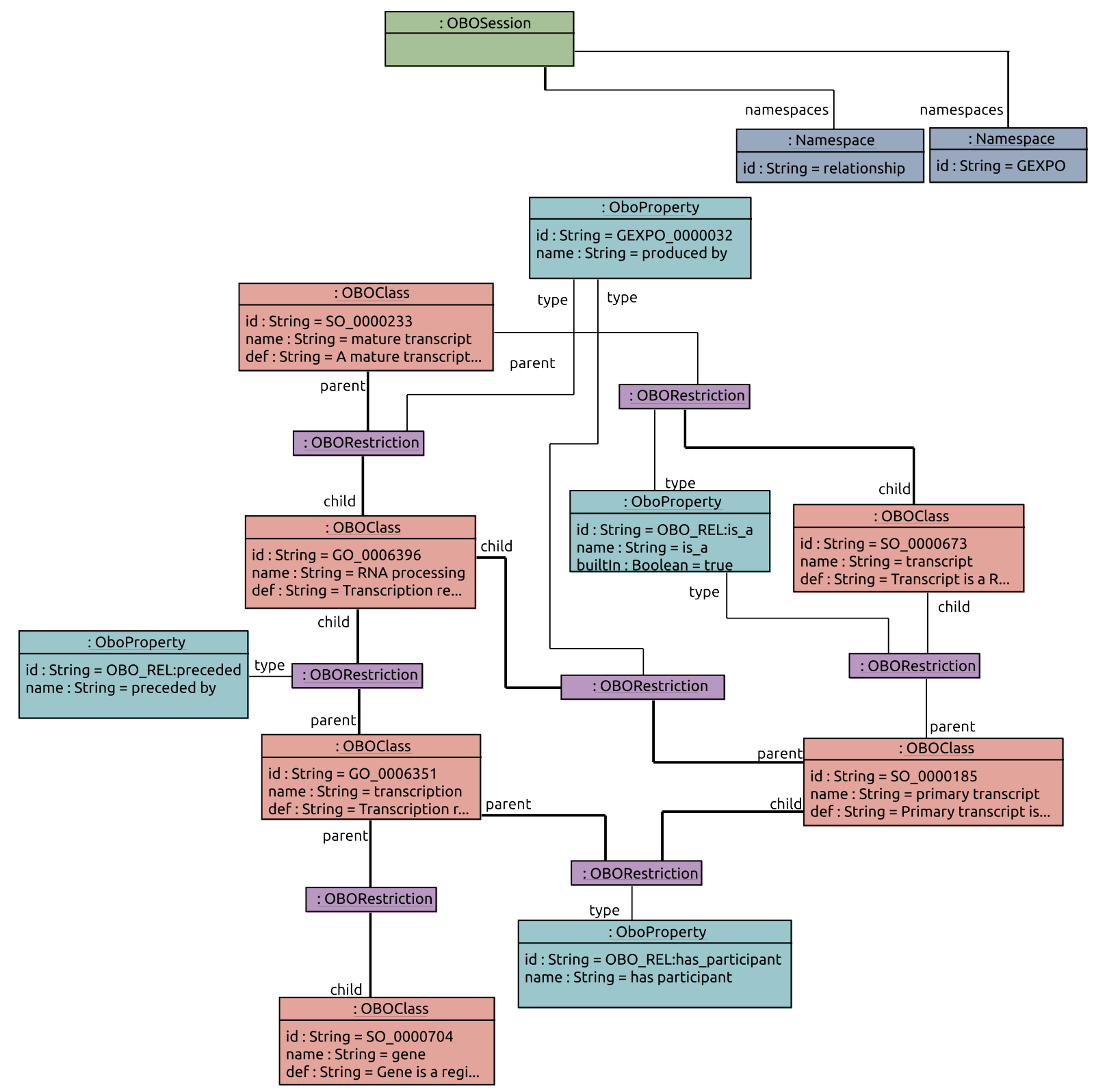

Figura 44: Instâncias das metaclasses do metamodelo ODM obtido após a injeção do fragmento da Ongologia GEXPO.

propriedade child é associada à classe de entidade referenciada pelo relacionamento. Cada instância de OBORestriction referencia uma instância de OBOP roperty que representa o tipo de relacionamento associado. Instâncias de Namespace agregam os elementos definidos e/ou importados pela ontologia. Uma instância de OBOSession, raiz do modelo, agrega instâncias de Namespace e os demais objetos da ontologia. Duas instâncias de Namespace são apresentadas: o namespace GEXPO, definido pela ontologia em edição, e o namespace relationship, definido pela OR-OBO. 


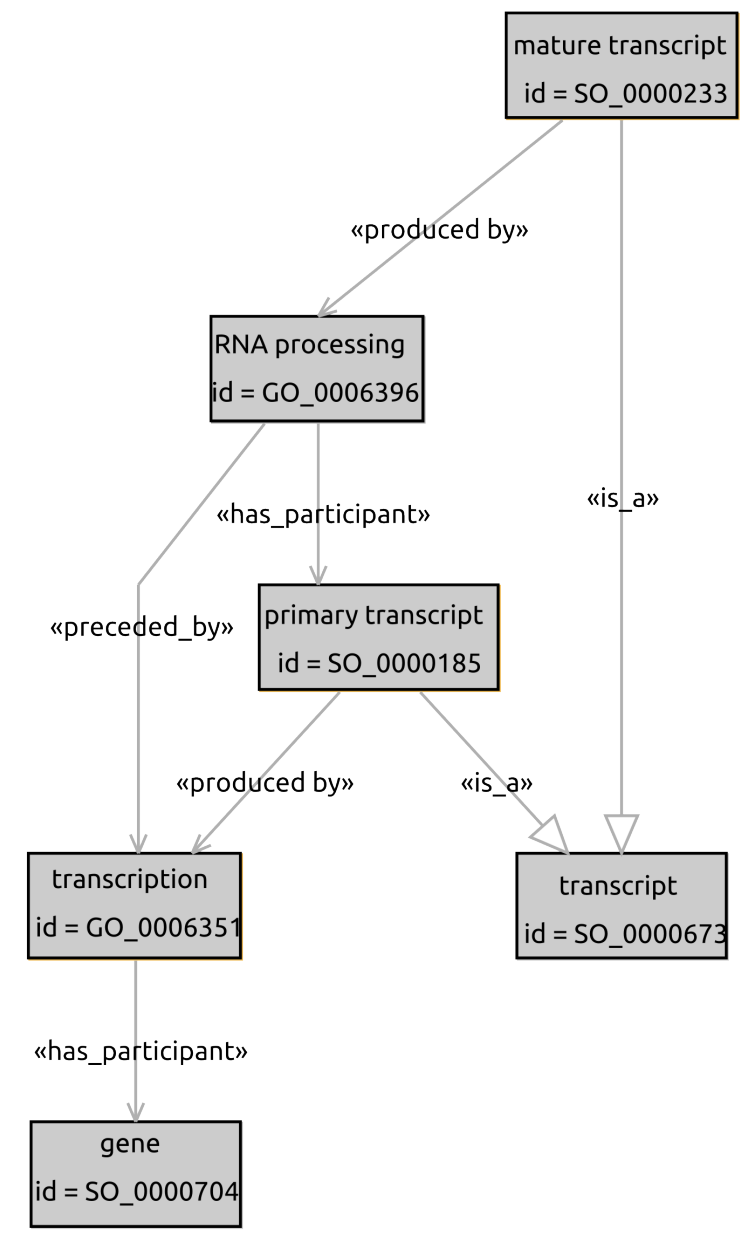

«relation_def» produced by id = GEXPO_0000032

Figura 45: Fragmento de interesse após a transformação para o metamodelo OR-OBO. Um retângulo cinza representa uma classe de entidades da ontologia. Um retângulo branco representa a definição de um novo tipo de relacionamento.

A partir do um modelo ODM do fragmento de interesse, podemos obter um modelo OROBO equivalente por meio de uma transformação ATL. A Figura 45 ilustra o fragmento de interesse exibido pelo $O B O-R O$ Editor após a transformação do modelo ODM em um modelo OR-OBO. As instâncias de OBOClass (do metamodelo ODM) foram transformadas em instâncias de OboClass (do metamodelo OR-OBO). A instância de OBOP roperty foi transformada em uma instância de RelationshipDefinition. Objetos OBO implicitamente definidos no $O B O$ File Format são suprimidos durante a transformação. Por fim, as relações existentes são representadas como arcos estereotipados.

Podemos editar um modelo OR-OBO de maneira a incluir novos elementos a esse modelo e/ou associar estereótipos aos elementos desse modelo. A Figura 46 ilustra o fragmento do frag- 


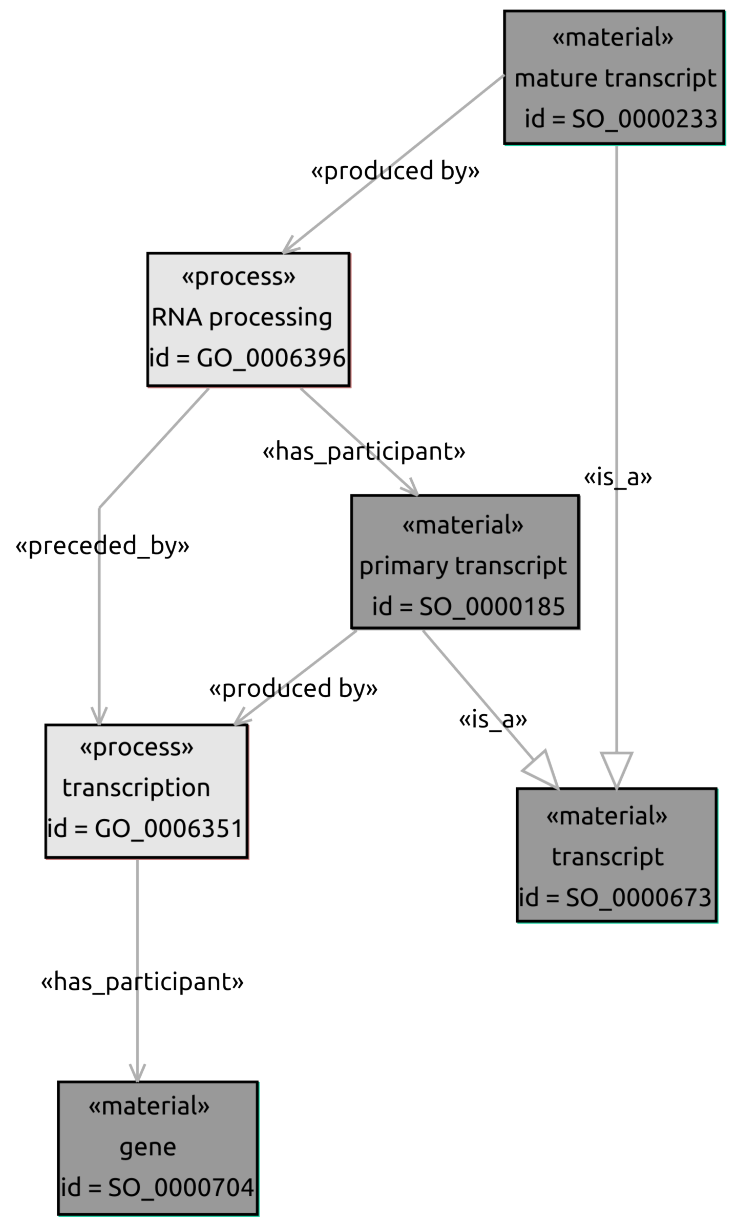

Figura 46: Fragmento de interesse como modelo OR-OBO após ediçao pelo usuário. Um retângulo cinza claro representa uma classe de entidades da ontologia que foi estereotipada como $\ll$ process». Um retângulo cinza escuro representa uma classe de entidades da ontologia que foi estereotipada como «material». Um retângulo branco representa a definição de um novo tipo de relacionamento.

mento de interesse após a adição de um conjunto de estereótipos ao modelo. Os estereótipos $<<$ process $>>$ e $<<$ material $>>$ foram adicionados aos elementos do modelo. Neste sentido, o estereótipo «material»foi adicionado às classes de entidades "gene" (SO_0000704), “transcript" (GO_0006351), "primary transcript" (GO_0006351), e "mature transcript" (GO_0006351). Por sua vez, o estereótipo «process» foi adicionado às classes de entidades “transcription" (GO_0006351) e "RNA processing" (GO_0006351).

A partir do modelo OR-OBO do fragmento de interesse modificado podemos obter um modelo ODM atualizado que será exportado posteriormente para o OBO File Format. A Figura 47 apresenta o fragmento de interesse atualizado após a execução da transformação do modelo 


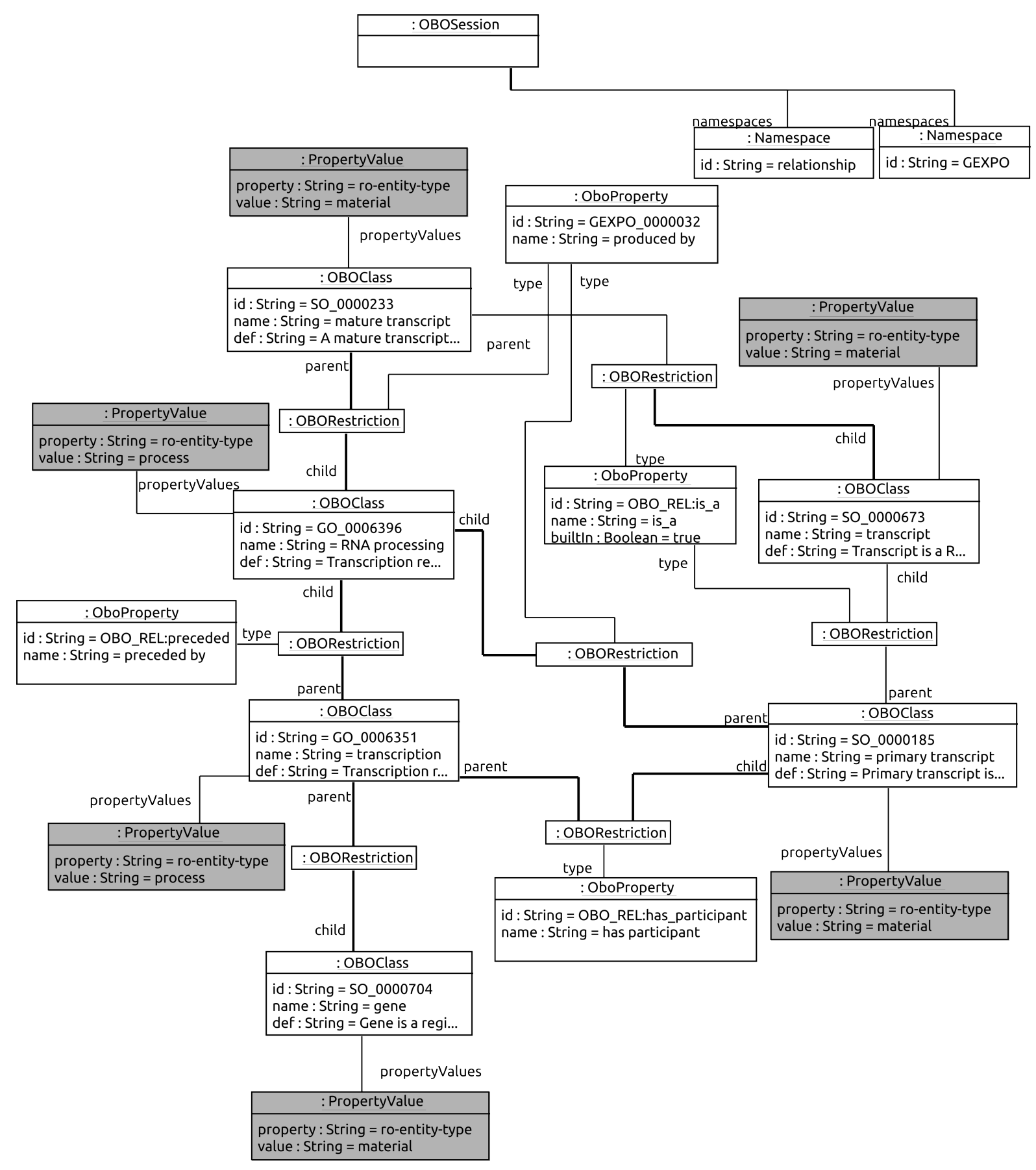

Figura 47: Ontologia como modelo ODM atualizado. A figura apresenta em destaque as instâncias da metaclasse PropertyValue adicionadas para armazenar a informação do estereótipo associado às classes de entidade modeladas.

OR-OBO em um modelo ODM. Durante essa transformação, instâncias de PropertyValue são criadas e associadas às instâncias de $\mathrm{OBOClass} \mathrm{de} \mathrm{forma} \mathrm{a} \mathrm{indicar} \mathrm{que} \mathrm{o} \mathrm{usuário} \mathrm{associou}$ previamente a essas entidades um dos estereótipos definidos para as classes de entidades definidos no perfil. Estas instâncias de PropertyValue adicionadas são apresentadas em cinza na figura. Adicionalmente, os tipos de relacionamentos definidos pela OR OBO são importados e 
incluídos no modelo ODM após a transformação. Porém, estes tipos de relacionamento foram abstraídos da figura de forma a simplificá-la.

Com base na representação do modelo ODM atualizado podemos exportar esta representação para o $O B O$ File Format. Esta atividade é realizada por meio do extrator desenvolvido. A Figura 48 apresenta o fragmento de interesse da ontologia representado no OBO File Format, após a extração do modelo ODM atualizado. Neste sentido, observamos a adição de um par tag-valor a cada declaração de termo da ontologia onde houve a associação de um termo da ontologia a uma classe de entidade definida na OR-OBO. Esses pares adicionados derivam das instâncias da metaclasse PropertyValue adicionadas durante a transformação do modelo OR-OBO em um modelo ODM. Dessa maneira, é possível recuperar a informação do estereótipo associado a uma classe de entidade em uma edição posterior (importação) da ontologia.

\subsection{Conclusão}

Neste capítulo apresentamos os principais aspectos do desenvolvimento do suporte à integração de ontologias OBO e modelos UML criados pelo OBO-RO Editor. Inicialmente apresentamos o desenvolvimento do metamodelo ODM, utilizado para a representação de ontologias OBO utilizando os conceitos implícitamente definidos na sintaxe da linguagem $O B O$ File Format por meio de um modelo Ecore. Em seguida, apresentamos o desenvolvimento de um mecanismo de injeção e extração de modo a obter/serializar modelos ODM de/para ontologias representadas na linguagem $O B O$ File Format. Por fim, apresentamos a definição de um conjunto de transformações entre o metamodelo ODM e o metamodelo OR-OBO, bem como ilustramos a execução das transformações definidas por meio de um exemplo.

O suporte à integração de ontologias OBO e modelos UML precisa considerar diferenças no nível de detalhamento dos conceitos existentes em cada metamodelo. Alguns elementos existentes em uma ontologia representada como um modelo ODM não possuem representação em um modelo UML, de maneira que estes elementos são omitidos durante a importação de uma ontologia. As transformações definidas tratam a diferença no nível de detalhamento por meio da restauração (reconciliação) dos elementos omitidos previamente à exportação da 


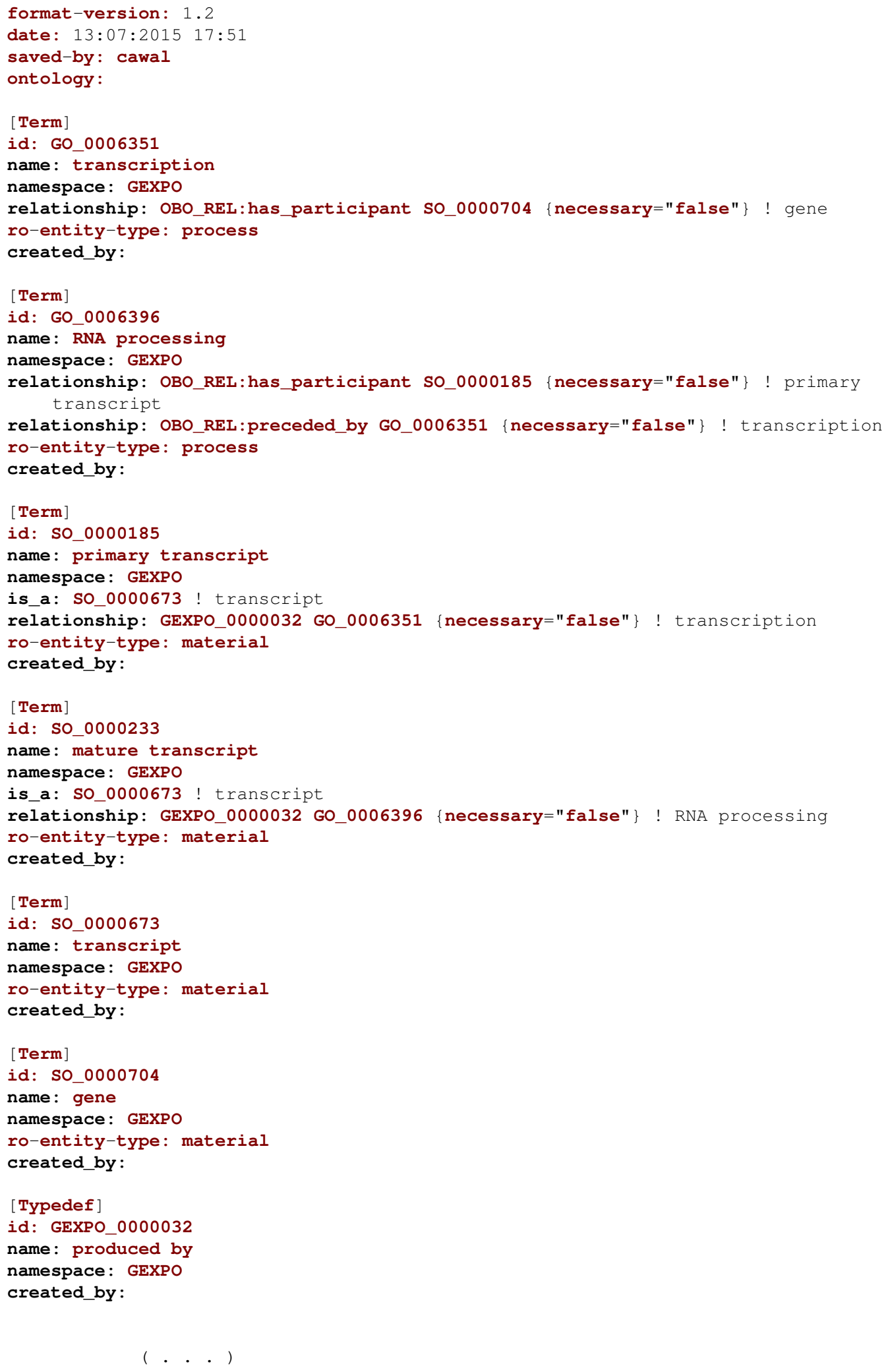

Figura 48: Ontologia após serialização como OBO File Format. 
ontologia (editada) para o OBO File Format. Dessa maneira, embora estes elementos não possam ser criados e/ou modificados durante a edição da ontologia usando o $O B O$-RO Editor, eles são mantidos na ontologia após a edição. Adicionalmente, a criação e/ou modificação destes elementos pode ser realizada por meio de outras ferramentas, tais como o OBO-Edit, após a exportação da ontologia para o OBO File Format. 


\section{Conclusão}

Este projeto teve como objetivo investigar o suporte ao desenvolvimento de ontologias biomédicas na linguagem UML. Investigamos o desenvolvimento de uma ferramenta de modelagem gráfica para o suporte ao desenvolvimento de ontologias utilizando o perfil UML para a OR OBO. Adicionalmente, investigamos a integração das ontologias desenvolvidas com essa ferramenta com ontologias desenvolvidas usando o $O B O$ File Format. Neste sentido, este capítulo discute as principais contribuições deste trabalho, limitações e apresenta trabalhos futuros.

O restante desse capítulo está estruturado da seguinte forma: a seção 8.1 apresenta as principais contribuições deste trabalho; a seção 8.2 posiciona este trabalho em relação a estudos similares e discute suas principais limitações; e a seção 8.3 apresenta nossas considerações finais e trabalhos futuros.

\subsection{Principais contribuições}

O principal resultado deste trabalho é a ferramenta gráfica de modelagem UML para ontologias biomédicas, chamada de OBO-RO Editor. Esta ferramenta provê suporte ao desenvolvimento de ontologias utilizando os conceitos definidos em um perfil UML para a Ontologia de Relacionamentos da $O B O$ Foundry. Neste sentido, a ferramenta apresenta uma interface gráfica intuitiva para o desenvolvimento de ontologias biomédicas e disponibiliza um conjunto de elementos gráficos de modelagem definidos a partir dos conceitos presentes no perfil UML usado como base para este trabalho. A disponibilidade de elementos gráficos de modelagem facilita a captura, compreensão e comunicação do conhecimento entre os usuários de uma ontologia. 
As ontologias desenvolvidas também podem ser validadas sintaticamente segundo as restrições definidas no perfil. Estas restrições limitam como as classes de entidades e tipos de relacionamentos podem ser utilizados na especificação de uma ontologia. Dessa maneira, inconsitências sintáticas podem ser encontradas e corrigidas mais rapidamente, de maneira a favorecer o desenvolvimento de ontologias mais corretas e consistentes.

Finalmente, o $O B O-R O$ Editor provê suporte à integração das ontologias desenvolvidas com outras ontologias biomédicas na medida em que os modelos desenvolvidos podem ser exportados para o formato de representação de ontologias da OBO, o OBO File Format (OFF). Esta ferramenta é também capaz de importar uma ontologia representada na linguagem $O B O$ File Format, com subsequente edição e validação sintática da ontologia importada e a eventual exportação desta ontologia para o seu formato de representação original.

Para alcançar os objetivos propostos, foi definida uma arquitetura de referência e um processo de desenvolvimento para o OBO-RO Editor. A arquitetura de referência proposta consiste de um conjunto de artefatos interrelacionados que formam a base para a implementação da ferramenta de modelagem. Um processo de desenvolvimento orientado a modelos foi utilizado para a definição desses artefatos e a obtenção de código fonte implementando a ferramenta de forma (semi) automática. Este processo utiliza linguagens e frameworks providos pelo Eclipse Modeling Project (EMP) para o desenvolvimento orientado a modelos de linguagens específicas de domínio. Neste sentido, a definição deste processo de desenvolvimento permitiu que o desenvolvimento da ferramenta fosse realizado em um nível mais alto de abstração e que os ciclos de desenvolvimento fossem mais rápidos. Adicionalmente, eventuais alterações, tais como extensões ao metamodelo e suporte a outras linguagens de representação, podem ser mais rapidamente incorporadas à ferramenta.

\subsection{Discussão}

Diferentes trabalhos envolvendo o suporte ao desenvolvimento e validação de ontologias como modelos UML podem ser encontrados na literatura. Neste sentido, Benevides et al. $[112,39]$ desenvolve um editor gráfico para a linguagem de modelagem OntoUML. O meta- 
modelo da linguagem OntoUML é definido de maneira estender um conjunto de conceitos do metamodelo UML para representar e validar sintaticamente os conceitos definidos por uma ontologia fundamental usada no desenvolvimento de linguagens para modelagem conceitual, chamada de Unified Foundational Ontology (UFO) [7]. O trabalho também utiliza os frameworks EMF e GMF para o desenvolvimento da ferramenta de modelagem gráfica baseada em UML. Adicionalmente, o trabalho utiliza o framework ATL para a transformação de um modelo OntoUML em uma representação equivalente na linguagem Alloy. Esta representação é, então, utilizada para validar a consistência do modelo OntoUML por meio de simulações. Durante uma simulação é criado um conjunto de instâncias dos conceitos/estruturas definidas no modelo Alloy. Este conjunto de instâncias representa uma possível configuração do universo de discurso, dado o modelo definido. O conjunto de instâncias simulado é, então, validado em relação a um conjunto de axiomas lógicos. Neste sentido, este trabalho relaciona-se ao nosso enquanto ambos provêem suporte a verificação e validação dos modelos criados. Porém, enquanto nosso trabalho utiliza as restrições OCL definidas no perfil UML para validar sintaticamente uma ontologia, o trabalho de Benevides et al. apresenta um mecanismo de validação baseado na análise de diferentes configurações que uma dada representação pode assumir.

Outros esforços para a obtenção de ontologias em uma linguagem de representação própria a partir de modelos UML também são conhecidos. Neste sentido, o Ontology Definition Metamodel (ODM) [113] é uma especificação do Object Management Group (OMG) que define como os conceitos da arquitetura orientada a modelos podem ser utilizados no desenvolvimento de ontologias. A especificação ODM propõe um conjunto de metamodelos baseados no Essential MOF (EMOF), além de mapeamentos entre esses metamodelos, e define uma arquitetura de metamodelagem para ontologias com diferentes níveis de expressividade. Dentre os metamodelos definidos na especificação ODM está o metamodelo OWL. Adicionalmente, esta especificação define um conjunto de perfis UML relacionados a uma parte dos metamodelos definidos. Dessa maneira, esta especificação busca permitir a representação dos conceitos destes metamodelos usando a notação da linguagem UML, bem como facilitar a transformação de ontologias representadas no metamodelo UML para uma representação equivalente nestes metamodelos. 
Os mapeamentos propostos na especificação ODM são apenas informativos, isto é, são passíveis de interpretação em relação a diferentes aspectos desses mapeamentos quando da definição de um conjunto de transformações executáveis. Neste sentido, Ontology UML Profile (OUP) [114] propõe um perfil para a representação dos conceitos do ODM como um modelo UML e provê um conjunto de transformações entre uma ontologia OUP fonte e sua representação na linguagem OWL. Assim, o OUP pode ser usado na modelagem UML de uma ontologia biomédica e na exportação desta ontologia para OWL, um dos formatos de representação usados pela $O B O$ Foundry. Porém, este trabalho não provê suporte para a validação sintática dos modelos desenvolvidos. Adicionalmente, este trabalho não apresenta uma solução para a obtenção de um modelo OUP a partir de uma ontologia representada na linguagem OWL.

Finalmente, Zamborlini [115] propõe a representação de informação temporal, presente em um modelo OntoUML, na linguagem OWL. Dado que a linguagem OWL não provê suporte para a representação de informação temporal, o trabalho propõe mapeamentos entre modelos OntoUML e a linguagem OWL de maneira a permitir a representação desta informação. Adicionalmente, o trabalho implementa, na linguagem Java, um mecanismo para a execução de uma transformação de um modelo OntoUML fonte para uma ontologia OWL alvo segundo estes mapeamentos. De forma análoga ao trabalho anterior, este trabalho pode ser usado para a modelagem UML de uma ontologia biomédica e a exportação dessa ontologia para a linguagem OWL. Porém, este trabalho também não apresenta uma solução para a obtenção de um modelo a partir de uma ontologia na linguagem em OWL.

Embora na definição da arquitetura de referência tenhamos considerado o uso do framework ATL para a especificação das transformações de modelos, outras abordagens alternativas poderiam ter sido consideradas, como por exemplo, o uso do framework QVTo e da linguagem Extensible Stylesheet Language Transformations (XSLT). O framework QVTo, também provido pelo EMP, provê suporte à linguagem QVTOperational, uma das linguagens definidas pela OMG para a transformação de modelos EMOF [116]. A opção pelo framework ATL foi baseada na maior disponibilidade de exemplos e suporte histórico para a transformação de modelos Ecore do que o framework QVTo. 
Por sua vez, a linguagem XSLT provê suporte à definição de transformações entre arquivos XML [117]. Uma vez que modelos ODM e modelos OR-OBO são serializados em XMI e são, portanto, essenciamente XML, esta linguagem poderia ser utilizada para prover as transformações de modelos necessárias ao trabalho. Porém, o uso desta linguagem faria com que o desenvolvimento dessas transformações fosse realizado em um nível mais baixo de abstração do que aquele obtido pelo uso do framework ATL. Neste sentido, o uso de XSLT tornaria necessário lidar com aspectos relacionados à representação de um modelo na linguagem XMI/XML de forma explícita.

Abordagens alternativas para o desenvolvimento dos artefatos da arquitetura de referência poderiam ser consideradas para o desenvolvimento de novo a partir do uso de novas tecnologias. Neste sentido, o metamodelo UML2, provido pelo projeto Model Development Tools (MDT) do EMP, consolidou-se ao longo do desenvolvimento do OBO-RO Editor como uma alternativa ao uso do Ecore/EMOF para o desenvolvimento de metamodelos. Dessa maneira, poderíamos reutilizar esse metamodelo para a definição das classes UML de interesse existentes no metamodelo OR-OBO. Este reuso poderia ser realizado de forma a alinhar a ferramenta a futuras evoluções do metamodelo UML2 e da linguagem UML propriamente dita. Adicionalmente, os mecanismos de serialização providos pelo projeto MDT poderiam ser utilizados para transformar modelos OR-OBO em modelos UML compartilhados por outras ferramentas de modelagem UML.

Embora a utilização do metamodelo UML2 como base para a construção do metamodelo OR-OBO abra a possibilidade de estender as funcionalidades providas pelo editor e facilite a eventual evolução do mesmo, o uso do Ecore para a construção destes metamodelos provou-se bastante flexível e adequada para alcançar os objetivos deste projeto. Neste sentido, os conceitos do metamodelo UML necessários para a validação de uma ontologia segundo o perfil UML estão representados no metamodelo OR-OBO. Quanto à representação de um modelo OR-OBO como um modelo UML, a definição de uma transformação ATL de um modelo OR-OBO para um modelo UML2 permitiria obter essa representação. Uma vez que as metaclasses UML de interesse estão representadas de forma muito próxima da representação dessas metaclasses no 
metamodelo UML2, essa transformação pode ser definida de forma direta. Adicionalmente, o uso de mecanismos de extensão baseados na criação de novas metaclasses em Ecore/EMOF ainda é mais comum entre os desenvolvedores de ferramentas para o suporte a linguagens específicas de domínio baseadas em GMF.

O $O B O-R O$ Editor não permite a representação de todos os conceitos usados na representação de uma ontologia OBO no metamodelo OR-OBO. Neste sentido, ainda não é possível o desenvolvimento de uma ontologia OBO completamente apenas com o uso do OBO-RO Editor. Contudo, tal limitação não é relevante pois os conceitos que não estão contemplados são secundários. Adicionalmente, a representação destes conceitos em modelos de alto nível de abstração como, por exemplo, modelos UML não é comum e tampouco desejável.

Por fim, os diferentes artefatos desenvolvidos podem ser reutilizados em outros contextos. Por exemplo, podemos utilizar o framework Xtext para a geração de texto a partir de um modelo desenvolvido. Neste sentido, é possível mapear os conceitos apresentados no metamodelo ODM para uma representação em uma dada linguagem de programação, por exemplo, a linguagem Java. Assim, seria possível reutilizar o metamodelo ODM e o mecanismo de injeção de forma a gerar (semi) automaticamente um conjunto de classes nesta linguagem que implementariam o modelo conceitual representado por uma ontologia biomédica. Tal característica facilitaria o desenvolvimento de aplicações no domínio de interesse a partir da ontologia desenvolvida para este domínio.

\subsection{Considerações finais e trabalhos futuros}

Ontologias biomédicas geralmente são artefatos grandes e complexos. Dessa forma, o suporte ao desenvolvimento gráfico das mesmas é fundamental. Neste sentido, o OBO-RO Editor permite a um usuário modelar uma ontologia biomédica utilizando os elementos gráficos definidos no perfil. Esta ontologia pode, então, ser validada sintaticamente segundo as restrições definidas no perfil e eventuais inconsistências sintáticas encontradas podem ser corrigidas. Por fim, o usuário pode realizar a exportação dessa ontologia para uma representação na linguagem OBO File Format. Adicionalmente, também é possível a um usuário a importar uma ontologia 
biomédica representada na linguagem $O B O$ File Format, editar esta ontologia com a adição de novos conceitos e/ou a adição de estereótipos ao conceitos definidos e, então, exportar a ontologia em edição novamente para o $O B O$ File Format, de forma a poder utilizá-la em outras ferramentas com suporte a essa linguagem.

Durante este trabalho, o mecanismo de validação sintática de uma ontologia no $O B O-R O$ Editor foi validado por meio do desenvolvimento e validação sistemática de um conjunto de pequenos exemplos. Estes exemplos permitiram avaliar separadamente cada restrição definida para os elementos do perfil. Adicionalmente, verificamos os mecanismos de injeção, extração e as transformações entre modelos por meio da importação de diferentes ontologias OBO, como por exemplo as ontologias RNA Ontology (RNAO), Gene Expression Ontology (GEXPO) e Population and Community Ontology (PCO). Uma vez importadas, estas ontologias foram editadas pela adição dos estereótipos definidos pelo perfil UML. A adição destes estereótipos permitiu a validação sintática dos elementos estereotipados e de suas relações. Ao final deste processo, estas ontologias foram exportadas novamente para seu formato de representação original.

Diferentes trabalhos futuros podem ser desenvolvidos a partir dos resultados deste projeto. Neste sentido, vemos três principais vertentes para a extensão da ferramenta $O B O-R O$ Editor: a provisão do suporte à exportação de um modelo para outras ferramentas UML; o suporte a diferentes técnicas e metodologias para a apresentação de elementos de uma ontologia; e a atualização do $O B O-R O$ Editor frente às evoluções da OR OBO.

O suporte à exportação de uma ontologia para outras ferramentas UML é desejável. Neste sentido, uma transformação de um modelo OR-OBO em um modelo reutilizável por outras ferramentas de modelagem UML pode ser provida. Assim, um usuário poderia facilmente derivar modelos UML a partir de ontologias biomédicas, de modo a reutilizar o conhecimento sobre este domínio previamente formalizado em uma ontologia.

Outras metolodogias de visualização dos elementos de uma ontologia biomédica podem ser investigadas e incorporadas ao editor. Por exemplo, o model slicing [118] é uma metodologia para a seleção automática de um conjunto de elementos relacionados a um conceito de interesse, e a apresentação destes elementos ao usuário. Dessa maneira, a compreensão das relações 
envolvendo um conceito de interesse é facilitada.

Finalmente, o $O B O-R O$ Editor necessitará de atualizações face às alterações eventualmente incorporadas à Ontologia de Relacionamentos da OBO. Neste sentido, duas novas ontologias estão sendo definidas com o propósito de substituir a OR OBO no alinhamento e curação de ontologias biomédicas: Basic Formal Ontology (BFO) e uma nova Ontologia de Relacionamentos (OR). Entre as alterações que estão sendo propostas, a BFO irá incorporar um conjunto de relações mais genéricas definidas pela antiga OR OBO. Adicinalmente, a nova Ontologia de Relacionamentos muda o foco de definição de relações, anteriormente realizada ao nível das classes de entidades. Neste sentido, a definição formal de uma relação passa a ser realizada ao nível das instâncias. Por fim, a nova OR OBO também abandona a redefinição de tipos de relacionamentos built-ins, tais como is_a. Quando essas alterações forem aprovadas, o perfil deve ser redefinido para refletir as mudanças introduzidas. Por conseguinte, a ferramenta $O B O-R O$ Editor será atualizada para acompanhar essa evolução. 


\section{Referências Bibliográficas}

1 PIRES, L. F. et al. Use of Models and Modelling Techniques for Service Development. In: 3rd IFIP Int. Conf. e-Commerce, E-bus. e-Government. [S.1.: s.n.], 2004. p. 22-25.

2 OBJECT MANAGEMENT GROUP. OMG Unified Modeling Language (TM) Infrastructure Version 2.4.1. 2011.

3 HERRMANNSDOERFER, M.; RATIU, D.; WACHSMUTH, G. Language Evolution in Practice: The History of GMF. Lect. Notes Comput. Sci., v. 5969, p. 3-22, 2010.

4 GENE ONTOLOGY CONSORTIUM. Ontology Detail : Biological process. Data de acesso: 10 de Novembro de 2015. Disponível em: <http : / / www . obofoundry • org/cgi-bin/ detail.cgi?id=biological_process $>$.

5 GUARDIA, G. D. A.; VENCIO, R. Z. N.; FARIAS, C. R. G. de. A UML profile for the OBO relation ontology. BMC Genomics, BioMed Central Ltd, v. 13, n. Suppl 5, p. S3, 2012.

6 BELL, G.; HEY, T.; SZALAY, A. Beyond the Data Deluge. Science (80-. )., v. 323, p. 1297$1298,2009$.

7 GUIZZARDI, G. Ontological Foundations for Structural Conceptual Models. Tese (Doutorado) - Universiteit Twente, Twente, Netherlands, 2005.

8 GUARINO, N. Formal Ontology and Information Systems. In: Proc. FOIS'98. [S.l.: s.n.], 1998. p. 3-15.

9 BODENREIDER, O. Biomedical Ontologies in Action: Role in Knowledge Management, Data Integration and Decision Support. Yearb. Med. Inform., v. 3841, p. 67-79, 2008.

10 FELDMAN, H. J. et al. CO: A chemical ontology for identification of functional groups and semantic comparison of small molecules. FEBS Lett., v. 579, n. 21, p. 4685-4691, 2005. 
11 GRUBER, T. R.; OLSEN, G. R. An Ontology for Engineering Mathematics. 1994.

12 BREUKERS, J. A. P. J.; HOEKSTRA, R. J. Epistemology and ontology in core ontologies: FOLaw and LRI-Core, two core ontologies for law. CEUR, 2004. Data de acesso: 10 de Novembro de 2015. Disponível em: <http: // dare.uva.nl/record/135063>.

13 GENE ONTOLOGY CONSORTIUM. Gene Ontology: tool for the unification of biology. Nat. Genet., v. 25, n. may, p. 25-29, 2000.

14 BRAZMA, A. et al. Minimum information about a microarray experiment (MIAME)toward standards for microarray data. Nat. Genet., v. 29, n. 4, p. 365-371, 2001.

15 DEGTYARENKO, K. et al. ChEBI: a database and ontology for chemical entities of biological interest. Nucleic Acids Res., v. 36, n. Database issue, p. D344-D350, 2008.

16 BODENREIDER, O. The Unified Medical Language System (UMLS): integrating biomedical terminology. Nucleic Acids Res., v. 32, n. Database issue, p. D267-D270, 2004.

17 FREITAS, F.; SCHULZ, S.; MORAES, E. Pesquisa de terminologias e ontologias atuais em biologia e medicina. Rev. Eletrônica Comun. Informação e Inovação em Saúde, v. 3, n. 1, p. 8-20, 2009. Data de acesso: 10 de Novembro de 2015. Disponível em: <http: / /www . reciis.cict.fiocruz.br/index.php/reciis/article/view/239/248>.

18 SMITH, B. et al. The OBO Foundry: coordinated evolution of ontologies to support biomedical data integration. NIH Public Access, v. 25, n. 11, 2007.

19 SOLDATOVA, L. N.; KING, R. D. Are the current ontologies in biology good ontologies? Nat. Biotechnol., v. 23, n. 9, p. 1095-1098, 2005.

20 OBO FOUNDRY. The Open Biological and Biomedical Ontologies. Data de acesso: 10 de Novembro de 2015. Disponível em: <http: / / www . obofoundry . org/>.

21 SMITH, B. et al. Relations in biomedical ontologies. Genome Biol., v. 6, n. 5, p. R46, 2005. 
22 DAY-RICHTER, J. The OBO Flat File Format Specification, version 1.2. Data de acesso: 10 de Novembro de 2015. Disponível em: <http://www.geneontology.org/Go. format.obo-1_2.shtml>.

23 WORLD WIDE WEB CONSORTIUM. OWL Web Ontology Language Overview. 2004. 122 p. Data de acesso: 10 de Novembro de 2015. Disponível em: <http: / /www.w3.org/ TR/owl-features/>.

24 BRAZMA, A.; KRESTYANINOVA, M.; SARKANS, U. Standards for systems biology. Nat. Rev. Genet., v. 7, n. 8, p. 593-605, 2006.

25 OBJECT MANAGEMENT GROUP. OMG Unified Modeling Language (TM) Superstructure Version 2.4.1. 2011.

26 OBJECT MANAGEMENT GROUP. OBJECT MANAGEMENT GROUP. Data de acesso: 10 de Novembro de 2015. Disponível em: <http: / /www . omg • org/>.

27 OBJECT MANAGEMENT GROUP. UML Profile For Enterprise Distributed Object Computing (EDOC). Data de acesso: 10 de Novembro de 2015. Disponível em: <http: / /www . omg.org/spec/EDOC/>.

28 OBJECT MANAGEMENT GROUP. UML Profile For Enterprise Application Integration (EAI). Data de acesso: 10 de Novembro de 2015. Disponível em: <http: / / www . omg • org / spec/EAI/>.

29 OBJECT MANAGEMENT GROUP. UML Profile For Advanced And Integrated Telecommunication Services (TelcoML). Data de acesso: 10 de Novembro de 2015. Disponível em: <http://www.omg.org/spec/TelcoML/>.

30 MELLOR, S. J.; CLARK, A. N.; FUTAGAMI, T. Model Driven Development. IEEE Softw., v. 20, n. 5 , p. 14-18, 2003.

31 SEIDEWITZ, E. What models mean. IEEE Softw., v. 20, n. 5, p. 26-32, 2003.

32 SELIC, B. The pragmatics of model-driven development. IEEE Softw., v. 20, n. 5, p. 19-25, 2003. 
33 HAREL, D.; RUMPE, B. Modeling Languages: Syntax, Semantics and all that Stuff. IEEE Softw., p. 1-19, 2004.

34 PRESSMAN, R. S. Software engineering: a practitioner's approach. 6. ed. [S.1.]: McGrawHill, 2005.

35 DENNO, P. et al. Model-driven integration using existing models. IEEE Softw., v. 20, n. 5, p. 59-63, 2003.

36 OBJECT MANAGEMENT GROUP. MDA Guide Version 1.0.1. 2003. Data de acesso: 10 de Novembro de 2015. Disponível em: <http: / /www. omg •org/cgi-bin/doc?omg/ 03-06-01.pdf $>$.

37 PIRES, L. F.; SOUZA, W. L. de. Step-wise refinement design example using LOTOS. FORTE, p. 1-8, 1990.

38 ATKINSON, C.; KUHNE, T. Model-driven development: a metamodeling foundation. IEEE Softw., v. 20, n. 5, p. 36-41, 2003.

39 BENEVIDES, A. B. A Model-based Graphical Editor for Supporting the Creation, Verification and Validation of OntoUML Conceptual Models. Dissertação (Mestrado) - Universidade Federal do Espírito Santo, 2010.

40 OBJECT MANAGEMENT GROUP. OMG Meta Object Facility (MOF) Core Specification Version 2.4.1. 2006.

41 HEY, T.; TREFETHEN, A. The Data Deluge: An e-Science Perspective. In: BERMAN, F.; FOX, G.; HEY, A. J. (Ed.). Grid Comput. - Mak. Glob. Infrastruct. a Real. [S.1.]: Wiley, 2013. p. 1-17.

42 USCHOLD, M. Building Ontologies: Towards a Unified Methodology. In: Proceeedings Expert Syst. '96. [S.1.: s.n.], 1996.

43 GRUBER, T. R. Toward Principles for the Design of Ontologies Used for Knowledge Sharing. In: Form. Ontol. Concept. Anal. Knowl. Represent. [S.1.]: Guarino, N., 1993. 
44 GUARINO, N.; GIARETTA, P. Ontologies and Knowledge Bases: Towards a Terminological Clarification. Towar. Very Large Knowl. Bases, 1995.

45 SCHREIBER, G.; WIELINGA, B.; JANSWEIJER, W. The KACTUS View on the 'O' Word. In: IJCAI Work. Basic Ontol. Issues Knowl. Shar. [S.1.: s.n.], 1995.

46 FERNANDEZ-LOPEZ, M.; GOMEZ-PEREZ, A. Overview and analysis of methodologies for building ontologies. Knowl. Eng. Rev., v. 17, n. 02, p. 129-156, 2003.

47 LENAT, D. B. et al. Cyc: Toward programs with common sense. Commun. ACM, v. 33, 1990.

48 USCHOLD, M.; KING, M. Towards a methodology for building ontologies. In: Work. Basic Ontol. Issues Knowl. Shar. [S.1.]: The University of Edinburg, 1995.

49 GRUNINGER, M.; FOX, M. S. Methodology for the Design and Evaluation of Ontologies. 1995. Data de acesso: 10 de Novembro de 2015. Disponível em: <http:// citeseerx. ist.psu.edu/viewdoc/summary?doi=10.1.1.44.8723>.

50 NOY, N. F.; MCGUINNESS, D. L. Ontology Development 101: A Guide to Creating Your First Ontology. [S.1.], 2001. 1-25 p. Relat. técn.

51 FERNANDEZ-LOPEZ, M.; GOMEZ-PEREZ, A.; JURISTO, N. Methontology: from ontological art towards ontological engineering. AAAI Tech. Rep., p. 33-40, 1997.

52 EUZENAT, J. Building consensual knowledge bases: context and architecture. In: 2nd Int. Conf. Build. Shar. Very Large-scale Knowl. Bases. [S.1.: s.n.], 1995. p. 143-153.

53 BENJAMINS, V. R.; FENSEL, D. The ontological engineering initiative (KA) 2. In: Form. Ontol. Inf. Syst. [S.1.: s.n.], 1998. p. 287--301.

54 GOMEZ-PEREZ, A.; ROJAS-AMAYA, M. D. Ontological reengineering for reuse. In: EKAW'99. [S.1.]: Springer-Verlag Berlin Heidelberg, 1999. p. 139-156.

55 PINTO, H. S.; MARTINS, J. P. A methodology for ontology integration. In: Int. Conf. Knowl. Capture - K-CAP 2001. [S.1.]: ACM Press, 2001. p. 131. 
56 EUZENAT, J. Towards a principled approach to semantic interoperability. In: Proc. IJCAI 2001 workshop on ontology and information sharing. Seattle, United States: No commercial editor., 2001. (Proc. IJCAI 2001 workshop on ontology and information sharing), p. 19-25.

57 KULKARNI, V.; REDDY, S. Separation of concerns in model-driven development. IEEE Softw., v. 20, n. 5, p. 64-69, 2003.

58 OBJECT MANAGEMENT GROUP. Model Driven Architecture. 2000. 1-12 p.

59 STEVENS, P. A landscape of bidirectional model transformations. In: LäMMEL, R.; VISSER, J.; SARAIVA, J. (Ed.). Generative and Transformational Techniques in Software Engineering II. [S.1.]: Springer Berlin Heidelberg, 2008, (Lecture Notes in Computer Science, v. 5235). p. 408-424. ISBN 978-3-540-88642-6.

60 GARWOOD, K. et al. Model-driven user interfaces for bioinformatics data resources: regenerating the wheel as an alternative to reinventing it. BMC bioinformatics, v. 7, n. 1, 2006.

61 MONTEIRO, R. S. et al. The MDArte experience: OrgAnizational aspects acquired from a successful partnership between government and academia using model-driven development. In: Model-Driven Engineering and Software Development (MODELSWARD), 2014 2nd International Conference on. [S.1.: s.n.], 2014.

62 THE ANDROMDA TEAM. AndroMDA. 2010. Disponível em: <http://www. andromda. org/>.

63 VOGELSANG, A. et al. Supporting concurrent development of requirements and architecture: A model-based approach. In: Model-Driven Engineering and Software Development (MODELSWARD), 2014 2nd International Conference on. [S.1.: s.n.], 2014.

64 COUTINHO, C.; CRETAN, A.; JARDIM-GONCALVES, R. Modelling services for interoperability negotiation. In: Model-Driven Engineering and Software Development (MODELSWARD), 2014 2nd International Conference on. [S.1.: s.n.], 2014.

65 KROPF, S.; CHALOPIN, C.; DENECKE, K. Template and model driven development of standardized electronic health records. In: MEDINFO 2015: EHealth-enabled Health: Proce- 
edings of the 15th World Congress on Health and Biomedical Informatics. [S.1.: s.n.], 2015. v. 216.

66 OPENEHR FOUNDATION. openEHR. 2015. Data de acesso: 10 de Novembro de 2015. Disponível em: <http: //www. openehr.org >.

67 HEALTH LEVEL SEVEN INTERNATIONAL. HL7 Version 3 Standard: Model Interchange Format, Release 1. 2010. Data de acesso: 10 de Novembro de 2015. Disponível em: <http://www.hl7.org/implement/standards/product_brief. cfm?product_id=101>.

68 HEALTH LEVEL SEVEN INTERNATIONAL. HL7 International. 2015. Data de acesso: 10 de Novembro de 2015. Disponível em: <http: //www.hl7. org/>.

69 MARTINEZ-GARCIA, A. et al. Working with the HL7 metamodel in a Model Driven Engineering context. Journal of Biomedical Informatics, v. 57, 2015.

70 OBJECT MANAGEMENT GROUP. MOF 2 XMI Mapping (XMI®). Data de acesso: 10 de Novembro de 2015. Disponível em: <http: / / wWw . omg . org/spec/XMI/>.

71 OBJECT MANAGEMENT GROUP. Common Warehouse Metamodel (CWM) Specification Version 1.1. 2003.

72 OBJECT MANAGEMENT GROUP. OMG Object Constraint Language (OCL) Version 2.3.1. 2012.

73 ECLIPSE FOUNDATION. Eclipse Modeling Project. Data de acesso: 10 de Novembro de 2015. Disponível em: <http://www.eclipse.org/modeling/>.

74 ECLIPSE FOUNDATION. Eclipse IDE. Data de acesso: 10 de Novembro de 2015. Disponível em: <http://www.eclipse.org/>.

75 ECLIPSE FOUNDATION. Eclipse Modeling - EMF - Home. Disponível em: <http: //www.eclipse.org/modeling/emf/>. 
76 ECLIPSE FOUNDATION. Eclipse Modeling - MDT - Home. Data de acesso: 10 de Novembro de 2015. Disponível em: <http: / / www.eclipse.org/modeling/mdt/>.

77 ECLIPSE FOUNDATION. Graphical Modeling Framework. Data de acesso: 10 de Novembro de 2015. Disponível em: <http: / / www . eclipse. org/modeling/gmp/>.

78 JOUAUlT, F. et al. ATL: A model transformation tool. Sci. Comput. Program., v. 72, n. 1-2, p. 31-39, 2008.

79 ECLIPSE FOUNDATION. ATL Transformation Language. Data de acesso: 10 de Novembro de 2015. Disponível em: <https: / / eclipse.org/atl/>.

80 GRONBACK, R. C. Eclipse Modeling Project A Domain Specific Language (DSL) Toolkit. [S.1.]: Addison Wesley, 2009.

81 ECLIPSE FOUNDATION. The Eclipse Modeling Framework (EMF) Overview. Data de acesso: 10 de Novembro de 2015. Disponível em: <http://help.eclipse.org/ juno/index.jsp?topic=/org.eclipse.emf.doc/references/overview/ EMF.html\&cp $=23 \_0 \_0>$.

82 CHIMIAK-OPOKA, J. et al. OCL Tools Report based on the IDE4OCL FeatureModel. In: Work. OCL Textual Model. (OCL 2011). [S.1.: s.n.], 2011. v. 44, p. 1-18.

83 ECLIPSE FOUNDATION. OCL Documentation - Overview. Data de acesso: 10 de Novembro de 2015. Disponível em: <http://help.eclipse.org/juno/index.jsp? topic=/org.eclipse.ocl.doc/help/Overview.html\&cp=49_0>.

84 ECLIPSE FOUNDATION. MDT/OCL/4.X Architecture - Eclipsepedia. Data de acesso: 10 de Novembro de 2015. Disponível em: <http: / / wiki .eclipse.org/MDT/OCL/4 . X_ Architecture>.

85 CHANDRASEKARAN, B.; JOSEPHSON, J. R.; BENJAMINS, V. R. What are ontologies, and why do we need them? IEEE Intell. Syst., v. 14, n. 1, p. 20-26, 1999.

86 CAMON, E. et al. The Gene Ontology Annotation (GOA) Database: sharing knowledge in Uniprot with Gene Ontology. Nucleic Acids Res., v. 32, n. Database issue, p. D262-D266, 2004. 
87 BAIROCH, A. et al. The Universal Protein Resource (UniProt). Nucleic Acids Res., v. 33, n. Database issue, p. D154-D159, 2005.

88 RUBIN, D. L.; SHAH, N. H.; NOY, N. F. Biomedical ontologies: a functional perspective. Brief. Bioinform., v. 9, n. 1, p. 75-90, 2008.

89 CHAUDHURI, S.; DAYAL, U. An overview of data warehousing and OLAP technology. In: ACM SIGMOD Rec. [S.1.: s.n.], 1997. v. 26, n. 1, p. 65-74.

90 WIDOM, J. Research problems in data warehousing. In: Proc. Fourth Int. Conf. Inf. Knowl. Manag. [S.1.]: ACM Press, 1995. p. 25-30.

91 PATRAO, D. F. C. et al. Ontocloud - a clinical information ontology based data integration system. In: BAX, M. P.; ALMEIDA, M. B.; WASSERMANN, R. (Ed.). VI Semin. Ontol. Res. Brazil. [S.1.: s.n.], 2013. p. 118-129.

92 RINDFLESCH, T. C.; FISZMAN, M.; LIBBUS, B. Semantic Interpretation for the Biomedical Research Literature. In: Med. Informatics. Kluwer Academic Publishers, 2005, (Integrated Series in Information Systems, v. 8). Data de acesso: 10 de Novembro de 2015. Disponível em: <http://www.springerlink.com/index/10.1007/b135955>.

93 GOLBREICH, C.; ZHANG, S.; BODENREIDER, O. The foundational model of anatomy in OWL: Experience and perspectives. J. Web Semant., v. 4, n. 3, p. 181-195, 2006.

94 GENE ONTOLOGY CONSORTIUM. The Gene Ontology in 2010: extensions and refinements. Nucleic Acids Res., v. 38, n. Database issue, p. D331-D335, 2010. Data de acesso: 10 de Novembro de 2015. Disponível em: <http://www.pubmedcentral.nih. gov/articlerender.fcgi?artid=2808930\&tool=pmcentrez\&rendertype= abstract $>$.

95 EILBECK, K. et al. The Sequence Ontology: a tool for the unification of genome annotations. Genome Biol., v. 6, n. 5, p. R44, jan. 2005. Data de acesso: 10 de Novembro de 2015. Disponível em: <http://www •pubmedcentral.nih.gov/articlerender. fcgi ?artid=1175956\&tool=pmcentrez\&rendertype=abstract $>$. 
96 WORLD WIDE WEB CONSORTIUM. OWL Web Ontology Language Semantics and Abstract Syntax. 2009. 1-11 p. Data de acesso: 10 de Novembro de 2015. Disponível em: <http://www.w3.org/TR/2004/REC-owl-semantics-20040210/>.

97 DAY-RICHTER, J. et al. OBO-Edit-an ontology editor for biologists. Bioinformatics, v. 23, n. 16, p. 2198-2200, 2007.

98 OBO FOUNDRY. OBO Flat File Format 1.4 Syntax and Semantics [WORKING DRAFT]. Data de acesso: 10 de Novembro de 2015. Disponível em: <http://oboformat. googlecode.com/svn/branches/2011-11-29/doc/obo-syntax.html>.

99 WORLD WIDE WEB CONSORTIUM. OWL 2 Web Ontology Language Quick Reference Guide. 2012. 1-15 p. Data de acesso: 10 de Novembro de 2015. Disponível em: <http: //www.w3.org/TR/owl-quick-reference>.

100 WORLD WIDE WEB CONSORTIUM. RDF - Semantic Web Standards. Data de acesso: 10 de Novembro de 2015. Disponível em: <http: / / www .w3 . org/RDF />.

101 WORLD WIDE WEB CONSORTIUM. Extensible Markup Language (XML). Data de acesso: 10 de Novembro de 2015. Disponível em: <http: / / www . w3 . org/XML/>.

102 WORLD WIDE WEB CONSORTIUM. OWL 2 Web Ontology Language Document Overview (Second Edition). 2012. Data de acesso: 10 de Novembro de 2015. Disponível em: <http://www.w3.org/TR/owl2-overview/>.

103 GOLBREICH, C.; HORROCKS, I. The obo to owl mapping, go to owl 1.1. In: OWLED 2007 Work. OWL Exp. Dir. [s.n.], 2007. Data de acesso: 10 de Novembro de 2015. Disponível em: <http://citeseerx.ist.psu.edu/viewdoc/summary?doi=10. $1.1 .66 .2237>$.

104 TIRMIZI, S. H. et al. Mapping between the OBO and OWL ontology languages. J. Biomed. Semantics, BioMed Central Ltd, v. 2, n. Suppl 1, p. S3.1--S3.16, 2011.

105 AITKEN, S.; CHEN, Y.; BARD, J. OBO Explorer: an editor for Open Biomedical Ontologies in OWL. Bioinformatics, v. 24, n. 3, p. 443-444, fev. 2008. 
106 HOEHNDORF, R. et al. Relations as patterns: bridging the gap between OBO and OWL. BMC Bioinformatics, v. 11, p. 441, 2010.

107 OBO FOUNDRY. Ontology Detail : OBO relationship types (legacy). Data de acesso: 10 de Novembro de 2015. Disponível em: <http://www.obofoundry.org/cgi-bin/ detail.cgi?id=relationship>.

108 OBJECT MANAGEMENT GROUP. Business Process Model and Notation (BPMN) Version 2.0. 2011.

109 MIYAZAKI, F. A. et al. Semantic integration of gene expression analysis tools and data sources using software connectors. BMC Genomics, BioMed Central Ltd, v. 14, n. Suppl 6, p. S2, 2013.

110 ECLIPSE FOUNDATION. Xtext - Language Development Made Easy! Data de acesso: 10 de Novembro de 2015. Disponível em: <http: / / www . eclipse.org/Xtext/>.

111 ONTODEV. ROBOT is an OBO Tool. Disponível em: <https://github.com/ ontodev/robot>.

112 BENEVIDES, A. B.; GUIZZARDI, G. A model-based tool for conceptual modeling and domain ontology engineering in OntoUML. In: 11th Int. Conf. Enterp. Inf. Syst. [S.1.: s.n.], 2009. p. 528-538.

113 OBJECT MANAGEMENT GROUP. Ontology Definition Metamodel version 1.0. 2009.

114 DJURIC, D. et al. A uml profile for owl ontologies. In: AßMANN, U.; AKSIT, M.; RENSINK, A. (Ed.). Model Driven Architecture. [S.1.]: Springer Berlin Heidelberg, 2005, (Lecture Notes in Computer Science, v. 3599). p. 204-219. ISBN 978-3-540-28240-2.

115 ZAMBORLINI, V. C. Estudo de Alternativas de Mapeamento de Ontologias da Linguagem OntoUML Para OWL: Abordagens Para Representação de Informação Temporal. Dissertação (Mestrado), 2011. 
116 OBJECT MANAGEMENT GROUP. Meta Object Facility (MOF) 2.0 Query/View/Transformation, v1.1. Data de acesso: 10 de Novembro de 2015. Disponível em: <http: / /www . omg.org/spec/QVT/1.1/>.

117 WORLD WIDE WEB CONSORTIUM. XSL Transformations (XSLT) Version 2.0. Disponível em: <http://www.w3.org/TR/xslt20/>.

118 KAGDI, H.; MALETIC, J. I.; SUTTON, A. Context-free slicing of uml class models. In: Software Maintenance, 2005. ICSM'05. Proceedings of the 21st IEEE International Conference on. [S.1.: s.n.], 2005. p. 635-638. 